\title{
Interactions between cytomegalovirus and the immunesystem
}

Citation for published version (APA):

van Duijvestijn-van Dam, J. G. (2004). Interactions between cytomegalovirus and the immunesystem. [Doctoral Thesis, Maastricht University]. Universiteit Maastricht. https://doi.org/10.26481/dis.20041217jd

Document status and date:

Published: 01/01/2004

DOI:

10.26481/dis.20041217jd

Document Version:

Publisher's PDF, also known as Version of record

\section{Please check the document version of this publication:}

- A submitted manuscript is the version of the article upon submission and before peer-review. There can be important differences between the submitted version and the official published version of record.

People interested in the research are advised to contact the author for the final version of the publication, or visit the DOI to the publisher's website.

- The final author version and the galley proof are versions of the publication after peer review.

- The final published version features the final layout of the paper including the volume, issue and page numbers.

Link to publication

\footnotetext{
General rights rights.

- You may freely distribute the URL identifying the publication in the public portal. please follow below link for the End User Agreement:

www.umlib.nl/taverne-license

Take down policy

If you believe that this document breaches copyright please contact us at:

repository@maastrichtuniversity.nl

providing details and we will investigate your claim.
}

Copyright and moral rights for the publications made accessible in the public portal are retained by the authors and/or other copyright owners and it is a condition of accessing publications that users recognise and abide by the legal requirements associated with these

- Users may download and print one copy of any publication from the public portal for the purpose of private study or research.

- You may not further distribute the material or use it for any profit-making activity or commercial gain

If the publication is distributed under the terms of Article $25 \mathrm{fa}$ of the Dutch Copyright Act, indicated by the "Taverne" license above, 


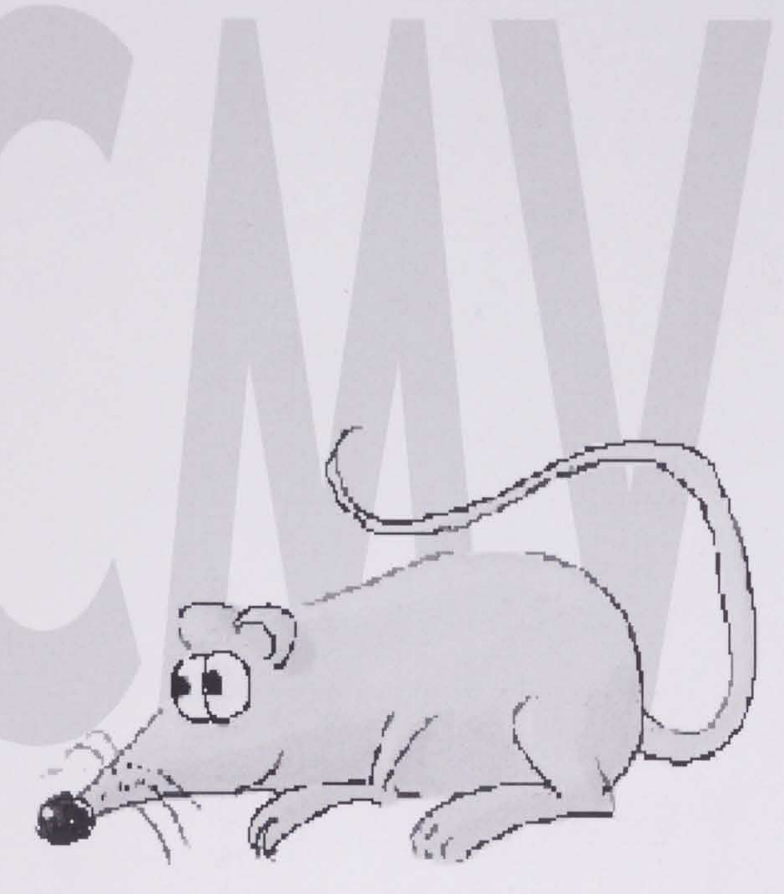

Interactions between

cytomegalovirus and the immunesystem

Joanne G. Duijvestijn-van Dam 



\section{Interactions between cytomegalovirus and the immunesystem}

Proefschrift

Ter verkrijging van de graad van doctor aan de Universiteit Maastricht op gezag van de Rector Magnificus Prof. Mr. G.P.M.F. Mols volgens het besluit van het College van Decanen in het openbaar te verdedigen op vrijdag 17 december 2004 om 16.00 uur door Joanne Gertrude Duijvestijn-van Dam 


\section{Promotor}

Prof. dr. C.A. Bruggeman

\section{Beoordelingscommissie}

Prof. dr. W.A. Buurman (voorzitter)

Prof. dr. J.P. van Hooff

Prof. dr. K.M.L. Leunissen

Prof. dr. T.H. The (Academisch Ziekenhuis Groningen)

Prof. dr. E.J.H.J. Wiertz (Leiden Universitair Medisch Centrum) 
Mama, wil je me opdragen?

Natuurlijk!

\section{voor Dirk}





\section{Table of Contents}

List of abbreviations $\quad 8$

$\begin{array}{ll}\text { Chapter } 1 & 11\end{array}$

General introduction

Chapter 2

Infection with rat cytomegalovirus (CMV) in kidney transplant recipients results in the appearance of a $T$ cell population with reduced CD8 and T cell receptor (TCR) expression

Chapter 3

Acute primary infection with cytomegalovirus (CMV) in kidney transplant recipients results in the appearance of a phenotypically aberrant CD8+ T cell population

Chapter 4

Rat Cytomegalovirus induces a temporal downregulation of Major Histocompatibility Comples class I cell surface expression

Chapter 5

Effects of cytomegalovirus infection and prolonged cold ischemia on chronic rejection of rat renal allografts

Chapter 6

Cytomegalovirus-enhanced development of transplant arteriosclerosis in the rat: effect of timing of infection and recipient responsiveness

Chapter 7

Summary and general discussion

Samenvatting en discussie

Dankwoord

Publications 


\section{List of abbreviations}

$\begin{array}{ll}B_{2} m & \text { - } B_{2} \text {-microglobulin } \\ \text { AIDS } & \text {-acquired immune deficiency syndrome } \\ \text { APC } & \text {-antigen presenting cell } \\ \text { BMT } & \text {-bone marrow transplant } \\ \text { CID } & \text {-cytomegalovirus inclusion disease } \\ \text { CIITA } & \text {-class II tranactivator } \\ \text { CMV } & \text {-cytomegalovirus } \\ \text { CTL } & \text {-cytotoxic T lymphocytes } \\ \text { E } & \text {-early } \\ \text { ELAM-1 } & \text {-endothelial leukocyte adhesion molecule 1 } \\ \text { ER } & \text {-endoplasmic reticulum } \\ \text { gP } & \text {-glycoprotein } \\ \text { GVHD } & \text {-graft-versus-host disease } \\ \text { HCMV } & \text {-human CMV } \\ \text { HIV } & \text {-human immune deficiency virus } \\ \text { HLA } & \text {-human leukocyte antigen } \\ \text { ICAM-1 } & \text {-intercellular adhesion molecule 1 } \\ \text { IE } & \text {-immediate early } \\ \text { IFNY } & \text {-interferon Y } \\ \text { Ii } & \text {-invariant chain trimers } \\ \text { II-6 etc. } & \text {-interleukin 6 } \\ \text { Jak1 } & \text {-Janus kinase 1 } \\ \text { L } & \text {-late } \\ \text { LFA-3 } & \text {-leukocyte function antigen 3 } \\ \text { LIR-1 } & \text {-leukocyte immunoglobulin-like receptor 1 } \\ \text { MCMV } & \text {-murin CMV } \\ \text { MCP-1 } & \text {-monocyte chemotactic protein 1 } \\ \text { MHC } & \text {-major histocompatibility complex } \\ \text { MIP-1a } & \text {-macrophage inflammatory protein 1a } \\ \text { NK cells } & \text {-natural killer cells } \\ \text { PDGF-BB } & \text {-platelet-derived growth factor BB } \\ \text { RANTES } & \text {-regulated upon activation, normally T expressed and secreted } \\ \text { RCMV } & \text {-rat CMV } \\ \text { STAT-1 } & \text {-signal transducer and activator of transcription 1 } \\ \text { TAP } & \text {-transporter associated with antigen presentation } \\ \text { TGF-B } & \text {-transforming growth factor B } \\ \text { Th1 } & \text {-T helper 1 } \\ \text { TNFa } & \text {-tumor necrosis factor a } \\ \text { TXAA } & \text {-transplant-associated arteriosclerosis } \\ \text { UL } & \text {-unique long } \\ \text { US } & \text {-unique short } \\ \text { VCAM-1 } & \text {-vascular adhesion molecule 1 } \\ \text { VLA-4 } & \text {-very late antigen 4 } \\ & \end{array}$




CHAPTER 1

General introduction 
Cytomegalovirus infection 25.

\section{Introduction}

Cytomegalovirus (CMV) infections are characterized by the enlargement of infected cells, called cytomegaly (76). Based on its architecture, genomic organization, species specificity, long reproduction cycle and enlargement of infected cells, the virus is classified as a $\beta$-herpesvirus (197).

Infections with HCMV (Human CMV) are very common and the percentage of HCMV seropositive individuals ranges from $50 \%$ to $80 \%(114$, 240). The prevalence of HCMV infections varies between different areas in the world and also between different age and socio-economic groups (232). The percentage of infection increases with age and with low socio-economic status. Transmission of the virus occurs by urine, respiratory secretion, blood, semen, breast milk, feces and transplanted organs $(210,233,275)$. Primary infections are usually acquired from the mother by breast feeding, after transmission from child to child in day care centers and schools $(185,233)$ or during young adulthood through sexual contact (95). The species specificity of the virus makes that research on CMV has to occur with a correct combination of host and virus. To learn more about the pathogenesis of human CMV (HCMV), specific animal models are used for studies in mouse (murine CMV; $M C M V$ ) and rat (rat CMV; RCMV).

\section{Course of infection}

When the host for the first time acquires a CMV infection, this is called a primary infection. The outcome of an infection depends on the immune status of the host. In an immunocompetent host infection with the virus mostly results in an asymptomatic infection, only occasionally leading to a mononucleosis-like disease (241). However, the immunesystem is unable to eliminate the virus completely, allowing the virus to persist in the host. Cells known to be susceptible for CMV infection are hepatocytes, dendritic cells, endothelial cells, fibroblasts, smooth muscle cells and monocytes/macrophages (103, 212, 223-225, 262). Animal models, especially rat and mouse models, offer the opportunity to study in vivo infections and the pathogenesis they induce $(26,196)$. In the mouse model it has been shown that after primary infection there are two peaks of viremia, i.e. the period in which the virus is present in blood(cells). In the first peak (day 2-3) only small amounts of CMV DNA were detected, while in the second peak (day 5-7) more DNA was found. This is probably the result of replication and release of infectious virus from organs such as spleen and liver. Viral RNA consisting of both immediate early and late transcripts was detected only in the mononuclear phagocytes, indicating viral replication $(45,242)$. In the rat, infectious virus particles can be detected in most organs during the acute phase of the RCMV infection (day 5-14) (24, 25, 27, 263). The amount of virus detected in the organs of infected animals depends on the immune status of the host, the infection route, the amount of virus that is injected and genetic factors of the host $(10,27,202,222)$.

In the chronic phase of the infection the virus only replicates in the salivary glands and is excreted in the saliva. In these glands the virus persists 
for several weeks to several months, depending on the rat strain used. Later on, when infectious virus or viral antigens are no longer detectable, a period of latency occurs (27). Despite the absence of viral antigens during latency, low amounts of viral DNA can still be detected in many organs $(1,71,90,123$, 193). Recent work in a mouse model shows that during latency no infectious virus or viral productive cycle transcripts could be detected (203). Especially the lung and progenitor blood cells are mentioned as major organ sites of CMV latency $(11,63,82,124,125,137,173,192,286)$.

Under certain conditions, e.g. during periods of immunosuppression or after organ transplantation, the virus can reactivate from this latent state. Because of the high incidence of latent CMV infection in healthy subjects, clinically apparent HCMV infection is mostly the result of reactivation of a latent infection. The exact mechanisms involved in reactivation are unknown, but studies suggest that it is a multistep process which is initiated by factors induced as a result of allogeneic transplantation $(101,102)$. In vitro reactivation of latent CMV has been shown to occur by explantation, or by coculture techniques $(75,112,165,194)$. The risk of reactivation depends on the load of viral genome in organs, which depends on the conditions of the primary infection (202). Recently, it has been shown that in latently infected mice lungs focal transcription of the virus genome occurs, while the latent viral DNA is evenly distributed in the organ (137). However, when pieces of lung were cultured in the absence of immune cells, reactivation did not occur, suggesting that reactivation is not a spontaneous process, but rather an induced event (138). Known stimuli for reactivation are immunosuppression, allograft rejection and other infections $(23,24,30,83,100,202,228)$, as shown by reactivation of CMV after transplantation or in patients suffering from AIDS. Tumor necrosis factor-alpha (TNF $\alpha$ ) has been shown to stimulate CMV activity in human monocytic cells. This cytokine is enhanced in plasma of many patients with liver cirrhosis, immunodeficiency and leukemia, and may thus have a central role in CMV reactivation $(61,70,237)$. NF- $\kappa B$ is also suggested to be involved in the multistep reactivation process (102). The viral genome contains genes that encode for proteins involved in cell-cycle progression. The human cytomegalovirus protein UL69 can cause a block in the $\mathrm{G} 1$-phase $(59,157)$ and the IE $1-72$ and IE2-86 proteins are able to induce cell proliferation (38). Infection of cells with HCMV during S-phase results in a blockade to IE-gene expression. This blockade could be overcome by proteasome inhibitors (72). These data indicate that the virus is able to reactivate itself under certain conditions.

\section{Pathology}

In the immunocompetent host CMV-infection mostly results in an asymptomatic infection, only occasionally leading to a mononucleosis-like disease. Complications such as pneumonia, myocarditis, meningoencephalitis and hepatosplenomegaly seldomly do occur $(120,241)$.

While in healthy individuals CMV infections only seldomly cause clinical symptoms, in immunocompromised patients such as AIDS patients or transplant recipients, CMV can be the cause of morbidity and mortality. CMV infections are also dangerous to embryos and fetuses with an incomplete 
immune system, resulting in abortion or congenital disorders. Primary infection of the mother during pregnancy cari result in cytomegalic inclusion disease (CID) of the fetus. Of the congenitally infected children about $10 \%$ develop acute symptoms such as hepatosplenomegaly, disorders of the central nervous system and deafness $(96,140,141,186)$.

In human immunodeficiency virus (HIV) seropositive adults the prevalence of CMV infection is nearly $100 \%$. At low CD4 T cell numbers, generalized infection with viremia and infectious virus excretion is common. The infection results in symptoms as retinitis, gastrointestinal ulcers and CMV pneumonia (217). However, CMV infection may also contribute to morbidity and mortality in other ways. Evidence is found that CMV infection affects the course of other opportunistic infections (87) and that a CMV infection can alter the course of the HIV infection. Both in vivo and in vitro data support the theory that CMV infection can accelerate the development of AIDS (199, 273).

In the past few years there is increasing evidence that CMV is involved in vascular pathology. CMV-infected capillaries and venules have been described in a variety of organs. Melnick et al (168) were the first to describe a relation between the presence of CMV and atherosclerosis. These data were confirmed in animal models, where MCMV infection exacerbates the atherosclerotic process in apoE knockout mice and increases T-cell influx in atherosclerotic lesions (261). However, the existence of this relation is not always confirmed (52). Others have mentioned an association between CMV infection, high plasma factor VIII levels, peripheral arterial disease and venous thromboembolism. The group of Epstein detected an association between prior CMV infection and the risk of restenosis after coronary arthrectomy $(64,284)$ that was confirmed in an animal model $(285)$. The HCMV IE84 protein may contribute to the development of restenosis by inhibition of the tumor suppressor protein p53 (230).

Due to a combination of high prevalence of (latent) CMV infection, immunosuppressive therapy and alloreaction-induced reactivation of the virus, CMV infections occur frequently in organ transplant recipients. Primary infections are rare in transplanted patients. CMV infection in the transplant recipients mostly occurs by reactivation of latent virus from either the recipient or from an infected organ graft. The latter may result in a primary infection in the previously seronegative recipient, since this pathogen is new to the recipients immunesystem. Previously CMV-infected recipients can also be reinfected with a new strain from the donor (44). The manifestation of CMV infection depends on several variables, such as the immunosuppression regimen, the graft match, the infection being primary or reactivated and the type of organ that is transplanted. The symptoms tend to be more severe in primary than in reactivated infections (18). Also patients receiving a heart or liver are more at risk for CMV disease than kidney transplant recipients $(70$, $97,215)$. It is assumed that latently infected cells in the allograft carry the infection to the donor. Some have suggested that contaminated blood leukocytes may be the site of latent infection. The high frequency of primary infections in the group of seronegative recipients receiving a seropositive donor organ suggests that infected blood cells are present in the transplanted 
organ. The absence of high numbers of infected cells in the peripheral blood makes this hypothesis questionable. The frequency of transmission of CMV in a unit of blood has been estimated to be less than $3 \%(8)$. However, during latency (low amounts of) viral DNA can still be detected in many organs (1, $90,123,193)$, thus explaining the high incidence of primary infections in organ transplant recipients. Which cells transmit the virus from the donor to the recipient will remain unclear until more sensitive methods will be available to detect these infected cells. Apart from symptoms associated with acute infection as pneumonia and hepatitis, CMV has also been associated with acute and chronic rejection of the transplanted organ $(6,66,99,167$, 195). Chronic rejection, also called transplant-associated arteriosclerosis (TXAA), or accelerated allograft arteriosclerosis, is a major cause of graft failure in almost all solid organ transplants $(128,130,131,146,152,164$, 238). The most common observed pathological manifestations of TXAA are perivascular inflammation (perivasculitis) and intimal thickening in the arteries of the graft $(29,78,129,150,152)$. It is hypothesized that inflammatory cells and the factors they produce are important for the process of intimal thickening. In agreement with this hypothesis is the fact that immunosuppression of the recipient increases the perivasculitis, through an increase in viral load (151). Furthermore, the increased inflammation and neointima formation caused by RCMV could be prevented by using antiviral $(31,145)$ or immunosuppressive drugs (147). However, conflicting data on the effect of CMV infection on chronic rejection are found $(35,52,274)$.

Suggestions are made that $T$-cell reponse to allogeneic infected endothelial cells and thereby vascular sclerosis can not be prevented by antiviral drugs (267). Recent studies suggest that CMV disease plays a role in the pathogenesis of chronic rejection only in the presence of acute rejection (66, 99). Therefore special attention has to be paid to inclusion criteria for CMV infection in transplant recipients when studying the influence of CMV on chronic rejection.

As in organ transplant recipients, CMV infection frequently occurs in allogeneic bone marrow transplant recipients. CMV infection, which can cause an interstitial pneumonitis with a high overall mortality, is also a frequent cause of death in bone marrow transplant recipients (169). Apart from that, the virus is associated with an increased incidence of graft-versushost disease (GVHD) (215). Studies in mice have shown that only active virus present early after infection in a MHC class I mismatched transplantation accelerates the GVHD $(50,106,258)$. The production of a CMV-induced CD-13 specific autoimmune reaction is suggested to be a possible cause of chronic GVHD $(226,227)$.

\section{Immune response to $\mathrm{CMV}$}

\section{Humoral immune response}

Both cellular and humoral immune responses play a role in the control of CMV infection. Although the humoral immune response to viruses is often not able to prevent disease $(60)$, it has been shown that the maternal immune 
response is important in preventing cin ato are able to neutralize free virus particies, and swenk shos have shown that the presence of circulating antibodies protects from reintection (2) and is positively correlated with low viral load and survival after bone marrow transplantation (219). Rat studies revealed that the persistence of RCMV in the salivary glands contributes to the anti-RCMV humoral immunity of infected rats (122). Antibodies are generated against both CMV early and CMV late proteins, but only antibodies directed against the glycoproteins gB and $\mathrm{gH}$ are able to neutralize circulating virus particles and limit dissemination of virus in the host $(163,252)$. The appearance of these glycoprotein-specific antibodies in primary CMV-infected patients is delayed compared to immunoglobulins directed against other HCMV-specific antigens. In contrast, during reactivation or reinfection, a synchronized production of antibodies is found (218). An intense and early antibody response to $\mathrm{gB}$ in patients undergoing primary HCMV infection has shown to have no effect on clinical manifestations of the disease, but a deficient response in neutralizing antibodies was observed more often in patients with more severe clinical symptoms, suggesting that the strength of the neutralizing antibody response to HCMV generated early after infection might determine the severity of the infection (4).

\section{Cellular immune response}

The immune response to viruses is mainly achieved by the cellular immune response. The cellular immune response consists especially of CD8 $T$ cells, $\mathrm{CD}^{+} \mathrm{T}$ cells and NK cells. Studies in rat have shown that CMV infection increases the number of inflammatory cells in the perivascular areas of transplanted organs $(129,150,164,239)$ and induces damage in the allograft $(130,150,164)$. Different studies report increases in CD4 ${ }^{\prime}$ and CD8' T cells, NK cells and macrophages in or around the transplanted organ. The intensity of CMV infection is correlated to the amount of allograft damage (151) and can be reduced by antiviral (145) or immunosuppressive (147) treatment. These data indicate that CMV infection triggers the immunesystem. The activated immunesystem reacts with the cells of the transplanted organ and is able to cause damage to the allograft (33). In transplant recipients with a CMV infection, the increase in $\mathrm{CD} 4^{+} \mathrm{T}$ cells, CD8 ${ }^{+} \mathrm{T}$ cells and NK cells is suggested to be related to the risk of developing CMV disease $(134,149,198,207,208$, 257).

Also in the absence of transplantation acute CMV infection has been shown to have effects on the immunesystem. Due to acute CMV infection the number of CD4 $\mathrm{T}$ cells, CD8 ${ }^{+} \mathrm{T}$ cells and NK cells in the peripheral blood increases $(12,37,62,265)$. A subpopulation of the T lymphocytes, the $(\alpha \beta 3-T$ cells, seems to play protective roles at an early phase of the CMV infection $(56,178)$. Part of this effect can still be detected in latently infected volunteers and blood donors, showing increases in the number of CD4 $\mathrm{T}$ cells and $\mathrm{CD}^{+} T$ cells and changes in the CD4/CD8 ratio $(75,77,148,155,270$, 272). Stimulation of these primed $\mathrm{CD} 4^{+} \mathrm{T}$ cells and $\mathrm{CD} 8^{+} \mathrm{T}$ cells results in a rapid anti-CMV response $(54,84)$.

Studies on the effect of depletion of (subsets of) T cells or NK cells in CMV-infected animals show that depletion of one subset of these cells has an 
effect on the control of the CMV infection. The depletion of NK cells resulted in an increase in disease $(32,104,221,279)$ while the depletion of CD4 ${ }^{*} T$ cells caused a delay in clearance of the virus or an increase in viral load (49, $65,110,132)$. The CD8 ${ }^{+} \mathrm{T}$ cells are important in preventing CMV disease in bone marrow transplant (BMT) recipients $(9,139)$. These data lead to the idea that restoration of the CMV-response of $\left(C D 8^{+}\right) \mathrm{T}$ cells in BMT-recipients may prevent lethal disease and studies show that the transfer of CMV-specific $T$ cells may be an effective therapy $(211,234,269)$. However, the cellular defense mechanisms seem to be flexible: in the absence of one of the subsets of cells, other subsets are sometimes able to take over their task $(111,139$, 191). The mechanism used by the NK/CD8 + T cells to control the virus infection even seems to be organ-dependent $(213,246)$.

\section{Cytokines, chemokines and growth factors}

CMV infection increases the production of many cytokines, chemokines and growth factors like IL $1 \alpha, \mathrm{IL}-6, \mathrm{IL}-8, \mathrm{IL}-12, \mathrm{IFN}-\gamma, \mathrm{TNF} \alpha, \mathrm{MIP} 1 \alpha, \mathrm{MCP}-1, \mathrm{TGF}-\beta$, PDGF-BB and RANTES $(80,144,175,180,216,282)$. CMV induces this increase either directly, by inducing or stimulating the production in infected cells, or indirect, by activating immune cells. The upregulation of cytokines and their receptors are critical for the initiation and coordination of immune responses. Chemokines are able to attract cells to the place they are needed and growth factors can induce cell division. In the fine tuning of all these processes a very broad spectrum of communication molecules is involved, explaining the high number of different molecules produced upon CMV infection.

CMV can infect many different cell types, that are known to produce different molecules upon infection. CMV-infected endothelial cells produce IL6 , a cytokine that is suggested to play a role in thrombosis and vascular plaque instability (259), while infected fibroblasts can increase the excretion of IL- 8 that stimulates neutrophil transendothelial migration (48) and induces an endothelial cell growth factor (5). The CMV-induced neutrophil recruitment could enhance CMV dissemination since the infected neutrophils are able to transport the virus through the host (181). The production of IL-8 is suggested to be suitable as a marker for the development of CMV disease: In patients who develop CMV disease the plasma levels of IL-8 are higher, whereas the levels of MIP-1 $\alpha$ (macrophage inflammatory protein-1 $\alpha$ ) are lower than in patients who do not develop CMV disease (181). Infected splenocytes produce increased amounts of TGF- $\beta$ (transforming growth factor- $\beta$ ), a factor that inhibits IL-2-induced proliferation of T cells and may thus contribute to a state of immunosuppression during CMV infection (80). This factor is also produced by infected allografts, together with PDGF-BB (platelet-derived growth factor-BB) (144). In infected monocytes the IE genes of CMV are able to upregulate the TNF- $\alpha$ gene expression (74).

Apart form the direct stimulation of the production of cytokines, chemokines and growth factors by CMV, different leukocytes are able to produce soluble molecules upon activation by infected cells or virus particles. Induced by the presence of virus particles, mononuclear cells produce IFN- $c$, a protein that together with IFN- $\gamma$ is suggested to play a role in the reduction of CMV replication $(57,93)$, but on the other hand may be an important 
mediator of CMV-induced immunosuppression by inhibiting phagocytic activicy of monocytes (179). Activated anti-CMV CD4 T cells show an increased production of IFN-y and TNF- $x$ (53), that have shown to play an important role in the reduction of CMV replication $(28,57,89)$. Gamma-interferon represents one of the essential factors involved in salivary gland clearance, establishment of latency and control of virus transmission (158) and is able to restore CMV antigen presentation after viral intervention in the antigen presentation route (93). Helper T cells are important in developing an immune response suitable for the situation, and are divided in a Thelper 1 (Th1) and Th2 response. The Th1 cells produce IL- 2 and IFN $-\gamma$, whereas Th2 cells produce IL-4 and IL-10. Th1 cells are involved in cell-mediated inflammatory reactions, while Th2 cytokines encourage antibody production (176). Hence, the production of IFN- $\gamma$ after stimulation of anti-CD4+ T cells stimulates a cellular immune response, suitable for a virus infection. Surprisingly, IFN- $\%$ has also been suggested to be able to play opposite roles in CMV replication, since low concentrations of the cytokines enhance viral replication (81). Injection of mice with anti-CD3 antibodies 4 weeks after CMV infection results in a lethal pneumonitis with high levels of TNF- $\alpha$ and IFN- $\gamma$ and no detectable levels of MCMV (245), showing that T cel! responsiveness to stimulation by CD3 molecules has probably been modified by the CMV infection. Monocytes are able to produce different cytokines upon CMV infection, some with opposite effects: TNF- $\alpha$, a proinflammatory cytokine and IL-10, an anti-inflammatory cytokine. The balance between these two cytokines might be indicative for the development of CMV-disease (182). Also the expression of TNF- $x$ is suggested to be an indicator for the development of CMV disease, since high TNF- $\alpha$ levels are associated with CMV reactivation $(102,249)$.

These data suggest that the virus can either directly cause disease or increase the production of factors. This increase in cytokines, chemokines or growth factors may, as described above, result in increased blood clothing, inflammation or cell growth, thus inducing CMV-related diseases like chronic rejection or atherosclerosis. Some of the produced factors help to clear the virus or control the viral infection, but others have immunosuppressive effects and support the survival of the virus. Therefore cytokines may be useful as markers for the development of CMV-disease or CMV-related diseases.

\section{Adhesion molecules and MHC}

For the leukocytes to leave the bloodstream and to enter the organ containing the infected cells, expression of adhesion molecules on both leukocytes and endothelial cells is necessary. Expression of adhesion molecules on other cells can facilitate the interaction between leukocytes and their target cells, and thereby contribute to the destruction of the infected cells or, in case of organ transplantation, the rejection of the transplanted organ $(34,36,231)$. In vitro studies have shown that CMV is able to induce upregulation of ICAM-1, VCAM1, ELAM-1, E-selectin, LFA-3 and CD44 expression (47, 58, 105, 220, 229, 256, 266,268 ). The expression of some of these adhesion molecules is induced directly by the CMV infection, while others are induced by increased production of cytokines. A direct effect of $C M V$ was shown to be the 
expression of ICAM-1, LFA-3 and CD44 (47, 105, 220, 256) while the upregulation of VCAM-1, E-selectin, ELAM-1 and ICAM-1 could be detected on non-infected cells $(58,229,266,268)$. This indirect effect of CMV infection could lead to a facilitated interaction between the leukocytes and the infected cells. In vivo the effect of CMV infection on adhesion molecule expression is always examined in combination with transplantation. This combination is important, since a very promising method to prevent allograft rejection seems to be the treatment with monoclonal antibodies to various cell adhesion molecules $(85,280,281)$. CMV infection after transplantation has been shown to induce ICAM-1, VCAM-1, LFA-1 and VLA-4 expression (121, $127,145,164,238,283)$. These results indicated that CMV infection is able to induce different adhesion molecules involved in multiple steps of leukocyte adhesion and migration.

It is known that MHC class I and II molecule expression are very important in viral immunity. The MHC class I complex is present on almost all cells and is able to present viral proteins on the cell membrane when the cell is infected. The CD8 ${ }^{+} \mathrm{T}$ cells scan the MHC class I molecules for foreign (viral) proteins and can thus detect and remove infected cells. MHC class II molecules are present on antigen presenting cells (APCS) and can be induced on other cell types like endothelial en epithelial cells. The MHC class II molecule expressing cells can present (viral) proteins they detect in their surroundings to $T$ cells. The $C D 4^{+} T$ cells will react on the presentation of proteins by $\mathrm{MHC}$ class II by multiplication and excretion of cytokines. The cytokines are able to activate other cells of the immune system. The expression of MHC class II molecules on endothelial cells is upregulated due to CMV infection $(250,253,255,256,266,268)$. This effect is most likely not a direct effect, but induced by infection of surrounding cells $(256,268)$. This effect is not only detected in vitro, but also in vivo when animals with transplanted organs are infected with CMV $(145,238,254)$. On endothelial cells the expression of $\mathrm{MHC}$ class I complexes also seems to be increased after CMV infection $(250,256,266,268)$. However, only a small percentage of the endothelial cells becomes infected with CMV and the upregulation of $\mathrm{MHC}$ class I expression is probably an indirect effect. Recent data show tílat on infected cells the expression of $\mathrm{MHC}$ class $1(92,94,113,268,276)$ and $M H C$ class II molecules $(88,171,204,248)$ is decreased. This downregulation of the $\mathrm{MHC}$ molecule expression and its effect will be described later.

\section{Escape mechanisms of CMV}

\section{Introduction}

Many viruses have been described to evade the immune response of the host. During a long coevolution with their host, these viruses have developed mechanisms to prevent rapid clearance by the immune system of the host $(166,190,277)$. The herpesviruses, and especially the cytomegaloviruses, use different immune evasion strategies ranging from downregu' I and II molecules to the expression of decoy receptors and cytokines $(91,94,154)$. 


\section{MHC class I downregulation}

Studies with murine and humain $\mathrm{Cm}$ se p-herpesviruses are capable of inhibiting the presentati: molecules in numerous ways $(94,190,2$; des by MHC class 1 from proteolytic degradation of virally encoded proteins by a multicatalytic cytosolic complex, the proteasome. The peptides are transported from the cytosol into the Endoplasmic Reticulum (ER) by the Transporter associated with Antigen Presentation (TAP). In the ER, the trimolecular complex consisting of the MHC class I heavy chain, the light chain $\beta_{2}$-microgtobulin $\left(\beta_{2} \mathrm{~m}\right)$ and peptide is formed. Only the complexes consisting of a properly folded $M H C$ class I heavy chain, $\beta_{2} \mathrm{~m}$ and a peptide are stable, whereas other forms are rapidly degraded. The MHC class I complex is transported from the ER to the cell membrane, where it presents the endogenous peptides to cytotoxic T cells $(86,166,214)$.

To date, 4 genes have been identified in HCMV that affect MHC class I restricted antigen presentation. The HCMV US3 gene encodes a protein, which prevents intracellular transport of MHC class I molecules from the ER $(3,109)$. US2 and US11 encode proteins that cause rapid degradation of MHC class I molecules by dislocating the class I heavy chain from the ER to the cytosol, where they are degraded by the proteasome $(107,108,243,276,278)$. The protein encoded by US6 acts in yet another way. The US6 gene product blocks translocation of peptides into the ER by TAP. As a consequence, the MHC class I molecules can no longer form stable complexes and are degraded (143). Interestingly, this degradation of MHC class I heavy chain occurs in the cytosol, via the same pathway that is used by HCMV US2 and US11 to target the MHC class I molecules for destruction. This pathway was first described in the context of US2 and US11 and is used generally by the cell to dispose off proteins that do not fold and assemble properly. This degradation pathway forms a part of the cellular quality control process $(243,278)$. The presence of these diverse defense mechanisms resulting in a similar effect is probably evolved as a response to MHC class I polymorphism, since the US11 and US2 gene products are known to differ in their ability to attack allelic forms of murine MHC class I heavy chains (161). The proteins encoded by US3 and US6 are able to cause a decrease in the expression of HLA-G and HLA-C expressed on trophoblasts and might be responsible for HCMV-related spontaneous pregnancy loss (113). The expression of these immunoregulatory viral proteins could be used in the future as a potential strategy to prolong transgene expression in vivo (17).

MCMV encodes at least three glycoproteins that affect the expression of class I MHC complexes, but these gene products have no homologs in HCMV. The protein encoded by the $\mathrm{m} 152$ gene prevents export of class I complexes from the post-ER/early Golgi $(135,287)$. The gene product encoded by m06 binds to the MHC complex in the ER and accompanies the MHC molecules through the Golgi. However, instead of migrating to the cell surface, the complex is degraded in a lysosomal compartment (206). A third gene product, the m04-encoded gp34, associates with the properly folded MHC class I molecule in the ER. The resulting complex is transported to the cell membrane. The gp34-MHC class I complex has been suggested to act as a non- 
functional decoy, preventing recognition by $\mathrm{T}$ cells and at the same time inhibiting NK cell activation $(116,117,119)$.

Two additional cellular proteins, aminopeptidase N (CD13) and neutral endopeptidase (CD10) are now identified as proteins that are downregulated during HCMV infection in fibroblasts. These molecules are known to have a role in peptide processing in both the MHC class I and II antigen processing pathway, but the exact advantage of the virus by downregulating CD10 and CD13 is yet unknown (189).

\section{NK cell evasion}

NK cells selectively kill targets that lack expression of MHC class I (153). Downregulation of MHC class I expression upon CMV infection would place the infected cells at risk for NK-mediated lysis. The above mentioned $\mathrm{mo4}^{-}$ encoded gp34-MHC class I complex might contribute to NK cell evasion (116, $117,119)$. Another mechanism described to occur in both MCMV, RCMV and HCMV infected cells is the expression of a MHC class I homolog $(13,15,42,46$, 68). The HCMV and MCMV MHC class I homologs (the UL18 and m144 gene products, respectively) both form complexes with $\beta_{2} m(22,42)$ and UL18 binds endogenous peptides (67). Expression of the UL18 or m144 gene product protects at least partially from NK cell function $(51,69,115,136,209)$. A recent study shows that HCMV-infected endothelial cells and macrophages are less susceptible to NK cell lysis than non-infected cells, independent of HLA class I downregulation or UL18 expression (183). The UL18 encoded protein binds to LIR-1 (leukocyte immunoglobulin-like receptor-1), a receptor that is expressed on B cells and subsets of NK and T cells. LIR-1 binds to MHC class I molecules and activation of the receptor results in an inhibitory signal (43, 46, 260). MCMV has been shown to encode another MHC-like protein (m157) that binds to an inhibitory NK cell receptor in certain MCMV-susceptible mice. In $M C M V$-resistant mice this viral protein engages a related activating recepiou and confers host protection (7).

Recently it has been shown that HCMV possesses other mechanisms, related neither to target cell expression of HLA-I nor to NK cell expression of LIR-1. A HCMV-encoded glycoprotein gpUL40 enhances the surface expression of HLA-E. HLA-E is a nonclassical MHC class I molecule, that can protect target cells from NK cell lysis $(39,40,247,251,271)$.

\section{MHC class II downregulation}

CMV has evolved different mechanisms for inhibiting MHC class II expression and thus escaping $\mathrm{CD}^{+} \mathrm{T}$ cell immunosurveillance. Professional APC, $1 \mathrm{~B}$ macrophages and dendritic cells, express MHC class II molecules constitutively, while cytokines, particularly IFN- $\gamma$, induce MHC class II expression on endothelial and epithelial cells (21). Class II transactivator (CIITA) is the limiting and essential factor in the regulation of both constitutive and inducible $\mathrm{MHC}$ class II expression (235, 236) of CIITA is regulated by four distinct promoter regions. Wher. expressed constitutively, the CIITA promoter regions I and III and in the case of IFN- $\gamma$-induced expression, region IV is activ the IFN- $\gamma$ signal transduction pathway, INF- $\gamma$ binds to its receF 
the phosphorylation of the receptor-associated kinases Jakt (Janus knase 1 ) and Jak2. These kinases phosphorylate latent cytoplasmic STAT-1 (signal transducer and activator of transcription 1) that forms a homodimer and translocates to the nucleus, to activate IFN- $\gamma$-stimulated genes, that induce CIITA transcription (170).

The transcription and translation of $M H C$ class $I$ genes results in the production of $\alpha$ and $\beta$ chains, that dimerize in the ER. Here, three class II dimers bind invariant chain trimers (li) forming a complex. Ii regulates class $I I$ trafficking through the Golgi complex to the late endosomes (184). In the endosomes, li is degraded and small fragments remain associated with the class II heterodimers until they are loaded with peptides in the MHC class II compartments and expressed on the membrane (170).

Studies with HCMV and MCMV reveal two distinct mechanisms for the CMV-mediated block in IFN- $\gamma$-inducible MHC class II transcriptions, operative at different times. Early after infection there is an HCMV- and MCMVmediated repression of CIITA expression or function while the IFN- $\gamma$-stimulated signal transduction pathway remains intact $(88,142)$. At later times after infection, HCMV blocks the IFN- $\gamma$-stimulated CIITA activation through a decrease in Jak1 expression (171). The constitutive MHC class II expression is downregulated in a completely different way. Using an in vitro transfection model, evidence is found that the HCMV US2-encoded protein, which mediates the reverse translocation of $M H C$ class I heavy chains from the ER to the cytosol, may similarly target HLA-DR and HLA-DM for degradation (248).

Apart from these mechanisms of decrease in MHC class II expression, cytokines are also believed to play a role. The type I interferons (IFN- $\alpha$ and IFN- $\beta$ ) downregulate $M H C$ class II expression at the transcriptional level by a mechanism downstream of CIITA expression (156). These IFNs do not mediate a decrease of MHC class II molecules on infected cells, but rather in the surrounding tissues $(88,172)$. Recently also IL-10, which is induced in the course of MCMV infection, was shown to indirectly donwregulate constitutive MHC class II expression in both noninfected and MCMV-infected macrophages (204). This downregulation is the result of inhibition of the presentation of peptide-loaded class II molecules and recycling of these molecules at the plasma membrane (126).

\section{CMV-encoded $G$ protein-coupled receptors and cytokines}

$G$ protein-coupled receptors (GCRs) are members of a ige and diverse family of receptors that function in signal transduction through cell membranes. All $G$ proteins consist of seven transmembrane loops and most of these receptors can activate intracellular $G$ proteins and thus transduce messages inco the $\mathrm{cen}$ (187). The genomes of HCMV, MCMV and RCMV all encode several genes that are capable of encoding homologues of host cell GCRs. The HCMV genome encodes four GCRs: US27, US28, UL33 and UL78 $(162,244)$, but RCMV $(14,16)$ and MCMV (201) only encode for homologues of UL33 and UL78 and $M 78$, respectively). US28 is the most characterized of the homologues. The US28 protein was reported to be able to binc like RANTES, MIP-1 and MCP-1 (162). The function of the US28 receptor is unknown, although it has been suggested that it me 
inflammatory events during HCMV infection by sequestering chemokines ( 20 , 118). Stimulation of the US28-encoded receptor with RANTES can prevent infected cells from apoptosis as induced by growth factor withdrawal (19). Recently a link has been made between the presence of viral GCRs and the accelerating influence of CMV infection on vascular disease. Expression of the US28 protein in SMCs in the presence of these chemokines causes SMC migration (244), which may result in thickening of the vessel and decrease in the blood flow through the vessel. The UL33 and UL78-like proteins have been studied both in vitro and in vivo. The UL33, M33 and R33 genes were found to be dispensable for in vitro replication of CMV, but both $M 33$ and R33 were shown to be essential for virus replication in vivo $(16,55,162)$. Also a significantly lower mortality was seen among rats infected with a deletion mutant of RCMV missing the R33 gene (16). The protein encoded by R33 is expressed as a functional GCR, that signals in an agonist-independent manner and, in contrast to its human homolog pR33, does not bind RANTES (79).

Only little is known about the proteins derived from UL78-like genes. Recombinant RCMV viruses lacking the R78 gene produced 10 - to 100 -fold lower virus titers than wild type virus in vitro, and in vivo the deletion mutant viruses showed decreased mortality but no decrease in replication (14). Although these data underline the importance of the viral G protein-coupled receptors in the pathogenesis of CMV infection, the exact function of these genes is still unknown.

The group of cytomegaloviruses also encodes for homologs of chemokines. Chemokines are chemoattractant cytokines that play a role in inflammatory responses against various pathogens by promoting the infiltration of leukocytes. To date, only in the genomes of HCMV and MCMV homologs of chemokines have detected. HCMV encodes three chemokines (UL146, UL147 and UL152) $(41,188)$ and MCMV encodes one chemokine (m131/129) $(68,159,160)$. A deletion mutant MCMV strain lacking the $\mathrm{m} 131$ gene was cleared faster after in vivo infection and elicited a weaker inflammatory response than wild type virus (68). The HCMV UL146 encodes a fully functional $\alpha$ chemokine, inducing calcium mobilization, chemotaxis and degranulation of neutrophils (188). The chemokines may ensure the active recruitment of inflammatory cells during CMV infection, thereby providing efficient dissemination during acute infection.

Finally, HCMV encodes for another type of cytokine. UL111a encodes an IL-10 homologue that can bind the human IL-10 ceptor and can compete with human IL-10 for binding sites (133). IL-10 is able to block

proinflammatory cytokines and suppresses the ability of macrophages to serve as antigen presenting cells or as costimulatory cells. By expressing

encoded IL-10 the virus has found yet another way of suppressing the immune response.

The reason why there are so many viral proteins involved in immune evasion and the fact that they sometimes even seem to conot jet clear. Despite of the broad range of immune-evasic is not always completely hidden from the immune respons infection of different cell types could be a reason for a brc immune evasion strategies, but for spreading of the virus a 
and the presence of an mmune response may be necessary. In this light it is not surprising that CMV uses diforent strategies in different stages of the infection, in different cell types on ussues and in a genetically diverse population $(174,200)$.

\section{Outline of this thesis}

This thesis describes the interactions between cytomegalovirus infection and the immune system of the host. Infection with a microorganism like CMV result in the induction of an immune response, leading to both a humoral and a cellular immune response. Each of them contributes towards destruction or elimination of the microorganism that induced it. However, in the case of CMV the immune system is not able to kill or to remove all virus and the virus remains present in the body in a latent state. Reactivation of latent virus is a phenomenon that occurs especially in situations of severe suppression of the immune system (e.g. in transplant recipients) and may lead to serious disease. In this thesis different aspects of the interaction of CMV with components of the immune system were studied.

In chapter 2 the effect of RCMV infection on the composition of different cell types of the immune system in both immunocompetent and immunocompromised rats is described. The detection of an aberrant population of CD8 $+T$ cells with reduced expression of CD8 and TCR in immunosuppressed animals, resulted in the experiments as reported in chapter 3. Here we investigate whether this phenotypically deviant population of CD8+ T cells, that is associated with anergy, could be detected in kidney transplant recipients undergoing primary HCMV infection.

Since the virus is able to remain present in the host in a latent state, it has to be able to escape the normal immune response. Some herpes viruses are known to inhibit the expression of MHC class I, a molecule that is able to present small parts of the infecting virus on the outside of the cell, thereby enabling the $T$ cells to remove infected cells. In chapter 4 we investigate whether RCMV is able to influence the expression of MHC class I on the cell membrane and what mechanism it uses to prevent presentation of RCMV peptides on the cell membrane.

Previous studies have demonstrated that CMV infection is one of the factors that is associated with chronic rejection. CMV infection results in an increased influx of CD4+ cells and macrophages early after infection and in an increase in glomerular sclerosis and intima proliferation later on. The next two chapters focus on the influence of RCMV infection combined with other factors on chronic transplant rejection. The purpose of chapter 5 is to investigate the effect of CMV infection, of cold ischemia of the allograft $(\mathrm{Cl})$ and of the combination of both on the progression of chronic rejection in kidney transplants. We also obtain more detailed insight in their effects on the expression of adhesion molecules. In chapter 6 we describe the effects of different donor / recipient combinations and timing of the infection on RCMVenhanced development of transplant arteriosclerosis (TA). In chapter 7 the obtained results are summarised and discussed. 


\section{References}

1. Abecasses, MM, $X$ Jiang, ME O'Neil, and JF Jr Bale. 1993. Detection of murine cytomegalovirus (MCMV) DNA in skin using the polymerase chain reaction (PCR). Microb Pathogenesis. 15:17-22.

2. Adler, SP, SE Starr, SA Plotkin, SH Hempfling, J Buis, ML Manning, and AM Best. 1995. Immunity induced by primary human cytomegalovirus infection protects against secondary infection among women of childbearing age. J Inf Dis. 171:26-32.

3. Ahn, K, A Angulo, P Ghazel, PA Peterson, Y Yang, and K Fruh. 1996. Human cytomegalovirus inhibits antigen presentation by a sequential multistep process. Proc Natl Acad Sci USA. 93:10990-5.

4. Alberola, J, A Tamarit, R Igual, and D Navarro. 2000. Early neutralizing and glycoprotein B (gB)-specific antibody responses to human cytomegalovirus (HCMV) in immunocompetent individuals with distinct clinical presentations of primary infection. J Clin Virol. 16:113-22.

5. Alcami, J, T Barzu, and S Michelson. 1991. Induction of an endothelial cell growth factor by human cytomegalovirus infection of fibroblasts. J Gen Virol. 72:2765-70.

6. Almond, P.S, A Matas, K Gillingham, D.L Dunn, W.D Payne, P Gores, R Gruessner, and J.S Najarian. 1993. Risk factors for chronic rejection in renal allograft recipients. Transpl. 55:752-6.

7. Arase, H, ES Mocarski, AE Campbell, AB Hill, and LL Lanier. 2002. Direct recognition of cytomegalovirus by activating and inhibitory NK cell receptors. Science. 296:1323-6.

8. Armstrong, JA, GC Tarr, and $M$ Ho. 1976. Viral infections in renal transplant recipients. Infect Immun. 14:970-5.

9. Atherton, SS, CK Newell, MY Kanter, and SW Cousins. 1992. T cell depletion increases susceptibility to murine cytomegalovirus retinitis. Invest Ophthalmol Vis Sci. 33:3353-60.

10. Bale, JF, and ME O'Neil. 1989. Detection of murine cytomegalovirus DNA in circulating leucocytes harvested during acute infection of mice. J Virol. 63:2667-73.

11. Balthesen, M, M Messerle, and MJ Reddehase. 1993. Lungs are a major organ site of cytomegalovirus latency and recurrence. J Virol. 67:5360-6.

12. Bancroft, GJ, GR Shellam, and JE Chalmer. 1981. Genetic influences on the augmentation of natural killer (NK) cells during murine cytomegalovirus infection: correlation with patterns of resistance. J Immunol. 126:988-94.

13. Beck, S, and BG Barrell. 1988. Human cytomegalovirus encodes a glycoprotein homologous to MHC class-I antigens. Nature. 331:269-72.

14. Beisser, PS, G Grauls, CA Bruggeman, and C Vink. 1999. Deletion of the R78 G proteincoupled receptor gene from rat cytomegalovirus results in an attenuated, syncytiuminducing mutant strain. J Virol. 73:7218-30.

15. Beisser, PS, JS Kloover, GE Grauls, MJ Blok, CA Bruggeman, and C Vink. 2000. The r144 major histocompatibility complex class I-like gene of rat cytomegalovirus is dispensable for both acute and long-term infection in the immunocompromised host. J Virol. 74:1045-50.

16. Beisser, PS, C Vink, JG Van Dam, G Grauls, SJV Vanherle, and CA Bruggeman. 1998. The R33 $G$ protein-coupled receptor gene of rat cytomegalovirus plays an essential role in the pathogenesis of viral infection. J Virol. 72:2352-63.

17. Berger, C, S Xuereb, DC Johnson, KS Watanabe, HP Kiem, PD Greenberg, and SR Riddell. 2000. Expression of herpes simplex virus ICP47 and human cytomegalovirus US11 prevents recognition of transgene products by $C D 8+$ cytotoxic $T$ lymphocytes. J Virol. 74:4465-73.

18. Besse, T, J Malaise, M de Meyer, M Mouras, and JP Squifflet. 2000. Renal allograft outcome from cytomegalovirus seronegative donor into cytomegalovirus seronegative recipient: poor prognosis after seroconversion. Transplant Proc. 32:408-10.

19. Billstrom Schroeder, M, R Christensen, and GS Worthen. 2002. Human cytomegalovirus protects endothelial cells from apoptosis induced by growth factor withdrawal. J Clin Virol. 25:5149-57.

20. Bodaghi, B, TR Jones, D Zipeto, C Vita, L Sun, L Laurent, F Arenzana-Seisdedos, JL Virelizier, and $S$ Michelson. 1998. Chemokine sequestration by viral chemokinereceptors as a novel viral escape strategy; withdrawel of chemokines from the environment of cytomegalovirusinfected cells. J Exp Med. 188:855-66.

21. Boss, JM. 1997. Regulation of transcription of MHC class II genes. Curr Opin Immunol. 9:10713.

22. Browne, H., G. Smith, S. Beck, and T. Minson. 1990. A complex between the MHC class I homologue encoded by human cytomegalovirus and beta 2 microglobulin. Nature. 347:770-2. 
23. Bruggeman, CA. 1991. Reactivation of lateni ChV in the rat. Transplant Proc. 23:22-4.

24. Bruggeman, CA, WMH Debie, G Grauis, G Majoor, and CPA Van Boven. 1983. Infection of laboratory rats with a new cytomegalo-like virus. Arch Virol. 76:189-99.

25. Bruggeman, CA, G Grauls, and CPA Van Boven. 1985. Susceptibility of peritoneal macrophages to rat cytomegalovirus infection. FEBS Microb Lett. 27:263-6.

26. Bruggeman, CA, FL Li, and FS Stals. 1995. Pathogenicity: Animal models. Scand. J. Infect. Dis. $99: 43-50$.

27. Bruggeman, CA, H Meijer, F Bosman, and CP Van Boven. 1985. Biology of rat cytomegalovirus infection. Intervirol. 24:1-9.

28. Bruggeman, CA, H Schellekens, G Grauls, WHM Debie, and CPA Van Boven. 1983. Rat cytomegalovirus: induction of and sensitivity to interferon. Antiviral Research. 3:315-24.

29. Bruggeman, CA, and JG Van Dam. 1998. Role of cytomegalovirus infection in transplant arteriosclerosis, vol. 21. Karger, Basel.

30. Bruning, JH, CA Bruggeman, CP Van Boven, and PJ Van Breda Vriesman. 1986. Passive transfer of cytomegalovirus by cardiac and renal organ transplants in a rat model. Transplantation. 41:695-8.

31. Bruning, JH, M Persoons, K Lemstrom, FS Stals, E De Clercq, and CA Bruggeman. 1994. Enhancement of transplantation-associated atherosclerosis by $C M V$ which can be prevented by antiviral therapy in the form of HPMPC. Transpl int. 7:5365-9.

32. Bukowski, JF, JF Warner, G Dennert, and RM Welsh. 1985. Adoptive transfer studies demonstrating the antiviral effect of natural killer cells in vivo. J Exp Med. 161:40-52.

33. Burrows, SR, R Khanna, SL Silins, and DJ Moss. 1999. The influence of antivirai T-cell responses on the alloreactive reportoire. Immunol Today. 20:203-7.

34. Butcher, EC. 1991. Leukocyte-endothelial cell recognition: three (or more) steps to specificity and diversity. Cell. 67:1033-6.

35. Cappel, R, O Hestermans, C Toussaint, P Vereerstraeten, D van Beers, J de Braekeleer, and E Schoutens. 1978. Cytomegalovirus infection and graft survival in renal graft recipients. Arch Virol. 56:149-56.

36. Carlos, TM, and JM Harlan. 1994. Leukocyte-endothelial adhesion molecules. Blood. 84:2068101.

37. Carney, WP, RH Rubin, RA Hoffman, WP Hansen, K Healey, and MS Hirsch. 1981. Analysis of lymphocyte subsets in cytomegalovirus mononucleosis. The Journal of Immunology. 126:2114-6.

38. Castillo, JP, AD Yurochko, and IF Kowalik. 2000. Role of human cytomegalovirus immediateearly proteins in cell growth control. j Virol. 74:8028-37.

39. Cerboni, C, M Mousavi-Jazi, A Linde, K Soderstrom, M Brytting, B Wahren, K Karre, and $E$ Carbone. 2000. Human cytomegalovirus strain-dependent changes in NK cell recognition of infected fibroblasts. J Immunol. 164:4775-82.

40. Cerboni, C, M Mousavi-Jazi, H Wakiguchi, E Carbone, K Karre, and K Soderstrom. 2001. Synergistic effect of IFN-gamma and human cytomegalovirus protein UL40 in the HLA-Edependent protection from NK cell-mediated cytotoxicity. Eur J Immunol. 31:2926-35.

41. Cha, TA, E Tom, GW Kemble, GM Duke, ES Mocarski, and RR Spaete. 1996. Human cytomegalovirus clinical isolates carry at least 19 genes not found in laboratory strains. J Virol. 70:78-83.

42. Chapman, TL, and PJ Bjorkman. 1998. Characterization of a murine cytomegalovirus class I Major Histocompatibility Complex (MHC) homolog: comparison to MHC molecules and to the human cytomegalovirus MHC homolog. J Virol. 72:460-6.

43. Chapman. TL, AP Heikema, and PJ Bjorkman. 1999. The inhibitory receptor LIR-1 uses a common binding interaction to recognize class I MHC molecules and the viral homolog UL18. Immunity. 11:603-13.

44. Chou, SW. 1986. Acquisition of donor strains of cytomegalovirus by renal-transplant recipients. N Engl J Med. 314:1418-23.

45. Collins, TM, MR Quirk, and MC Jordan. 1994. Biphasic viremia and viral gene expression in leucocytes during acute cytomegalovirus infection of mice. J Virol. 68:6305-11.

46. Cosman, D., N. Fanger, and L. Borges. 1999. Human cytomegalovirus, MHC class I and inhibitory signaling receptors: more questions than answers. Immunol Rev. 168:177-85.

47. Craigen, JL, and JE Grundy. 1996. Cytomegalovirus induced up-regulation of LFA-3 (CD58) and ICAM-1 (CD54) is a direct viral effect that is not prevented by Ganciclovir or Foscarnet treatment. Transplantation. 62:1102-8. 
48. Craigen, JL, KL Yong, NJ Jordan, LP MacCormac, J Westwick, AN Akbar, and JE Grundy. 1997. Human cytomegalovirus infection up-regulates interleukin-8 gene expression and stimulates neutrophil transendothelial migration. Immunology. 92:138-45.

49. Craighead, JE, WB Martin, and SA Huber. 1992. Role of CD4+ (helper) T cells in the pathogenesis of murine cytomegalovirus myocarditis. Lab Invest. 66:755-61.

50. Cray, C, and RB Levy. 1990. The presence of infectious virus but not conventional antigen can exacerbate graft-versus-host reactions. Scand J Immunol. 32:177-82.

51. Cretney, E, MA Degli-Esposti, EH Densley, HE Farrell, NJ Davis-Poynter, and MJ Smyth. 1999. M144, a murine cytomegalovirus (MCMV)-encoded major histocompatibility complex class I homologue, confers tumor resistance to natural killer cell-mediated rejection. J Exp Med. 190:435-43.

52. Danesh, J. 1999. Coronary heart disease, helicobacter pylori, dental disease, Chlamydia pneumoniae, and cytomegalovirus: Meta-analyses of prospective studies. Am Heart J. 138:5434-7.

53. Davignon, JL, P Castanie, JA Yorke, N Gaytier, D Clement, and C Davrinche. 1996. Antihuman cytomegalovirus activity of cytokines produced by CD4+ T-cell clones specifically activated by IE1 peptides in vitro. J Virol. 70:2162-9.

54. Davignon, JL, D Clement, J Alriquet, S Michelson, and C Davrinche. 1995. Analysis of the proliferative $T$ cell response to human cytomegalovirus major immediate-early protein (IE1): phenotype, frequency and variability. Scand J Immunol. 41:247-55.

55. Davis-Poynter, NJ, DM Lynch, H Vally, GR Shellam, WD Rawlinson, BG Barrell, and HE Farrell. 1997. Identification and characterization of a G-protein coupled receptor homolog encoded by murine cytomegalovirus. J Virol. 71:1521-9.

56. Dechanet, J, P Merville, A Lim, C Retiere, V Pitard, X Lefarge, S Michelson, C Meric, MM Hallet, P Kourilsky, L Potaux, M Bonneville, and JF Moreau. 1999. Implication of gammadelta $T$ cells in the human immune response to cytomegalovirus. J Clin Invest. 103:1437-49.

57. Delannoy, AS, D Hober, A Bouzidi, and P Wattre. 1999. Role of interferon alpha (IFN-a) and interferon gamma (IFN-g) in the control of the infection of monocyte-like cells with human cytomegalovirus (HCMV). Microbiol Immunol. 43:1087-96.

58. Dengler, TJ, MJ Raferty, M Werle, R Zimmerman, and G Schionrich. 2000. Cytomegalovirus infection of vascular cells induces expression of pro-inflammatory adhesion molecules by paracrine action of secreted interleukin-1beta. Transplantation. 69:1160-8.

59. Dittmer, D., and E. S. Mocarski. 1997. Human cytomegalovirus infection inhibits $\mathrm{G} 1 / \mathrm{S}$ transition. J Virol. 71:1629-34.

60. Dix, RD, C Cray, and SW Cousins. 1997. Antibody alone does not prevent experimental cytomegalovirus retinitis in mice with retrovirus-induced immunodeficiency (MAIDS). Ophtalmic Res. 29:381-92.

61. Docke, WD, S Prosch, E Fietze, V Kimel, H Zuckermann, C Klug, U Syrbe, DH Kruger, R von Baehr, and HD Volk. 1994. Cytomegalovirus reactivation and tumour necrosis factor. Lancet. 343:268-9.

62. Doody, DP, EJ Wilson, DN Medearis, and RH Rubin. 1986. Changes in the phenotype of T-cell subset determinants following murine cytomegalovirus infection. Clin Immunol Immunopathol. 40:466-75.

63. Dumont, LJ, J Luka, T Vandenbroeke, P Whitley, DR Ambruso, and MD Elfath. 2001. The effect of leukocyte-reduction method on the amount of human cytomegalovirus in blood products: a comparison of apheresis and filtration methods. Blood. 97:3640-7.

64. Epstein, SE, E Speir, YF SZhou, E Guetta, M Leon, and T Finkel. 1996. The role of infection in restenosis and atherosclerosis: focus on cytomegalovirus. The Lancet. 348:513-7.

65. Erlich, KS, J Mills, and JD Shanley. 1989. Effects of L3T4+ lymphocyte depletion on acute murine cytomegalovirus infection. J Gen Virol. 70:1765-71.

66. Evans, PC, A Soin, TG Wreghitt, CJ Taylor, DGD Wight, and GJM Alexander. 2000. An association between cytomegalovirus infection and chronic rejection after liver transplantation. Transplantation. 69:30-5.

67. Fahnestock, ML, JL Johnson, RM Feldman, JM Neveu, WS Lane, and PJ Bjorkman. 1995. The MHC class I homolog encoded by human cytomegalovirus binds endogenous peptides. Immunity. 3:583-90.

68. Farrell, HE, MA Degli Esposti, and NJ Davis Poynter. 1999. Cytomegalovirus evasion of natural killer cell responses. Immunol Rev. 168:187-97. 




1997. Inhibition of natural killer cells by a c: :

Nature. 286:510-4.


Von Baehr, DH Kruger, and HD Volk. 1994. Cytomegalovinus infeclon in transplant recipients. Transplantation. 58:675-80.

71. Fish, KN, C Soderberg-Naucles, LK Mills, S Stenglein, and JA Nelson. 1998. Human cytomegalovirus persistently infects aortic endothelial cells. J Virol. 72:5661-8.

72. Fortunato, EA, V Sanchez, JY Yen, and DH Spector. 2002. Infection of cells with human cytomegalovirus during $S$ phase results in a blockade to Immediate-Early gene expression that can be overcome by inhibition of the proteasome. J Virol. 76:5369-79.

73. Fowler, KB, S Stagno, RF Pass, WJ Britt, TJ Boll, and CA Alford. 1992. The outcome of congenital cytomegalovirus infections in relation to maternal antibody status. $\mathrm{N}$ Engl $\mathrm{J}$ Med. 326:663-7.

74. Geist, LJ, MM Monick, MF Stinski, and GW Hunninghake. 1994. The immediate early genes of huan cytomegalovirus upregulate tumor necrosis factor-alpha gene expression. J Clin Invest. 93:474-8.

75. Gillespie, GMA, MR Wills, V Appay, C O'Callaghan, M Murphy, N Smith, P Sissons, S RowlandJones, Jl Bell, and PAH Moss. 2000. Functional heterogeneity and high frequencies of cytomegalovirus-specific CD8+ T lymphocytes in healthy seropositive individuals. J Virol. 74:8140-50.

76. Goodpasture, E, and T Talbot. 1921. Concerning the nature of protozoa-like cells in certain lesions of infancy. Am J Dis Child. 21:415-25.

77. Gratama, JW, M Kardol, AMIH Naipal, J Slats, A den Ouden, T Stijnen, H The, and JW Bruning. 1987. The influence of cytomegalovirus carrier status on lymphocyte subsets and naturel immunity. Clin Exp Immunol. 68:16-24.

78. Grattan, MT, CE Moreno-Cabral, VA Starnes, PE Oyer, EB Stinson, and NE Shumway. 1989. Cytomegalovirus infection is associated with cardiac allograft rejection and atherosclerosis. JAMA. 261:3561-66.

79. Grujjthuijsen, YK, P Casarosa, SJF Kaptein, SLV Broers, R Leurs, CA Bruggeman, MJ Smit, and $C$ Vink. 2002. The rat cytomegalovirus $R 33$-encoded $G$ protein-coupled receptor signals in a constitutive fashion. J Virol. 76:1328-38.

80. Haagmans, BL, KJ Teerds, AJM van den Eijnden-van Raay, MC Horzinek, and VEC Schijns. 1997. Transforming growth factor beta production during rat cytomegalovirus infection. J Gen Virol. 78:205-13.

81. Haagmans, BL, PH Van der Meide, FS Stals, AJ Van den Eertwegh, E Claassen, CA Bruggeman, MC Horzinek, and VE Schijns. 1994. Suppression of rat cytomegalovirus replication by antibodies against gamma interferon. J Virol. 68:2305-12.

82. Hahn, G, R Jores, and ES Mocarski. 1998. Cytomegalovirus remains latent in a common precursor of dendritic and myeloid cells. Proc Natl Acad Sci USA. 95:3937-42.

83. Hamilton, JD, and BJ Seaworth. 1985. Transmission of latent cytomegalovirus in a murine kidney transplantation model. Transplantation. 39:290-6.

84. Hazzan, M., M. Labalette, C. Noel, G. Lelievre, and J. P. Dessaint. 1997. Recall response to cytomegalovirus in allograft recipients: mobilization of CD57+, CD28+ cells before expansion of CD57+, CD28- cells within the CD8 + T lymphocyte compartment. Transplantation. 63:6938.

85. Heemann, UW, SG Tullius, H Azuma, J Kupiec-Weglinsky, and NL Tilney. 1994. Adhesion molecules and transplantation. Ann Surg. 219:4-12.

86. Heemels, MT, and H Ploegh. 1995. Generation, translocation, and presentation of MHC class 1-restricted peptides. Annu Rev Biochem. 64:463-91.

87. Heilbronn, R, I Albrecht, 5 Stephan, A Burkle, and H zur-Hausen. 1993. Human cytomegalovirus induces $J C$ virus DNA replication in human fibroblasts. J Acquir Immune Defic Syndr. 4:S6-10.

88. Heise, MT, M Connick, and HW Virgin IV. 1998. Murine cytomegalovirus inhibits interferon gamma-induced antigen presentation to CD4 cells by macrophages via regulation of expression of Major Histocompatibility Complex class II-associated genes. J Exp Med. 187:1037-46.

89. Heise, MT, and HW Virgin. 1995. The T-cell-independent role of gamma interferon and tumor necrosis factor alpha in macrophage activation during murine cytomegalovirus and herpes simplex virus infections. J Virol. 69:904-9. 
90. Hendrix, MGR, E Beuken, RL Slobbe, and CA Bruggeman. 1996. Detection and sequence analysis of the Major Immediate Early and PP150 gene of latent human cytomegalovirus in spleen, liver and kidney tissues of trauma victims. J Med Virol. 50:193-7.

91. Hengel, H, W Brune, and UH Koszinowski. 1998. Immune evasion by cytomegalovirus-survival strategies of a highly adapted opportunist. Trends in Microbiology. 6:190-7.

92. Hengel, H, T Htohr, GJ Hammerling, UH Koszinowski, and F Momburg. 1996. Human cytomegalovirus inhibits peptide translocation into the endoplasmic reticulum for MHC class I assembly. J Gen Virol. 77:2287-96.

93. Hengel, H, P Lucin, S Jonjic, T Ruppert, and UH Koszinowski. 1994. Restoration of cytomegalovirus antigen presentation by gamma interferon combats viral escape. J Virol. 68:289-97.

94. Hengel, H, U Reusch, A Gutermann, H Ziegler, S Jonjic, P Lucin, and UH Koszinowski. 1999. Cytomegaloviral control of MHC class I function in the mouse. Immunol Rev. 168:167-76.

95. Ho, M. 1990. Epidemiology of cytomegalovirus infections. Rev Inf Dis. 12:5701-10.

96. Ho, M. 1991. Congenital and perinatal human cytomegalovirus infections, p. 205-27. in M Ho (ed.), Cytomegalovirus, biology and infection. Plenum Medical, Co., N.Y.

97. Ho, M. 1994. Advances in understanding cytomegalovirus infection after transplantation. Transplant Proc. 26:7-11.

98. Holtappels, R, NKA Grzimek, CO Simon, D Thomas, D Dreis, and MJ Reddehase. 2002. Processing and presentation of murine cytomegalovirus pORFm164-derived peptide in fibroblasts in the face of all viral immunosubversive early gene functions. J Virol. 76:604453.

99. Humar, A, KJ Gillingham, WD Payne, DL Dunn, DER Sutherland, and AJ Matas. 1999. Association between cytomegalovirus disease and chronic rejection in kidney transplant recipients. Transplantation. 68:1879-83.

100. Humar, A, G Malkan, G Moussa, P Grieg, G Levy, and T Massulli. 2000. Human herpesvirus-6 is associated with cytomegalovirus reactivation in liver transplant recipients. J Inf Dis. $181: 1451 \cdot 3$.

101. Hummel, M, and MM Abecassis. 2002. A model for reactivation of CMV from latency. J Clin Virol. 2002:5123-36.

102. Hummel, M, Z Zhang, 5 Yan, I Deplaen, P Golia, T Varghese, G Thomes, and MI Abecasses. 2001. Allogeneic transplantation induces expression of cytomegalovirus Immedite-Early genes in vivo: a model for reactivation from latency. J Virol. 75:4814-22.

103. Ibanez, CE, R Schrier, P Ghazal, C Wiley, and JA Nelson. 1991. Human cytomegalovirus productively infects primary differentiated macrophages. J Virol. 65:6581-8.

104. Inoue, Y, P Minasi, and JO Oh. 1993. The role of natural killer cells in murine cytomegalovirus eye infection. Invest Ophthalmol Vis Sci. 34:1954-62.

105. Ito, M, M Watanabe, T Ihara, H Kamiya, and M Sakurai. 1995. Increased expression of adhesion molecules (CD54, CD29 and CD44) in fibroblasts infected with cytomegalovirus. Microbiol Immunol. 39:129-33.

106. Jones, M, C Cray, and RB Levy. 1996. Concurrent MCMV infection augments donor antihostspecific activity and alters clinical outcome following experimental allogeneic bone marrow transplantation. Transplantation. 61:856-61.

107. Jones, TR, LK Hanson, L Sun, JS Slater, RM Stenberg, and AE Campbell. 1995. Multiple independent loci within the Human Cytomegalovirus Unique Short region down-regulate expression of Major Histocompatibility Complex class I heavy chains. J Virol. 69:4830-41.

108. Jones, TR, and L Sun. 1997. Human cytomegalovirus US2 destabilizes Major Histocompatibility Complex class I heavy chains. J Virol. 71:2980-9.

109. Jones, TR, EJHJ Wiertz, L Sun, KN Fish, and JA Nelson. 1996. Human cytomegalovirus US3 impairs transport and maturation of major histocompatibility complex Class I heavy chains. Proc Natl Acad Sci USA. 93:11327-33.

110. Jonjic, S, W Mutter, F Weiland, MJ Reddehase, and UH Koszinowski. 1989. Site-restricted persistent cytomegalovirus infection after selective long-term depletion of CD4+ T lymphocytes. J Exp Med. 169:1199-212.

111. Jonjic, S, I Pavic, P Lucin, D Rukavina, and UH Koszinowski. 1990. Efficacious control of cytomegalovirus infection after long-term depletion of CD8+ T lymphocytes. J Virol. 64:545764.

112. Jordan, $M C$, and $V$ Mar. 1982. Spontaneous activation of murine cytomegalovirus form murine spleen explants. Role of lymphocytes and macrophages in release and replication of virus. J Clin Invest. 70:762-8. 
113. Jun, Y, E Kim, M Jin, HC Sung. H Han, DE Geraghty, and K Ahn. 2000. Human cytomegalovirus gene products US3 and US6 down-regulate trophoblast class I MF-C molecules. J Immunol. 164:805-11.

114. Kane, RC. WE Rousseau. GR Noble, GE Tegtmeier, H Wulff, H Brooks, TDY Chin, and WL Bayer. 1975. Cytomegalovirus infection in a volunteer blood donor population. Infec Immunity. 11:719-23.

115. Karre, K, and RM Welsh. 1997. Viral decoy vetoes killer cells. Nature. 386.

116. Kavanagh, DG, MC Gold, M Wagner, UH Koszinowski, and AB Hill. 2001. The multiple immune-evasion genes of murine cytomegalovirus are not redundant: $m 4$ and $m 152$ inhibit antigen presentation in a complementary and cooperative fashion. J Exp Med. 194:967 - 77.

117. Kavanagh, DG, UH Koszinowski, and AB Hill. 2001. The murine cytomegalovirus immune evasion protein $\mathrm{m} 4$ /gp34 forms biochemically distinct complexes with class I MHC at the cell surface and in a pre-Golgi compartment. J Immunol. 167:3894-902.

118. Kledal, TN, MM Rosenkilde, and TW Schwartz. 1998. Selective recognition of the membranebound $\mathrm{C} \times 3 \mathrm{C}$ chemokine, fractalkine, by the human cytomegalovirus-encoded broad spectrum receptor US28. FEBS lett. 441:209-14.

119. Kleijnen, MF, JB Huppa, P Lucin, AE Campbell, UL Koszinowski, AB Hill, and r,L Ploegh. 1997. A mouse cytomegalovirus glycoprotein, pg34, forms a complex with folded class I $\mathrm{MHC}$ molecules in the ER which is not retained but is transported to the cell surface. EMBO J. $16: 685-94$.

120. Klemola, E. 1973. Cytomegalovirus infection in previously healthy adults. Am Intern Med. 79:267-8.

121. Kloover, JS, AP Soots, LA Krogerus, HO Kauppinen, RJ Loginov, KL Holma, CA Bruggeman, J Ahonen, and IT Lautenschlager. 2000. Rat cytomegalovirus infection in kidney allograft recipients is associated with increased expression of intracellular adhesion molecules-1, vascular adhesion molecule-1 and their ligands leukocyte function antigen-1 and very late antigen-4 in the graft. Transplantation. 69:2641-7.

122. Kloover, JS, AE van den Boogaard, JG van Dam, GELM Grauls, C Vink, and CA Bruggeman. 2002. Persistent rat cytomegalovirus (RCMV) infection of the salivary glands contributes to the anti-RCMV humoral immune response. Virus Research. 85:163-72.

123. Klotman, ME, SC Henry, RC Greene, PC Brazy, PE Klotman, and JD Hamilton. 1990. Detection of mouse cytomegalovirus nucleic acid in latently infected mice by in vitro enzymatic amplification. J Inf Dis. 161:220-5.

124. Kondo, K, H Kaneshima, and ES Mocarski. 1994. Human cytomegalovirus latent infection of granulocyte-macrophage progenitors. Proc Natl Acad Sci USA. 91:11879-83.

125. Kondo, K, J Xu, and ES Mocarski. 1996. Human cytomegalovirus latent gene expression in granulocyte-macrophage progenitors in culture and in seropositive individuals. Proc Natl Acad Sci USA. 93:11137-42.

126. Koppelman, B, JJ Neefjes, JE De Vries, and R De Waal Malefyt. 1997. Interleukin-10 downregulates MHC class II alpha/beta peptide complexes at the plasma membrane of monocytes by affecting arrival and recycling. Immunity. 7:861-71.

127. Koskinen, PK. 1993. The association of the induction of vascular cell adhesion molecule-1 with cytomegalovirus antigenemia in human heart allografts. Transplantation. 56:1103-8.

128. Koskinen, P, EA Kallio, CA Bruggeman, and KB Lemstrom. 1997. Cytomegalovirus infection enhances experimental obliterative bronchiolitis in rat tracheal allografts. Am J Respir Crit Care Med. 155:2078-88.

129. Koskinen, P, K Lemstrom, C Bruggeman, I Lautenschlager, and P Hayry. 1994. Acute cytomegalovirus infection induces a subendothelial inflammation (endothelialitis) in the allograft vascular wall. A possible linkage with enhanced allograft arteriosclerosis. Am $J$ Pathol. 144:41-50.

130. Koskinen, P, K Lemstrom, H Bruning, M Daemen, C Bruggeman, and P Hayry. 1995. Cytomegalovirus infection induces vascular wall inflammation and doubles arteriosclerotic changes in rat cardiac allografts. Transplant Proc. 27:574-5.

131. Koskinen, P.K, S Yilmaz, E Kallio, C.A Bruggeman, P.J Hayry, and K Lemstrom. 1996. Rat cytomegalovirus infection and chronic kidney allograft rejection. Transpl 1nt. 9:53-4.

132. Koszinowski, UH. 1991. Molecular aspects of immune recognition of cytomegalovirus. Transplant Proc. 23:70-3.

133. Koteno, SV, S Saccani, LS Izotova, OV Mirochnitchenko, and S Pestka. 2000. Human cytomegalovirus harbors its own unique IL-10 homolog (cmvIL10). PNAS. 97:1695-700. 
134. Krause, H, H Hebart, G Jahn, CA Muller, and H Einsele. 1997. Screening for CMV-specific I cell proliferation to identify pationts at risk of developing late onset CMV disease. Bone Marrow Transpl. 19:1111-6.

135. Krmpotic, A, M Messerle, I Crnkovic-kietens, B Polic, S Jonjic, and UH Koszinowski. 1999. The immunoevasive function encoded by the mouse cytomegalovirus gene m152 protects the virus against T cell control in vivo. J Exp Med. 190:1285-95.

136. Kubota, A, S Kubota, HE Farrell, N Davis Poynter, and F Takei. 1999. Inhibition of NK cells by murine CMV-encoded class I MHC homologue m144. Cell Immunol. 191:145-51.

137. Kurz, SK, M Rapp, HP Steffens, NKA Grzimek, S Schmalz, and MJ Reddehase. 1999. Focal transcription activity of murine cytomegalovirus during latency in the lungs. J Virol. 73:48294.

138. Kurz, S, and MJ Reddehase. 1999. Patchwork pattern of transcriptional reactivation in the lungs indicates sequential checkpoints in the transition from murine cytomegalovirus iatency to recurrence. J Virol. 73:8612-22.

139. Lathbury, LJ, JE Allan, GR Shellam, and AA Scalzo. 1996. Effect of host genotype in determining the relative roles of natural killer cells and $T$ cells in mediating protection against murine cytomegalovirus infection. J Gen Virol. 77:2605-13.

140. Lazzarotto, T, S Varani, B Guerra, A Nicolosi, M Lanari, and MP Landini. 2000. Prenatal indicators of congenital cytomegalovirus infection. J Pediatr. 137:90-5.

141. Lazzarotto, T, S Varani, P Spezzacatena, L Gabrielli, P Pradelli, B Guerra, and MP Landini. 2000. Maternal IgG avidity and IgM detected by blot as diagnostic tools to identify pregnant women at risk of transmitting cytomegalovirus. Viral Immunol. 13:137-41.

142. Le Roy, E, A Muhlethaler Mottet, C Davrinche, B Mach, and JL Davigno. 1999. Escape of human cytomegalovirus from HLA-DR-restricted CD4(+) T-cell response is mediated by repression of gamma interferon-induced class II transactivator expression. J Virol. 73:6582-9.

143. Lehner, PJ, JT Karttunen, GWG Wilkinson, and P Cresswell. 1997. The human cytomegalovirus US6 glycoprotein inhibits transporter associated with antigen processingdependent peptide translocation. Immunol. 74:6904-9.

144. Lemstrom, KB, PT Aho, CA Bruggeman, and PJ Hayry. 1994. Cytomegalovirus infection enhances mRNA expression of Platelet-Derived Growth Factor-BB and Transforming Growth Factor-beta1 in rat aortic allografts. Arterioscler Thromb. 14:2043-52.

145. Lemstrom, KB, JH Bruning, CA Bruggeman, PK Koskinen, PT Aho, 5 Yilmaz, IT Lautenschlager, and PJ Hayry. 1994. Cytomegalovirus infection-enhanced allograft arteriosclerosis is prevented by DHPG prophylaxis in the rat. Circulation. 90:1969-73.

146. Lemstrom, KB, JH Bruning, CA Bruggeman, IT Lautenschlager, and PJ Hayry. 1993. Cytomegalovirus infection enhances smooth muscle cell proliferation and intimal thickening of rat aortic allografts. J Clin Invest. 92:549-58.

147. Lemstrom, KB, JH Bruning, CA Bruggeman, IT Lautenschlager, and PJ Hayry. 1994. Triple drug immunosuppression significantly reduces immune activation and allograft arteriosclerosis in cytomegalovirus-infected rat aortic allografts and induces early latency of viral infection. Am J Pathol. 144:1334-47.

148. Lenkei, R, and B Andersson. 1995. High correlation of anti-CMV titers with lymphocyte activation status and CD57 antibody-binding capacity as estimated with three-color, quantitative flow cytometry in blood donors. Clin Immunol Immunopathol. 77:131-8.

149. Li, CR, PD Greenberg, MJ Gilbert, JM Goodrich, and SR Riddell. 1994. Recovery of HLArestricted cytomegalovirus (CMV)-specific $T$-cell responses after allogeneic bone marrow transplant: correlation with CMV disease and effect of ganciclovir prophylaxis. Blood. 83:1971-9.

150. Li, F, G Grauls, JG van Dam, M Yin, and CA Bruggeman. 1997. Cytomegalovirus infection enhances the perivascular inflammatory reaction in transplanted aortic allografts. Cardiovasc Engin. 2:207-14.

151. Li, FL, G Grauls, M Yin, and CA Bruggeman. 1996. Correlation between the intensity of cytomegalovirus infection and the amount of perivasculitis in aorta allografts. Transpl Int. $9: 51-5$.

152. Li, F, M Yin, JG Van Dam, G Grauls, J Rozing, and CA Bruggeman. 1998. Cytomegalovirus infection enhances the neointima formation in rat aortic allografts. Transplantation. $65: 1298-304$.

153. Ljunggren, $H G$, and $K$ Karre. 1990. In search of the 'missing self': $M H C$ molecules and NK cell recognition. Immunol Today. 11:237-44. 
154. Loenen, WA, CA Bruggeman, and EJ Wiertz. 2001. Immune evasion by human cytomegalovirus: lessons in immunology and cell biology. Semin Immunol. 13:41-9.

155. Looney, RJ, A Falsey, D Campbell, TJ Kolassa, C Brower, R McCann, M Menegus, K McCormick, M Frampton, W Hall, and GN Abraham. 1999. Role of cytomegalovirus in the $T$ cell changes seen in elderly individuals. Clin Immunol. 90:213-9.

156. Lu, HT, JL Riley, GT Babcock, M Huston, GR Stark, JM Boss, and RM Ransohoff. 1995. Interferon (IFN) beta acts downstream of IFN-gamma induced class II transactivator messenger RNA accumulation to block major histocompatibility complex class II gene expression and requires the 48-kD DNA-binding protein, ISGF3-gamma. J Exp Med. 182:151725.

157. Lu Hayashi, ML, C Blankenship, and T Shenk. 2000. Human cytomegalovirus UL69 protein is required for efficient accumulation of infected cells in the G1 phase of the cell cycle. PNAS. 97:2692-6.

158. Lucin, P, I Pavic, B Potic, S Jonjic, and UH Koszinowski. 1992. Gamma interferon-dependent clearance of cytomegalovirus infection in salivary glands. J Virol. 66:1977-84.

159. MacDonald, MR, MW Burney, SB Resnick, and HW Virgin IV. 1999. Spliced mRNA encoding the murine cytomegalovirus chemokine predicts a beta chemokine of novel structure. J Virol. 73:3682-91.

160. MacDonald, MR, XY Li, and HW Virgin IV. 1997. Late expression of a beta chemokine homolog by murine cytomegalovirus. J Virol. 71:1671-8.

161. Machold, RP, EJHJ Wiertz, TR Jones, and HL Ploegh. 1997. The HCMV gene products US11 and US2 differ in their ability to attack allelic forms of murine Major Histocompatibility Complex (MHC) class I heavy chain. J Exp Med. 185:363-6.

162. Margulies, BJ, H Browne, and W Gibson. 1996. Identification of the human cytomegalovirus $G$ protein-coupled receptor homologue encoded by UL33 in infected cells and enveloped virus particles. Virology. 225:111-25.

163. Marshall, GS, GG Stout, ME Knights, GP Rabalais, R Ashleu, H Miller, and E Rossier. 1994. Ontogeny of glycoprotein gB-specific antibody and neutralizing activity during natural cytomegalovirus infection. J Med Virol. 43:77-83.

164. Martelius, T, L Krogerus, K Hockerstedt, C Bruggeman, and I Lautenschlager. 1998. Cytomegalovirus infection is associated with increased inflammation and severe bile duct damage in rat liver allografts. Hepatology. 27:996-1002.

165. Mayo, D, JA Armstrong, and $\mathrm{M}$ Ho. 1978. Activation of latent murine cytomegalovirus: cocultivation, cell transfer and the effect of immunosuppression. J Infect Dis. 138:890-6.

166. McFadden, $G$, and $K$ Kane. 1994. How DNA viruses perturb functional MHC expression to alter immune recognition. Adv Cancer Res. 63:117-209.

167. McLaughlin, K, C Wu, G Fick, N Muirkead, D Hollomby, and A Jevnikar. 2002. Cytomegalovirus seromismatching increases the risk of acute renal allograft rejection. Transplantation. 74:813-6.

168. Melnick, JL, E Adam, and ME DeBakey. 1995. Cytomegalovirus and atherosclerosis. Bioassays. 17:899-903.

169. Meyers, JD, N Fournoy, and ED Thomas. 1986. Risk factors for cytomegalovirus infection after human marow transplantation. J Infect Dis. 153:478-51.

170. Miller, DM, CM Cebulla, BM Rahill, and DD Sedmak. 2001. Cytomegalovirus and transcriptional down-regulation of major histocompatibility complex class II expression. Semin Immunol. 13:11-8.

171. Miller, DM, BM Rahill, JM Boss, MD Lairmore, JE Durbin, WJ Waldman, and DD Sedmak. 1998. Human cytomegalovirus inhibits Major Histocompatibility Complex class II expression by disruption of the Jak/Stat pathway. J Exp Med. 187:675-83.

172. Miller, DM, Y Zhang, BM Rahill, WJ Waldman, and DD Sedmak. 1999. Human cytomegalovirus inhibits IFN-alpha-stimulated antiviral and immunoregulatory responses by blocking multiple levels of IFN-alpha signal transduction. J Immunol. 162:6107-13.

173. Mitchell, BM, A Leung, and JG Stevens. 1996. Murine cytomegalovirus DNA in peripheral blood of latently infected mice is detectable only in monocytes and polymorphonuclear leukocytes. Virology. 273:198-207.

174. Mocarski Jr., ES. 2002. Immunomodulation by cytomegaloviruses: manipulative strategies beyond evasion. Trends in Microbiologie. 10:332-9.

175. Monti, G, A Magnan, M Fattal, B Rain, M Humbert, JL Mege, M Noirclerc, P Dartevelle, J Cerrina, G Simonneau, P Galanaud, and D Emilie. 1996. Intrapulmonary production of 
RANTES during rejection and CMV pneumonitis after lung transplantation. Transplantation. $61: 1757-62$.

176. Mosmann, T.R, and S Sad. 1996. The expanding universe of T-cell subsets: Th1, Th2 and more. Immunol Today. 17:138-46.

177. Muhlethaler-Mottet, A, W Di Bernardine, LA Otten, and B Mach. 1998. Activation of the MHC class II transactivator CIITA by interferon-gamma requires cooperative interaction between Stat1 and USF-1. Immunity. 8:157-66.

178. Ninomiya, T, H Takimoto, G Matsuzaki, S Hamano, H Yoshida, Y Yoshikai, and G Kimura. 2000. Vgamma1+ gamma-delta cells play protective roles at an early phase of murine cytomegalovirus infection through production of interferon-gamma. Immunology. 99:187-94.

179. Noraz, N, J.L Lathey, and S.A Spector. 1997. Human cytomegalovirus-associated immunosuppression is mediated through interferon-alfa. Blood. 89:2443-52.

180. Nordoy, I, F Muller, KP Nordal, H Rollag, P Aukkrust, and S5 Froland. 2000. Chemokines and soluble molecules in renal transplant recipients with cytomegalovirus infection. Clin Exp Immunol. 120:333-7.

181. Nordoy, I, F Muller, KP Nordal, H Rollag, E Lien, P Aukrust, and SS Froland. 1999. Immunologic parameters as predictive factors of cytomegalovirus disease in renal allograft recipients. J Infect Dis. 180:195-8.

182. Nordoy, I, F Muller, KP Nordal, H Rollg, E Lien, Aukrust.P, and SS Froland. 2000. The role of tumor necrosis factor system and interleukin-10 during cytomegalovirus infection in renal transplant recipients. J Infect Dis. 181:51-7.

183. Odeberg, J, C Cerboni, H Browne, K Karre, E Moller, E Carbone, and C Soderberg-Naucler. 2002. Human cytomegalovirus (HCMV)-infected endothelial cells and macrophages are less susceptible to Natural Killer lysis independent of the downregulation of classical HLA class 1 molecules or expression of the HCMV class I homologue, UL18. Scand J Immunol. 55:149-61.

184. Odorizzi, CG, IS Trowbridge, L Xue, CR Hopkins, CD Davis, and JF Collawn. 1994. Sorting signals in the $M H C$ class II invariant chain cytoplasmic tail and transmembrane region determine trafficking to an endocytic processing compartment. J Cell Biol. 126:317-30.

185. Pass, RF, R Hutto, and GA Cloud. 1986. Increased rate of cytomegalovirus infection among parents of children attending day-care centers. N Engl J Med. 314:1414-8.

186. Pass, RF, S Stagno, GJ Myers, and CA Alford. 1980. Outcome of symptomatic congenital cytomegalovirus infection: results of long-term longitudinal follow-up. Pediatrics. 66:758-62.

187. Pelchen-Matthews, A, N Signoret, PJ Klasse, A Fraile Ramos, and M Marsh. 1999. Chemokine receptor trafficking and viral replication. Immunol Rev. 168:33-49.

188. Penfold, ME, DJ Dairaghi, GM Duke, N Saederup, ES Mocarski, GW Kemble, and TJ Schal! 1999. Cytomegalovirus encodes a potent alfa chemokine. Proc Natl Acad Sci USA. 96:983944.

189. Phillips, AJ, P Tomasec, ECY Wang, GWG Wilkinson, and LK Borysiewicz. 1998. Human cytomegalovirus infection downregulates expression of the cellular aminopeptidases CD10 and CD13. Virology. 250:350-8.

190. Ploegh, HL. 1998. Viral strategies of immune evasion. Science. 280:248-53.

191. Podlech, J, R Holtappels, N Wirtz, HP Steffens, and MJ Reddehase. 1998. Reconstitution of CD8 T cells is essential for the prevention of multiple-organ cytomegalovirus histopathology after bone marrow transplantation. J Gen Virol. 79:2099-104.

192. Pollock, JL, RM Presti, S Peatzold, and HW Virgin IVth. 1997. Latent murine cytomegalovirus infection in macrophages. Virology. 227:168-79.

193. Pomeroy, C, PJ Hilleren, and MC Jordan. 1990. Latent murine cytomegalovirus DNA in splenic stromal cells of mice. J Virol. 65:3330-4.

194. Porter, KR, DM Starnes, and JD Hamilton. 1985. Reactivation of latent murine cytomegalovirus from kidney. Kidney In. 28:922-5.

195. Pouteil-Noble, C, R Ecochard, G Landrivon, A Donia Maged, JC Tardy, S Bosshard, 5 Colon, H Betuel, $M$ Aymard, and JL Touraine. 1993. Cytomegalovirus infection- an etiological factor for rejection? Transplantation. 55:851-7.

196. Price, P, and SD Olver. 1996. Animal models of human immunopathological disease. Syndromes induced by Cytomegalovirus infection. Clin immunol immunopath. 80:215-24.

197. Pringle, CR. 1995. The universal system of virus taxonomy of the international committee on virus taxonomy (ICTV), including new proposals ratified since publication of the Sixth ICTV report in 1995. Arch Virol. 143:203-10.

198. Quinnan, GV, N Kirmani, AH Rook, JF Manischewitz, L Jackson, G Moreschi, GW Santos, R Saral, and WH Burns. 1982. Cytotoxic T cells in Cytomegalovirus infection. HLA-restricted T- 
lymphocyte and non-T-lymphocyte cytotoxic responses correlate with recovery from Cytomegalovirus infection in Bone-Marrow-Transplant recipients. N Engl J Med. 307:7-13.

199. Rabkin, CS, A Hatzakis, PD Griffiths, D Pillay, MV Ragni, MW Hilgartner, and JJ Goedert. 1993. Cytomegalovirus infection and risk of AIDS in human immunodeficiency virus-infected hemophilia patients. I Infect Dis. 168:1260-3.

200. Raftery, MJ, M Schwab, SM Eibert, Y Samstag, H Walczak, and G Schonrich. 2001. Targeting the functions of mature dendritic cells by human cytomegalovirus: A multilayered viral defense strategy. Immunity. 15:997-1009.

201. Rawlinson, WD, HE Farrell, and BG Barrell. 1996. Analysis of the complete DNA sequence of murine cytomegalovirus. J Virol. 70:8833-49.

202. Reddehase, MJ, M Balthesen, M Rapp, S Jonjic, I Pavic, and UH Koszinowski. 1994. The conditions of primary infection define the load of latent viral genome in organs and the risk of recurrent cytomegalovirus disease. J Exp Med. 179:185-93.

203. Reddehase, MJ, KJ Podlech, and NKA Grzimek. 2002. Mouse models of cytomegalovirus latency: overview. J Clin Virol. 25:S23-36.

204. Redpath, S., A. Angulo, N. R. J. Gascoigne, and P. Ghazal. 1999. Murine cytomegalovirus infection down-regulates $M H C$ class II expression on macrophages by induc:ion of $\mathrm{IL}-10$. $\mathrm{J}$ Immunol. 162:6701-7.

205. Rehm, A, A Engelsberg, D Tortorella, Korner, IJ, I Lehnmann, HL Ploegh, and UE Hopken. 2002. Human cytomegalovirus gene product US2 and US11 differ in their ability to attack Major Histocompatibility Class I heavy chains in dendritic cells. J Virol. 76:5043-50.

206. Reusch, U, W Muranyi, P Lucin, HG Burgert, H Hengel, and UH Koszinowski. 1999. A cytomegalovirus glycoprotein re-routes $M H C$ class I complexes to lysosomes for degradation. EMBO J. 18:1081-91.

207. Reusser, P, R Attenhofer, H Hebart, C Helg, B Hapuis, and H Einsele. 1997. Cytomegalovirusspecific $T$-cell immunity in recipients of autologous peripheral blood stem cell of bone marrow transplants. Blood. 89:3873-9.

208. Reusser, P, SR Riddell, JD Meyers, and PD Greenberg. 1991. Cytotoxic T-lymphocyte response to cytomegalovirus after human allogeneic bone marrow transplantation: Pattern of recovery and correlation with cytomegalovirus infection and disease. Blood. 78:1373-80.

209. Reyburn, HT, O Mandelboim, M Vales-Gomez, DM Davis, L Pazmany, and JL Strominger. 1997. The class $1 \mathrm{MHC}$ homologue of human cytomegalovirus inhibits attack by natural killer cells. Nature. 386:514-7.

210. Reynolds, DW, S Stagno, TS Hosty, M Tiller, and CA ALford. 1973. Maternal cytomegalovirus excretion and perinatal infection. N Engl J Med. 289:1-5.

211. Riddell, SR, P Reusser, and PD Greenberg. 1991. Cytotoxic T cells specific for cytomegalovirus: a potential therapy for immunocompromised patients. Rev Infect Dis. 13 (S11):5966-73.

212. Riegler, S, H Hebart, H Einsele, P Brossart, G Jahn, and C Singzer. 2000. Monocyte-derived dendritic cells are permissive to the complete replicative cycle of human cytomegalovirus. J Gen Virol. 81:396-9.

213. Riera, L, M Gariglio, G Valente, A Mullbacher, C Museteanu, 5 Landolfo, and MM Simon. 2000. Murine cytomegalovirus replication in salivary glands is controlled by both perforin and granzymes during acute infection. Eur J Immunol. 30:1350-5.

214. Rock, KL, and AL Goldberg. 1999. Degradation of cell proteins and the generation of $M H C$ class I-presented peptides. Annu Rev Immunol. 17:739-79.

215. Rubin, RH. 1990. Impact of cytomegaloviris infection on organ transplant recipients. Rev Infect Dis. 12:5754-66.

216. Ruzek, MC, AH Miller, SM Opal, BD Pearce, and CA Biron. 1997. Characterization of early cytokine responses and an interleukin $(\mathrm{IL})-6$-dependent pathway of endogenous glucocorticoid induction during murine cytomegalovirus infection. J Exp Med. 185:1185-92.

217. Schooley, RT. 1990. Cytomegalovirus in the setting of infection with human immunodeficiency virus. Rev Infect Dis. 12:5811-9.

218. Schoppel, K, B Kropff, C Schmidt, R Vornhagen, and M Mach. 1997. The humoral immune response against human cytomegalovirus is characterized by a delayed synthesis of glycoprotein-specific antibodies. J Infect Dis. 175:533-44.

219. Schoppel, K, C Schmidt, H Einsele, H Hebart, and M Mach. 1998. Kinetics of the antibody response against human cytomegalovirus-specific proteins in allogeneic bone marrow transplant recipients. J Infect Dis. 178:1233-43. 
220. Sedmak, DD, DA Knight, NC Vook, and JW Waldman. 1994. Divergent patterns of ELAM-1, ICAM-1, and VCAM-1 expression on cytomegalovirus-infected endothelial cells.

Transplantation. 58:1379-85.

221. Shanley, JD. 1990. In vivo administration of monoclonal antibody to the NK 1.1 antigen of natural killer cells: effect on acute murine cytomegalovirus infection. J Med Virol. 30:58-60.

222. Shanley, JD, L Biczak, and SJ Forman. 1993. Acute murine cytomegalovirus infection induces lethal hepatitis. J Infect Dis. 167:264.9.

223. Sinzger, C, AL Bissinger, R Viebahn. H Oettle, C Radke. CA Schmidt, and G Jahn. 1999. Hepatocytes are permissive for human cytomegalovirus infection in human liver cell culture and in vivo. J Inf Dis. 180:976-86.

224. Sinzger, C, A Grefte, B Plachter, ASH Gouw, TH The, and G Jahn. 1995. Fibroblasts, epithelial cells, endothelial cells and smooth muscle cells are major targets of human cytomegalovirus infection in lung and gastrointestinal tissues. J Gen Virol. 76:741-50.

225. Sinzger, C, B Plachter, A Grefte, TH The, and G Jahn. 1996. Tissue macrophages are infected by human cytomegalovirus in vivo. J Infect Dis. 173:240-5.

226. Soderberg, C, 5 Larsson, BL Rozell. S Sumitran-Karuppan, P Ljungman, and F Moller. 1996. Cytomegalovirus-induced CD13-specific autoimmunity. . A possible cause of chronic graftversus-host disease. Transplantation. 61:600-9.

227. Soderberg, C, S Sumitran-Karuppan, P Ljungman, and E Moller. 1996. CD13-specific autoimmunity in cytomegalovirus-infected immunocompromised patients. Transplantation. 61:594-600.

228. Soderberg-Naucler, C, KN Fish, and JA Nelson. 1997. Reactivation of latent human cytomegalovirus by allogeneic stimulation of blood cells from healthy donors. Cell. 91:119. 26.

229. Span, A.H.M, W Mullers, A.M.M Miltenburg, and C.A Bruggeman. 1991. Cytomegalovirus induced PMN adherence in relation to an ELAM- 1 antigen present on infected endothelial cell monolayers. Immunology. 72:355-60.

230. Speir, E, R Modali, ES Huang, MB Leon, F Shawl, T Finkel, and SE Epstein. 1994. Potential role of human cytomegalovirus and p53 interaction in coronary restenosis. Science. 265:391. 4.

231. Springer, TA. 1990. Adhesion receptors of the immune system. Nature. 346:425-34.

232. Stagno, S, RF Pass, and ME Dworsky. 1982. Congenital cytomegalovirus infection: The relative importance of primary and recurrent maternal infections. N Engl J Med. 306:945-9.

233. Stagno, S, DW Reynolds, RF Pass, and CA Alford. 1980. Breast milk and the risk of cytomegalovirus infection. N Engl J Med. 302:1073-4.

234. Steffens, HP, S Kurz, R Holtappels, and MJ Reddehase. 1998. Preemptive CD8 T-cell immunotherapy of acute cytomegalovirus infection prevents lethal disease, limits the burden of latent viral genomes, and reduces the risk of virus recurrence. J Virol. 72:1797-804.

235. Steimle, V, LA Otten, M Zufferey, and B Mach. 1993. Complementation cloning of an MHC class II transactivator mutated in hereditary $M H C$ class II deficiency (or bare lymphocyte
syndrome). Cell. 75:135-46.

236. Steimle, V, CA Siegrist, A Mottet, B Lisowska-Grospierre, and B Mach. 1994. Regulation of MHC class II expression by interferon-gamma mediated by the transactivator gene CIITA. Science. 265:106-9.

237. Stein, J, HD Volk, C Liebenthal, DH Kruger, and S Prosch. 1993. Tumor necrosis factor alpha stimulates the activity of the human cytomegalovirus immediate-early enhancer/promotor in immature monocytic cells. J Gen Virol. 74:2333-8.

238. Steinhoff, G, X.M You, C Steinmuller, D Bauer, M.L Lehmann-Matthes, C.A Bruggeman, and A Haverich. 1996. Enhancement of cytomegalovirus infection and acute rejection after allogeneic lung transplantation in the rat. Transplantation. 61:1250-60.

239. Steinmuller, C, G Steinhoff, D Bauer, XM You, H Denzin, G Franke-Ullmann, B Hausen, CA Bruggeman, TOF Wagner, ML Lohmann-Matthes, and A Emmendorffer. 1997. Analysis of leukocyte activation during acute rejection of pulmonary allografts in non-infected and cytomegalovirus-infected rats. J Leukocyte Biol. 61:40-9.

240. Stern, H, and SD Elek. 1965. The incidence of infection with cytomegalovirus in a normal population. J Hyg. 63:79-87.

241. Sterner, G, BO Agell, B Wahren, and A Espmark. 1970. Acquired cytomegalovirus infection in older children and adults. Scand J Infect Dis. 2:95-103. 
242. Stoddart. CA. RD Cardin, JM Boname, WC Manning, GB Abenes, and ES Mocarski. 1994. Peripheral blood mononticleai phagocytes mediate dissemination of murine cytomegalovirus. J Virol. 68:6243-53.

243. Story, CM. MH Furman, and HL. Ploegh. 1999. The cytosolic tail of class I MHC heavy chain is required for its dislocation by the human cytomegalovirus US2 and US11 gene products. Proc Natl Acad Sci USA. 96:8516-21.

244. Streblow, DN, C Soderberg-Naucler, J Vieira, P Smith, E Wakabayashi, F Ruchti, K Mattison, Y Altschuler, and YA Nelson. 1999. The human cytomegalovirus chemokine receptor US28 mediates vascular smooth muscle cell migration. Cell. 99:511-20.

245. Tanaka, K, Y Koga, YY Lu, XY Zhang, Y Wang, G Kimura, and K Nomoto. 1994. Murine cytomegalovirus-associated pneumonitis in the lungs free of the virus. J Clin Invest. 94:101925.

246. Tay, CH, and RM Welsh. 1997. Distinct organ-dependent mechanism for the control of murine cytomegalovirus infection by natural killer cells. J Virol. 71:267-75.

247. Tomasec, P, VM Braus, C Rickards, MB Powell, BP McSharry, S Gadola, V Cerundolo, LK Beyrsiewicz, AJ MCMichael, and GWG Wilkinson. 2000. Surface expression of HLA-E, an inhibitor of natural killer cells, enhanced by human cytomegalovirus gpUL4U. Science. 287:1031-3.

248. Tomazin, R, J Boname, NR Hedge, DM Lewinsohn, Y Altschuler, TR Jones, P Cresswell, JA Nelson, SR Ridell, and DC Johnson. 1999. Cytomegalovirus US2 destroys two components of the MHC class II pathway, preventing recognition by CD4+ T cells. Nature Medicine. 5:103943.

249. Tong, CY, A Bakran, H Williams, LE Cuevas, JS Peiris, and CA Hart. 2001. Association of tumour necrosis factor alpha and interleukin levels with cytomegalovirus DNA detection and disease after renal transplantation. J Med Virol. 64:29-34.

250. Tuder, RM, A Weinberg, N Panajotopoulos, and J Kalil. 1991. Cytomegalovirus enhances PBMC binding and HLA class I expression on cultured endothelial cells. Transplant Proc. 23:91-2.

251. Ulbrecht, M, 5 Martinozzi, M Grzeschik, H Hengel, JW Ellwart, M Pla, and E Weiss. 2000. Cutting Edge: The human cytomegalovirus UL 40 gene product contains a ligand for HLA-E and prevents NK cell-mediated lysis. J Immunol. 164:5019-22.

252. Urban, M, M Klein, WJ Britt, E Hassfurther, and M Mach. 1996. Glycoprotein $H$ of human cytomegalovirus is a major antigen for the neutralizing humoral immune response. J Gen Virol. 77:1537-47.

253. Ustinov, JA, TT Lahtinen, CA Bruggeman, PJ Hayry, and IT Lautenschlager. 1994. Direct induction of class II molecules by cytomegalovirus in rat heart microvascular endothelial cells is inhibited by ganciclovir (DHPG). Transplantation. 58:1027-31.

254. Ustinov, J, R Loginov, C Bruggeman, J Suni, P Hayry, and I Lautenschlager. 1994. CMVinduced class II antigen expression in various rat organs. Transplant Int. 7:302-8.

255. Ustinov, J, R Loginov, C Bruggeman, P van der Meide, P Hayry, and I Lautenschlager. 1993. Direct induction of class || antigens by cytomegalovirus in rat heart endothelial cells. Transplant Proc. 25:1143-4.

256. Van Dorp, WT, PA Van Wieringen, E Marselis Jonges, CA Bruggeman, MR Daha, L.A Van Es, and $\mathrm{F}$ Van der Woude. 1993. Cytomegalovirus directly enhances MHC class I and intercellular adhesion molecule-1 expression on cultured proximal tubular epithelial cells. Transplantation. 55:1367-71.

257. Venema, H, AP Van den Berg, C Van Zanten, WJ Van Son, M Van der Giessen, and TH The. 1994. Natural killer cell responses in renal transplant patients with cytomegalovirus infection. J Med Virol. 42:188-92.

258. Via, CS, JD Shanley, and GM Shearer. 1990. Synergistic effect of murine cytomegalovirus on the induction of acute graft-vs-host disease involving MHC class I differences only. Analysis of in vitro T cell function. J Immunol. 145:3283-9.

259. Visseren, FLJ, MSA Verkerk, KP Boutier, RJA Diepersloot, and DW Erkelens. 1999. Interleukin6 production by endothelial cells after infection with influenza virus and cytomegalovirus. $J$ Lab Clin Med. 134:623-30.

260. Vitale, M, R Castriconi, S Parolini, D Pende, ML Hsu, L Moretta, D Cosman, and A Moretta. 1999. The leukocyte lg-like receptor (LIR)-1 for the cytomegalovirus UL18 protein displays a broad specificity for different HLA class I alleles: analysis of LIR-1+ NK cell clones.

International Immunol. 11:29-35. 
261. Vliegen, I, F Stassen, G Grauls. R Blok, and C Bruggeman. 2002. MCMV infection increases early $\mathrm{T}$-lymphocyte influx in atherosclerotic lesions in apoE knockout mice. J Clin Virol. $2.5: 5159-71$

262. Von Laer, D, U Meyer Koenig, A Serr, J Finke, L Kanz, AA Fauser, D Neumann Haefelin, W Brugger, and FT Hufert. 1995. Detection of cytomegalovirus DNA in CD34+ cells from blood and bone marrow. Blood. 86:4086-90.

263. Vossen, RCRM, JG Derhaag. MEP Slobbe-van Drunen, AM Duijvestijn, MCE van Dam-Mieras, and CA Bruggeman. 1996. A dual role for endothelial cells in cytomegalovirus infection? A study of cytomegalovirus infection in a series of rat endothelial cell lines. Virus Research. 46:65-74.

264. Wagner, M, A Gutermann, J Podlech. MJ Reddehase, and UH Koszinowski. 2002. Major Histocompatibility Complex class I allele-specific cooperative and competitive interactions between immune evasion proteins of cytomegalovirus. J Exp Med. 196:805-16.

265. Waldman, WJ, PW Adams, CG Orosz, and DD Sedmak. 1992. T lymphocyte activation by cytomegalovirus-infected, allogeneic cultured human endotheiial cells. Transplantation. 54:887-96.

266. Waldman, WJ, and DA Knight. 1996. Cytokine-mediated induction of endothelial adhesion molecule and histocompatibility leukocyte antigen expression by cytomegalovirus-activated T cells. Am J Pathol. 148:105-19.

267. Waldman, WJ, JD LeClaire, and DA Knight. 2002. T-cell activation response to allogeneic CMV-infected endothelial cells is not prevented by Ganciclovir or foscarnet: implications for transplant vascular sclerosis. Transplantation. 73:314-20.

268. Waldman, W.J, D.A Knight, P.W Adams, C.G Orosz, and D.D Sedmak. 1995. In vitro induction of endothelial adhesion molecule and $M H C$ antigen expression by cytomegalovirus-activated CD4+ T cells. Transplant Proc. 27:1269-71.

269. Walter, EA, PD Greenberg, MJ Gilbert, RJ Finch, KS Watanabe, ED Thomas, and SR Riddell. 1995. Reconstitution of cellular immunity against cytomegalovirus in recipients of allogeneic bone marrow by transfer of T-cell clones from the donor. N Engl J Med. 333:1038-44.

270. Wang, ECY, and LK Borysiewicz. 1995. The role of CD8+, CD57+ cells in human cytomegalovirus and other viral infections. Scand J Infect Dis. Suppl. 99:69-77.

271. Wang, ECY, B MCSharry, C Retiere, P Tomasec, S Williams, LK Borusiewicz, VM Braud, and GWG Wilkinson. 2002. UL40-mediated NK evasion during productive infection with human cytomegalovirus. Procl Natl Acad Sci USA. 99:7570-5.

272. Wang, ECY, J Taylor-Wiedeman, P Perera, J Fisher, and LK Borysiewicz. 1993. Subsets of CD8+, CD57+ cells in normal, healthy individuals: correlations with human cytomegalovirus (HCMV) carrier status, phenotypic and functional analyses. Clin Exp Immunol. 94:297-305.

273. Webster, A. 1991. Cytomegalovirus as a possible cofactor in HIV disease progression. J Acquir Immune Defic Syndr. 4:547-52.

274. Weimar, W, AHM Balk, HJ Metselaar, B Mochtar, and PH Rothbarth. 1991. On the relation between cytomegalovirus infection and rejection after heart transplantation.

Transplantation. 52:162.

275. Wertheim, P, C Buurman, J Geelen, and J van der Noordaa. 1983. Transmission of cytomegalovirus by renal allograft demonstrated by restriction enzyme analysis. Lancet. 1:980-1.

276. Wiertz, EJHJ, TR Jones, L Sun, M Bogyo, HJ Geuze, and HL Ploegh. 1996. The human cytomegalovirus US11 gene product dislocates MHC class I heavy chains from the endoplasmatic reticulum to the cytosol. Cell. 84:769-79.

277. Wiertz, EJHJ, 5 Mukherjee, and HL Ploegh. 1997. Viruses use stealth technology to escape from the host immune system. Mol Med Today. march:116-23.

278. Wiertz, EJHJ, D Tortella, M Bogyo, J Yu, W Mothes, WR Jones, TA Rapoport, and HL Ploegh. 1996. SEC61-mediated transfer of a membrane protein from the endoplasmic reticulum to the proteasome for destruction. Nature. 384:432-8.

279. Wu, CA, L Puddington, HE Whiteley, CA Yiamouyiannis, CM Schramm, F Mohammadu, and RS Thrall. 2001. Murine cytomegalovirus infection alters TH1/TH2 cytokine expression, decreases airway eosinophilia and enhances mucus production in allergic airway disease. $J$ Immunol. 167:2798-807.

280. XU, XY, K Honjo, D Devore-Carter, and RP Bucy. 1997. Immunosuppression by inhibition of cellular adhesion mediated by leukocyte function-associated antigen-1/intercellular adhesion molecule-1 in murine cardiac transplantation. Transplantation. 63:876-85. 
281. Yang, H, TB Issekutz, and JR Wright Jr. 1995. Prolongation of rat islet allograft survival by treatment with monoclonal antibodies against VLA-4 and LFA-1. Transplantation. 60:71-6.

282. Yerkovich, ST, SD Otver, JC Lenzo, CD Peacock, and P Price. 1997. The roles of tumour necrosis factor-alfa, interleukin-1 and interleukin-12 in murine cytomegalovirus infection. Immunology. 91:45-52.

283. Yilmaz, 5, PK Koskinen, E Kaltio, CA Bruggeman, PJ Hayry, and KB Lemstrom. 1996. Cytomegalovirus infection-enhanced chronic kidney allograft rejection is linked with intercellular adhesion molecule-1 expression. Kidney Int. 50:526-37.

284. Zhou, YF, MB Leon, MA Waclawiw, JJ Popma, ZX Yu, T Finkel, and SE Epstein. 1996. Association between prior cytomegalovirus infection and the risk of restenosis after coronary atherectomy. N Eng J Med. 335:624-30.

285. Zhou, YF, M SHou, RF Harrell, ZX YU, EF Unger, and SE Epstein. 2000. Chronic non-vascular cytomegalovirus infection: effects on the neointimal response to experimental vascular injury. Cardiovasc Res. 45:1019-25.

286. Zhuravskaya, T, JP Maciejewski. DM Netski, E Bruening. FR Mackintosh, and S St Jeor. 1997. Spread of human cytomegalovirus (HCMV) after infection of human hematopoietic progenitor cells: model of HCMV latency. Blood. 90:2482-91.

287. Ziegler, H, R Thale, P Lucin, W Muranyi, T Flohr, H Hengel, H Farrell, W Rawlinson, and UH Koszinowski. 1997. A mouse cytomegalovirus glycoprotein retains MHC class I complexes in the ERGIC/cis-Golgi compartments. Immunity. 6:57-66. 


\section{CHAPTER 2}

\section{Infection with rat cytomegalovirus (CMV) in the immunocompromised host is associated with the appearance of a T cell population with reduced $\mathrm{CD} 8$ and $\mathrm{T}$ cell receptor (TCR) expression}

J.G. van Dam', J.G.M.C. Damoiseaux ${ }^{2}$, H.A.M.D. van der Heijden ${ }^{1,2}$, G. Grauls ${ }^{1}$, P.J.C. van Breda Vriesman ${ }^{2}$ and C.A. Bruggeman'.

Departments of Medical Microbiology ${ }^{1}$ and Immunology ${ }^{2}$, University of Maastricht, Maastricht, The Netherlands. 


\section{Summary}

Infection with human cytomegalovinus (HCMV) mosty rostits in a chronic subclinical infection; the immune system is unable to eliminate the virus and is apparently in equilibrium with the persistent virus. In the immunosuppressed host this equilibrium is disturbed, resulting in clinical infection. Rat cytomegalovirus (RCMV) infection in its host can be used as a model for HCMV infection. Using flow cytometry we examined the effect of acute RCMV infection on the composition of leucocyte subsets in the peripheral blood of both immunocompetent and immunosuppressed ( $5 \mathrm{~Gy}$ total body irradiation) Lewis rats. Special attention was paid to the natural killer (NK) cells and the CD8 ${ }^{+} T$ cells known to be involved in the control of viral infections. Furthermore, we determined the presence of leucocyte subsets in the internal organs by immunohistochemistry. In immunocompetent rats, infection caused a small increase in NK cells and a large increase in CD8. $T$ cells. In contrast, infection of immunosuppressed rats caused a marked increase in NK cells and a small increase in CD8 T cells, consisting of $T$ cells with reduced expression of both CD8 and TCR. This phenomenon is characteristic of anergic CD8 $\mathrm{T}$ cells, possibly explaining the ability of the virus to escape elimination by the immune system. The increase of NK cells in the peripheral blood of immunosuppressed, RCMV-infected rats could also be detected in kidney, liver, lung and pancreas, but not in salivary gland. This could explain the long persistence of infectious virus in the salivary gland. 


\section{Introduction}

Human cytomegalovirus ( $\mathrm{HCMV}$ ) is a $\beta$-herpesvirus, that often causes an infection in man. Infection with the virus mostly results in a chronic subclinical infection; the immune system is unable to eliminate the virus completely, allowing virus to persist in the host in a latent state. In the immunocompromised host, e.g. a transplant recipient, the equilibrium is disturbed, allowing the latent virus to reactivate and to cause clinical disease. HCMV infection has also been associated with increased allograft rejection (23) and recently with the occurrence of coronary restenosis (40, 48).

Like many viruses, HCMV has evolved a strategy to escape immune attack by down-regulation of MHC class I expression on infected cells $(1,25$, $42,46)$. Down-regulation of MHC class I molecules, however, makes cells susceptible to natural killer (NK) cell destruction (29). Recently, it has been described that lysis of infected cells by NK cells is circumvented by the expression of a viral MHC class I homologue $(22,35)$. If this mechanism makes the virus completely invisible to the immune system, immunosuppressed hosts should be expected to have the same course of infection as immunocompetent hosts. Given the clear differences in the clinical course of infection in immunocompetent and immunosuppressed hosts, the escape mechanism of the virus apparently is insufficient to avoid the attack of the immune system of the immunocompetent host.

To investigate the effects of CMV-infection on the host animal models are often used. Rat CMV (RCMV) infection in immunocompetent rats does not result in clinical symptoms. Acute infection in immunosuppressed rats, however, results in a widespread infection with infectious virus being present in almost every organ, eventually resulting in establishment of a latent infection $(8,10)$. Using the rat model, $L i$ et al. described the influence of RCMV infection on transplant associated arteriosclerosis (TAA) after aorta transplantation (27) and the correlation between immunosuppression and the effects of RCMV on the allograft (28). The rat model has proved to be a very useful model to study the course of CMV infection, CMV pathogenesis, the role of CMV on transplant arteriosclerosis and therapeutic interventions (9, 30, 41). Detailed knowledge about the course of RCMV infection in the rat is therefore important for complete understanding of the effects of RCMV on transplant arteriosclerosis. This study investigates the relation between the composition of the peripheral blood leucocytes (PBL), the influx of blood cells in the internal organs and the presence of virus after infection with RCMV. Special attention was paid to the NK cells, CD8 $T$ cells and the CD4/CD8 T cell ratio.

\section{Materials and Methods}

\section{Animals}

Male specific pathogen free (SPF, according to the recommendations of the Federation of European Laboratory Animal Science Association) (34) inbred 
Lewis rats (LEW; RT $1^{1}$ ), obtained from the Central Animal Facility of Maastricht University (The Netherlands), were used in this study. The rats were approximately $250 \mathrm{~g}$ at the start of the experiments. The animals were housed under standardized conditions, fed with commercially available pellet diet and had free access to acidified demineralized water $(\mathrm{pH} \pm 3)$.

\section{Infection and immunosuppression}

The RCMV stock (Maastricht strain) was obtained by homogenization of salivary glands of acutely infected rats as described previously (8). Each animal received $3 \times 10^{5}$ plaque-forming units (PFU) of RCMV intraperitoneally at the start of the experiment (day 0 ). Immunosuppression was induced by giving 5 Gy total body irradiation (TBI) 1 day before infection (day -1)(12). This dose dramatically reduces the number of PBL but the hematopoietic stem cells remain viable.

\section{Design of the experiment}

For the analysis of leucocyte subsets in peripheral blood, RCMV-infected and immunosuppressed rats $(\mathrm{CMV}+\mathrm{TBI}+)$ were used and blood analysis was performed at day 3, 5, 7, 10, 14, 19, 24 and 29 post-infection. Controls consisted of non-infected immunosuppressed rats (CMV-TBI+), infected nonimmunosuppressed rats (CMV+TBI-) and non-infected non-immunosuppressed rats (CMV-TBI-).

In order to follow the course of the RCMV infection in different organs and the effect of the infection on the inflammatory response in these organs, $\mathrm{CMV}+\mathrm{TBI}+$ rats were studied at day 7 and day 14 post infection. As controls, CMV-TBI+ rats were used. The salivary gland, spleen, kidney, liver, lung, heart and pancreas were collected for plaque assay, polymerase chain reaction $(P C R)$, frozen sections and paraffin sections.

\section{Monoclonal antibodies}

The MoAbs used for immunohistochemistry have been described previously (17). MoAb 341 (CD8 $\alpha \beta$ heterodimers, only present on $C D 8^{+}$cytotoxic $T$ cells) (43) and R73 (TCR $\alpha \beta$ ) (24) were kindly provided by Th. Hünig (Würzburg, Germany). W3/25 (directed against CD4) was purchased from Serotec (Oxford, UK). The MoAbs ED1 (inflammatory macrophages) and ED2 (resident tissue macrophages) (18) were kindly provided by C.D. Dijkstra (Free University, Amsterdam, The Netherlands). The MoAb 323 is directed against NK cells (16) and MoAb 8 is directed against early RCMV antigens (14).

For flow cytometry, the MoAb R73 (TCR $\alpha \beta, 10 \mu \mathrm{g} / \mathrm{ml}$ ) conjugated to biotin, MoAb OX35 (CD4, $10 \mu \mathrm{g} / \mathrm{ml}$ ) conjugated to FITC, MoAb OX8 (CD8c, 8 $\mu \mathrm{g} / \mathrm{ml}$ ) conjugated to PE and the second step labelling streptavidin conjugated to the fluorochrome Cy-chrome $(2.5 \mu \mathrm{g} / \mathrm{ml})$ were purchased from Pharmingen (San Diego, CA).

\section{Immunohistochemistry}

Paraffin-embedded sections ( $4 \mu \mathrm{m}$ thick) were used for immunohistochemical detection of RCMV (10). Frozen sections $(4 \mu \mathrm{m})$ were used for all other 
detections, using the indirect immunoperoxidase technique. The slides were scored by comparing the non-infected with infected group. The number of cells present in the infected group was equal $(=)$, moderately increased ( 8 , the number of cells in the infected organ was $<15$ per field of view (magnification 400) or the infected organ contained no more than two times the number of cells present in non-infected organs), or strongly increased ( 8 s, more than two-fold) compared to the non-infected group on the same day after infection and irradiation.

\section{Plaque assay}

To detect the presence of infectious virus in the different organs, the organs were homogenized in a tissue grinder and suspended in minimal essential medium with $2 \%$ fetal calf serum (FCS) as described previously (11). Ten- and 100 -fold dilutions of $10 \%$ homogenates $(w / v)$ were inoculated on a confluent rat embryonic fibroblast monolayer. After an incubation period of 7 days, under $0.25 \%$ agarose, the number of plaques was determined microscopically after fixation and methylene blue staining.

\section{Semiquantitative nested $P C R$}

To determine the presence of viral DNA, organs were cut in small pieces and stored at $-70^{\circ} \mathrm{C}$ until use. After an incubation period of 6 h with extraction buffer, DNA was isolated according to the description of the manufacturers of the XTRAX DNA Extraction Kit (Gull Laboratories, Salt Lake City, UT). DNA concentration was determined spectrophotometrically, and $1 \mu \mathrm{g}$ of DNA was used in the PCR.

In the first run primers were used that hybridize with the RCMV DNA polymerase gene (6). The sequences of the primers are $5^{\prime}$ -

AAGGGATCCGATTTCGCCAGCCTCTACC-3' (in which the sequence in italics represents nucleotides 11726 to 11744 of GenBank file U50550) and $5^{\prime}$ AAGGGATCCTGTCGGTGTCCCCGTACAC-3' (in which the sequence in italics represents the sequence complementary to nucleotides 12221 to 11239 of GenBark file U50550). The primers generate a product of 536bp. The nested $P C R$ resulted in a product with a length of $431 \mathrm{bp}$, using primers 5 '-

AAGGGATCCCCTCTGTTACTCCACCCTGC-3' (in which the sequence in italics represents nucleotides 11767 to 11786 of GenBank file U50550) and 5'TTCGGATCCACGCCGACCTCGGAGACCAG-3' (in which the sequence in italics represents the sequence complementary to nucleotides 12158 to 12177 of GenBank file U50550). PCR products were separated on 1.2\% agarose gels followed by staining with ethidium bromide $(0.5 \mu \mathrm{g} / \mathrm{ml})$. For semiquantitative analysis of the amount of virus present, DNA was diluted 10-fold (maximal nine times) before running the first PCR.

\section{Flow cytometry}

To determine the effect of RCMV infection on the different subsets of leucocytes in the peripheral blood, $1 \mathrm{ml}$ of heparinized blood was collected from the retro-orbital plexus per rat. The absolute number of PBL was determined by diluting blood in Türk solution and counting the nucleated cells 
in a Bürker Hemocytometer. The erythrocytes were lysed with ammoniumchloride-solution $(0.155 \mathrm{M}$ ammoniumchloride, $0.01 \mathrm{M}$ potassiumcarbonate and $0.1 \mathrm{mM}$ EDTA, pH7.4 at $4^{\circ} \mathrm{C}$ ). For three-colour flow cytometry, $5 \times 10^{5}$ cells per sample were resuspended in $20 \mu \mathrm{l} \mathrm{PBS}$ containing $0.5 \%$ bovine serum albumin (BSA), $10 \mathrm{mM} \mathrm{NaN}_{3}$ and the MoAbs directed against CD4, CD8 and TCR $\alpha \beta$. The expression of CD4, CD8 and TCR $\alpha \beta$ and the forward scatter (FSC) and side scatter patterns (SSC) were determined using a FACSort (Becton Dickinson, Etten Leur, The Netherlands) and the LYSYS II software package (Becton Dickinson). In list mode 10000 events were acquired with gating on viable cells using the FSC parameter. In order to get a more detailed insight in the CD4/CD8 T cell ratio, another 5000 events were acquired with gating on viable T cells using FSC and TCR expression. Granulocytes were identified by their typical scatter profile in a FSC versus SSC plot. Monocytes were identified by the dim expression of CD4 and the absence of TCR expression, whereas NK cells stain positive for CD8 and lack TCR expression (4).

\section{Results}

RCMV infection causes an increase in the number of leucocytes in immunocompetent rats.

To study the effect of RCMV infection on the different fractions of leucocytes in the peripheral blood, both immunosuppressed and immunocompetent rats were infected. The absolute number of leucocytes in the CMV-TBI- rats stayed between $6.2 \times 10^{6}$ and $8.6 \times 10^{6}$ cells per $\mathrm{ml}$ blood during the experiment (Fig. 1). Infection with RCMV in the non-irradiated rats $(C M V+T B I-)$ resulted in a slight increase in the number of leucocytes on days 10 and 14 . In the $\mathrm{CMV}+\mathrm{TBI}+$ rats leucocytes were depleted, caused by the irradiation. Next, the number of leucocytes gradually increased to normal over a period of 4 weeks. An increase in the number of leucocytes was not observed in the CMV+TBI+ group compared with the CMV-TBI+ group.

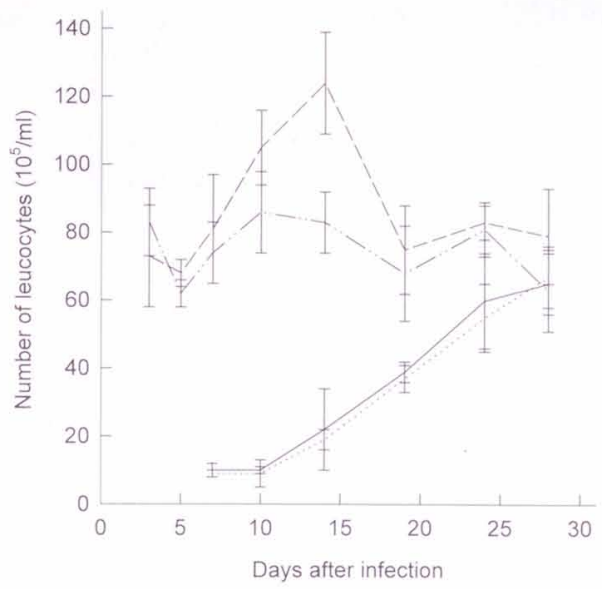

Figure 1.

Increased peripheral blood leucocyte numbers upon rat CMV (RCMV) infection in

immunocompetent rats. Results are the mean $\left( \pm\right.$ s.d.) , leucocyte numbers $\left(x 10^{5}\right)$ determined in a Bürker haemocytometer in infected and irradiated rats $(\mathrm{CMV}+\mathrm{TB} \mid+,---; \mathrm{n}=4)$, irradiated rats $(\mathrm{CMV}-\mathrm{TB}++, \ldots \ldots \ldots ; n=3)$, infected rats (CMV+TBI-, .......; $n=3)$, and untreated control rats (CMV-TBI-, -....... ; $n=3$ ). 
Days after infection
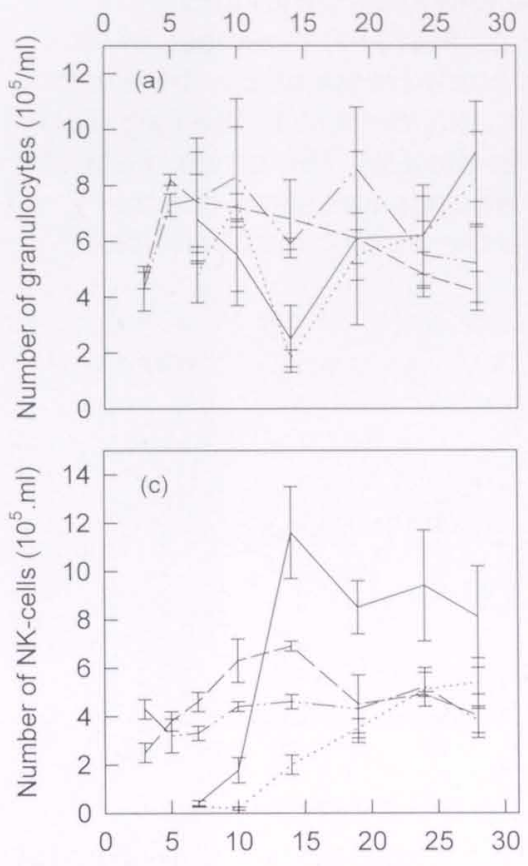

Days after infection
Days after infection


Days after infection

Figuur 2. Rat CMV (RCMV) infection results in an increase in the specific immunity in immunocompetent rats and in non-specific immunity in the immunosuppressed rats. Periphera! blood cells were analyzed by five parameter flow cytometry. Granulocytes (a) were identified by their forward and side scatter profile, monocytes (b) as CD4 TCR natural killer (NK) cells (c) as CD8 ${ }^{+} T C R \alpha \beta$ and T cells (d) as TCR $\alpha \beta^{+}$. Results are the mean ( \pm s.d.) number of cells $\left(\times 10^{5}\right)$ per ml blood of infected and irradiated rats $(\mathrm{CMV}+\mathrm{TBI}+,-\ldots ; \mathrm{n}=4)$, irradiated rats $(\mathrm{CMV}-\mathrm{TBI}+, \ldots \ldots \ldots$; $n=3)$, infected rats $(\mathrm{CMV}+\mathrm{TBI}-, \ldots \ldots \ldots . ; \mathrm{n}=3)$, and untreated control rats $(\mathrm{CMV}-\mathrm{TBI}-, \cdots \ldots \ldots$; $n=3)$.

RCMV infection in immunocompetent and immunosuppressed rats results in a preferential increase in the T cell and NK cell compartment, respectively. Four subsets of leucocytes could be specified using the five-parameter analysis, i.e. granulocytes, monocytes, NK cells and T cells. In the (CMV-TBI-) control group the numbers of granulocytes ranged from $6 \times 10^{5}$ to $8 \times 10^{5}$ cells per $\mathrm{ml}$ blood. For the monocytes the range was $7 \times 10^{5}-12 \times 10^{5}$, for the NK cells $3 \times 10^{5}-5 \times 10^{5}$ and for the T cells $3.3 \times 10^{6}-4.7 \times 10^{6}$ cells per $\mathrm{ml}$ blood. Infection with CMV (CMV+TBI-) had no effect on the number of granulocytes (Fig. 2a) and monocytes (Fig. 2b), but resulted on days 10 and 14 in a small increase in the number of NK cells (Fig. 2c) and a strong increase in the number of T cells (Fig. 2d).

Irradiation caused a depletion of the number of PBL that correlated with a depletion of monocytes, NK cells and T cells (Fig. 2b,c,d). The number of granulocytes was already restored to normal at day 4 post-irradiation (Fig. 
$2 a)$. Compared with the CMV-TBI+ rats no changes in the number of granulocytes and $\mathrm{T}$ cells were detected in the $\mathrm{CMV}+\mathrm{TBI}+$. The number of monocytes, however, showed an accelerated recovery. The number of NK cells in the $\mathrm{CMV}+\mathrm{TBI}+$ group showed an enormous increase at day 14 after infection, resulting in six times the number of cells present in the CMV-TBI+ group and twice the number of cells present in the CMV-TBI- group. From day 14 to day 28 a slow decline in the number of NK cells was seen, but the numbers remained elevated as compared with the three control groups.

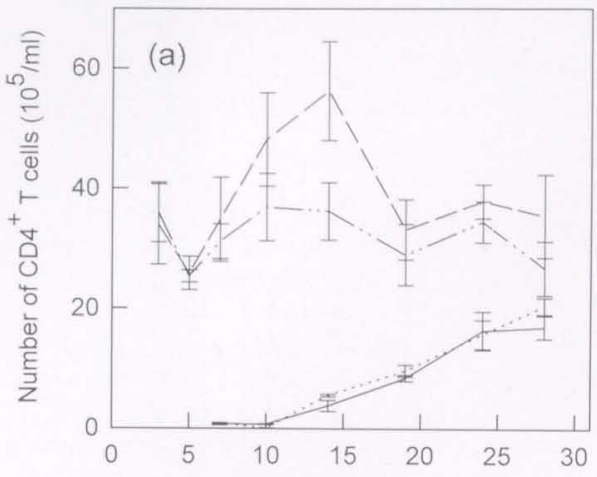

Days after infection



Days after infection

Figure 3. Rat CMV (RCMV) infection causes an increase in the absolute number of $C D 4^{+}$and $C D 8^{+} T$ cells in immunocompetent rats. In immunosuppressed rats infection with RCMV causes an increase in the absolute number of $\mathrm{CD}^{+} \mathrm{T}$ cells. Peripheral blood cells were analysed by three-colour flow cytometry. Helper T cells (a) were identified as CD4 TCR $\alpha \beta^{+}$and cytotoxic T cells (b) as CD8 ${ }^{+} T C R \alpha \beta^{+}$. Results are presented as the mean ( \pm s.d.) number of cells $\left(\times 10^{5}\right)$ per $\mathrm{ml}$ blood of infected and irradiated rats $(\mathrm{CMV}+\mathrm{TBI}+,--; n=4)$, irradiated rats $(\mathrm{CMV}-\mathrm{TBI}+, \ldots \ldots \ldots ; \mathrm{n}=3)$, infected rats $(\mathrm{CMV}+\mathrm{TBI}-, \ldots \ldots \ldots ; n=3)$, and untreated control rats (CMV-TBI-, -...-...; $n=3)$.

Decrease in CD4/CD8 ratio in immunosuppressed RCMV-infected rats is caused by the appearance of an aberrant $C D 8^{+} T$ cell subset.

Because it is known that T cells play an important role in the defense against herpes virus infections in general, the effect of RCMV infection on the subpopulations of T cells (CD4 and CD8) was further analysed. Figure 3 presents the absolute numbers of $C D 4^{+} T$ cells and $C D 8^{+} T$ cells (Fig. $3 a, b$ ).

In the CMV-TBI- rats, the number of $\mathrm{CD}^{+} \mathrm{T}$ cells ranged between $2.5 \times 10^{6}$ to $3.6 \times 10^{6}$ cells per $\mathrm{ml}$ blood and the number of $\mathrm{CD} 8^{+} \mathrm{T}$ cells between $7 \times 10^{5}$ and $1 \times 10^{6}$. This resulted in a CD4/CD8 ratio of 3.0-4.1 (Fig. 4). In the $\mathrm{CMV}+\mathrm{TBI}-$ rats, the absolute number of both $\mathrm{CD} 4^{+}$and $\mathrm{CD} 8^{+} \mathrm{T}$ cells was increased on day 10 and 14 (Fig. 3a,b). This increase caused no relative changes in the $\mathrm{CD} 4^{+}$and $\mathrm{CD} 8^{+} \mathrm{T}$ cells and therefore no alterations in the $\mathrm{CD} 4 / \mathrm{CD} 8$ ratio (Fig 4). Irradiation (CMV-TBI+) resulted in an enormous decrease in the absolute number of both $\mathrm{CD} 4^{+}$and $\mathrm{CD} 8^{+} \mathrm{T}$ cells at day 7 . Both subsets slowly increased and reached almost normal levels at day 28 (Fig. $3 a, b)$. The recovery from irradiation was slower in $C D 8^{+} T$ cells than in $C D 4^{+} T$ cells, resulting in an increased CD4/CD8 ratio on day 7 and 10 (Fig. 4). 
In the $\mathrm{CMV}+\mathrm{TBI}+$ group, the infection caused no changes in the number of $\mathrm{CD}^{+} \mathrm{T}$ cells, but in the population of $\mathrm{CD} 8^{+} \mathrm{T}$ cells an increase was detected as compared with the CMV-TBI+ group. This resulted in a relative decrease in the number of $\mathrm{CD} 4^{+} \mathrm{T}$ cells and a relative increase in the number of $\mathrm{CD} 8^{+} \mathrm{T}$ cells, leading to a decrease in the CD4/CD8 ratio (Fig. 4) starting at day 10. The CD4/CD8 ratio was restored to about the normal level at day 28 .

A detailed examination of the results of the flow cytometry revealed a phenotypically aberrant subpopulation of $\mathrm{CD} 8^{+} \mathrm{T}$ cells , showing a decreased expression of CD8 and TCR (Fig. $5 a, b$ ) in the CMV+TBI+ group. Figure $5 c$ shows the percentage of $T$ cells expressing low amounts of TCR and CD8. The $C M V+T B I+$ group shows a marked increase in the number of $C D 8^{\text {low }} T C R^{\text {low }}$ cells reaching on day 14 a maximum of $15.5 \%$ of the total number of T cells, being as much as $40 \%$ of the total number of $\mathrm{CD} 8^{+} \mathrm{T}$ cells.



Figure 4.

Infection with rat CMV (RCMV) causes a decrease in the ratio of CD4/CD8 T cells in immunosuppressed rats. Peripheral blood cells were analysed by three-colour flow cytometry. Helper T cells were identified as CD4 TCR $\alpha \beta^{+}$and cytotoxic T cells as CD8 ${ }^{+} T C R \alpha \beta^{+}$. Results are presented as the mean ( \pm s.d.) ratio of $\mathrm{CD}^{+} \mathrm{T}$ cells and $\mathrm{CD} 8^{+}$ $T$ cells of infected and irradiated rats $(\mathrm{CMV}+\mathrm{TBI}+, \ldots ; \mathrm{n}=4)$, irradiated rats (CMV-TBI+, ....... $n=3)$, infected rats $(\mathrm{CMV}+\mathrm{TBI}-, \ldots \ldots \ldots+\mathrm{n}=3)$, and untreated control rats (CMV-TBI-, $\cdots \ldots \ldots ; n=3)$.

Table 1. The influence of CMV infection on the presence of T cells, natural killer (NK) cells and macrophages in immunosuppressed rats.

\begin{tabular}{|c|c|c|c|c|c|c|c|c|}
\hline \multirow[b]{2}{*}{ Organ } & \multicolumn{2}{|c|}{ T cells } & \multicolumn{2}{|c|}{ NK cells } & \multicolumn{2}{|c|}{ Resident macroph. } & \multicolumn{2}{|c|}{ Infiltrating macroph. } \\
\hline & Day 7 & Day 14 & Day 7 & Day 14 & Day 7 & Day 14 & Day 7 & Day 14 \\
\hline Salivary Gland & $=$ & $\uparrow$ & $=$ & $=$ & $=$ & $=$ & $=$ & $\uparrow$ \\
\hline Kidney & $=$ & $=$ & $=$ & $\uparrow$ & $=$ & $=$ & $\uparrow$ & $\uparrow$ \\
\hline Liver & $=$ & $=$ & $i$ & $\uparrow$ & $i$ & $\uparrow$ & $\Uparrow$ & $\Uparrow$ \\
\hline Lung & $=$ & $=$ & $=$ & $\uparrow$ & $=$ & $=$ & $=$ & $\uparrow$ \\
\hline Heart & $=$ & $=$ & $=$ & $=$ & $\uparrow$ & $\uparrow$ & $\uparrow$ & $\uparrow$ \\
\hline Pancreas & $=$ & $\uparrow$ & $\uparrow$ & $\Uparrow$ & $\uparrow$ & $\uparrow$ & $\uparrow$ & $\Uparrow$ \\
\hline
\end{tabular}

The presence of T cells, NK cells and macrophages in the internal organs on days 7 and 14 after infection was determined using immunohistochemistry. The animals were immunosuppressed by total body irradiation ( $5 \mathrm{~Gy}$ ) and infected by i.p. injection of $3 \times 10^{5}$ plaque-forming units (PFU) rat CMV (RCMV).

$=$, no difference between infected and non-infected rats; $\uparrow$, moderate increase (the number of cells in the infected organs was less than 15 per field of view (magnificationx400) or the infected organ contained no more than a twice the number of cells present in non-infected organs); $₫$, strong increase (more than two-fold) in the number of stained cells in the infected compared with the non-infected rats. 



Figure 5. Rat CMV (RCMV) infection in immunosuppressed rats results in the development of an aberrant CD8 ${ }^{+}$T cell subset with a decreased expression of CD8 and TCR. The expression of TCR and CD8 on CD8 ${ }^{-} T C R^{+}$cells in $C M V$ - $T B 1+$ rats (a) and $C M V+T B I+$ rats (b) was determined using three-colour flow cytometry staining for CD4, CD8 and TCR.

$C D 8^{\text {low }} T C R^{\text {low }}$ cells were identified as CD8 ${ }^{+} T C R \alpha \beta^{+}$with relatively low expression CD8 and $T C R \alpha \beta$ (c). Results are the percentage ( \pm s.d.) of $C D 8^{\text {low }} T C R{ }^{\text {low }}$ of the total number of $T$ cells of infected and irradiated rats $(\mathrm{CMV}+\mathrm{TBI}+, \ldots-\ldots=4)$, irradiated rats $(\mathrm{CMV}-\mathrm{TBI}+$, $\ldots \ldots \ldots ; n=3)$, infected rats $(\mathrm{CMV}+\mathrm{TBI}-, \ldots \ldots \ldots \ldots ; \mathrm{n}=3)$, and untreated control rats (CMV. TBI-,$-\cdots \cdots ; n=3)$.

The salivary gland escapes NK cell infiltration upon RCMV infection.

To determine whether the increase in the number of NK and CD8+ T cells found in the peripheral blood of the $\mathrm{CMV}+\mathrm{TBI}+$ group could also be detected in the internal organs, immunohistochemical techniques were used. For this purpose, the salivary gland, kidney, liver lung, heart and pancreas were examined for the presence of infiltrating T cells, NK cells and macrophages. Table 1 shows the presence of the leucocytes in the different organs on days 7 and 14 in infected animals compared with the presence of leucocytes in noninfected animals.

$T$ cells. At day 14 after infection, no differences in the number of $T$ cells were seen in the kidney, liver, lung and heart, while in the pancreas and the salivary gland a clear diffuse increase in the number of $T$ cells was seen in the infected group compared with the non-infected group, being most prominent in the pancreas. This increase seemed to be caused mainly by an increase in $\mathrm{CD}^{+} \mathrm{T}$ cells.

NK cells. In most organs of infected animals there was a diffuse increased infiltration of NK cells compared with non-infected rats. In the liver and pancreas, this could already be detected on day 7 , while in the lung and kidney this was only visible on day 14 . On day 14 the infiltration of NK cells 
was most prominent in the pancreas. In the salivary gland and the heart, no difference in the number of infiltrating NK cells was visible at both measure points.

Macrophages. The presence of macrophages was determined using MoAbs ED1 (inflammatory macrophages) and ED2 (resident macrophages). The liver, heart and pancreas showed a small increase in the number of resident macrophages in the infected rats on both days 7 and 14 . The number of resident macrophages was not increased in the infected compared with the non-infected group in the salivary gland, kidney and lung. As determined by ED1 expression, on day 7 the RCMV infection caused an increase in macrophage infiltration in the kidney, the liver (strong increase), heart and pancreas, while no effects were seen in the salivary gland and lung. At day 14, infection caused infiltration of macrophages in all organs. The largest increases in infiltrating macrophages were detected in the liver and the pancreas.

Table 2. Detection of virus and virus-infected cells in immunosuppressed rats.

\begin{tabular}{|c|c|c|c|c|c|c|c|c|}
\hline \multirow[t]{2}{*}{ Organ } & \multicolumn{2}{|c|}{ Immunohistochemistry } & \multicolumn{2}{|c|}{ Plaque assay } & \multicolumn{4}{|c|}{ PCR } \\
\hline & Day 7 & Day 14 & Day 7 & Day 14 & Day 7 & $\begin{array}{c}\text { Mean } \\
\text { titre }\end{array}$ & Day 14 & $\begin{array}{c}\text { Mean } \\
\text { titre }\end{array}$ \\
\hline Salivary gland & $0 / 2$ & $3 / 3$ & $0 / 2$ & $3 / 3^{4}$ & $2 / 2$ & $10^{!}$ & $3 / 3$ & $10^{4}$ \\
\hline Spleen & $0 / 2$ & $0 / 3$ & $2 / 2^{*}$ & $0 / 3$ & $2 / 2$ & $10^{n}$ & $3 / 3$ & 10 \\
\hline Kidney & $0 / 2$ & $0 / 3$ & $1 / 2^{*}$ & $0 / 3$ & $2 / 2$ & $10^{?}$ & $3 / 3$ & $10^{2}$ \\
\hline Liver & $0 / 2$ & $0 / 3$ & $0 / 2$ & $0 / 3$ & $0 / 2$ & - & $3 / 3$ & $10^{4}$ \\
\hline Lung & $0 / 2$ & $0 / 3$ & $1 / 2^{*}$ & $0 / 3$ & $2 / 2$ & $10^{3}$ & $2 / 3$ & $10^{\prime}$ \\
\hline Heart & $0 / 2$ & $0 / 3$ & $0 / 2$ & $0 / 3$ & $2 / 2$ & $10^{5}$ & $3 / 3$ & $10^{\prime}$ \\
\hline Pancreas & $1 / 2$ & $1 / 3$ & $0 / 2$ & $1 / 3^{*}$ & $2 / 2$ & $10^{2}$ & $3 / 3$ & $10^{*}$ \\
\hline
\end{tabular}

The presence of virus or virus-infected cells was determined at day 7 and 14 after infection using immunohistochemistry (viral antigens), plaque assays (infectious virus) and polymerase chain reaction ( $P C R$ ) (viral DNA). The rats were immunosuppressed by total body irradiation (5 Gy) and were infected by intraperitoneal injection with $3 \times 10^{\prime \prime}$ plaque forming units (PFU) rat CMV (RCMV). The results are presented as the number of positive organs/the total number of organs tested. For the PCR also the mean titre is presented. * $<166 \mathrm{PFU} / \mathrm{ml}, ">10^{4} \mathrm{PFU} / \mathrm{ml}$.

\section{RCMV persists in many organs of the rat}

In order to correlate the presence of infiltrating cells with the presence of virus in the internal organs, analysis of RCMV infection was performed using three different techniques (Table 2).

$$
\text { Using immunohistochemistry the presence of viral antigens was }
$$

detected, by plaque assay the amount of infectious virus was determined and by semiquantitative PCR the amount of viral DNA in the tested organ was determined. In the plaque assay at day 7 two of the two spleens, one of the two kidneys and one of the two lungs were positive. At day 14 all three salivary glands and one pancreas were positive. All positive organs contained $<166 \mathrm{pfu} / \mathrm{ml}$, except for the salivary glands, that contained $>10^{4} \mathrm{pfu} / \mathrm{ml}$. Using immunohistochemistry, on day 7 only in one pancreas viral antigen could be detected. At day 14, all salivary glands and one pancreas were positive. In the pancreas the positive signal was present in the exocrine secretory cells and in 
the salivary gland in the mucous cells. Viral DNA could be detected in almost every organ: only the livers at day 7 and one lung at day 14 were negative. The concentration of viral DNA in spleen, lung and heart was decreased at day 14 compared with day 7 , while it remained constant in kidney and increased in the pancreas, salivary gland and liver. For the non-infected rats, all organs were negative in all three tests.

\section{Discussion}

The main findings of this study are three-fold. First, infection with RCMV in the immunocompetent and immunosuppressed rat leads to reactions similar to those in human and mouse, resulting in a preferential increase in the $T$ cell and NK cell compartment, respectively. Next, the effects found in the PBL of immunosuppressed rats can in general also be detected in the internal organs. The salivary gland, however, seems to escape additional NK cell infiltration upon RCMV infection. Finally, in the immunosuppressed RCMV-infected animals an aberrant CD8 ${ }^{+} T$ cell subset appears with decreased expression of both CD8 and TCR, a phenotype which has keen associated with anergy $(5,37$, 47).

In mice both CD8 ${ }^{+} T$ cells, CD4 $T$ cells and NK cells have been shown to be important in recovery from murine CMV (MCMV) infection. In immunocompetent mice MCMV infection resulted in an increase in CD8 T cells, causing a decrease in the CD4/CD8 ratio at 6-13 days after infection (20). CD8 ${ }^{+} \mathrm{T}$ cells specific for immediate early antigens can protect immunosuppressed mice from a lethal course of MCMV infection (33). Depletion of CD4 T cells or NK cells resulted in high levels of virus in various organs $(21,39)$. In severe combined immunodeficient (SCID) mice (void of functional T- and B-cells) the NK cells were activated to high levels of cytotoxicity with a peak on day 3-5 after infection. However, in contrast to normal, these mice were unable to clear the infection (45).

In man, Carney et.al. described a reversal of the normal CD4/CD8 T cell ratio during acute CMV-mononucleosis, caused by an increase in CD8 and a decrease in CD4-cells (15). Furthermore, recovery from HCMV-infection in transplant recipients is associated with activation and up-regulation of CD8 $\mathrm{T}$ cells $(19,26,31,36,44)$.

Taken together, these data suggest that in case of a CMV infection of an immunocompetent host the CD4 T cells, CD8 T cells and NK cells play a role in limitation of the infection. Depletion of one of these cell types results in increased CMV replication in several organs and sometimes severe pathology. Absence of T cells and B-cells, as seen in SCID-mice, results in more profound NK cell activation. The results in our rat model are quite similar to the results found in mice and in human. RCMV infection in immunocompetent rats results in a small increase in the number of NK cells and a large increase in the number of T cells. In the immunosuppressed animals where especially the number of T cells is very low after infection, there is a marked increase in the number of NK cells. 
The effects of infection on the different leucocyte subsets in the peripheral blood of the CMV+TBl+rats could also be detected in internal organs. These effects were correlated with the presence of virus or virusinfected cells within these organs. To detect the virus or the virus-infected cells, we used immunohistochemistry, plaque assays and PCR. Viral detection using plaque assay of various organs has been described before. Infectious virus and viral antigen could be detected in many organs early after infection but starting at about 2 weeks post-infection, virus could only be detected in the salivary gland $(8,10,41)(13)$. The detection of viral DNA using PCR has not been used before in rats. Our results show that even if no infectious virus or viral antigen can be detected, the viral DNA can still be present. Since all organs at day 14 after infection do contain viral DNA, all organs from seropositive donors might be able to transfer RCMV. It has been reported that the conditions of primary infection define the overall load witn latent CMV, and that the copy numbers of latent viral genome in organs is the key parameter that determines the overall and organ-specific risk of recurrence (32). For mice the lungs contain the highest viral load and it has therefore been described that the lungs are a major site of CMV latency (3). On the other hand, Balthesen et.al. (2) described that the control of viral replication in a particular organ, and thus the control of the number of viral DNA copies present in that organ after acute infection, is not linked to the copy number of latent virus. If in the rat the viral copy number in organs at day 14 is correlated with latency, the salivary glands, liver and pancreas are the most susceptible sites for latency.

Increased infiltration of T cells in the infected organs was detected in the salivary gland and pancreas. As expected, the presence of antigen seems to correlate with infiltration of T cells. Increased infiltration of NK cells after infection was detected in most organs: the heart and the salivary glanci are the only organs that escape NK cell invasion. In the heart no viral antigens or infectious virus could be detected and the absence of additional infiltrating NK cells can thereby be explained. In the salivary gland, however, both viral antigen and infectious virus are present, suggesting that there is a difference between the infected cells in the salivary gland and in other tissues. This phenomenon, not previously described, could be explained by the expression of a vira! MHC class I homologue, which inhibits attack by NK cells $(22,35)$. A deletion mutant for the MHC class I homologue of MCMV causes a decrease in infection of the spleen, liver and lung. However, in the salivary gland the titre remained as high as in case of infection with wild-type MCMV (22). These results suggest that the salivary gland does not use this mechanism to escape the NK cell reaction. Apparently, there is some kind of tissue-specific barrier for the additional NK cells to enter the salivary gland upon RCMV infection. This might contribute to the fact that infectious virus remains detectable in the salivary gland for at least a few months (13).

An interesting observation in the group of infected immunosuppressed rats is the detection of a phenotypically aberrant subpopulation of CD8 $\mathrm{T}$ cells, showing a decreased expression of both CD 8 and TCR. At day 14 postinfection, this subpopulation covered about $40 \%$ of the total number of CD ${ }^{\circ} \mathrm{T}$ 
cells. The increase in the number of CD8 ${ }^{\circ} T$ cells is entirely caused by the increase in the number of CD8 ${ }^{\text {low }} T C R^{\text {low }}$ cells (data not shown).

Three-colour staining excluded the possible characterization of this CD4-CD8 ${ }^{\text {low }} T C R^{\text {low }}$ subset as being NK cells (CD4-CD8 ${ }^{\text {lov }} T C R-$ ), activated CD4 T


forward and side scatter profile of these cells was similar to the profile of normal T cells, the possibility of these cells being dying cells was excluded. Dying cells are expected to have reduced forward and increased side scatter profiles. Down-regulation of both TCR and CD8 occurs in anergic T cells $(5,37$, 47), which are unresponsive to antigen. Anergy is induced if the antigen is presented in the absence of proper costimulatory signals (38). Beside clonal deletion and suppression, induction of anergy is an important mechanism of peripheral tolerance induction for self-antigens. Our results suggest that in the rat model CMV infection not only interferes with MHC class I expression $(1,25,42,46)$, but also interferes with the costimulatory signals upon antigen presentation of viral antigens. This renders the virus-specific $T$ cells anergic and enables the virus to escape further elimination by the immune system of immunocompromised hosts. Tests are being performed to obtain more functional information about this $C D 8^{\text {low }}{ }^{2} \mathrm{R}^{\text {low }}$ subpopulation.

\section{Acknowledgements}

The authors wish to thank Professor Th. Hünig (Würzberg, Germany) and Professor C. D. Dijkstra (Amsterdam, The Netherlands) for the generous gift of monoclonal antibodies. The authors would like to thank S. J. V. Vanherle for her excellent technical assistance. 


\section{References}

1. Ahn, K, A Angulo, P Ghazel, PA Peterson, Y Yang, and K Fruh. 1996. Human cytomegalovirus inhibits antigen presentation by a sequential multistep process. Proc Natl Acad Sci USA. 93:10990-5.

2. Balthesen, M, L Dreher, P Lucin, and MJ Reddehase. 1994. The establishment of cytomegalovirus latency in organs is not linked to local virus production during primary infection. J Gen Virol. 75:2329-36.

3. Balthesen, M, M Messerle, and MJ Reddehase. 1993. Lungs are a major organ site of cytomegalovirus latency and recurrence. J Virol. 67:5360-6.

4. Beijleveld, L.J.J., H. Groen, C.P.M. Broeren, F.A. Klatter, J. Kampinga, J.G.M.C. Damoiseaux, and P.J.C. van Breda Vriesman. 1996. Susceptibility to clinically manifest cyclosporine A (CSA)-induced autoimmune disease is associated with interferon-gamma (IGFgamma)-producing CD45RC+RT6-T helper cells. Clin Exp Immunol. 105:486-96.

5. Bellgrau, D, and AC Lagarde. 1990. Cytotoxic T-cell precursors with iow-level CD8 in the diabetes-prone Biobreeding rat: Implications for generation of an autoimmune T-cell repertoire. Proc Natl Acad Sci USA. 87:313-7.

6. Beuken, E., R Slobbe, C.A. Bruggeman, and C. Vink. 1996. Cloning and sequence analysis of the genes encoding DNA polymerase, glycoprotein B, ICP18.5 and major DNA-binding protein of rat cytomegalovirus. J Gen Virol. 77:1559-62.

7. Bevan, . DJ, and PM Chisholm. 1986. Co-expression of CD4 and CD8 molecules and de novo expression of $M H C$ class II antigens on activated rat T-cells. Immunology. 59:621-5.

8. Bruggeman, CA, WMH Debie, G Grauls, G Majoor, and CPA Van Boven. 1983. Infection of laboratory rats with a new cytomegalo-like virus. Arch Virol. 76:189-99.

9. Bruggeman, CA, FL Li, and FS Stals. 1995. Pathogenicity: Animal models. Scand J Infect Dis. 99:43-50.

10. Bruggeman, CA, H Meijer, F Bosman, and CP Van Boven. 1985. Biology of rat cytomegalovirus infection. Intervirol. 24:1-9.

11. Bruggeman, C.A, H Meijer, P.H.J Dormans, W.M.H Debie, G.E.L.M Grauls, and C.P.A Van Boven. 1982. Isolation of a cytomegalovirus-like agent from wild rats. Arch Virol. 73:231-41.

12. Bruning, JH, CA Bruggeman, CP Van Boven, and PJ Van Breda Vriesman. 1986. Passive transfer of cytomegalovirus by cardiac and renal organ transplants in a rat model. Transplantation. 41:695-8.

13. Bruning, JH, CA Bruggeman, and PJ Van Breda Vriesman. 1988. The transfer of cytomegalovirus infection in rats by latently infected renal allografts, and the role of various immunosuppressive regimens in virus reactivation. Transplantation. 46:623-4.

14. Bruning, J.H, W.H Debie, P.H Dormans, H Meijer, and C.A Bruggeman. 1987. The development and characterization of monoclonal antibodies against rat cytomegalovirus induced antigens. Arch Virol. 94:55-70.

15. Carney, WP, RH Rubin, RA Hoffman, WP Hansen, K Healey, and MS Hirsch. 1981. Analysis of lymphocyte subsets in cytomegalovirus mononucleosis. J Immunol. 126:2114-6.

16. Chambers, WH, NL Vujanovic, AB DeLeo, MW Olsowy, RB Herberman, and JC Hiserodt. 1989. Monoclonal antibody to a triggering structure expressed on rat natural killer cells and adherent lymfokine-activated killer cells. J Exp Med. 169:1373-89.

17. Damoiseaux, JGMC, LJJ Beijleveld, and PJC Van Breda Vriesman. 1995. Cutaneous immunopathology of cyclosporin-A-induced autoimmunity in the rat. Clin Immunol Immunopath. 77.

18. Dijkstra, CD, EA Dopp, P Joling, and G Kraal. 1985. The heterogeneity of mononuclear phagocytes in lymphoid organs: distinct macrophage subpopulations in the rat recognized by monoclonal antibodies ED1, ED2 and ED3. Immunology. 54:589-99.

19. Dolstra, H, E Van de Wiel-van Kemenade, T De Witte, and F Preijers. 1996. Clonal predominance of cytomegalovirus-specific CD8+cytotoxic Tlymphocytes in bone marrow recipients. Bone Marrow Transplant. 18:339-45.

20. Doody, DP, EJ Wilson, DN Medearis, and RH Rubin. 1986. Changes in the phenotype of T-cell subset determinants following murine cytomegalovirus infection. Clin Immunol Immunopathol. 40:466-75.

21. Erlich, KS, J Mills, and JD Shanley. 1989. Effects of L3T4+ lymphocyte depletion on acute murine cytomegalovirus infection. J Gen Virol. 70:1765-71. 
22. Farrell, HE, H Vally, DM Lynch, P Fleming, GR Shellam, AA Scalzo, and NJ Davis-Poynter. 1997. Inhibition of natural killer cells by a cytomegalovirus MHC class I homologue in vivo. Nature. 286:510-4.

23. Grattan, MT, CE Moreno-Cabral, VA Stames, PE Oyer, EB Stinson, and NE Shumway. 1989. Cytomegalovirus infection is associated with cardiac allograft rejection and atherosclerosis. JAMA. 261:3561-66.

24. Hunig, T, HJ Wallny, JK Hartley, A Lawetzky, and G Tiefenthaler. 1989. A monoclonal antibody to a constant determinant of the rat $T$ cell antigen receptor that induces $T$ cell activation. J Exp Med. 169:73-86.

25. Jones, TR, EJHJ Wiertz, L Sun, KN Fish, and JA Nelson. 1996. Human cytomegalovirus US3 impairs transport and maturation of major histocompatibility complex Class I heavy chains. Proc Natl Acad Sci USA. 93:11327-33.

26. Li, CR, PD Greenberg, MJ Gilbert, JM Goodrich, and SR Riddell. 1994. Recovery of HLArestricted cytomegalovirus (CMV)-specific $T$-cell responses after allogeneic bone marrow transplant: correlation with CMV disease and effect of ganciclovir prophylaxis. Blood. 83:1971-9.

27. Li, F, G Grauls, M Yin, and CA Bruggeman. 1995. Initial endothelial inju.y and cytomegalovirus infection accelerate the development of allograft arteriosclerosis. Transplant Proc. 27:3552-4.

28. Li, FL, G Grauls, M Yin, and CA Bruggeman. 1996. Correlation between the intensity of cytomegalovirus infection and the amount of perivasculitis in aorta allografts. Transpl Int. $9: 51-5$.

29. Ljunggren, HG, and K Karre. 1990. In search of the 'missing self': MHC molecules and NK cell recognition. Immunol Today. 11:237-44.

30. Price, P, and SD Olver. 1996. Animal models of human immunopathological disease. Syndromes induced by Cytomegalovirus infection. Clin Immunol Immunopath. 80:215-24.

31. Quinnan, GV, N Kirmani, AH Rook, JF Manischewitz, L Jackson, G Moreschi, GW Santos, R Saral, and WH Burns. 1982. Cytotoxic T cells in Cytomegalovirus infection. HLA-restricted Tlymphocyte and non-T-lymphocyte cytotoxic responses correlate with recovery from Cytomegalovirus infection in Bone-Marrow-Transplant recipients. N Engt J Med. 307:7-13.

32. Reddehase, MJ, M Balthesen, M Rapp, S Jonjic, I Pavic, and UH Koszinowski. 1994. The conditions of primary infection define the load of latent viral genome in organs and the risk of recurrent cytomegalovirus disease. J Exp Med. 179:185-93.

33. Reddehase, MJ, W Mutter, K Munch, HJ Buhring, and UH Koszinowski. 1987. CD8-positive T lymphocytes specific for murine cytomegalovirus immediate-early antigens mediate protective immunity. J Virol. 61:3102-8.

34. Rehbinder, C., P. Baneux, D. Forbes, H. Van Herck, W. Nicklas, Z. Rugaya, and G. Winkler. 1996. FELASA recommendations for the health monitoring of mouse, rat, hamster, gerbil, guineapig and rabbit experimental units. Lab Anim. 30:193-208.

35. Reyburn, HT, O Mandelboim, M Vales-Gomez, DM Davis, L Pazmany, and JL Strominger. 1997. The class I MHC homologue of human cytomegalovirus inhibits attack by natural killer cells. Nature. 386:514-7.

36. Riddell, SR, P Reusser, and PD Greenberg. 1991. Cytotoxic T cells specific for cytomegalovirus: a potential therapy for immunocompromised patients. Rev Infect Dis. 13 (S11):5966-73.

37. Schonrich, G, U Kalinke, F Momburg, M Malissen, AM Schmitt-Verhulst, B Malissen, GJ Hammerling, and B Arnold. 1991. Down-regulation of T cell receptors on self-reactive T cells as a novel mechanism for extrathymic tolerance induction. Cell. 65:293-304.

38. Schwartz, RH. 1996. Models of T cell anergy: is there a common molecular mechanism? J. Exp. Med. 184:1-8.

39. Shanley, JD. 1990. In vivo administration of monoclonal antibody to the NK 1.1 antigen of natural killer cells: effect on acute murine cytomegalovirus infection. J Med Virol. 30:58-60.

40. Speir, E, R Modali, ES Huang, MB Leon, F Shawl, T Finkel, and SE Epstein. 1994. Potential role of human cytomegalovirus and p53 interaction in coronary restenosis. Science. 265:391. 4.

41. Stals, FS, F Bosman, CP van Boven, and CA Bruggeman. 1990. An animal model for therapeutic intervention studies of $\mathrm{cmv}$ infection in the immunocompromised host. Arch virol. 114:91-107. 
42. Thale, R, U Szepan, H Hengel. G Geginat, P Lucin, and UH Koszinowski. 1995. Identification of the mouse cytomegalovirus genomic region affecting major histocompatibility complex class I molecule transport. J Virol. 69:6098-105.

43. Torres-Nagel, N. E Kraus, MH Brown, G Tiefenthater, R Mitnacht, AF Williams, and T Hunig. 1992. Differential thymus dependence of rat CD8 isoform expression. Eur J Immunol. 22:2841-8.

44. Van den Berg, AP, WJ Van Son, RA Janssen, NH Brons, AA Heyn, A Scholten Sampson, S Postma, M Van der Giessen, AM Tegzess, and TH De Leij. 1992. Recovery from cytomegalovirus infection is associated with activation of peripheral blood lymphocytes. J Infect Dis. 166:1228-35.

45. Welsh, RM, JO Brubaker, M Vargas Cortes, and CL O'Donnell. 1991. Natural killer (NK) cell response to virus infections in mice with severe combined immunodeficiency. The stimulation of NK cells and the NK cell-dependent control of virus infections occur independently of T and B cell function. J Exp Med. 173:1053-63.

46. Wiertz, EJHJ, TR Jones, L Sun, M Bogyo, HJ Geuze, and HL Ploegh. 1996. The human cytomegalovirus US11 gene product dislocates MHC class I heavy chains from the endoplasmic reticulum to the cytosol. Cell. 84:769-79.

47. Zhang, L. 1996. The fate of adaptively transferred antigen-specific T cells in vivo. Eur J Immunol. 26:2208-14.

48. Zhou, YF, MB Leon, MA Waclawiw, JJ Popma, ZX Yu, T Finkel, and SE. Epstein. 1996. Association between prior cytomegalovirus infection and the risk of restenosis after coronary arthrectomy. N Eng J Med. 335:624-30. 



\section{Acute primary infection with cytomegalovirus (CMV) in kidney transplant recipients results in the appearance of a phenotypically aberrant CD8 + $T$ cell population}

Joanne G. van Dam¹, Jan G.M.C. Damoiseaux², Maarten H.L Christiaans ${ }^{2}$ and Cathrien A. Bruggeman¹.

${ }^{1}$ Department of Medical Microbiology, University of Maastricht, Maastricht, The Netherlands

${ }^{2}$ Department of Internal Medicine, University hospital Maastricht, Maastricht, The Netherlands 


\section{Abstract}

Human cytomegalovirus (CMV) is a $\beta$-herpesvirus that causes a chronic subclinical infection in healthy man. The immune system is unable to eliminate the virus completely, allowing virus to persist in a latent state. In the immunocompromised host, this equilibrium is disturbed, resulting in a clinical infection. In immunocompromised rats, clinical CMV infection is associated with an increase in NK cells and CD8 $T$ cells, including a phenotypically aberrant CD8' T cell population. Using flow cytometry, we examined the effect of acute CMV infection on the composition of leukocyte subsets in immunocompromised patients. Therefore, we used peripheral blood of CMV seronegative patients receiving a kidney from a seronegative (control group) or a seropositive donor. Of the patients receiving a seropositive kidney, only the patients undergoing acute CMV infection were included (experimental group). Special attention was paid to the phenotype of the cytotoxic T cells. The development of acute CMV infection resulted in an increased NK cell number and an activation of both CD4' and CD8' T cells, as determined by HLA-DR expression. An aberrant CD8 ' $T$ cell subset with decreased expression of CD8 and TCR appeared in the infected patients. Furthermore, the size of this subpopulation of $\mathrm{CD} 8^{+} \mathrm{T}$ cells is positively correlated with the viral load. 


\section{Introduction}

Infection with human cytomegalovirus (CMV) mostly results in a chronic subclinical infection. The immune system is unable to eliminate the virus completely, allowing virus to persist in a latent state. In the immunocompromised host, e.g., upon immunosuppressive therapy in a transplant recipient, the equilibrium is disturbed, allowing latent virus to reactivate and to cause clinical disease. Since the course of rat cytomegalovirus (RCMV) infection in the rat resembles that of CMV infection in humans $(6,8)$, RCMV infection in its host is often used as a model for CMV infection $(7,18,21)$. In a previous study we have studied the effect of RCMV infection on the composition of peripheral blood leukocytes (PBLs) in the rat. Infection of immunosuppressed animals caused a marked increase in the number of NK cells and a small increase in the number of CD8 T cells. The increase in the population of CD8 $T$ cells was predominantly composed of cells with a reduced expression of CD8 and TCR(x) (22). This phenotype of downregulated TCR $x$ / 3 and $C D 8$ has been shown to be related to a state of unresponsiveness in T cells, which is referred to as anergy $(1,4,19)$. Anergy is induced if antigen is presented to the $T$ cell in the absence of proper costimulatory signals (20). The induction of anergy is an important mechanism of peripheral tolerance induction for self-antigens. Interference of RCMV in the costimulatory signals upon presentation of viral antigens might thus enable the virus to escape elimination by the immune system of the host.

To determine if such a mechanism might also be involved in CMV infection, we wanted to investigate the effects of CMV infection on the PBL composition and in particular on the phenotype of cytotoxic $T$ cells in immunosuppressed patients undergoing primary CMV infection. Since most infections do not result in clinical symptoms, it is very difficult to study the effects of acute CMV infection in otherwise healthy patients. Even when clinical symptoms occur, it is not known when the infection started. Since transplant patients are at risk for CMV infection resulting in severe clinical symptoms, these patients were monitored for the onset of CMV infection. Therefore, in the current investigation the PBL composition of CMV seronegative kidney transplant recipients receiving a seropositive (experimental group) or seronegative (control group) donor organ was examined at different times post transplantation. Of the seropositive donor organ recipients, only the patients undergoing acute CMV infection were included.

\section{Materials and Methods}

\section{Patients}

CMV seronegative patients receiving a kidney from either a CMV seronegative $(n=3$, control group, CMV-) or a CMV seropositive donor ( $n=5$, experimental group, $\mathrm{CMV}+$ ) were followed after kidney transplantation two times a week during admission and once a week thereafter. Only the CMV+ patients that passed through an active CMV-infection, as determined by pp65 antigenemia 
assay, were included in this study. All patients were on immunosuppressive treatment with tacrolimus and prednisolon. In case of acute rejection

episodes, incidentally methylprednisolon (CMV+ patient 2 at day 11-18, CMV+ patient 3 at day 42-46, and CMV-patient 2 at day 6), mycofenolaatmofetil (CMV+ patient 5 permanently and CMV-patient 2 starting at day 17), ATG (CMV-patient 2 at day 6-17) or plasmapheresis (CMV-patient 2 day 17-26) were added. Treatment for CMV infection (ganciclovir) was started, when indicated by clinical symptoms (CMV+ patient 2 day 26-44, patient 3 day 41-63 and patient 5 day 34-54).

Of the CMV+ patients, heparinized and EDTA blood was collected at day 7-10 post transplantation (measurement $(M) 1$ ), within three days of the first CMV pp65 antigenemia becoming positive (M2, CMV+ patient 1 at day 60 , patient 2 at day 28, patient 3 at day 28, patient 4 at day 55 and patient at 5 day 26), and 18-21 days after M2 (M3). Heparinized and EDTA blood of the CMV-patients was collected at day 7-10 post transplantation (measurement 1 , M1) and at day 48-52 post transplantation. Measurement 2 in the CMV-group takes place around the same period of time as $M 3$ in the $C M V+$ group and is therefore referred to as M3. Additionally, a group of 19 healthy volunteers was used for evaluation of the CD8 T cell plienotype.

\section{Flow cytometry}

The absolute number of leukocytes and the percentage of lymphocytes were determined in EDTA blood using a Coulter Max-M counter (Becton Dickinson, San José, Calif., USA). From the heparinized blood, mononuclear cells were isolated by density centrifugation using lymphoprep (Nycomed Pharma AS, Oslo, Norway). For three-color flow cytometry, $5 \times 10^{5}$ cells per sample were resuspended in PBS containing $0.5 \%$ bovine serum albumine (BSA), $10 \mathrm{mM} \mathrm{NaN}$ and the monoclonal antibodies (MoAbs). Measurements were performed using a FACSCalibur and the Cell Quest software package (both Becton Dickinson). In each measurement 10,000 events were acquired with gating on viable mononuclear cells using the FSC and SSC parameters. The CD45/CD14 staining was used to gate for lymphocytes (CD45 $\left.\mathrm{CD} 14^{\text {low }}\right)$. The triple stainings HLADR/CD4/CD3 and HLA-DR/CD8/CD3 were performed to determine the number of $\mathrm{CD} 4^{+} \mathrm{T}$ cells and $\mathrm{CD} 8^{+} \mathrm{T}$ cells and their state of activation. With the CD16/CD56/CD3 staining the number of NK cells (CD16 CD56 CD3) was determined. Finally, the TCR/CD4/CD8 staining was performed to examine the existence of a CD8 ${ }^{\text {low }} \mathrm{TCR}^{\text {low }}$ subpopulation of CD8 ${ }^{\circ} \mathrm{T}$ cells in the immunosuppressed, CMV-infected patients.

\section{Monoclonal antibodies}

The cells were stained using different combinations of the following antibodies: CD45-FITC (clone 2D1), anti-HLA-DR-FITC (BRA30), CD16-FITC (BE1), anti-TCR $\alpha$ 3-FITC (WT31), CD14-PE (UCHM1), CD4-PE (SK3), CD8-PE (MCD8), CD56-PE (MOC-1), CD3-PERCP (SK7) and CD8-PERCP (SK1). The CD45FITC, anti-TCR f -FITC, CD4-PE, CD3-PERCP and CD8-PERCP were purchased from Becton Dickinson. All other antibodies are from IQ products (Groningen, The Netherlands). 


\section{CMV pp65 antigenemia}

The pp65 antigen was detected immunohistochemically essentially as described previously (24). Briefly, leukocytes were isolated from heparinized whole blood with dextran and $2 \times 10^{5}$ cells were centrifuged onto glass slides within $4 \mathrm{hr}$ of collection. The cells were subsequently fixed for $10 \mathrm{~min}$ in methanol and incubated with mouse monoclonal antibody anti-pp65 IgG (produced in our laboratory). After incubation with rabbit-anti-mouse IgG HRP (DAKO A/S, Glostrup, Denmark), the substrate 3-amino-9-ethylcarbazole was added. Results are expressed as number of pp65-positive cells per $5 \times 10^{4}$ polymorphonuclear cells.

\section{Results}


Figure 1. Acute HCMV infection has no effect on the number of leukocytes or lymphocytes in kidney transplant recipients. CMV seronegative patients received a kidney from either a seronegative (CMV-) or seropositive $\left(\mathrm{CMV}^{+}\right)$donor. Using flow cytometry, the number of leukocytes (A) and lymphocytes (B) was determined at three time points post transplantation. Measurement $1(M 1)=$ day $7-10 ; M 2$ = within 3 days of the $C M V$ pp67 antigenemia becoming positive (CMV+ group, day 26-60); $M 3=$ day $48-52$ (CMV- group) or 18-21 days post M2 (CMV+ group).

\section{Acute CMV infection resulted in an increased number of NK cells}

To study the effect of CMV infection on the composition of leukocytes in the peripheral blood of immunocompromised humans, blood samples of CMV seronegative transplant patients receiving a kidney from a CMV seronegative (CMV-patients) or seropositive donor (CMV+ patients) were examined. The absolute number of leukocytes in the peripheral blood was not influenced by CMV infection (Fig. 1A). One sample of a CMV-patient (CMV-patient 3) showed increased leukocyte numbers in the first measurement due to a bacterial infection. The number of lymphocytes was increased in 1 out of 5 $\mathrm{CMV}+$ patients undergoing CMV infection, but no effect of the CMV infection on lymphocyte counts was observed (Fig. 1B). Using the CD16/CD56/CD3 staining, the number of $\mathrm{NK}$ cells $\left(\mathrm{CD}_{16} \mathrm{C}^{+} \mathrm{CD} 56^{+} \mathrm{CD} 3^{-}\right)$was determined. All $\mathrm{CMV}+$ patients showed an increase in the absolute number of NK cells in the period 
three weeks after the onset of CMV infection $(M 3=622 \pm 303)$ compared to previous measurements $(M 1=99 \pm 31$ and $M 2=305 \pm 497)$ and compared to the two measurements of the CMV-group (M1, 108 \pm 71 and M3, 121 \pm 86 , Fig. 2A). One CMV+ patient already showed an increase in NK cells in M2 (first detection of CMV infection). This may be due to detection limits of the pp65 antigenemia assay. A CMV infection with a very low viral load could be missed by the pp65 antigenemia assay, but still have effects on the leukocyte subset composition. The number of T cells was not clearly influenced by CMV infection (Fig. 2B). These data show that an active CMV infection results in an increased number of NK cells.


Figure 2. Acute HCMV infection increases the number of NK cells in kidney transplant recipients. CMV seronegative patients received a kidney from either a seronegative (CMV-) or seropositive $(\mathrm{CMV}+)$ donor. Using flow cytometry, the number of NK cells (A) and T cells (B) was determined at three time points past transplantation. Measurement $1(M 1)=$ day $7-10 ; M 2$ = within 3 days of the $C M V$ pp67 antigenemia becoming positive ( $C M V+$ group, day 26-60); $M 3=$ day 48-52 (CMV-group) or 18-21 days post M2 (CMV+ group only).



The activation state of $C D 4^{+}$and $C D 8^{+} T$ cells is increased by acute infection

Although infection with CMV did not result in an increased number of T cells, changes in the T cell population were detected. Figure 3 shows the effect of CMV infection on the CD8 $8^{+}$and $C D 4^{+} T$ cell subsets and activation of these cells as determined by HLA-DR expression. The absolute number of both $C D 4^{+}$(Fig. $3 \mathrm{~A}$ ) and $\mathrm{CD} 8^{+} \mathrm{T}$ cells (Fig. 3B) was not affected by CMV infection. However, the activation state of these cells was changed as shown by HLA-DR expression. Both the $\mathrm{CD}^{+} \mathrm{T}$ cells (Fig. $3 \mathrm{C}$ ) and in particular the $\mathrm{CD} 8^{+} \mathrm{T}$ cells (Fig. 3D) exhibited an increase in HLA-DR expression after CMV infection. In most patients, the percentage of activated $C D 4^{+} T$ cells was already increased in the early period of the infection $(M 2,7.6 \pm 2.6)$ compared to $M 1(4.5 \pm 1.4)$ and still visible in $M 3(24.7 \pm 36.6)$, i.e. 3 weeks after $M 2$. A significant difference could be detected between $M 2$ of the CMV- and M2 of the CMV+ group using the non-parametric Mann-Whitney test. The activation of the CD8 ${ }^{+}$


antigenemia assay became positive, no effect of CMV-infection could be




became HLA-DR ${ }^{+}$. In summary, infection with CMV results in activation of both $\mathrm{CD}^{+}$and $\mathrm{CD}^{+} \mathrm{T}$ cells.


Figure 3. Acute HCMV infection activates both CD4+ and CD8+ T cells in kidney transplant recipients. CMV seronegative patients received a kidney from either a seronegative (CMV-) or seropositive $(\mathrm{CMV}+)$ donor. Using flow cytometry, the number of CD4+ T cells (A) and CD8+ T cells (B) and the percentage of CD4+ T cells and CD8 + T cells being HLA-DR positive ( $C$ and D, respectively) was determined at three time points past transplantation. Measurement $1(M 1)=$ day $7-10 ; M 2=$ within 3 days of the $C M V$ pp67 antigenemia becoming positive (CMV+ group, day 26-60);


$M 3$ = day $48-52$ (CMV- group) or 18-21 days post M2 (CMV+ group only).

\section{CMV infection causes the appearance of an aberrant $C D 8^{+} T$ cell subpopulation}

Three weeks after the onset of CMV infection, a small but distinct aberrant $\mathrm{CD}^{+} \mathrm{T}$ cell subpopulation could be detected, showing decreased CD8 and TCR $\alpha \beta$ expression (mean fluorescence intensity decreased about $50 \%$ and $70 \%$ respectively). Figure 4 shows the mean $\left( \pm S D\right.$ ) percentage of $C D 8^{+} T$ cells expressing low levels of CD8 and TCR $\alpha \beta$ for the combined measurements of the CMV- patients, the 3 measurements of the $C M V+$ group and a group of healthy volunteers. The CD8 ${ }^{+} T$ cells were all CD4- and show normal FSC and SSC patterns. The percentage of $\mathrm{CD} 8^{\text {low }} \mathrm{T}$ cells was about $2 \%$ in all groups, except in $M 3$ in the CMV+ transplant recipients (Fig. 4A). In this group the percentage of $\mathrm{CD} 8{ }^{\text {low }} \mathrm{T}$ cells varied between $0.5 \%$ and $9.5 \%$. Figure $4, \mathrm{~B}$ and $\mathrm{C}$ shows the expression of $\mathrm{CD} 8$ and TCR $\alpha \beta$ on the $C D 8^{+} T$ cells in a CMV+ patient in $M 1$ (Fig. 4B) and M3 (Fig. 4C). It is clearly visible that the percentage of 



Figure 4. Acute HCMV infection in kidney transplant recipients results in the development of an aberrant CD8+ T cells subset with a decreased expression of CD8 and TCR. The expression of TCR and CD8 was determined using three colour flow cytometry staining at three time points post transplantation. CMV seronegative patients received a kidney from either a seronegative (CMV-) or seropositive $(\mathrm{CMV}+)$ donor. The control group consists of healthy volunteers. Data obtained from control patients at different times post transplantation were combined. Measurement $1(M 1)=$ day $7-10 ; M 2=$ within 3 days of the CMV pp67 antigenemia becoming positive (day 26-60); M3 = 18-21 days post M2. Data are presented as mean \pm SD.

CD8 T cells expressing low levels of CD8 is increased after the CMV infection, being $9.5 \%$ in three weeks after onset of CMV infection (M3) and $1.0 \%$ before CMV infection (M1). Table 1 shows the percentage of CD8 ${ }^{+} \mathrm{T}$ cells expressing low levels of CD8, the maximum pp65 antigenemia levels that were detected and the antigenemia level as measured at $\mathrm{M} 3$. The percentage of $\mathrm{CD}^{+} \mathrm{T}$ cells expressing low levels of CD8 is positively correlated with the presence of active CMV infection as shown by the pp65 antigenemia level at the third detection point. 
Table 1. The size of the aberrant CD8 $T$ cell subset with decreased expression of CD8 and TCR depends on the pp67 antigenemia (AgMIE)

\begin{tabular}{cccc}
\hline CMV+ patient & CD8 & AgMIE at M3 & AgMIE max \\
\hline 1 & 0.5 & 0 & 0.5 \\
2 & 2.5 & 0 & 2 \\
3 & 9.5 & 20.8 & 31.5 \\
4 & 3.8 & 1.6 & 92 \\
5 & 7.2 & 72 & 246 \\
\hline
\end{tabular}

CMV seronegative patients receiving a kidney from a CMV seroposii ive donor (+/-patients) were monitored for active HCMV infection. Three weeks aftei the firs AgmlE became positive (M3), three color flow cytometry was used to detemine the expression of CD8 and TCR on CD8 ${ }^{\top}$ cells. Shown is the percentage of CD8 T cells with decreased CD8 and TCR expression of the total population of CD8. T cells. ") Maximal CMV antigenemia level detected during the infertion

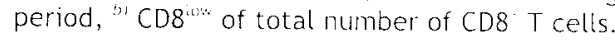

\section{Discussion}

In this study we have investigated the effect of acute primary CMV infection on the composition of the peripheral blood leukocytes. The effects seen in kidney transplant recipients due to acute, primary CMV infection are threefold. First, CMV infection results in an increase in NK cell numbers. Next, although there are no clear increases in the absolute numbers of CD4 and CD8 ${ }^{*} \mathrm{~T}$ cells, both cell types show an increase in their state of activation, as shown by the increased percentage of HLA-DR expressing cells. Finally, a phenotypically aberrant CD8* T cell subset appears with decreased expression of both CD8 and TCR $\times$ ß

In immunosuppressed renal allograft recipients with acute CMV infection, increased numbers of CD8 ${ }^{*} \mathrm{~T}$ cells, CD4 ${ }^{+} \mathrm{T}$ cells and NK cells have been reported, together with increased activation (HLA-DR expression) of CD8 $T$ cells $(3,12,14,16,23)$. The effects seen in our patient groups resemble the results of previous studies in seeing an increase in HLA-DR expression in CD4 $4^{+} \mathrm{T}$ cells and CD8 ${ }^{+} \mathrm{T}$ cells. However, no clear increases in the number of $C D 4^{+} T$ cells or $C D 8^{+} T$ cells could be detected. The absence of increases in the number of $\mathrm{CD} 4^{*}$ and $\mathrm{CD} 8^{*} \mathrm{~T}$ cells resembles the effects seen in immunosuppressed rats, where only a small increase in CD8 ${ }^{*} T$ cells could be detected (22). The fact that we do not see an increase in $\mathrm{CD}^{\circ}$ or $\mathrm{CD} 4^{\circ} \mathrm{T}$ cells in the kidney transplant recipients might be due to the immunosuppression regimen used. In previous papers patients received combinations of prednisolone, azathioprine and cyclosporin A, while our patients were treated with tacrolimus and prednisolon. In the CMV+ patients a subset of CD8 ${ }^{*} \mathrm{~T}$ cells appears with decreased expression of CD8 and TCRu $\beta$. The CD3 expression of these cells remains normal. The $C D 8^{\text {low }} \mathrm{TCR}^{\text {low }}$ phenotype has previously been reported to be associated with anergy $(1,4,5,15)$. Anergy is induced if antigen is presented to the $T$ cell in the absence of proper costimulatory signals (20). The size of the decrease in the mean fluorescence intensity of both CD8 and TCR $\alpha \beta$ is comparable to that seen in CD8 and Thy -1.2 in anergic mouse cells (5). The presence of a CD ${ }^{\text {low }} T C R(x)$ low subpopulation in the CD8 $T$ cells suggests that $C M V$ infection interferes with the (Co)stimulatory signats 
upon presentation of viral antigens. Anergy of the virus-specific T cells would enable the virus to escape further elimination by the immune system of the immunosuppressed host. Since the CD8 $8^{\text {low }} T C R^{\text {low }}$ cells only appear in the CMVinfected patients, it seems likely to assume that these cells are HCMVspecific. Tests have to be performed to obtain more functional information about this population of T cells. In the immunosuppressed rat with acute RCMV infection, the population of CD8 $8^{\circ}$ cells consisted for a substantial part (up to $40 \%$ ) of cells with a reduced expression of both TCRa $\beta$ and CD8 (22). In $M 3$ of the $C M V+$ patients, the mean percentage of $C D 8^{\text {low }} T C R^{\text {low }}$ cells is increased compared to the other groups. The values range from $0.5 \%$ to $9.5 \%$. The fact that these numbers are far less than in the rats might be due to the differences in immunosuppression. The rats received a sublethal dose of total body irradiation, reducing the number of $T$ cells at the moment of infection to nondetectable values. In the transplant recipients the immunosuppression is not given at one moment in time, but permanently. Therefore the rat model is a good system to further investigate the phenotype and function of the $\mathrm{CD} 8^{\text {low }} \mathrm{T}$ cells. Striking is the fact that there seems to be a strong correlation between the percentage of CD8 ${ }^{*} T$ cells expressing low levels of CD8 and the pp65 antigenemia assay at the third detection point. This suggests that a productive CMV-infection is necessary to result in the generation of $C D 8^{\text {low }} T$ cells.

Many viruses have been described to evade the immune response of the host. Studies with murine CMV (MCMV) and CMV have shown that these viruses are capable of inhibiting the presentation of antigenic peptides by major histocompatibility complex (MHC) class I molecules in numerous ways $(13,17,25)$. This enables virus-infected cells to escape recognition by $T$ cells. In addition to the gene products that affect the expression of $\mathrm{MHC}$ class 1 molecules on the surface of infected cells, CMV, MCMV and also RCMV each encode homologs of MHC class I heavy chains $(2,11)$, that have been suggested to inhibit the activation of NK cells (9-11). The presence of a CD8 ${ }^{\text {low }}$ subpopulation of $T$ cells suggests that the virus has an extra way of escaping the immune response of its host. Although the presence of so many different immune evasion strategies may seem overdone, most likely the different strategies are used during different stages of infection and are therefore all necessary for the persistence of the infection.

In summary, primary, acute CMV infection in immunosuppressed kidney transplant recipients results in an increase in the number of NK cells and activation of both $\mathrm{CD}^{+}$and $\mathrm{CD} 8^{+} \mathrm{T}$ cells. An aberrant CD8 $\mathrm{T}$ cell subset with decreased expression of both CD8 and TCR $\alpha \beta$ appeared in the infected patients. This phenotype has previously been described to be associated with anergy. The rat model is a good system to further investigate the phenotype and function of the $\mathrm{CD} 8^{\text {low }} \mathrm{T}$ cells 


\section{References}




selection. Cellular Immunology. 175:111-9.

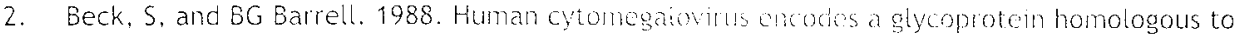
MHC class-1 antigens. Nature. 331:269-72.

3. Beik, Al, AG Morris, RM Higgins, and FT Lann. 1998. Sol al i iow cytometric analysis of $T$-cell surface markers can be useful in differential diagnosis of remal allogiaft dysfunction. Clin Transplantation. 12:24-9.

4. Bellgrau, D, and AC Lagarde. 1990. Cytotoxic T-cell precursors with low-level CD8 in the diabetes-prone Biobreeding rat: Implications for generation of an autoimnune T-coll repertoire. Proc Natl Acad Sci USA. 87:313-7.

5. Blish, CA, SR Dillon, AG Farr, and PJ Fink. 1999. Anergic CD8 + I cells can persist and function in vivo. J Immunol. 163:155-64.

6. Bruggeman, CA, WMH Debie, G Grauls, G Majoor, and CPA Van Boven. 1983. Infection of laboratory rats with a new cytomegalo-like virus. Arch Virol. 76:189-99.

7. Bruggeman, CA, FL Li, and FS Stals. 1995. Pathogenicity: Animal models. Scand $J$ Infect Dis. $99: 43-50$.

8. Bruggeman, CA, H Meijer, F Bosman, and CP Van Boven. 1985. Biology of rat cytomegalovirus infection. Intervirol. 24:1-9.

9. Cretney, E, MA Degli-Esposti, EH Densley, HE Farrell, NJ Davis-Poynter, and MJ Smyth. 1999. M144, a murine cytomegalovirus (MCMV)-encoded major histocompatibility complex class 1 homologue, confers tumor resistance to natural killer cell-mediated rejection. J Exp Med. 190:435-43.

10. Farrell, HE, MA Degli Esposti, and NJ Davis Poynter. 1999. Cytomegalovirus evasion of natural killer cell responses. Immunol Rev. 168:187-97.

11. Farrell, HE, H Vally, DM Lynch, P Fleming, GR Shellam, AA Scalzo, and NJ Davis-Poynter. 1997. Inhibition of natural killer cells by a cytomegalovirus MHC class I homologue in vivo. Nature. 286:510-4.

12. Hazzan, M., M. Labalette, C. Noel, G. Lelievre, and J. P. Dessaint. 1997. Recall response to cytomegalovirus in allograft recipients: mobilization of CD57+, CD28+ cells before expansion of CD57+, CD28- cells within the CD8+ T lymphocyte compartment. Transplantation. 63:6938 .

13. Hengel, H, U Reusch, A Gutermann, H Ziegler, S Jonjic, P Lucin, and UH Koszinowski. 1999. Cytomegaloviral control of MHC class I function in the mouse. Immunol Rev. 168:167-76.

14. Labalette, M, F Salez, FR Pruvot, C Noel, and JP Dessiant. 1994. CD8 lymphocytosis in primary cytomegalovirus (CMV) infection of allograft recipients: expansion of an uncommon CD8 + CD57- subset and its progressive replacement by CD8+CD57+ T cells. Clin Exp Immunol. 95:465-71.

15. Lee, MS, M vov Herrath, H Reiser, MBA Oldstone, and N Sarvetnick. 1995. Sensitization to self (virus) antigen by in situ expression of murine interferon-gamma. J Clin Invest. 95:48692.

16. Nordoy, I, F Muller, KP Nordal, H Rollag, E Lien, P Aukrust, and 5S Froland. 1999. Immunologic parameters as predictive factors of cytomegalovirus disease in renal allograft recipients. J Inf Dis. 180:195-8.

17. Ploegh, HL. 1998. Viral strategies of immune evasion. Science. 280:248-53,

18. Price, $P$, and SD Olver. 1996. Animal models of human immunopathological disease. Syndromes induced by Cytomegalovirus infection. Clin Immunol Immunopath. 80:215-24.

19. Schonrich, G, U Kalinke, F Momburg, M Malissen, AM Schmitt-Verhulst, B Malissen, GJ Hammerling, and B Arnold. 1991. Down-regulation of T cell receptors on self-reactive T cells as a novel mechanism for extrathymic tolerance induction. Cell. 65:293-304.

20. Schwartz, RH. 1996. Models of T cell anergy: is there a common molecular mechanism? J Exp Med. 184:1-8.

21. Stals, FS, F Bosman, CP van Boven, and CA Bruggeman. 1990. An animal model for therapeutic intervention studies of CMV infection in the immunocompromised host. Arch Virol. 114:91-107.

22. van Dam, J.G, J.G.M.C Damoiseaux, H.A.M.D van der Heijden, G Grauls, P.J.C van Breda Vriesman, and C.A Bruggeman. 1997. Infection with rat cytomegalovirus (CMV) in the 
immunocompromised host is associated with the appearance of a $T$ cell population with reduced CD8 and T cell receptor (TCR) expression. Clin Exp Immunol. 110:349-57.

23. Van den Berg. AP, WJ Van Son. RA Janssen, NH Brons, AA Heyn, A Scholten Sampson, S Postma, M Van der Giessen, AM Tegzess, and TH De Leij. 1992. Recovery from cytomegalovirus infection is associated with activation of peripheral blood lymphocytes. J Infect Dis. 166:1228-35.

24. Van der Bij, W, J Schirm, R Torensma, WJ Van Son, AM Tegzess, and TH The. 1988. Comparison between viremia and antigenemia for detection of cytomegalovirus in blood. $J$ Clin Microbiol. 26:2531-5.

25. Wiertz, EJHJ, S Mukherjee, and HL Ploegh. 1997. Viruses use stealth technology to escape from the host immune system. Mol Med Today. march:116-23. 


\section{CHAPTER 4 downregulation of Major Histocompatibility Complex class I cell surface expression}

Joanne G. Duijvestijn-van Dam ${ }^{2 *}$, Gerco C. Hassink ${ }^{1 *}$, Danijela Koppers-Lalic ${ }^{1}$, Jacqueline van Gaans-van den Brink ${ }^{3}$, Daphne van Leeuwen ${ }^{1}$, Cornelis Vink ${ }^{\text {, }}$, Cathrien A. Bruggeman ${ }^{2}$, Emmanuel J.H.J. Wiertz ${ }^{1}$

${ }^{1}$ Department of Medical Microbiology, Leiden University Medical Center, Leiden, The Netherlands

${ }^{2}$ Department of Medical Microbiology, Cardiovascular Research Institute Maastricht, University of Maastricht, Maastricht, The Netherlands

${ }^{3}$ Laboratory for Vaccine Research, Netherlands Vaccine Institute, Bilthoven, The Netherlands

* GH and JDvD contributed equally to this study 


\section{Summary}

Herpesviruses are known to influence expression of Major Histocompatibility Complex (MHC) class I molecules on the surface of infected cells.

Downregulation of $M H C$ class I expression prohibits detection and elimination of infected cells by cytotoxic $T$ lymphocytes. To investigate the effect of rat cytomegalovirus (RCMV) infection on MHC class I expression, we infected immortalized and primary rat fibroblasts with RCMV and monitored surface expression of $\mathrm{MHC}$ class I molecules by flow cytometry at various time-points post infection. These experiments revealed a dramatic downregulation of $\mathrm{MHC}$ class I surface expression by RCMV, a phenomenon that has also been reported for human and murine CMV. However, in contrast to the other

cytomegaloviruses, RCMV only causes a temporal downregulation of MHC class I, with a maximum decrease at 12 hrs post infection. Unlike murine and human CMV, RCMV does not induce proteolytic degradation of MHC class I molecules. In RCMV-infected cells, the MHC class I molecules are stable, but are retained in an ER/cisGolgi compartment. 


\section{Introduction}

To investigate the effects of human Cytomegalovirus (HCMV) infection on the host, rat CMV (RCMV) is often used as a model. RCMV has proven to be a useful model to study CMV pathogenesis, for example in the context of transplant associated arteriosclerosis and therapeutic interventions related to this disease $(10,43,49)$. Like HCMV infection in humans, RCMV infection does not result in clinical symptoms in immunocompetent rats. In immunosuppressed rats, however, RCMV causes a generalized infection with infectious virus being present in almost every organ. Eventually, RCMV establishes a latent infection $(9,11)$.

Elimination of virus-infected cells by cytotoxic T lymphocytes (CTL) relies on the recognition of antigenic peptides in the context of Major Histocompatibility Complex (MHC) class I molecules. The antigenic peptides result from proteolytic degradation of virus-encoded proteins by a multicatalytic cytosolic complex, the proteasome $(45,47,48)$. The peptides are transported from the cytosol into the Endoplasmic Reticulum (ER) by the Transporter associated with Antigen Processing (TAP) (3). In the ER, the trimolecular complex consisting of the MHC class I heavy chain, the light chain $\beta_{2}$-microglobulin $\left(\beta_{2} m\right)$ and peptide is formed. Only those complexes that consist of a properly folded MHC class I heavy chain, $\beta 2 \mathrm{~m}$ and peptide are stable; all others are degraded (30). The MHC class I complex is transported from the ER to the cell membrane, where it presents its peptide content to cytotoxic T cells.

During a long co-evolution with their host, herpesviruses have developed effective mechanisms to prevent rapid clearance by the immune system of the host. Studies with murine and human CMV have shown that these $\beta$-herpesviruses are capable of inhibiting the presentation of peptides by $M H C$ class I molecules in numerous ways $(6,18,26,50,53)$. To date, four genes affecting $\mathrm{MHC}$ class I-restricted antigen presentation have been identified in the HCMV genome. The HCMV US3 gene encodes a protein causing retention of $M H C$ class I molecules in the ER $(1,34,39,42)$. The US2 and US11 gene products mediate rapid degradation of MHC class I molecules by dislocating class I heavy chains from the ER to the cytosol, where they are degraded by proteasomes $(32,33,56,57)$. The protein encoded by US6 acts in yet another way, blocking translocation of peptides into the ER by TAP $(2,24,27,38,40)$. As a consequence, in HCMV-infected cells, MHC class 1 molecules can no longer form stable complexes and are degraded (40). Degradation of MHC class I heavy chains occurs in the cytosol, via the same pathway that is used by HCMV US2 and US11 to target the MHC class I molecules for destruction (30). This pathway, first described in the context of US2 and US11(56,57), is generally used by the cell to dispose of proteins that do not fold and assemble properly, and thus plays an important role in the quality control during cellular protein synthesis.

Different species of CMV have developed different strategies to elude the immune system. This is exemplified by the diversity of immune evasion strategies identified for murine and human CMV. MCMV interferes with the function of MHC class I molecules through three glycoproteins, none of which 
has homologs in HCMV. The protein erroted I complexes from the post-ER/early Gotgi (58.58). induces lysosomal degradation of the MHC complex after a transient interaction in the ER (46). A third gene product, the m04-encoded gp 34 , associates with properly folded MHC class I molecules in the ER. The resulting complex is transported to the cell membrane where it may modulate the function of NK cells $(36,37)$. The MCMV-encoded immune evasion genes appear to counteract $\mathrm{MHC}$ class I restricted $\mathrm{T}$ cell activation in a cooperative fashion $(35,41)$.

In addition to gene products that affect the expression of MHC class I molecules on the surface of infected cells, HCMV, MCMV and also RCMV encode homologs of MHC class I heavy chains $(5,8,21)$. The HCMV and MCMV MHC class I homologs, encoded by UL18 and m144, respectively, inhibit activation of NK cells $(5,16,19-21)$. In addition, the UL18 protein may interact with other leukocytes than NK cells, since the Leukocyte Immunoglobulin-like Receptor (LIR-1), identified as a UL18 receptor (15), is primarily expressed on B-lymphocytes and macrophages, but only on a small proportion of the NK cells (52).

As both HCMV and MCMV encode multiple gene products interfering with $T$ cell recognition of infected cells, it is likely that the closely related RCMV also eludes host immunity. In view of the diversity of immune evasion mechanisms identified for HCMV and MCVM, the strategies employed by RCMV may be completely different again. In this study, the integrity of the MHC class I antigen presentation pathway was evaluated in RCMV-infected cells using flow cytometry and biochemical assays. We present the first evidence that RCMV causes a temporal downregulation of MHC class I molecules at the surface of infected cells. This downregulation does not involve degradation of MHC class I complexes, but is caused by retention of class I molecules in an ER/cis-Golgi compartment.

\section{Materials and Methods}

Cell culture and virus.

Primary rat embryo fibroblasts (REF) and the rat fibroblast cell line Rat2 were cultured as described previously (54). RCMV (Maastricht strain) was obtained by homogenization of salivary glands of acutely infected rats as described previously (9).

\section{Antibodies.}

Mouse monoclonal antibodies recognizing RT1a MHC class I molecules (OX18) and rat transferrin receptor (OX26) were purchased from Serotec (UK). Monoclonal antibody RCMV 35, directed against a 29-kDa RCMV protein, has been described previously (12). For FACS, either FITC-conjugated rabbit antimouse IgG (Dako A/S, Denmark) or PE-conjugated goat anti-mouse IgG (Jackson ImmunoResearch Laboratories, West Grove, PA) were used as secondary antibody. 
Infection.

The cells were infected at 80-90\% confluency, washed with PBS, placed on EMEM containing $2 \%$ FCS for $30 \mathrm{~min}$, and washed again with PBS. The virus was diluted in EMEM with $2 \%$ NCS. The cells were infected with an m.o.i. of 1 . To increase the efficiency of infection, cells were centrifuged at $700 \mathrm{~g}$ at $20 \mathrm{C}$ for $45 \mathrm{~min}$ and placed at $37 \mathrm{C}$ for another 10-15 min (29). The infection medium was replaced by culture medium containing $2 \%$ NCS. For biochemical experiments, RPMI was used for cell culture and infections.

Flow cytometry.

Cell surface expression of MHC class I molecules, transferrin receptor and EGFP were analysed by flow cytometry using FACSort equipment and Cell Quest software (Becton Dickinson, The Netherlands). Cells were stained in PBS containing $1 \% \mathrm{BSA}$ and $10 \mathrm{mM} \mathrm{NaN}_{3}$ (4).

Metabolic labeling, immunoprecipitations and SDS-PAGE.

For pulse-chase experiments, cells were starved in Met Cys medium at $37 \mathrm{C}$ for $1 \mathrm{hr}$, labeled with ${ }^{3.5}$ Promix (Amersham), and chased in medium with excess of $\mathrm{L}$-cystine and $\mathrm{L}$-methionine for the times indicated in the figures (4). Where indicated, media were supplemented with the proteasome inhibitor carboxybenzyl-leucyl-leucylleucinal $\left(\mathrm{ZL}_{3} \mathrm{H}\right)$. Cells were lysed in Nonidet-P40 lysis buffer containing leupeptin, AEBSF and $\mathrm{ZL}_{3} \mathrm{H}$ at $4 \mathrm{C}$ for 30 min. To remove cell debris, lysates were centrifugated at $10,000 \mathrm{~g}$ for $10 \mathrm{~min}$. Prior to immunoprecipitation, lysates were precleared twice using normal rabbit and normal mouse sera precoupled to mixed (1:1) Protein A-Sepharose and Protein G-Sepharose beads. Immunoprecipitations were performed on precleared lysates at $4 \mathrm{C}$ for $2-4 \mathrm{~h}$ using specific antisera precoupled to Protein A/G Sepharose beads. Subsequently, the beads were washed with NET buffer [50 mM Tris/HCl, pH 7.4/150 mM NaCl/5 mM EDTA/0.5\% (v/v) NP-40] supplemented with $0.1 \% \mathrm{SDS}$. The immunoprecipitates were boiled in sample buffer [40 mM Tris/HCl, pH 8.0/4 mM EDTA/8\% (w/v) SDS/40\% (v/v) glycerol $/ 0.1 \%$ Bromophenol Blue] for $5 \mathrm{~min}$ and separated using SDS/PAGE. Gels were dried and exposed to a storage phosphor imaging screen, which was scanned in a Personal Molecular Imager FX (Bio-Rad) and analysed using Quantity One software (Bio-Rad).

\section{Production of retrovirus and transduction.}

A retroviral vector expressing both $\mathrm{r} 152$ and enhanced green fluorescent protein (EGFP) was constructed by ligating an r152-encoding CDNA fragment into the PLZRS-IRES-EGFP vector (17). Wild-type (wt) or US2-IRES-EGFP constructs were transfected into the amphotrophic Phoenix packaging cell line for the production of retrovirus as described (4). Cells were transduced with retrovirus using retronectin-coated dishes (Takara Shuzo, Otsu, Japan). 


\section{Results}

MHC class I surface expression after RCMV infection

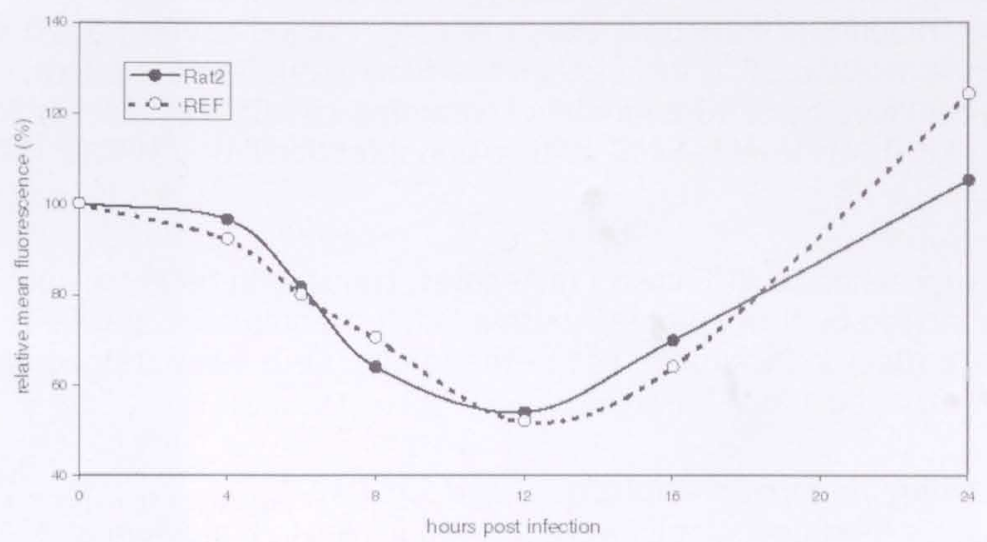

Figure 1. Temporal downregulation of rat MHC class I at the surface of RCMV-infected cells. Immortalized fibroblasts (Rat2) and primary rat embryonic fibroblasts (REF) were infected with RCMV or mock-infected. At 0, 4, 6, 8, 12, 16 and $24 \mathrm{~h} \mathrm{p.i.,} \mathrm{cells} \mathrm{were}$ stained with the MHC class I-specific monoclonal antibody OX18 and analyzed using flow cytometry. Indicated is the relative mean fluorescence calculated as (mean fluorescence RCMV-infected cells / mean fluorescence mock-infected cells) $\times 100$.

RCMV downregulates MHC class I expression at the cell surface.

We investigated surface expression of MHC class I molecules during infection with RCMV using flow cytometry. Primary rat embryo fibroblasts (REF) and immortalized rat fibroblasts (Rat2) were infected with RCMV. The expression of MHC class I molecules at the cell membrane was measured at different time points after infection, using the mouse monoclonal antibody OX-18 recognizing a monomorphic determinant in RT1a molecules, the rat MHC class I products. Both, REF and Rat2 cells showed a temporary downregulation of MHC expression at the cell surface with a maximum effect at $12 \mathrm{~h}$ p.i. (figure 1). At $24 \mathrm{~h} \mathrm{p.i.,} \mathrm{the} \mathrm{expression} \mathrm{of} \mathrm{MHC} \mathrm{class} \mathrm{I} \mathrm{products} \mathrm{was} \mathrm{normalized} \mathrm{or}$ slightly increased. To exclude the possibility that RCMV infection induced a general decrease of cell surface molecules, we also analyzed the expression of transferrin receptor (TfR). Staining of the plasma membrane with anti-TfR antibody revealed a similar mean fluorescence intensity at various time points after infection (data not shown). These results indicate that RCMV causes a temporal decrease in MHC class I expression at the cell membrane of both primary and immortalized fibroblasts.

OX-18 precipitates immature and mature forms of MHC class I molecules. Next, we investigated the biosynthesis and intracellular trafficking of MHC class I molecules in Rat2 cells. In the absence of RCMV, the monoclonal antibody OX18 immunoprecipitated RT1a MHC class I molecules from cells metabolically labeled with ${ }^{35} \mathrm{~S}$-methionine/cysteine (figure 2). A light chain or $\beta_{2} \mathrm{~m}$ of about $12 \mathrm{kDa}$ and two MHC class I heavy chain species of 45 and $47 \mathrm{kDa}$ 
can be distinguished. The shift in mobility of the $45-\mathrm{kDa}$ chain upon digestion with endoglycosidase $\mathrm{H}$ reflects removal of its $\mathrm{N}$-linked carbohydrate chains. These data demonstrate that the OX-18 antibody recognizes $\mathrm{MHC}$ class I heavy chains containing the immature, high-mannose $\mathrm{N}$-linked glycans that are endoglycosidase- $\mathrm{H}$ sensitive, as well as the mature, complex form which is endoglycosidase- $\mathrm{H}$ resistant. Since immature and mature MHC class I heavy chains can be distinguished on the basis of their mobility in SDS-PAGE, endoglycosydase $\mathrm{H}$ treatment is not required to visualize maturation of the MHC class I heavy chains in time. OX-18 thus can be used in biochemical experiments to monitor the biosynthesis and intracellular trafficking of $\mathrm{MHC}$ class I molecules.



Figure 2.

Biochemical analysis of MHC class i maturation in Rat2 cells. Rat2 cells were labeled with $\left[{ }^{35} \mathrm{~S}\right]$ methionine/cysteine for $45 \mathrm{~min}$ and lysed in the presence of detergent. MHC class I molecules were precipitated using the monoclonal antibody $0 \mathrm{X}-18$. Samples were digested with endoglycosidase $\mathrm{H}$ or mock-treated and separated using SDS-PAGE. Indicated are the light chain $\left(B_{2} \mathrm{~m}\right)$ and the mature (m), immature (i) and Endo $\mathrm{H}$-digested (d) forms of the class I heavy chain.

RCMV infection causes intracellular retention of MHC class I molecules.

To determine the cause of the RCMV-induced downregulation of MHC class I at the cell surface, we followed biosynthesis and intracellular trafficking of MHC class I molecules after RCMV infection. Rat2 cells were either infected with RCMV or mock-infected and labeled with ${ }^{35}$ S-methionine/cysteine at 4, 6 and 8 hours post infection (p.i.). Infection was monitored using the monoclonal antibody RCMV35, precipitating a 29-kDa early viral protein from lysates of infected cells (figure 3, right panel). MHC class I molecules were isolated using the OX-18 monoclonal antibody. At time point 0 , only $45-\mathrm{kDa}$ immature MHC class I heavy chains and $\beta_{2}$ m were detected. In the course of the chase, a fraction of the $45-\mathrm{kDa}$ products shifted to $47-\mathrm{kDa}$, reflecting maturation of the MHC class I heavy chains. Quantitative analysis revealed that $45 \%$ of the class I heavy chains had matured in mock-infected cells after 60 minutes of chase (figure 3, first three lanes). This ratio gradually changed, however, in RCMVinfected cells. After 60 min of chase, the amount of matured class I heavy 
chains had decreased to $34 \%$ and $23 \%$ at 6 and 8 hrs p.i., respectively, suggesting that maturation was inhibited.

This experiment furthermore showed that, although each lane contained material immunoprecipitated from identical numbers of cells, the total amount of labeled, precipitated protein clearly had increased at 6 hours after RCMV infection. This was not only the case for MHC class I heavy chains and $\beta_{2} \mathrm{~m}$, but also for transferrin receptor (data not shown).

These results demonstrate that intracellular trafficking of rat MHC class I molecules is compromized in RCMV-infected cells. MHC class I heavy chain $\beta_{2} \mathrm{~m}$ complexes are formed but their maturation is hindered, most likely due to retention in an ER/cis-Golgi compartment.



Figure 3. Maturation of MHC class I molecules is reduced in RCMV-infected cells. Rat2 cells were mock-infected or infected with RCMV for the times indicated. Subsequently, cells were metabolically labeled for 20 min and chased for the times indicated. MHC class I molecules were precipitated from cell lysates using monoclonal antibody $0 \mathrm{X}-18$ and analyzed using SDS-PAGE. Mature $(\mathrm{m})$ and immature (i) MHC class I heavy chains and light chains $\left(\mathrm{B}_{2} \mathrm{~m}\right)$ are indicated. To monitor RCMV infection, lysates were subjected to immunoprecipitation with monoclonal antibody RCMV 35, directed against a 29kDa RCMV early protein.

The 152 gene product is not responsible for downregulation of MHC class I surface expression.

HCMV US3, MCMV m152 and Adenovirus E3/19K gene products all prohibit export of class I complexes from the ER/cis-Golgi compartment $(1,31,34,39,44)$. The RCMV genome contains several m152-like genes, but lacks a gene demonstrating identity to US3 (51). We evaluated the most obvious m152 homolog, designated $\mathrm{r} 152$, with regard to MHC class I downregulation. Rat2 cells, transduced with retroviruses expressing either r152-IRES-EGFP or EGFP alone, were analyzed for surface expression of MHC class I by flow cytometry. Comparable levels of class I molecules were detected at the surface of r152-IRES-EGFP transduced, EGFP transduced cells and non-transduced cells using the OX18 antibody (figure 4, upper two 
panels). This indicates that $\mathrm{r} 152$ has no influence on the surface expression of MHC class I molecules.

r152-IRES-GFP



TfR

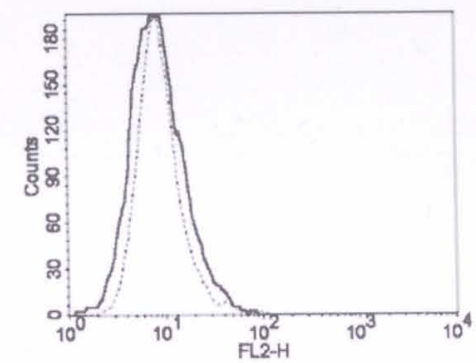

\section{- GFP positive population \\ -....... GFP negative population}

IRES-GFP


Figure 4. Influence of RCMV r152 gene product on MHC class I expression in Rat2 cells. Rat2 cells transduced with r152-IRES-EGFP-encoding retrovirus (left panels) or wt-IRES-EGFPencoding retrovirus (right panels), were analyzed for surface expression of MHC class I (upper panels) and transferrin receptor (TfR, lower panels) using flow cytometry. Shown are histograms representing transduced (thick black line) and nontransduced (thin dotted line) cells.

RCMV does not induce degradation of newly synthesized MHC class I molecules.

In HCMV-infected cells, MHC class I heavy chains are targeted for proteasomal degradation shortly after synthesis. RCMV infection results in a specific reduction of the amount of mature class I heavy chains (figure 3 ). To investigate whether the class I molecules are degraded prior to their exit from the ER, Rat2 cells were infected with RCMV for $8 \mathrm{hrs}$ and a pulse-chase experiment was performed in the presence or absence of the proteasome inhibitor $\mathrm{ZL}_{3} \mathrm{H}$. Inclusion of the proteasome inhibitor could have two effects. If RCMV targets the class I molecules for degradation by proteasomes, the proteasome inhibitor could block dislocation, resulting in increased amounts of mature class I heavy chains that would be stable throughout the chase. Alternatively, if the proteasome inhibitor would not block dislocation, but 
prevent subsequent degradation of the class I molecules in the cytosol, a deglycosylated breakdown intermediate would accumulate; this would became visible in the course of the chase as a discrete polypeptide band with increased mobility in SDS-PAGE.

The results of the pulse-chase experiment are shown in figure 5 . Normal maturation of class I molecules occurred in the absence of RCMV infection (lanes 1 and 2). $\mathrm{ZL}_{3} \mathrm{H}$ blocks the generation of antigenic peptides by the proteasome. As a result, $\mathrm{MHC}$ heavy chain- $\beta_{2} \mathrm{~m}$ complexes cannot be loaded with peptides and, consequently, are retained in the ER. This is illustrated in figure 5, lane 4 , where in the presence of $\mathrm{ZL}_{3} \mathrm{H}$ no maturation of the MHC complex was observed after a 20-min chase. RCMV infection of Rat2 cells did not result in decrease of $M H C$ class I heavy chain levels. In $\mathrm{ZL}_{3} \mathrm{H}$ treated RCMV-infected cells, neither a significant increase of mature class I heavy chain levels, nor breakdown intermediates were visible (lanes 7 and 8 ). These data indicate that RCMV does not cause degradation of MHC class I molecules.

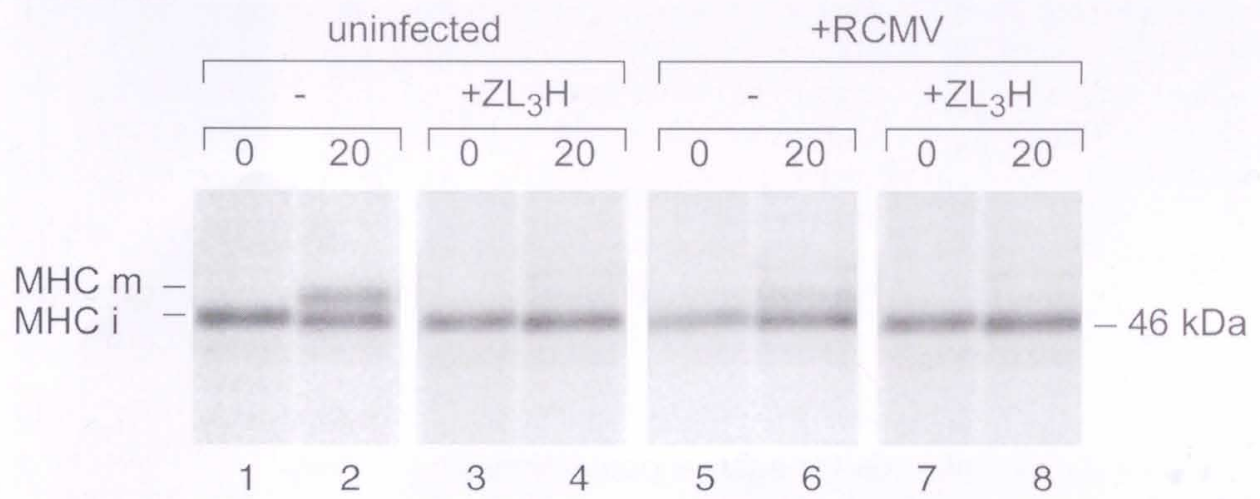

Figure 5. RCMV infection does not result in degradation of MHC class I molecules. Rat2 cells were mock-infected or infected with RCMV for 8 hrs. The cells were metabolically labeled for $10 \mathrm{~min}$ and chased for $20 \mathrm{~min}$ in the presence or absence of proteasome inhibitor $\left(\mathrm{ZL}{ }_{3} \mathrm{H}\right) . \mathrm{MHC}$ class I molecules were precipitated from lysates using monoclonal antibody OX-18 and separated using SDS-PAGE. Indicated are the mature $(\mathrm{m})$ and immature (i) class I heavy chains.

\section{Discussion}

Human, mouse and rat cytomegaloviruses all persist in their hosts for life, despite a fully competent immune system. This phenomenon is believed to involve specific evasion of host immunity, thus allowing these herpesviruses to replicate during primary infection, establish latency, and reactivate under circumstances profitable for these viruses. Immune escape by herpesviruses has been shown to involve very diverse mechanisms, even among members of the same virus family $(26,50,53)$. MHC class I molecules appear to represent a universal target for herpesvirus immune evasion. Antigen presentation via MHC class I molecules is inhibited by HCMV and MCMV through various strategies, including downregulation of class I complexes at the cell surface, alteration of the peptide array presented by MHC class I molecules, 
interference with $\mathrm{MHC}$ - $\mathrm{T}$ cell receptor interaction, and modification of the response of immune effector cells triggered upon recognition of class :peptide complexes (53). This is the first study to report on compromized $\mathrm{MHC}$ class I function in RCMV-infected cells. We found a temporal downregulation of class I molecules at the cell surface during the first 24 hours of RCMV infection. RCMV has been shown to resemble both HCMV and MCMV in genome organization as well as open reading frame homology (51). As both HCMV and MCMV downregulate class I expression at the cell surface at some point during infection it is not surprising to find that RCMV infection results in a similar phenotype. It should be emphasized, however, that HCMV and MCMV each use unique gene products and completely different strategies to achieve class I downregulation. Thus, although RCMV infection results in a similar phenotype, this may rely on gene products and mechanisms other than those identified for HCMV and MCMV.

Pulse-chase experiments indicated that the temporal downregulation of class I surface expression in RCMV-infected cells coincided with reduced maturation of class I molecules, probably as a result of retention of the class I complexes in an ER/cis-Golgi compartment. At later time points, this effect was counteracted, resulting in enhanced class 1 expression. This increased expression seems to be the result of a general increase in protein synthesis, as $\mathrm{B}_{2} \mathrm{~m}$ and TfR expression were also elevated. Although IFN $\mathrm{N}_{7}$ induction by the virus could explain the increase in MHC I levels, this is unlikely to be responsible for enhanced expression of $\beta_{2} \mathrm{~m}$ and $\mathrm{TfR}$.

The recovery of class I surface expression is remarkably fast in RCMVinfected cells compared to HCMV and MCMV-infected cells, in which class 1 downregulation persisted for a longer period $(13,23,55)$. HCMV blocks the display of MHC class I-peptide complexes through immediate early (US3), early and late gene products (US2, 6, 10 and 11). In MCMV, downregulation seems to occur mostly during the early and late phase of infection. RCMV, however, inhibits class I surface expression during the first 16 hours only, which most likely corresponds to the early phase of infection. Although expression of MHC class I molecules is restored after 24 hours, this does not imply that the viral gene products responsible for class | downregulation are no longer expressed after 24 hours. Inhibition of class I expression may be overruled by compensatory mechanisms (9). Another striking difference between HCMV and MCMV on the one hand and RCMV on the other, is that HCMV and MCMV induce proteolytic degradation of class I molecules, whereas no degradation of class I was observed in RCMV-infected cells.

In an attempt to identify the RCMV protein responsible for the observed ER retention of class I, we searched the RCMV genome for homologs of HCMV and MCMV genes known to affect class I expression. The only candidates found were genes resembling MCMV m152, the product of which effectively inhibits export of class I complexes from the ER/cis-Golgi compartment (1). Based on sequence similarity and genomic position, $r 152$ represents the most obvious $m 152$ homolog. When expressed in Rat 2 cells, the r152 gene product, however, did not influence MHC class I surface expression. This is not surprising, since the amino acid sequences of m152 and $r 152$ demonstrated only $19 \%$ identity (51). The effect of a viral immune evasion 
gene may be influenced dramatically by subile differences in amino acid composition. The efficiency of protein degradation can depend on single amino acid differences in target or effecter proteins, as has been shown for MHC class I degradation in the context of HCMV US11 (4) and Nef (14), and for the cell-specific class I retention by $\mathrm{m} 152$ (25). R152 forms part of the r145 gene cluster (51). Possibly, class I downregulation is mediated by one of the other r145 family members.

The herpes simplex virus (HSV) 1 and HSV 2-encoded ICP47 $(22,28)$ and the HCMV US6 gene product $(2,24,27,38,40)$ act as potent inhibitors of TAP. Genes with obvious similarity to US6 or ICP47 have not been found in the RCMV genome. MCMV does not interfere with peptide transport by TAP. In view of its genetic similarity to MCMV it is likely that RVMV retains class I through a mechanism that is also used by MCMV, such as retention by an $\mathrm{m} 152$ homolog, rather than inhibition of TAP. Recently, Ahn and co-workers showed that HCMV US3, in analogy with adenovirus E19, retains class I heavy chains in the ER by inhibiting tapasin-dependent peptide loading and optimization of class I peptide cargo (42). The authors hypothesized that m152 might cause retention of murine class I via a similar mechanism $(7,42)$. Likewise, a putative $\mathrm{m} 152$ homolog in RCMV might evoke MHC class I retention by interfering with tapasin function.

In conclusion, we have shown that RCMV, like its relatives MCMV and HCMV, decreases MHC class I expression at the cells surface. Contrary to MCMV and HCMV, this downregulation is temporary and is not the result of proteolytic degradation. The phenotype may be caused by an RCMV-encoded protein that prevents export of the class I complex from the ER, or by a protein that prevents proper peptide loading of class I molecules, thereby preventing egress of fully assembled complexes from the ER/cis-Golgi compartment. Further experiments will have to be performed to uncovel the gene product(s) responsible for this effect.

\section{Acknowledgements}

The authors would like to thank Maaike Ressing and Carola van IJperen for their contributions to this study. This study was supported by grant RUL 19981791 from the Dutch Cancer Society (to GH). 


\section{References}

1. Ahn, K., A.Angulo, P.Ghazal, P.A.Petersun, Kang, and K.Fruh. 1996. Human cytomegalovirus inhibits antigen presentiting sequential multistep process. Proc.Nati.Acad.Sci.U.S.A 93:10990-10995

2. Ahn, K., A.Gruhler, B.Galocha, T.R.Jones, E.J.Wing, H.L.Plocgh, P.A.Peterson, Y. Yang, and K.Fruh. 1997. The ER-luminal domain of the HCMV slycoprotein US6 inhibits peptide translocation by TAP. Immunity. 6:613-621.

3. Bangia,N., P.J.Lehner, E.A.Hughes, M.Surman, and P.Cresswell. 1999. The N-terminal region of tapasin is required to stabilize the MHC class I loading complex. Eur.J.Immunol. 29:1858. 1870.

4. Barel,M.T., N.Pizzato, D.van Leeuwen, P.L.Bouteiller, E.J.Wiertz, and F.Lenfant. 2003. Amino acid composition of alpha1/alpha2 domains and cytoplasmic tail of MHC class I molecules determine their susceptibility to human cytomegalovirus US11-mediated downregulation. Eur.J.Immunol, 33:1707-1716.

5. Beck,S., and B.G.Barrell. 1988. Human cytomegalovirus encodes a glycoprotein homologous to MHC Class-I antigens. Nature 331:269-272.

6. Beersma,M.F., M.J.Bijlmakers, and H.L.Ploegh. 1993. Human cytomegalovirus downregulates HLA class I expression by reducing the stability of class I H chains. J.Immunol. 151:4455-4464.

7. Beier,D.C., J.H.Cox, D.R.Vining, P.Cresswell, and V.H.Engehthard. 1994. Association of human class I MHC alleles with the adenovirus E3/19K protein. J.Immunol. 152:3862-3872.

8. Beisser,P.S., J.S.Kloover, G.E.Grauls, M.J.Blok, C.A.Bruggeman, and C.Vink. 2000. The 1144 major histocompatibility complex class I-like gene of rat cytomegalovirus is dispensable for both acute and long-term infection in the immunocompromised host. J.Virol. 74:1045-1050.

9. Bruggeman,C.A., W.M.Debie, G.Grauls, G.Majoor, and C.P.van Boven. 1983. Infection of laboratory rats with a new cytomegalo-like virus. Arch.Virol. 76:189-199.

10. Bruggeman,C.A., F.Li, and F.S.Stals. 1995. Pathogenicity: animal models. Scand.J.Infect.Dis. Suppl 99:43-50.

11. Bruggeman,C.A., H.Meijer, F.Bosman, and C.P.van Boven. 1985. Biology of rat cytomegalovirus infection. Intervirology 24:1-9.

12. Bruning, J.H., W.H.Debie, P.H.Dormans, H.Meijer, and C.A.Bruggeman. 1987. The development and characterization of monoclonal antibodies against rat cytomegalovirus induced antigens. Arch. Virol. 94:55-70.

13. Campbell,A.E., and J.S.Slater. 1994. Down-regulation of major histocompatibility complex class 1 synthesis by murine cytomegalovirus early gene expression. J.Virol. 68:1805-1811.

14. Cohen,G.B., R.T.Gandhi, D.M.Davis, O.Mandelboim, B.K.Chen, J.L.Strominger, and D.Baltimore. 1999. The selective downregulation of class I major histocompatibility complex proteins by HIV-1 protects HIV-infected cells from NK cells. Immunity. 10:661-671.

15. Cosman, D., N.Fanger, L.Borges, M.Kubin, W.Chin, L.Peterson, and M.L. Hsu. 1997. A novel immunoglobulin superfamily receptor for cellular and viral MHC class I molecules. Immunity. 7:273-282.

16. Cretney,E., M.A.Degli-Esposti, E.H.Densley, H.E.Farrell, N.J.Davis-Poynter, and M.J.Smyth. 1999. m144, a murine cytomegalovirus (MCMV)-encoded major histocompatibility complex class I homologue, confers tumor resistance to natural killer cell-mediated rejection.

J.Exp.Med. 190:435-444.

17. Dardalhon, V., N. Noraz, K.Pollok, C.Rebouissou, M.Boyer, A.Q.Bakker, H.Spits, and N.Taylor. 1999. Green fluorescent protein as a selectable marker of fibronectin-facilitated retroviral gene transfer in primary human T lymphocytes. Hum.Gene Ther. 10:5-14.

18. Del Val,M., H. Hengel, H. Hacker, U.Hartlaub, T.Ruppert, P.Lucin, and U.H.Koszinowski. 1992. Cytomegalovirus prevents antigen presentation by blocking the transport of peptide-loaded major histocompatibility complex class I molecules into the medial-Golgi compartment. J.Exp.Med. 176:729-738.

19. Fahnestock,M.L., J.L.Johnson, R.M.Feldman, J.M.Neveu, W.S.Lane, and P.J.Bjorkman. 1995. The MHC class I homolog encoded by human cytomegalovirus binds endogenous peptides. Immunity. 3:583-590.

20. Farrell,H.E., M.A.Degli-Esposti, and N.J.Davis-Poynter. 1999. Cytomegalovirus evasion of natural killer cell responses. Immunol.Rev. 168:187-197. 
21. Farrell,H.E., H.Vally, D.M.Lynch, P.Fleming, G.R.Shellam, A.A.Scalzo, and N.J.Din; Poynter. 1997. Inhibition of natural killer cells by a cytomegalovirus MHC class 1 homologutu: in vivo. Nature 386:510-514.

22. Fruh,K., K.Ahn, H.Djaballah. P.Sempe, P.M.van Endert, R. Tampe, P.A.Peterson, and Y. Yang. 1995. A viral inhibitor of peptide transporters for antigen presentation. Nature 375:415-418.

23. Gilbert,M.J., S.R.Riddell, C.R.Li, and P.D.Greenberg. 1993. Selective interference with class I major histocompatibility complex presentation of the major immediate-early protein following infection with human cytomegalovirus. J.Virol. 67:3461-3469.

24. Hengel,H., J.O.Koopmann, T.Flohr, W.Muranyi, E.Goulmy, G.J.Hammerling, U.H.Koszinowski, and F. Momburg. 1997. A viral ER-resident glycoprotein inactivates the MHC-encoded peptide transporter. Immunity. 6:623-632.

25. Hengel,H., U.Reusch. G.Geginat, R.Holtappels, T.Ruppert, E. Hellebrand, and U.H.Koszinowski. 2000. Macrophages escape inhibition of major histocompatibility complex. class 1-dependent antigen presentation by cytomegalovirus. J. Virol. 74:7861-7868.

26. Hengel,H., U.Reusch, A.Gutermann, H.Ziegler, S.Jonjic, P.Lucin, and U.H.Koszinowski. 1999. Cytomegaloviral control of $\mathrm{MHC}$ class I function in the mouse. Immunol. Rev. 168:167-176.

27. Hewitt,E.W., S.S.Gupta, and P.J.Lehner. 2001. The human cytomegalovirus ge ne product US6 inhibits ATP binding by TAP. EMBO J. 20:387-396.

28. Hill,A., P.Jugovic, I.York, G.Russ, J.Bennink, J.Yewdell, H.Ploegh, and D.Johnson. 1995 Herpes simplex virus turns off the TAP to evade host immunity. Naturc 375:411-415.

29. Hudson, J.B. 1988. Further studies on the mechanism of centrifugal enhancement of cytomegalovirus infectivity. J.Virol. Methods 19:97-108.

30. Hughes,E.A., C.Hammond, and P.Cresswell. 1997. Misfolded major histocompatibility complex class I heavy chains are translocated into the cytoplasm and degraded by the proteasome. Proc. Natl.Acad.Sci.U.S.A 94:1896-1901.

31. Jefferies,W.A., and H.G.Burgert. 1990. E3/19K from adenovirus 2 is an immunosubversive protein that binds to a structural motif regulating the intracellular transport of major histocompatibility complex class I proteins. J.Exp.Med. 172:1653-1664.

32. Jones, T.R., L.K.Hanson, L.Sun, J.S.Slater, R.M.Stenberg, and A.E.Campbell. 1995. Multiple independent loci within the human cytomegalovirus unique short region down-regulate expression of major histocompatibility complex class I heavy chains. J. Virol. 69:4830-4841.

33. Jones, T.R., and L.Sun. 1997. Human cytomegalovirus US2 destabilizes major histocompatibility complex class I heavy chains. J.Virol. 71:2970-2979.

34. Jones,T.R., E.J.Wiertz, L.Sun, K.N.Fish, J.A.Nelson, and H.L.Ploegh. 1996. Human cytomegalovirus US3 impairs transport and maturation of major histocompatibility complex class I heavy chains. Proc.Natl.Acad.Sci.U.S.A 93:11327-11333.

35. Kavanagh,D.G., M.C.Gold, M.Wagner, U.H.Koszinowski, and A.B.Hill. 2001. The multiple immune-evasion genes of murine cytomegalovirus are not redundant: $m 4$ and $m 152$ inhibit antigen presentation in a complementary and cooperative fashion. J.Exp.Med. 194:967-978.

36. Kavanagh,D.G., U.H.Koszinowski, and A.B.Hill. 2001. The murine cytomegalovirus immune evasion protein $\mathrm{m} 4$ /gp 34 forms biochemically distinct complexes with class I MHC at the cell surface and in a pre-Golgi compartment. J.Immunol. 167:3894-3902.

37. Kleijnen,M.F., J.B.Huppa, P.Lucin, S.Mukherjee, H.Farrell, A.E.Campbell, U.H.Koszinowski, A.B.Hill, and H.L.Ploegh. 1997. A mouse cytomegalovirus glycoprotein, gp 34, forms a complex with folded class I MHC molecules in the ER which is not retained but is transported to the cell surface. EMBO J. 16:685-694.

38. Kyritsis, C., S.Gorbulev, S. Hutschenreiter, K.Pawlitschko, R. Abele, and R. Tampe. 2001. Molecular mechanism and structural aspects of transporter associated with antigen processing inhibition by the cytomegalovirus protein US6. J. Biol.Chem. 276:48031-48039.

39. Lee,S., J.Yoon, B.Park, Y.Jun, M.Jin, H.C.Sung, I.H.Kim, S.Kang, E.J.Choi, B.Y.Ahn, and K.Ahn. 2000. Structural and functional dissection of human cytomegalovirus US3 in binding major histocompatibility complex class I molecules. J.Virol. 74:11262-11269.

40. Lehner,P.J., J.T.Karttunen, G.W.Wilkinson, and P.Cresswell. 1997. The human cytomegalovirus US6 glycoprotein inhibits transporter associated with antigen processingdependent peptide translocation. Proc. Natl.Acad.Sci.U.S.A 94:6904-6909.

41. LoPiccolo,D.M., M.C.Gold, D.G.Kavanagh, M.Wagner, U.H.Koszinowski, and A.B.Hill. 2003. Effective inhibition of $K(b)$ - and $D(b)$-restricted antigen presentation in primary macrophages by murine cytomegalovirus. J.Virol. 77:301-308. 
42. Park,B., Y.Kim, J.Shin, S.Lee, K.Cho, K.Fruh, S.Lee, and K.Ahn. 2004. Human Cytomegalovirus inhibits tapasin-dependent peptide loading and optimization of the MHC class I peptide cargo for immune evasion. Immunity. 20:71-85.

43. Price, P., and S.D.Olver. 1996. Syndromes induced by cytomegalovirus infection. Clin. Immunol. Immunopathol. 80:215-224.

44. Rawle,F.C., A.E.Tollefson, W.S. Wold, and L.R.Gooding. 198\%. Mouse anti-adenovirus cytotoxic T lymphocytes. Inhibition of lysis by E3 sp $19 \mathrm{~K}$ but not E3 14.7K. J.Immunol. $143: 2031-2037$.

45. Reits,E.A., J.C.Vos, M.Gromme, and J.Neefjes. 2000. The major substrates for TAP in vivo are derived from newly synthesized proteins. Nature 404:774-778.

46. Reusch,U., W.Muranyi, P.Lucin, H.G.Burgert, H. Hengel, and U.H.Koszinowski. 1999. A cytomegalovirus glycoprotein re-routes MHC class I complexes to lysosomes for degradation. EMBO J. 18:1081-1091.

47. Rock.K.L., and A.L.Goldberg. 1999. Degradation of cell proteins and the generation of MHC class I-presented peptides. Annu.Rev.Immunol. 17:739-779.

48. Schubert, U., L.C.Anton, J.Gibbs, C.C.Norbury, J.W.Yewdell, and J.R.Bennink. 2000. Rapid degradation of a large fraction of newly synthesized proteins by proteasomes. Nature 404:770-774.

49. Stals,F.S., F.Bosman, C.P.van Boven, and C.A.Bruggeman. 1990. An animal model for therapeutic intervention studies of CMV infection in the immunocompromised host. Arch. Virol. 114:91-107.

50. Tortorella,D., B.E.Gewurz, M.H.Furman, D.J.Schust, and H.L.Ploegh. 2000. Viral subversion of the immune system. Annu.Rev. Immunol. 18:861-926.

51. Vink, C., E. Beuken, and C.A.Bruggeman. 2000. Complete DNA sequence of the rat cytomegalovirus genome. J.Virol. 74:7656-7665.

52. Vitale,M., R.Castriconi, S.Parolini, D.Pende, M.L.Hsu, L.Moretta, D.Cosman, and A.Moretta. 1999. The leukocyte Ig-like receptor (LIR)-1 for the cytomegalovirus UL18 protein displays a broad specificity for different HLA class I alleles: analysis of LIR-1 + NK cell clones. Int. Immunol. 11:29-35.

53. Vossen,M.T., E.M.Westerhout, C.Soderberg-Naucler, and E.J.Wiertz. 2002. Viral immune evasion: a masterpiece of evolution. Immunogenetics 54:527-542.

54. Vossen,R.C., M.C.Persoons, M.E.Slobbe-van Drunen, C.A.Bruggeman, and M.C.Dam-Mieras. 1997. Intracellular thiol redox status affects rat cytomegalovirus infection of vascular cells. Virus Res. 48:173-183.

55. Warren,A.P., D.H.Ducroq, P.J.Lehner, and L.K.Borysiewicz. 1994. Human cytomegalovirusinfected cells have unstable assembly of major histocompatibility complex class I complexes and are resistant to lysis by cytotoxic T lymphocytes. J.Virol. 68:2822-2829.

56. Wiertz,E.J., T.R.Jones, L.Sun, M.Bogyo, H.J.Geuze, and H.L.Ploegh. 1996. The human cytomegalovirus US11 gene product dislocates MHC class I heavy chains from the endoplasmic reticulum to the cytosol. Cell 84:769-779.

57. Wiertz,E.J., D.Tortorella, M.Bogyo, J.Yu, W.Mothes, T.R.Jones, T.A.Rapoport, and H.L.Ploegh. 1996. Sec61-mediated transfer of a membrane protein from the endoplasmic reticulum to the proteasome for destruction. Nature 384:432-438.

58. Ziegler, H., W.Muranyi, H.G.Burgert, E.Kremmer, and U.H.Koszinowski. 2000. The luminal part of the murine cytomegalovirus glycoprotein g 40 catalyzes the retention of MHC class molecules. EMBO J. 19:870-881.

59. Ziegler,H., R.Thale, P.Lucin, W.Muranyi, T.Flohr, H.Hengel, H.Farrell, W. Rawlinson, and U.H.Koszinowski. 1997. A mouse cytomegalovirus glycoprotein retains MHC class I complexes in the ERGIC/Cis-Golgi compartments. Immunity. 6:57-66. 


\section{CHAPTER 5}

\section{Effects of cytomegalovirus infection and prolonged cold ischemia on chronic rejection of rat renal allografts}

Joanne G. van Dam ${ }^{1}$, Fengling Li ${ }^{1}$, Ming Yin ${ }^{1}$, Xiao-Mang You ${ }^{2}$, Gert Grauls ${ }^{1}$, Gustav Steinhoff ${ }^{2}$, Cathrien A. Bruggeman ${ }^{1}$

${ }^{1}$ Department of Medical Microbiology, Cardiovascular Research Institute Maastricht, University of Maastricht, Maastricht, The Netherlands.

${ }^{2}$ Department of Thoracic and Cardiovascular Surgery, Hannover Medical School, Hannover, Germany. 


\section{Abstract}

Previous studies have demonstrated that both cytomegalovirus (CMV) infection and prolonged cold ischemia of the allograft (Cl) are associated with chronic rejection of renal transplants. The purpose of this study is to investigate the effect of $\mathrm{CMV}$ infection, of $\mathrm{Cl}$ and of the combination of both on the progression of chronic rejection and to obtain a more detailed insight in their effects on the expression of adhesion molecules. Therefore, a rat transplantation model was used. Lewis recipients of renal allografts (with or without $\mathrm{Cl}$ ) from $\mathrm{MHC}$-incompatible Brown Norway rats were inoculated with rat CMV or left uninfected.

CMV infection alone resulted in an increased influx of CD4+ cells and macrophages early after infection and in an increase in glomerular sclerosis and intima proliferation. $\mathrm{Cl}$ caused an increase in infiltrating NK cells and an effect on intimal proliferation, glomerular sclerosis and tubular atrophy. When CMV infection and $\mathrm{Cl}$ were combined, an additive effect could be measured. This was however not the case for the function of the kidney. The creatinin showed a synergistic effect of the two influencing factors. Due to the CMV infection an increase in CD49d cells was detected. Cl resulted in an increase in CD18 cells and an increase in the expression of CD62P on vessels, and CD54 and CD44 on tubules. When CMV infection and CI were combined, all the effects caused by CMV and $\mathrm{Cl}$ alone were present in an additional way.

The results of the present study suggest that special attention should be paid to the recipient receiving an ischemically injured graft when either the donor or the recipient is CMV-infected. The patterns seen in histology, the infiltration of leukocytes and the expression of adhesion molecules, suggest that $\mathrm{Cl}$ and $\mathrm{CMV}$ infection both have an effect on rejection, but act by different mechanisms. 


\section{Introduction}

With the current immunosuppressive regimen, the incidence of graft loss due to acute rejection has been dramatically reduced. However, the expected half-life of the allograft has remained the same. This late allograft loss is mainly due to transplant arteriosclerosis, or so called "chronic rejection" (7). In renal allografts, chronic rejection has been defined as progressive functional deterioration occurring months or years after engraftment, and has proved resistant to therapeutic attempts. Although the pathogenesis of chronic rejection still remains largely unknown, several risk factors have been implicated, e.g. repeated episodes of acute rejection, viral infection, ischemia/reperfusion injury and loss of functional mass $(1,33)$.

In immunocompromised transplant recipients, cytomegalovirus (CMV) infection is the most common and important viral infection (10, 12). There is evidence of CMV infection in up to two thirds of all recipients, although clinical disease does not occur in all the infected patients (23). Unfortunately, CMV infection has been found to be associated with the development of chronic rejection both clinically and experimentally $(10,17,19)$. Donor kidneys usually undergo a period of warm and cold ischemia followed by reperfusion. Ischemia/reperfusion injury has also been found to play a role in chronic rejection $(1,10,18)$.

In rejection, leukocytes play an important role. For the leukocytes to enter the allograft, expression of adhesion molecules on both leukocytes and endothelial cells is necessary. Expression on other cells of the allograft can facilitate the interaction between leukocytes and their target cells and thereby contribute to rejection of the allograft $(5,6,30)$. A very promising method of preventing allograft rejection is treatment with monoclonal antibodies to various cell adhesion molecules $(13,42,43)$. These monoclonal antibodies inhibit the interaction between adhesion molecules and can thereby prevent the leukocytes to enter the allograft. To be able to optimize this therapy, the influence of multiple factors on the expression of adhesion molecules has to be investigated.

It has previously been described that kidney transplantation causes upregulation of the expression of adhesion molecules such as CD54 (ICAM-1), CD62E (E-selectin, ELAM-1), CD106 (VCAM) and LFA-1 (2, 16, 21). In-vitro studies have shown that CMV is able to induce upregulation of CD54, LFA-3 and CD44 (Pgp-1, HCAM) $(8,15,26,29,37,40)$. In vivo, the CD54 expression in transplanted kidneys of rat CMV (RCMV)-infected animals is increased compared to the allografts of non-infected animals (17). Cold ischemia $(\mathrm{Cl})$ followed by reperfusion causes an upregulation in CD62P and E-selectin early after transplantation (<24 hours) (32, 45). At 16 and 52 weeks after transplantation, CD54 is upregulated in kidneys subjected to $30 \mathrm{~min}$ of cold and 30 min of warm ischemic time (34). However, it is not known whether prolonged cold ischemia together with CMV infection increases the expression of adhesion molecules and thereby increases the severity of chronic rejection.

The purpose of this study is twofold: 1 . To determine whether CMV infection and $\mathrm{Cl}$ have an additional effect on the development of chronic allograft rejection. 2. To obtain a more detailed insight in the effect of CMV 
infection and $\mathrm{Cl}$ on the expression of adhesion molecules in the transplanted organ.

\section{Materials and Methods}

\section{Animals and surgery}

All experiments were performed in accordance with the law governing the protection of animals. The 'Principles of laboratory animal care' $(\mathrm{NIH}$ publication No.85-23, revised 1985) were followed. Specified pathogen free (SPF, according to the recommendations of the Federation of European Laboratory Animal Science Association) (22) male inbred rats, weighing 240$260 \mathrm{~g}$, obtained from the Central Animal Facility of the Maastricht University were used in all experiments. Lewis (LEW; RT1') rats were used as graft donors and Brown Norway (BN/M; RT1") rats as recipients. The animals were housed under standardized conditions, fed with commercially available pellet diet and had free access to acidified demineralized water $(\mathrm{pH} \pm 3$ ).

Orthotopic kidney transplantations were performed from Lewis to the $\mathrm{MHC}$-incompatible Brown Norway rat strain using a technique described previously (44). Briefly, the animals were anesthetized, the donor kidneys were harvested, cooled with UW (University of Wisconsin) solution (Dupont Pharma, USA), and transplanted into the recipient. The right native kidney was removed at the time of engraftment and the left 10 days later. The allograft recipients were treated with cyclosporine A (CSA, 15mg/kg per day, Novartis, Switzerland) subcutaneously for the first 10 days after engraftment to suppress an initial acute rejection episode.

\section{Experiment protocol}

The recipient rats were randomly allocated into 4 groups ( $n=6$ per group). In the control group ( $\mathrm{Cl}-\mathrm{CMV}$-), the donor kidneys were transplanted immediately into recipients. In this group the total period of cold ischemia varied from 35 $45 \mathrm{~min}$. The renal allograft recipient in the second group $(\mathrm{Cl}-\mathrm{CMV}+)$ received an intraperitoneal inoculation of $10^{5}$ plaque forming units (PFU) of Maastricht strain RCMV (3) on the day of transplantation. In the third group $(\mathrm{Cl}+\mathrm{CMV}-)$, renal allografts were stored for $24 \mathrm{~h}$ in the University of Wisconsin solution (UW solution) at $4 \mathrm{C}$ before transplantation. In the fourth group $(\mathrm{Cl}+\mathrm{CMV}+)$, the recipients received renal allografts with $24 \mathrm{~h}$ of $\mathrm{Cl}$, and were subsequently injected with RCMV. Rats were sacrificed on day 10 and 60 after transplantation. Tissue samples of the renal allografts and other organs (livers, spleens and salivary glands) were removed and processed either for freezing and paraffin sections, or for plaque assay.

\section{Virus detection}

For the detection of systemic virus infection, the salivary glands, spleen, and liver of the recipient were examined for the presence of infectious virus particles. The organs were homogenized in a tissue grinder and suspended in MEM with $2 \%$ foetal calf serum (FCS). Infectious virus particles were quantified by plaque assay (3). For this, 10 - and 100 -fold dilutions of $10 \%$ homogenates 
(wt/vol) were inoculated on a confunt rat embryonal fibroblast monolayer. After 7 days of incubation under $0.25 \%$ agarose, the number of plaques was monitored microscopically following fixation and methylene-blue staining. For detection of RCMV antigens, 4 ! m-thick formalin-fixed paraffin-embedded tissue sections were stained with RCMV monoclonal antibody 8 (4).

\section{Determination of serum creatinine}

Blood samples were taken from the 60-day surviving rats at days 7 and 14 post transplantation and at sacrifice. Serum creatinine was measured to determine the function of the transplanted kidney. Normal levels of serum creatinine were obtained by measuring the blood samples taken a few days before transplantation.

\section{Histological examination}

Formalin-fixed and paraffin-embedded kidney specimens were stained with hematoxylin and eosin for routine histology and with elastic van Giesen for evaluation of vascular changes. The general histological changes in renal allografts were assessed semi-quantitatively in both a longitudinal and a transversal section of each kidney. Different parameters were scored blindly from 0 to $3(0=$ normal, $1=$ mild, 2 = moderate, $3=$ severe changes $)$, without knowledge of group assignment. The intensity of chronic changes in the transplants was then expressed, as a single numerical figure by the chronic allograft damage index (CADI) which is the sum of 6 parameters: interstitial inflammation and fibrosis, glomerular mesangial matrix increase and sclerosis, vascular intimal proliferation, and tubular atrophy (14).

\section{Immunohistochemistry}

Four-micron-thick sections of frozen grafts were used for immunohistochemistry and stained with the two-layer indirect immunoperoxidase technique using monoclonal antibodies (mAbs). MAbs against CD4+ lymphocytes (W3/25) were obtained from Sera-Lab (Crawley Down, UK); mAbs against major histocompatibility complex (MHC) class $\|$ (OX6), CD54 (ICAM-1, clone 1A29) and the polyclonal antibody against CD62P (Pselectin, clone AK-6) were provided by Serotec (Wiesbaden, Gemany); mAbs against monocyte/macrophages and dendritic cells (ED-1) were kindly supplied by Dr. Dijkstra (Department of Immunology, Free University, Amsterdam, The Netherlands); NK cell markers (3.2.3) were supplied by the Department of Pathology of the University of Leiden, The Netherlands. The mAbs directed against CD11a (LFA-1 $\ell_{L}$ chain, clone WT.1), CD44 (PgP-1, HCAM, clone OX-49), CD49d (Integrin (1.4 chain, clone MRu4-1) and CD18 ( $\beta_{2}$ integrin, clone WT.3) were purchased from PharMingen (San Diego, USA). As second step labeling antibodies, rabbit-anti-mouse-HRP and goat-anti-rabbitHRP (DAKO, Denmark) were used.

\section{Quantification}

Quantification of positive immunohistochemical staining for infiltrating leukocytes and MHC class II expression was done semiquantitatively by scoring 
blindly the intensity of staining from 0-3 $(0=$ no visible staining, $1=$ few cells with faint staining, 2 = moderate intensity with multifocal staining, 3 = intense diffuse staining of cells analysed). The evaluation of intensity of positively-stained infiltrating leukocytes was focused on perivascular and interstitial areas. The analysis of expression of MHC class II antigens was focused on endothelial cells of arterioles. Immunohistochemical stainings of the adhesion molecules were evaluated blindly. The presence of positivelystained interstitial infiltrating leukocytes was determined by counting the number of positive cells per field of view (magnification 400x). Three fields were scored per section for the presence of CD18, CD49 and CD11a positive leukocytes. Expression of CD62P and CD54 on endothelial cells was determined by counting the number of positive vessels per field of view. In the cortex, three (CD62P, magnification 100x) or five (CD54, magnification 200x) fields were scored in each section. The expression of adhesion molecules on epithelial cells (CD54 and CD44) was scored by determining the percentage of positive tubules (magnification 200x), in three fields per section.

\section{Statistics}

All data were presented as mean \pm SEM. The significance of the differences within one staining group was determined using the Kruskal-Wallis 1-way Anova. If this test revealed a significance, the differences between the groups were determined using the Mann-Whitney U-Wilcoxon Rank Sum W test. P-values $<0.05$ were taken to be statistically significant.

\section{Results}

\section{Systemic CMV infection in allograft recipients}

The allograft recipients inoculated with RCMV did not show any clinical symptoms of CMV disease. Infectious RCMV was, using plaque assays, detected in salivary glands of all the CMV-inoculated recipients ( $\mathrm{Cl}-\mathrm{CMV}+$ and $\mathrm{Cl}+\mathrm{CMV}+$ ) at days 10 and 60, indicating a systemic CMV infection. No RCMV could be detected in any organ of the non-infected animals ( $\mathrm{Cl}-\mathrm{CMV}$ - and $\mathrm{Cl}+\mathrm{CMV}$-). The allografted kidneys were all but one $(\mathrm{Cl}+\mathrm{CMV}+$ group, day 10 post transplantation) negative in the RCMV immunohistochemical staining.

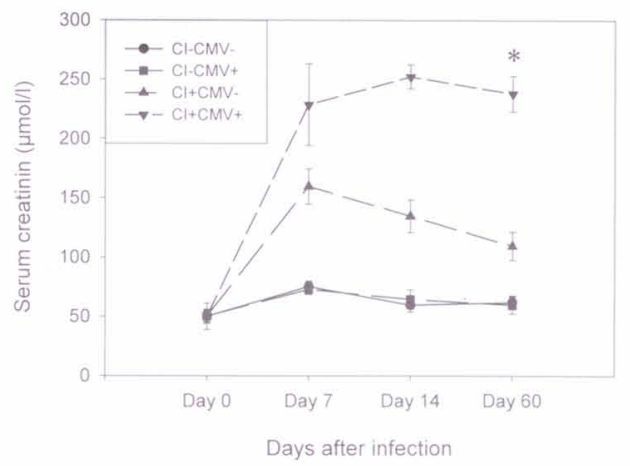

Figure1.

Effect of CMV infection and prolonged cold ischemia on the level of serum creatinin in renal allograft recipients. Data are presented as mean \pm SEM. ${ }^{*}=P<0.05$ compared to all other groups.

Days after infection 


\section{Function of renal allografts}

Figure 1 shows the effects of CMV infection, prolonged cold ischemia and their combination on the levels of serum creatinine. The creatinine levels in the non-ischemic groups ( $\mathrm{Cl}-\mathrm{CMV}$ - and $\mathrm{Cl}-\mathrm{CMV}+$ ) remained constantly low throughout the entire experimental period ( 60 days), compared to the normal (pre-operative) values. A moderate elevation of serum creatinine was observed in the recipients of renal allografts that were subjected to prolonged cold ischemia ( $\mathrm{Cl}+\mathrm{CMV}$-). The CMV-infected animals with ischemically injured renal grafts $(\mathrm{Cl}+\mathrm{CMV}+)$ demonstrated over 3 -fold higher values than the groups 1 and $2(P<0.05)$.


Figure 2. Hematoxilin-eosin staining of a kidney from the $\mathrm{Cl}-\mathrm{CMV}+$ group $(\mathrm{A})$ and the $\mathrm{Cl}+\mathrm{CMV}+$ group (B). In the $\mathrm{Cl}+\mathrm{CMV}+$ group interstitial inflammation and fibrosis, glomerular sclerosis, intimal proliferation and tubular atrophy are found (original magnification 200x).

Table 1. The effects of CMV infection and prolonged cold ischemia on histological changes of renal allografts

\begin{tabular}{lllll}
\hline & $\mathrm{Cl}-\mathrm{CMV}-$ & $\mathrm{Cl}-\mathrm{CMV}+$ & $\mathrm{Cl}+\mathrm{CMV}-$ & $\mathrm{Cl}+\mathrm{CMV}+$ \\
\hline Interstitial inflammation & $1.7 \pm 0.2$ & $1.9 \pm 0.1$ & $1.7 \pm 0.1$ & $2.2 \pm 0.1^{* * *}$ \\
Interstitial fibrosis & $0.4 \pm 0.2$ & $0.4 \pm 0.1$ & $1.8 \pm 0.1^{* * *}$ & $2.0 \pm 0.2^{* * * * * *}$ \\
Mesangial matrix increase & $1.5 \pm 0.1$ & $1.4 \pm 0.2$ & $1.3 \pm 0.1$ & $1.5 \pm 0.1$ \\
Glomerular sclerosis & $0.1 \pm 0.1$ & $0.5 \pm 0.1^{*}$ & $1.0 \pm 0.1^{* * *}$ & $1.1 \pm 0.1^{* * *}$ \\
Intimal proliferation & $1.3 \pm 0.1$ & $1.9 \pm 0.1^{*}$ & $1.3 \pm 0.2$ & $1.9 \pm 0.2^{* * * *}$ \\
Tubular atrophy & $0.6 \pm 0.2$ & $0.5 \pm 0.1$ & $1.9 \pm 0.1^{* * *}$ & $2.0 \pm 0.3^{* * *}$ \\
CADI & $5.6 \pm 0.5$ & $6.8 \pm 0.5$ & $8.9 \pm 0.3^{* * *}$ & $10.7 \pm 0.1^{* * * * * *}$ \\
\hline
\end{tabular}

CADI represents chronic allograft damage index. Data are presented as mean SEM

${ }^{*} \mathrm{P} \leq 0.05$ compared to the Cl-CMV-group

${ }^{* *} \mathrm{P} \leq 0.05$ compared to the $\mathrm{Cl}-\mathrm{CMV}+$ group

*** $\mathrm{P} \leq 0.05$ compared to the $\mathrm{Cl}+\mathrm{CMV}$ - group

\section{Morphological changes in allografts}

Effects of CMV infection and prolonged $\mathrm{Cl}$ on the pathology scores of renal allografts 60 days after transplantation were shown in Table 1 . When compared with the control group, $\mathrm{CMV}$ infection alone $(\mathrm{Cl}-\mathrm{CMV}+)$ caused 
marked vascular lesions, i.e. increaseo

proliferation in afferent and efferent glome hiai w wito.s.

ischemia alone $(\mathrm{Cl}+\mathrm{CMV}$-) resulted in a significant augmentation of interstitiat fibrosis, glomerular sclerosis and tubular atrophy, leading to a dramatic increase of the CADI. The $\mathrm{Cl}+\mathrm{CMV}+$ group exhibited significantly more interstitial fibrosis, glomerular sclerosis and tubular atrophy than the CI-CMVand $\mathrm{Cl}-\mathrm{CMV}+$ group, and demonstrated significant enhancement of interstitial inflammation comparing to the $\mathrm{Cl}+\mathrm{CMV}$ - group. As a result, the $\mathrm{CADI}$ of the $\mathrm{Cl}+\mathrm{CMV}+$ group was increased approximately two-fold compared to the $\mathrm{Cl}$ CMV-group ( $<<0.05$, Fig. 2 ). The $C A D \mid$ scores of the $\mathrm{Cl}+\mathrm{CMV}+$ group were also significantly increased compared to the scores of the $\mathrm{Cl}-\mathrm{CMV}+$ and $\mathrm{Cl}+\mathrm{CMV}$ group $(P<0.05$, Fig. 2$)$.

Table 2. The effects of CMV infection and prolonged cold ischemia on infiltrating cells and MHC class $\mid l$ expression in renal allografts

\begin{tabular}{lllll}
\hline & CI-CMV & Cl-CMV + & Cl+CMV- & Cl+CMV+ \\
\hline Perivascular CD4+ cells" & $1.50 \pm 0.02$ & $1.92 \pm 0.10^{*}$ & $1.70 \pm 0.09$ & $2.10 \pm 0.10^{*}$ \\
Interstitial macrophages" & $0.50 \pm 0.05$ & $1.69 \pm 0.11^{*}$ & $1.00 \pm 0.20$ & $1.41 \pm 0.08^{*}$ \\
Perivascular NK cells" & $0.33 \pm 0.17$ & $0.58 \pm 0.15$ & $0.80 \pm 0.12^{*}$ & $1.25 \pm 0.11^{* * *}$ \\
Interstitial NK cells" & $0.17 \pm 0.17$ & $0.33 \pm 0.10$ & $0.70 \pm 0.10^{*}$ & $1.00 \pm 0.18^{* * *}$ \\
MHC class II & $0.90 \pm 0.30$ & $1.58 \pm 0.30^{*}$ & $0.20 \pm 0.12$ & $1.50 \pm 0.39^{*}$ \\
\hline
\end{tabular}

"The number of infiltrating leukocytes was determined at day 10 post $\mathrm{Tx}$

${ }^{b} \mathrm{MHC}$ class II expression was scored on arterial endothelial cells at day 60 post $\mathrm{Tx}$

${ }^{*} \mathrm{P} \leq 0.05$ compared to the CI-CMV-group

** $\mathrm{P} \leq 0.05$ compared to the $\mathrm{Cl}-\mathrm{CMV}+$ group

\section{Infiltration patterns of inflammatory cells}

CD4+ cells, monocytes/macrophages, and NK cells were observed in the renal allografts. The most prevalent infiltrating cell was the CD4+ cell, that was found predominantly in perivascular areas. CMV infection increased the perivascular accumulation of CD4+ cells on day 10 after transplantation compared to the controls (Table 2 ), while prolonged cold ischemia alone did not influence the extravasation of CD4+ cells. Sixty days after transplantation, although the magnitude of perivascular invasion of $\mathrm{CD} 4+$ cells remained the same as on day 10 , there were no significant differences between the groups studied (data not shown).

CMV infection ( $\mathrm{Cl}-\mathrm{CMV}+$ and $\mathrm{Cl}+\mathrm{CMV}+)$ significantly increased the interstitial accumulation of monocytes/macrophages (ED1+ cells), on day 10 after transplantation, compared to the controls (Table 2). This CMV-induced increase in interstitial ED1+ cells disappeared at day 60 (data not shown). Prolonged cold ischemia did not exhibit influence on the accumulation of ED1 + cells. Although there were relatively more infiltrating ED1 + cells in the perivascular regions than in the interstitial areas, no effect of CMV infection or prolonged cold ischemia on the perivascular infiltration was observed (data not shown). 
The intensity of perivascular and interstitial infiltration of NK cells at 10 days was increased significantly by prolonged cold ischemia and further exacerbated by the combination of CMV infection with prolonged cold ischemia $(\mathrm{Cl}+\mathrm{CMV}+)$ compared to the controls (Table 2$)$. The differences between the groups could no longer be detected by day 60 (data not shown).

\section{Expression of MHC class-II antigens}

The scores of MHC class II antigens in arteriolar endothelium at day 60 after transplantation is shown in Table 2. CMV infection ( $\mathrm{Cl}-\mathrm{CMV}+$ and $\mathrm{Cl}+\mathrm{CMV}+$ ) significantly increased the expression of MHC class II antigens. Interestingly, a down-regulated expression of the antigens was observed in the allografts with prolonged cold ischemia alone $(\mathrm{Cl}+\mathrm{CMV}-)$. There was no endothelial expression of $\mathrm{MHC}$ class II antigen in any experimental group at day 10 after transplantation.

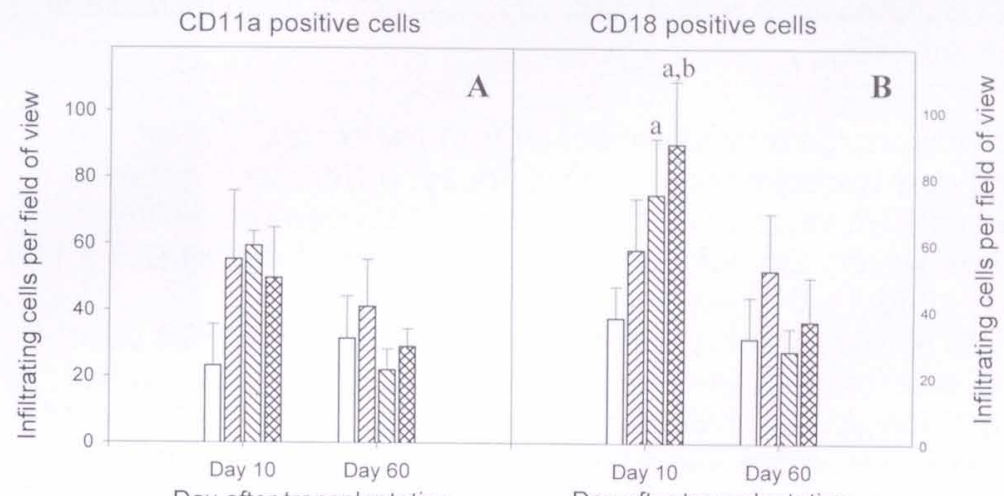

Day after transplantation

Day after transplantation



$$
\begin{aligned}
& \rightleftarrows \mathrm{Cl}-\mathrm{CMV} \text { - } \\
& \text { प्यm Cl-CMV+ } \\
& \text { जIIJ } \mathrm{Cl}+\mathrm{CMV} \text { - } \\
& \text { xxxxy } \mathrm{Cl}+\mathrm{CMV}+
\end{aligned}
$$

Dav after transplantation

Figure 3. The number of infiltrating CD11a, CD18 and CD49d positive cells in the cortex of that allografted kidney at day 10 and 60 post transplantation was determined per field of view (magnification 400x). Per section three fields were scored. Data are presented as mean \pm SEM. $a=P<0.05$ compared to the CI-CMV-group; $b=P<0.05$ compared to the $\mathrm{Cl}-\mathrm{CMV}+$ group. A. The number of CD11a positive leukocytes is not influenced by CMV infection or $\mathrm{Cl}$. B. At day 10 post transplantation $\mathrm{CMV}$ infection and $\mathrm{Cl}$ have a synergistic effect on the presence of CD18 positive leukocytes. C. CMV infection causes an increase in the number of CD49d positive leukocytes in the allografted kidney. 
CD11a, CD18 and CD49d expression on the interstitial infiltrating leukocytes. The influence of $\mathrm{CMV}$ infection, $\mathrm{Cl}$ or both, on the number of leukocytes expressing CD11a, CD18 and CD49d was determined using immunohistochemistry. The number of CD11a (LFA $\alpha$-chain)-positive cells present in the cortex (Fig. $3 \mathrm{~A}$ ) was not influenced by $\mathrm{CMV}$ infection or $\mathrm{Cl}$. The number of CD18-positive cells in the cortex at day 10 post transplantation was higher in the $\mathrm{Cl}+\mathrm{CMV}$ - and the $\mathrm{Cl}+\mathrm{CMV}+$ groups compared to the $\mathrm{Cl}-\mathrm{CMV}$ - group. The number of positive cells in the $\mathrm{Cl}+\mathrm{CMV}+$ group was also significantly higher compared to the $\mathrm{Cl}+\mathrm{CMV}$ - group. At day 60 these differences could no longer be seen (Fig.3B). At day 10 post transplantation, the number of CD49d (VLA$4 \alpha$-chain)-positive cells in the cortex was significantly increased in the CMVinfected groups ( $\mathrm{Cl}-\mathrm{CMV}+, \mathrm{Cl}+\mathrm{CMV}+)$ compared to the $\mathrm{Cl}$ - $\mathrm{CMV}$ - group (Fig. $3 \mathrm{C})$. At day 60 , no differences in the numbers of CD49d-positive cells were found between the groups. In summary, CMV infection results in a significant increase of the CD49d-positive leukocytes, while $\mathrm{Cl}$ results in an increase of CD18-positive leukocytes.

CD54 and CD62P expression on endothelial cells in the cortex.

At day 10 and 60 post transplantation, no significant differences in the number of CD54-positive vessels could be detected between the different groups (Fig.4A). However, the number of positive vessels at day $60(2.7 \pm 1.0)$ compared to day $10(0.3 \pm 0.3)$ was increased.

At day 10 , no significant differences in the number of CD62P-positive vessels could be detected between the different groups (Fig.4B). However, at day 60 after transplantation, a moderate increase $(\mathrm{P}<0.05)$ in the $\mathrm{Cl}+\mathrm{CMV}$ compared to the $\mathrm{Cl}-\mathrm{CMV}$ - group and a large $(\mathrm{P}<0.05)$ increase in the $\mathrm{Cl}+\mathrm{CMV}+$ compared to the $\mathrm{Cl}-\mathrm{CMV}$ - group and the $\mathrm{Cl}-\mathrm{CMV}$ + group was detected.

CD54 positive vessels CD62P positive vessels

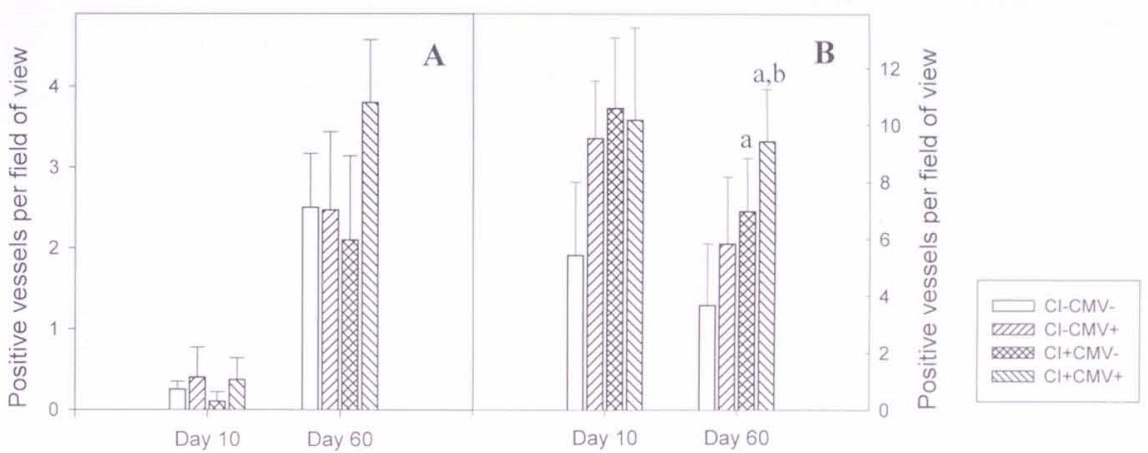

Days after transplantation

Days after transplantation

Figure 4. At day 10 and 60 post transplantation, the number of CD54 and CD62P positive vessels in the cortex of the allografted kidney was determined per field of view. For CD54, five fields were scored (magnification 200x), while for CD62P three fields per section were scored (magnification 100x). Data are presented as mean \pm SEM. $a=P<0.05$ compared to the $\mathrm{Cl}-\mathrm{CMV}$ - group; $\mathrm{b}=\mathrm{P}<0.05$ compared to the $\mathrm{Cl}-\mathrm{CMV}+$ group. $\mathrm{A}$. CMV infection and $\mathrm{Cl}$ have no effect on the expression of CD54 on the endothelium of allografted kidneys. B. At day 60 post transplantation, $\mathrm{CMV}$ infection and $\mathrm{CI}$ have a synergistic effect on the expression of CD62P on endothelium. 
CD54 and CD44 expression on epithelial cells in the cortex. At day 10 after transplantation, there was no significant difference between the four groups in the percentage of CD54-positive tubules in the cortex (Fig. 5A). At day 60, the percentage of positive tubules was higher in the $\mathrm{Cl}+$ groups $(\mathrm{Cl}+\mathrm{CMV}$ - and $\mathrm{Cl}+\mathrm{CMV}+)$ compared to that of the $\mathrm{Cl}-\mathrm{CMV}$ - group $(P<0.05)$.

The percentage of CD44-positive tubules presented a similar pattern early and late after transplantation (Fig.5B). At both time points, the $\mathrm{Cl}-\mathrm{CMV}+$ group showed a small increase, the $\mathrm{Cl}+\mathrm{CMV}$ - group showed a moderate increase and the $\mathrm{Cl}+\mathrm{CMV}+$ group a large increase, in the percentage of positive tubules, compared to the $\mathrm{Cl}-\mathrm{CMV}$ - group. At day 10 the percentage of $\mathrm{CD} 44$-positive tubules in the $\mathrm{CMV}+\mathrm{Cl}+$ group was significantly higher compared to that of all other groups. At day 60 , the percentage in the $\mathrm{Cl}+\mathrm{CMV}$ - group was significantly higher compared to that of the $\mathrm{Cl}-\mathrm{CMV}$ - group and the $\mathrm{Cl}+\mathrm{CMV}+$ group had a significantly higher percentage of CD44-positive tubules than both the $\mathrm{Cl}-\mathrm{CMV}$ - and the $\mathrm{Cl}-\mathrm{CMV}+$ groups. This suggests that $\mathrm{CMV}$ infection has a moderate effect and $\mathrm{Cl}$ a stronger effect on CD44 expression. Thus, $\mathrm{Cl}$ increases the expression of CD44 (day 10 and 60) and CD54 (day 60).

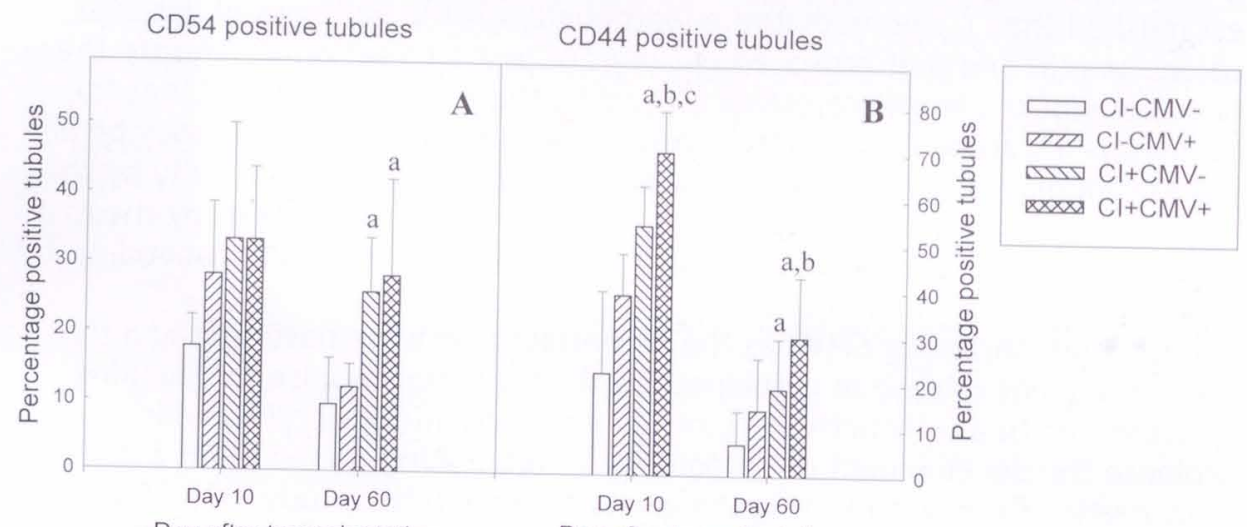

Day after transplantation

Day after transplantation

Figure 5. At day 10 and 60 post transplantation, the percentage of CD54 positive tubules in the cortex of the allografted kidney was determined using a magnification of 200x. Per section three fields were scored. Data are presented as mean \pm SEM. $a=P<0.05$ compared to the $\mathrm{Cl}-\mathrm{CMV}$ - group; $\mathrm{b}=\mathrm{P}<0.05$ compared to the $\mathrm{Cl}-\mathrm{CMV}+$ group; $\mathrm{C}=\mathrm{P}<0.05$ compared to the $\mathrm{Cl}+\mathrm{CMV}$ - group. $\mathrm{A}$. $\mathrm{Cl}$ increases the percentage of $\mathrm{CD} 54$ positive tubules in the allografted kidney. B. CMV infection and $\mathrm{Cl}$ have a synergistic effect on the expression of CD44 on epithelial cells. 


\section{Discussion}

The present study demonstrates that sed cold ischemia $(\mathrm{Cl})$ had additive effects on dete in of renal allografts. However, these histological efiecis or CMV infection and $\mathrm{Cl}$. CMV infection tended to induce vascular cinures (intimal proliferation and glomerular sclerosis), while $\mathrm{Cl}$ increased interstitial fibrosis, tubular atrophy and glomerular sclerosis. Both $\mathrm{CMV}$ infection and $\mathrm{Cl}$ also resulted in a different pattern in the expression of adhesion molecules. CMV infection led to an increase in the presence of CD49d-positive leukocytes while $\mathrm{Cl}$ increased the expression of CD18 on leukocytes, of CD54 and CD62P on tubules, and of CD44 on epithelium. The combination of CMV infection and $\mathrm{Cl}$ resulted in an additional effect on the expression of the adhesion molecules.

The increased intimal proliferation or allograft arteriosclerosis by CMV infection has been found not only in kidney transplants, but also in cardiac, pulmonary, and aortic allografts $(10,20,31)$, suggesting that the effect of CMV on the allograft vasculature is a general phenomenon. It has been well established that T-cell mediated endothelialitis is the hallmark of vascular rejection (25) and that repeated episodes of acute rejection accelerate the development of chronic rejection (33). It is, therefore, postulated that the accelerated transplant arteriosclerosis in CMV-infected recipients may be a process mediated by leukocytes that have been activated specifically by the early CMV infection. This hypothesis is supported, at least partly, by the fact that the early infiltration of CD4+ cells and macrophages was enhanced in the renal grafts of CMV-infected hosts. It is also possible that allograft endothelium harboring CMV has the potential to activate host cells and that the consequent release of cytokines has the potential to raise surrounding endothelium to a fully activated, highly immunogenic state (24), which may promote the development of chronic rejection in allografts without active virus particles being present in the grafts as seen in this study (39). However, previous studies have shown that, although 14 days after RCMV-infection of immunosuppressed rats, infectious virus and viral antigens could only be detected in the salivary gland, all tested organs (including the kidney) contained viral DNA (36). Therefore RCMV might be able to induce expression of adhesion molecules in the host cells without expressing detectable levels of viral antigen in these cells. Thus, the increased expression of adhesion molecules in CMV-infected animals can be either a direct or an indirect effect of CMV.

In vitro, human CMV (HCMV) is known to induce an increase in the expression of CD44 and CD54 on fibroblasts $(8,15)$, of CD54 and CD62E on endothelial cells $(26,40)$ and of CD54 on proximal tubular epithelial cells (37). In vivo, RCMV infection causes an increased CD54 expression on endothelial cells and an increased infiltration of CD11a and CD49d positive leukocytes in allografted lungs (31). In a kidney transplantation model, RCMV infection significantly increased the CD54 expression on endothelial and tubular epithelial cells (17). We could not detect a statistically significant effect of 
CMV infection on CD54 and CD11a, but the CD49d expression was increased in the CMV-infected groups at day 10.

Prolonged cold ischemia led to interstitial fibrosis, glomerular sclerosis and tubular atrophy, the histological alterations typically seen in biopsies of renal allografts undergoing chronic rejection $(1,33)$. It is known that the prolonged ischemia may cause the necrosis of tubular cells due to hypoxia and reperfusion injury early after transplantation (28). This may cause loss of functional mass, a factor held responsible for the development of chronic rejection (33). Endothelium represents the interface between the host immune system and allograft tissue (27), and endothelial injury plays an important role in the development of arteriosclerosis (24). Endothelial injury caused by prolonged ischemia and subsequent reperfusion may result in upregulation of adhesion molecules.

The recruitment of leukocytes from the circulation is regulated by adhesion molecules (reviewed in $(5,6,30)$ ). Since individual receptors often participate in multiple leukocyte-endothelial cell interactions, it is believed that leukocyte recruitment involves multiple steps. Previously, Butcher (5) described a three-step model for this process in which the first step involves primary adhesion ('rolling'), the second step is activation of the leukocyte and the third step is an activation-dependent adhesion resulting in stable binding of the leukocyte to the endothelium. The increased expression of adhesion molecules on the tubules might be considered as a 'fourth step', resulting in an increase of the efficiency of the immune reaction towards the target cells.

If we incorporate our data into the multiple step model, we can see that $\mathrm{Cl}$ leads to an increase in the number of blood vessels expressing CD62P. The second step, activation of the leukocyte, can occur by a large number of factors like cytokines and chemoattractants that are not studied here, but are known to be upregulated by both $\mathrm{CMV}$ infection and $\mathrm{Cl}(9,38,41)$. In the third step, activation-dependent adhesion, the expression of adhesion molecules like LFA-1 and VLA-4 on leukocytes and CD54 on endothelium is involved. The molecule CD49d we detected is a part of the adhesion receptor VLA-4. The number of CD49d positive cells was increased in CMV-infected animals. An increased number of CD18 positive cells was detected in allografted kidneys of rats subjected to $\mathrm{Cl}$. Finally in the 'fourth step', interaction of the leukocyte with the target cells, the expression of CD54 and CD44 on the tubules might be important. CD44 and CD54 expression was increased in the $\mathrm{Cl}+$ groups compared to the $\mathrm{Cl}$ - groups. Thus, $\mathrm{Cl}$ causes an increase in adhesion molecule expression in all steps necessary, whereas CMV infection causes at least upregulations in the second and third step.

The upregulated expression of MHC class II antigens is one of the factors known to be important in the development of allograft rejection (11, 35). Moreover, ischemia/reperfusion injury was recently shown to involve components of an inflammatory reaction, which may increase graft immunogenicity via events such as upregulation of MHC as well as of the cytokine-adhesion molecule cascade, followed by subsequent extravasation (18). In the present study, CMV infection alone, or in combination with prolonged cold ischemia, caused a significant upregulation of MHC class II 
antigen expression on endohelial cells at day 60 post infection. This

phenomenon was previously found in vitro (35). In vivo, however, this effect is seen while no viral antigens can be detected. This suggests that instead of a direct viral this is an indirect effect that starts late after infection. The enhanced expression of MHC class II may enable a direct presentation of foreign antigens to alloreactive T-cells, and the local macrophages that were increased, as noted in the study, may process donor alloantigens for indirect

$T$ - and B-cell activation, leading to further recruitment of $\mathrm{CD} 4+$ and $\mathrm{CD} 8+$ cells and macrophages into the graft, which in turn may induce local cytokine and growth factor production and ultimately graft deterioration.

In summary, the results of the present study suggests that special attention should be paid to the CMV-infected recipient receiving an ischemically injured kidney graft, since an accelerated development of chronic rejection may occur in this situation. CMV infection accelerates renal graft deterioration probably through pathways different from ischemiareperfusion injury. The knowledge about the expression of adhesion molecules due to CMV infection and $\mathrm{Cl}$ may be useful when judging the cause of rejection in biopsies and to develop new therapeutic approaches for control and prevention of graft rejection.

\section{Acknowledgements}

The authors wish to thank Wil Mullers and Anita Jacobs for their technical help and Kees Vink for critical reading of the manuscript. This work was supported by a grant of the Dutch Kidney Foundation (NSN), grant no. C 94.1421. 


\section{References}

1. Almond, P.S, A Matas, K Gilinghaim. D.L Dunn, W.D Payne, P Gores, R Gruessner, and J.S Najarian. 1993. Risk factors for chronic rejection in renal allograft recipients. Transpl. 55:752-6.

2. Briscoe, D.M., and R.S. Cotran. 1993. Role of leukocyte-endothelial cel! adhesion molecules in renal inflammation: In vitro and in vivo studies. Kidney Int. 44:S27-34.

3. Bruggeman, C.A, H Meijer, P.H.J Dormans, W.M.H Debie, G.E.L.M Grauls, and C.P.A Van Boven. 1982. Isolation of a cytomegalovirus-like agent from wild rats. Arch Virol. 73:231-41.

4. Bruning, J.H, W.H Debie, P.H Dormans, H Meijer, and C.A Bruggeman. 1987. The development and characterization of monoclonal antibodies against rat cytomegalovirus induced antigens. Arch Virol. 94:55-70.

5. Butcher, EC. 1991. Leukocyte-endothelial cell recognition: three (or more) steps to specificity and diversity. Cell. 67:1033-6.

6. Carlos, TM, and JM Harlan. 1994. Leukocyte-endothelial adhesion molecules. Blood. 84:2068101.

7. Cecka, IM. 1994. Outcome statistics of renal tiansplants with an emphasis on long-term survival. Clin Transpl, 8:324-7.

8. Craigen, JL, and JE Grundy. 1996. Cytomegalovirus induced up-regulation of LFA-3 (CD58) and (CAM-1 (CD54) is a direct viral effect that is not prevented by Ganciclovir or Foscarnet treatment. Transplantation. 62:1102-8.

9. Goes, N, J Urmson, V Ramassar, and P.F Halloran. 1995. Ischemic acute tubular necrosis induces an extensive local cytokine response. Tiansplantation. 59:565-72.

10. Grattan, MT, CE Moreno-Cabral, VA Starnes, PE Oyer, EB Stinson, and NE Shumway. 1989. Cytomegalovirus infection is associated with cardiac allograft rejection and atherosclerosis. JAMA. 261:3561-66.

11. Hayry, P, K Lemstrom, E Von Willebrand, J Tikkanen, and P Koskinen. 1998. CMV infection and allograft rejection. Transplant Proc. 30:916-7.

12. Hayry, P, A Mennander, A Raisanen-Sokolowski, J Ustinov, K Lemstrom, P Aho, S Yilmaz, I Lautenschlager, and T Paavonen. 1993. Pathophysiology of vascular wall changes in chronic allografts rejection. Transplant Rev. 7:1-5.

13. Heemann, UW, SG Tullius, H Azuma, J Kupiec-Weglinsky, and NL Tilney. 1994. Adhesion molecules and transplantation. Ann Surg. 219:4-12.

14. Isoniemi, H, E Taskinen, and P Hayry. 1994. Histological chronic allograft damage iıdex accurately predicts chronic renal allograft rejection. Transplantation. 58:1195-8.

15. Ito, M, M Watanabe, $T$ Ihara, H Kamiya, and M Sakurai. 1995. Increased expression of adhesion molecules (CD54, CD29 and CD44) in fibroblasis infected with cytomegalovirus. Microbiol Immunol. 39:129-33.

16. Kanagawa, K, H Ishikura, C Takahashi, T Tamatani, M Miyasaka, M Togashi, T Koyanagi, and T Yoshiki. 1991. Identification of ICAM-1-positive cells in the nongrafted and transplanted rat kidney- An immunohistochemical and ultrastructural study. Transplantation. 52:1057-62.

17. Koskinen, P.K, S Yilmaz, E Kallio, C.A Bruggeman, P.J Hayry, and K Lemstrom. 1996. Rat cytomegalovirus infection and chronic kidney allograft rejection. Transpl Int. 9:S3-4.

18. Land, W. 1994. The potential impact of the reperfusion injury on acute and chronic rejection events following organ transplantation. Transpl Proc. 26:3169-71.

19. Lautenschlager, I, A Soots, L Krogerus, H Kauppinen, O Saarinen, C Bruggeman, and J Ahonen. 1997. Effect of Cytomegalovirus on an experimental model of chronic renal allograft rejection under triple-drug treatment in the rat. Transplantation. 64:391-8.

20. Lemstrom, KB, JH Bruning, CA Bruggeman, IT Lautenschlager, and PJ Hayry. 1993. Cytomegalovirus infection enhances smooth muscle cell proliferation and intimal thickening of rat aortic allografts. J Clin Invest. 92:549-58.

21. Nagano, H, K.C Nadeau, M Takada, M Kusaka, and N.L Tilney. 1997. Sequential cellular and molecular kinetics in acutely rejecting renal allografts in rats. Transplantation. 63:1101-8.

22. Rehbinder, C., P. Baneux, D. Forbes, H. Van Herck, W. Nicklas, Z. Rugaya, and G. Winkler. 1996. FELASA recommendations for the heaith monitoring of mouse, rat, hamster, gerbil, guineapig and rabbit experimental units. Lab Anim. 30:193-208.

23. Robin, RH. 1990. Impact of cytomegalovirus infection on organ transplant recipients. Rev Infect Dis. 12 (suppl. 7):754-66.

24. Ross, R. 1993. The pathogenesis of atherosclerosis: a perspective for the 1990s. Nature. 362:801-9. 
25. Salomon, RN, CCHughes, FJ Schoen, DD Payne, JS Pober, and PLiblyy. 1991. Human coronary artery transplantatioon-associated arteriosclerosis: Evidence for a chonic immune reaction to activated graft endothelial cells. Am J Pathol. 138:791-8.

26. Sedmak, DD, DA Knight, NC Vook, and JW Waldman. 1994. Divergent patterns of ELAM-1, ICAM-1, and VCAM-1 expression on cytomegalovirus-infected endothelial cells. Transplantation. 58:1379-85.

27. Sedmak, DD, and CG Orosz. 1991. The role of vascular endothelial cells in transplantation. Arch Pathol Lab Med. 115:260-5.

28. Southard, JH, DC Marsh, JK MCAnulty, and FO Belzer. 1987. The importance of O2-derived free radical injury in organ preservation and transplantation. Transplant Proc. 19:1380-1.

29. Span, A.H.M, W Mullers, A.M.M Miltenburg, and C.A Bruggeman. 1991. Cytomegalovirus induced PMN adherence in relation to an ELAM-1 antigen present on infected endothelial cell monolayers. Immunology. 72:355-60.

30. Springer, TA. 1990. Adhesion receptors of the immune system. Nature. 346:425-34.

31. Steinhoff, G, X.M You, C Steinmuller, D Bauer, M.L Lehmann-Matthes, C.A Bruggeman, and A Haverich. 1996. Enhancement of cytomegalovirus infection and acute rejection after allogeneic lung transplantation in the rat. Transplantation. 61:1250-60.

32. Takada, M. K.C Nadeau, G.D Shaw, K.A Marquette, and N.L Tilney. 1997. The cytokineadhesion molecules cascade in ischemia/reperfusion injury of the rat kidney. $j$ Clin Invest. 99:2682-90.

33. Tullius, 5G, and NL Tilney. 1995. Both alloantigen-dependent and -independent factors influence chronic allograft rejection. Transplantation. 59:313-8.

34. Tullius, S.G, U Heemann, H Azuma, P Pradman, and N.L Tilney. 1994. Early ischemic injury leads to long-term furictional and morphologic deterioration of naive rat kidneys and may contribute to changes of chronic allograft rejection. Transplant Proc. 26:2041-2.

35. Ustinov, JA, RJ Loginov, CA Bruggeman, PH van der Meide, PJ Hayry, and IT Lautenschlager. 1993. Cytomegalovirus induces class II expression in rat heart endothelial cells. J Heart Lung Transplant. 12:644-51.

36. van Dam, J.G, J.G.M.C Damoiseaux, H.A.M.D van der Heijden, G Grauls, P.J.C van Breda Vriesman, and C.A Bruggeman. 199\%. Infection with rat cytomegalovirus (CMV) in the immunocompromised host is associated with the appearance of a $T$ cell population with reduced CD8 and T cell receptor (TCR) expression. Clin Exp Immunol. 110:349-57.

37. Van Dorp, WT, PA Van Wieringen, E Marselis Jonges, CA Bruggeman, MR Daha, L. A Van Es, and $F$ Van der Woude. 1993. Cytornegalovirus directly enhances MHC class I and intercellular adhesion molecule-1 expression on cultured proximal tubular epithelial cells. Transplantation. 55:1367-71.

38. Vossen, R.C.R.M, M.C.E Van Dam-Mieras, and C.A Bruggeman. 1996. Cytomegalovirus infection and vessel wall pathology. Intervirology. 39:213-21.

39. Waldman, WJ, and DA Knight. 1996. Cytokine-mediated induction of endothelial adhesion molecule and histocompatibility leukocyte antigen expression by cytomegalovirus-activated T cells. Am J Pathol. 148:105-19.

40. Waldman, W.J, D.A Knight, P.W Adams, C.G Orosz, and D.D Sedmak. 1995. In vitro induction of endothelial adhesion molecule and MHC antigen expression by cytomegalovirus-activated CD4+ T cells. Transplant Proc. 27:1269-71.

41. Wan, S, A Marchant, JM DeSmet, M Antoine, H Zhang, JL Vachiery, M Goldman, JL Vincent, and $\mathrm{JL}$ LeClerc. 1996. Human cytokine responses to cardiac transplantation and coronary artery bypass grafting. J Thorac Cardiovasc Surg. 111:469-77.

42. Xu, XY, K Honjo, D Devore-Carter, and RP Bucy. 1997. Immunosuppression by inhibition of cellular adhesion mediated by leukocyte function-associated antigen-1/intercellular adhesion molecule-1 in murine cardiac transplantation. Transplantation. 63:876-85.

43. Yang, H, TB issekutz, and JR Wright Jr. 1995. Prolongation of rat islet allograft survival by treatment with monoclonal antibodies against VLA-4 and LFA-1. Transplantation. 60:71-6.

44. Yin, M, M.H Booster, A.E.J.M Bogaard van den, and G Kootstra. 1994. A simple technique to harvest two kidneys from one donor rat for transplantation. Lab Anim. 28:387-90.

45. Zizzi, H.C, G.B Zibari, D.N Granger, I Singh, L.D Cruz, F Abreo, J.C McDonald, and M.F Brown. 1997. Quantification of P-selectin expression after renal ischemia and reperfusion. J Pediatr Surg. 32:1010-3. 


\section{CHAPTER 6 \\ Cytomegalovirus-enhanced development of transplant arteriosclerosis in the rat: effect of timing of infection and recipient responsiveness}

Joanne G. van Dam ${ }^{1,3}$, Jan-Luuk Hillebrands ${ }^{2,3}$, Flip A. Klatter ${ }^{2}$, Gert Grauls ${ }^{1}$ Cathrien A. Bruggeman ${ }^{1}$, Jan Rozing ${ }^{2}$

${ }^{1}$ Department of Medical Microbiology, Cardiovascular Research Institute Maastricht (CARIM), University Hospital Maastricht, Maastricht, the Netherlands

${ }^{2}$ Department of Cell Biology, Histology \& Immunology Section, Faculty of Medical Sciences, University of Groningen, Groningen, the Netherlands ${ }^{3}$ J.L. Hillebrands and J.G. van Dam contributed equally to this article 


\section{Abstract}

Background

Cytomegalovirus (CMV) is put forward as a risk factor for transplant arteriosclerosis (TA). In this paper, RatCMV-enhanced development of TA in different donor/recipient combinations and in relation to the timing of infection was studied.

\section{Methods}

Aorta transplantation was performed in different strain combinations (+/ RCMV infection at different time-points relative to transplantation) and the severity of TA was analyzed. Moreover, transmission of RCMV from grafts and its effect on TA was studied.

\section{Results}

Without RCMV, Lewis, Albino-Oxford and Wistar-Furth recipients developed weak TA after 4 weeks. Compared to Lew recipients, Brown-Norway recipients showed a four-fold increase in TA severity. RCMV-enhanced TA only developed in Lewis recipients and only after infection on day 1 after transplantation. Virus transmission only occurred from 5 and 10 days infected donor-grafts, however without affecting TA development.

\section{Conclusions}

These data suggest that acute rejection and acute infection need to be present simultaneously to enhance TA, however this effect cannot be generalized. 


\section{Introduction}

Solid organ transplantation has become an established therapy for patients with end-stage organ failure. However, despite the introduction of improved immunosuppressive agents in the last few decades, development of chronic transplant dysfunction (CTD) is still a complicating factor for long-term graft survival. To date, CTD has become the most important problem in clinical organ transplantation after the first perioperative year which cannot be prevented by current immunosuppressive protocols [1-3]. Irrespective of the organ grafted, graft vessels eventually develop so called transplant arteriosclerosis (TA) [4], which is, however, most prominent in cardiac allografts $[5,6]$. This vascular remodeling process consists of progressive concentric intimal thickening (neointima formation) coinciding with ongoing perivascular inflammation. TA has generally been accepted as the main cause for progressive deterioration in graft function. Pathogenesis of TA seems to be multifactorial but precise mechanisms involved in the development of this remodeling process still remain obscure. Risk factors appear to include cold ischemia time and reperfusion injury, MHC disparity between donor and recipient and number of rejection episodes $[3,7]$. In addition, cytomegalovirus (CMV) infection has been associated with the development of TA.

Studying human cardiac allografts, Grattan et al. showed a positive correlation between the presence of cytomegalovirus and graft atherosclerosis [8]. In addition, Almond et al. Demonstrated CMV to be a risk factor for the development of CTD in human kidney allografts [9]. However, also data have been described suggesting that CMV does not contribute to TA after solid organ transplantation [10-12]. A possible explanation for these conflicting results is that in some studies patients received ganciclovir prophylaxis preventing viral replication immediately after transplantation, whereas in other studies patients were treated pre-emptively. Ganciclovir prophylaxis has been shown to ameliorate TA in human cardiac allografts $[13,14]$.

Also in several experimental transplant models in rats (heart, kidney, liver and trachea) the role of CMV infection on the development of CTD related pathology has been studied. Using Rat Cytomegalovirus (RCMV), it was shown that viral infection accelerates the development of CTD related pathology [15-19]. In the aortic transplant model in rats, which is a well established and reproducible model to study development of TA [20], we and others showed that RCMV, administered 1 day after transplantation, enhances both the perivascular inflammatory response [21-23] and neointima formation [23-27]. The increase in perivascular inflammation observed after RCMV infection peaks around 1 month after transplantation, whereas the effects on neointima formation can be detected 2-3 months after transplantation. Based on this observation, it has been hypothesized that the increased perivascular inflammatory response after viral infection is the cause of enhanced neointima formation. In line with this, induction of donor-specific tolerance has been reported to prevent RCMV-induced accelerated TA in cardiac allografts [28]. 


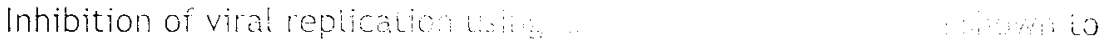

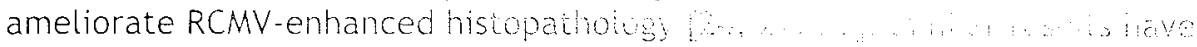
been reported in human cardiac iransplantation, implicating CAY as a causative agent in TA development.

Clinical data suggest that CMV enhances development of CTD related pathology only when active CMV infection and acute rejection are present simultaneously [30-32]. We previously showed that RCMV infection of aortic allograft recipients resulted in enhanced TA only in a donor/recipient combination in which only weak TA develops in the absence of RCMV [26]. In combinations that develop strong TA, additional RCMV infection seems not be able to further accelerate or enhance the the development of TA.

In this study we investigated the role of the donor/recipient combination and the timing of CMV infection on the development of TA after allogeneic aorta transplantation in rats. Therefore, we first analyzed the development and severity of TA in various $\mathrm{MHC}$-incompatible donor/recipient combinations without additional RCMV-infection. Based on these results we selected a donor/recipient combination with weak TA development to study the effect of timing of RCMV infection on the development of TA. To determine the generality of our results, we tested whether RCMV infection at the time of acute rejection resulted in enhanced TA in other 'weak TA' combinations. Although RCMV does enhance the development of TA if infected 1 day after transplantation, this effect can not be generalized. Obviously, there are other factors than the timing of infection and the 'weakness' of TA involved in determining whether CMV enhances development of TA.

\section{Materials and Methods}

\section{Animals}

Specified pathogen free male PVG $\left(R T-1^{c}\right), A O\left(R T-1^{\prime \prime}\right)$, DA (RT-1 $\left.1^{a}\right)$, WF (RT-1"), Lew $\left(R T-1^{\prime}\right)$, and $B N\left(R T-1^{n}\right)$ rats were obtained from Harlan (Zeist, the Netherlands). Lew and BN rats used for RCMV infection experiments were bred at the central animal facility of the Maastricht University. Rats were 8-10 wk of age, maintained under clean conventional conditions, and were fed standard rat chow and acidified water ad libitum. All animals received humane care in compliance with the Principles of Laboratory Animal Care (NIH Publication No. 86-23, revised 1985) and the Dutch Law on Experimental Animal Care.

\section{Aorta transplantation}

Aortic allografts (10-12 mm) were transplanted as described previously [20]. Briefly, the abdominal aorta between the left renal artery and the bifurcation was removed from the donor rat and perfused with saline to remove blood cells. Subsequently, the graft was orthotopically transplanted into the recipient rat via end-to-end anastomosis using 9-0 nylon suture. Total ischemic time was consistently less than 30 minutes during which the grafts were kept in ice-cold saline. Transplantations were performed in the following $\mathrm{MHC}$ incompatible strain combinations: PVG-to-AO, DA-to-WF, BN- 
to-Lew, and Lew-to-BN. The Bn-to-BN combination served as an isograft control.

\section{Experimental groups}

To study whether the development of TA differs among different donor/recipient combinations (in the absence of RCMV), transplantations were performed in the combinations as listed in Table $1 \mathrm{~A}$. BN allografts transp: anted in Lew recipient rats were explanted 4, 8, 12 and 24 weeks after transpliantation (groups 1-4). In addition, aortic allografts were transplanted in the Le'W-to-BN (group 5), PVG-to-AO (group 6) and DA-to-WF (group 7) strain combinations, and explanted 4 weeks after transplantation. BN isografts (group 8 ; served as controls and were sacrificed 12 weeks after transplantation.

To study the effect of timing of RCMV infection on the development of TA, recipient rats received 5 Gy total body irradiation (TBI) 6 hours before administration of virus to promote viral replication. Recipient rats were divided into 6 different treatment groups (groups 9-14) as listed in Table 1 B. Allograft recipients were mock-infected (group 9) or RCMV-infected shortly after transplantation (day 1 or day $1+5$; groups $10 \& 11$ ) or late after transplantation (daj, 21 or day $21+25$; groups 12 \& 13 ). In addition, one group of recipient rats was infected 21 days before transplantation (group 14) to study the effect of chronic RCMV infection of the host on the development of TA.

To analyze transmission of RCMV by the graft after transplantation (resulting in systemic infeciion of the recipient and possibly affecting TA), allografts were transplanted into irradiated hosts 5, 10, and 21 days post infection (p.i.) of the donor (groups 15, 16, and 17, respectively). Recipient rats were sacrificed 7 weeks after transplantation and grafts were removed for TA quantification and virus detection.

To analyze RCMV-enhanced TA development in other strain combinations, aortic transplantation and RCMV infection (+/ - TBI) was performed in the PVG-to-AO (groups 18-21) as well as the DA-to-WF (groups 22 \& 23) strain combination (Table 1C). Grafts were removed 12 weeks after transplantation.

At autopsy, grafts from all groups were removed and processed for computerized morphometric analysis (quantification TA).

\section{Infection with RCMV}

RCMV infection was performed by intraperitoneal (i.p.) injection of $3 \times 10^{5}$ plaque forming units (pfu) RCMV (Maastricht strain) [33]. The virus-pool consisted of a salivary gland homogenate which was prepared as described elsewhere [34]. Some recipients that were RCMV-infected were sublethally irradiated (5 Gy) 1 day after aortic transplantation in order to enhance replication and dissemination of $\operatorname{RCMV}[35,36]$. To analyze whether irradiation is a prerequisitie for RCMV-enhanced TA development, recipients from groups $18,20,22$, and 23 were not irradiated before infection (Table 1C). 
Transfer of infectious virus by aortic allografts

A sensitive infection transfer assay was used to analyze the transmission and dissemination of RCMV from aortic allografts into their recipients [37]. Donor $B N$ rats were sublethally irradiated ( 5 Gy) followed by i.p. injection of $3 \times 10$ pfu RCMV. After 5, 10, and 21 days post infection, allografts were transplanted into sublethally irradiated Lew recipient rats. At the time of transplantation, parts of the graft and salivary glands were removed and processed for RCMV detection (plaque assay, immunohistochemistry and PCR analysis). Recipient rats were sacrificed 7 weeks after transplantation afnd salivary glands and aortic tissue (both the graft and autologous part) were removed and processed for RCMV detection.

Detection of infectious virus by plaque-assay Presence of infectious virus was quantified using a plaque-assay as described previously [33]. Salivary glands and aortic tissue (graft as well as a/utologous part) were suspended in EMEM (supplemented with $2 \%$ fetal calf s,erum (FCS), $2 \mathrm{mM} \mathrm{L}$-glutamine, $1 \%$ non-essential amino acids (all obtained frojm Gibco, Invitrogen, Breda, the Netherlands) and $0.1 \mathrm{mg} / \mathrm{ml}$ gentamycin'(Centrafarm, Etten-Leur, the Netherlands) in a $10 \%$ weight/volume ratio. Tríssues were homogenized and sonicated, and subsequently 10 - and $100 \%$ old dilutions of the supernatants were inoculated on a confluent rat embryonal fibroblast monolayer in 24-well tissue culture plates (Greiner, Alphen a/d Rijn, the Netherlands). After 7-10 days of incubation in culture medium containing $0.25 \%$ agarose (Seakem ME, FMC Bioproducts, Rocklarid, Maine, USA), cells were fixed in 10\% formalin (in PBS) and stained with methylene-blue. The number of plaques was quantified microscopically, and the virus titer was calculated and expressed as plaque forming unit's (pfu).

\section{Detection of RCMV antigens}

For detection of RCMV antigens, $4 \mu \mathrm{m}$ formalin-fixed paraffin embedded tissue-sections were stained with RCMV monoclonal antibody (mAb 8) [38]. Briefly, after deparaffination tissue sections were incubated with mAb8 for 60 minutes. Subsequently, sections were incubated with a second step alkaline phosphatase-conjugated rabbit anti-mouse antibody (DAKO A/S, Glostrup, Denmark) for 30 minutes. The chromogen Fast Red was applied for 30 minutes, and subsequently sections were counterstained with Mayer's hematoxylin, dehydrated and coverslipped.

\section{Detection of RCMY DNA}

For detection of viral DNA, salivary glands and aortic tissue were cut in small pieces followed by DNA extraction. Subsequently, a semiquantitative nested PCR was performed using the RCMV DNA polymerase gene (GenBank accession no. U50550) as target sequence [39]. Total cellular DNA was extracted from the salivary glands and aorta with a DNA extraction kit (Gull Laboratories, Salt Lake City, Utah, USA). The DNA samples were serially diluted from $10^{\circ}$ to $10^{-8}$ $\mu \mathrm{g}$. Each of the diluted DNA samples was incubated for $10 \mathrm{~min}$. at $95 \mathrm{C}$, immediately cooled on ice, anci subjected to a two round (nested) PCR. The sequences of the primers as well as the PCR conditions are described 
elsewhere [39]. The first and second round PCR resulted in DNA fragments of $536 \mathrm{bp}$ and $431 \mathrm{bp}$, respectively. The PCR products were analyzed by agarose gel electrophoresis and visualized by ethidium bromide staining.

Quantification of transplant arteriosclerosis

Grafts removed at autopsy were divided into two parts, fixed in $10 \%$ formalin (in PBS) and embedded in paraffin. Tissue sections $(4 \mu \mathrm{m})$ were cut from each part of the graft (not near the anastomosis) and stained with Lawson solution (Klinipath, Duiven, The Netherlands) to visualize elastin fibers. TA was quantitated using a computerized morphometric analysis system (QWin Software, Leica Microsystems B.V., Rijswijk, the Netherlands). Surface of the media and neointima were calculated from two sections in each part and the mean of both parts was calculated. The severity of TA was erpressed as the neointima/media ratio.

Statistical analysis

To analyze differences in the neointima/media ratio for statistical significance, the Kruskal-Wallis One-Way ANOVA was performed. If this test revealed a significant difference, a Mann-Whitney $U$ test was performed to analyze differences between subgroups. Differences were considered to be statistically significant when $p$-values were $<0.05$. 
Table 1. Groups used for aorta transituran.

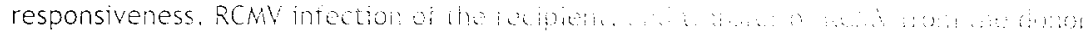
on the development of TA.

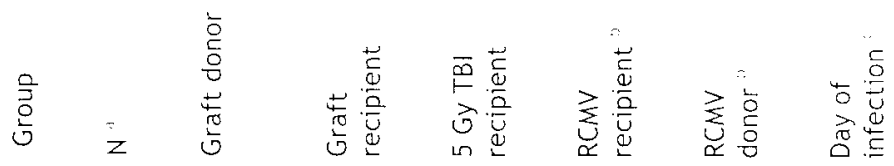

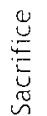

A

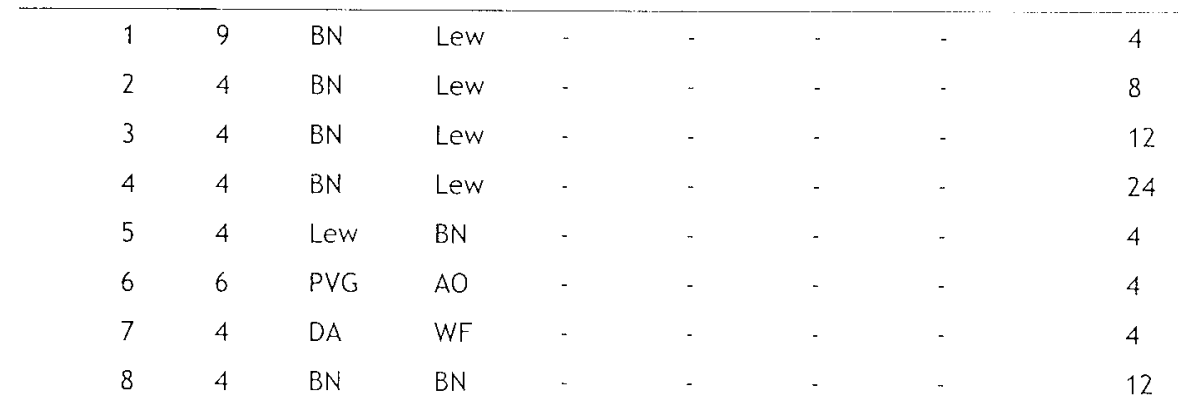

B

\begin{tabular}{|c|c|c|c|c|c|c|c|c|}
\hline 9 & 5 & $\mathrm{BN}$ & Lew & + & - & - & 1 (mock) & 7 \\
\hline 10 & 5 & $\mathrm{BN}$ & Lew & + & + & . & 1 & 7 \\
\hline 11 & 5 & $\mathrm{BN}$ & Lew & + & + & - & $1 \& 5$ & 7 \\
\hline 12 & 5 & $B N$ & Lew & + & + & - & 21 & 7 \\
\hline 13 & 5 & $\mathrm{BN}$ & Lew & + & + & - & $21 \& 25$ & 7 \\
\hline 14 & 5 & $\mathrm{BN}$ & Lew & + & + & - & -21 & 7 \\
\hline 15 & 5 & $\mathrm{BN}$ & Lew & + & - & + & -5 & 7 \\
\hline 16 & 6 & $\mathrm{BN}$ & Lew & + & - & + & -10 & 7 \\
\hline 17 & 4 & $\mathrm{BN}$ & Lew & + & - & + & -21 & 7 \\
\hline \multicolumn{9}{|l|}{ C } \\
\hline 18 & 6 & PVG & $\mathrm{AO}$ & - & - & - & - & 12 \\
\hline 19 & 4 & PVG & $\mathrm{AO}$ & + & - & . & - & 12 \\
\hline 20 & 6 & PVG & $\mathrm{AO}$ & - & + & - & 1 & 12 \\
\hline 21 & 5 & PVG & $\mathrm{AO}$ & + & + & - & 1 & 12 \\
\hline 22 & 4 & DA & WF & - & - & - & - & 12 \\
\hline 23 & 5 & $D A$ & WF & - & + & - & 1 & 12 \\
\hline
\end{tabular}

number of animals analyzed

"animals were infected with $3 \times 10$ " plaque forming units (pfu) RCMV salivary gland homogenate c animals were non-infected $(-)$ or infected before or after transplantation (day 0 )

"weeks after transplantation 


\section{Results}

TA development in different strain combinations

The development of TA in different strain combinations was quantified 4 weeks after transplantation and the results are shown in Figure 1A. BN allografts transplanted into Lew recipients (group 1) developed only weak TA. In contrast, Lew allografts transplanted into BN recipient rats (group 5) showed a four-fold increase in the amount of TA compared to Lew recipients $(p<0.05)$. Although slightly higher compared to Lew recipients, also AO recipients of PVG allografts (group 6) and WF recipients of DA allografts (group 7) showed weak TA 4 weeks after trarisplantation ( $p<0.05$ vs. Lew-to$\mathrm{BN})$. Representative photomicrographs of aortic allografts transplanted in the $\mathrm{BN}$-to-Lew and Lew-to-BN strain combinations are shown in Figu.es $1 \mathrm{C}$ and $\mathrm{D}$, respectively.

Since Lew recipients developed only weak TA 4 weeks after transplantation, we analyzed whether there is a further increase in TA at later time points. Figure $1 \mathrm{~B}$ shows the development of TA in BN allografts at different time points $(4,8,12$ and 24 weeks) after transplantation. One month after transplantation, BN allografts showed mild TA (similar to Figure 1A). An increase in the amount of TA is observed 8 and 12 weeks after transplantation, reaching maximal TA 24 weeks after engraftment. In contrast to Lew recipients, BN recipients developed the similar amount of TA within 4 weeks after transplantation and no further increase in time was observed (data not shown). BN isografts hardly show any signs of TA 12 weeks after transplantation.

\section{Effect of timing of RCMV infection on the development of TA}

Since Lew recipients presented as low TA responders and BN recipients as high $\mathrm{TA}$ responders (Figure 1), we used the $\mathrm{BN}$-to-Lew combination to study the effect of timing of RCMV infection on the development of TA. Recipients were mock-infected (group 9) or RCMV-infected 1 day (group 10) or 21 days (group 12) after transplantation. In addition, one group of rats was infected 21 days before the actual transplantation was performed (group 14). Seven weeks after transplantation grafts were removed and the surface neointima was quantified. Only infection 1 day after transplantation showed a significant increase $(p<0.05)$ in neointima formation compared to mock-infection (Figure 2A). Infection 21 days before (group14) and 21 days after (group 12)

transplantation did not enhance neointima formation. To analyze whether the absence of an enhancing effect of virus infection 21 days after transplantation was due to a low viral load, Lew recipients were infected twice shortly (days 1 \& 5 , group 11) or late (days 21 \& 25, group 13) after transplantation. Again, only infection shortly after transplantation resulted in increased neointima formation (ratio neointima/media: $1.68 \pm 0.14$ (days 1 \& 5 ) vs. $1.17 \pm 0.26$ (days $21 \& 25)$ and $1.11 \pm 0.25$ (day 1 mock) $(p<0.05)$. These results indicate that the viral load is not responsible for the differences observed, and that RCMV infection enhances TA only when infection is given shortly after engraftment. 

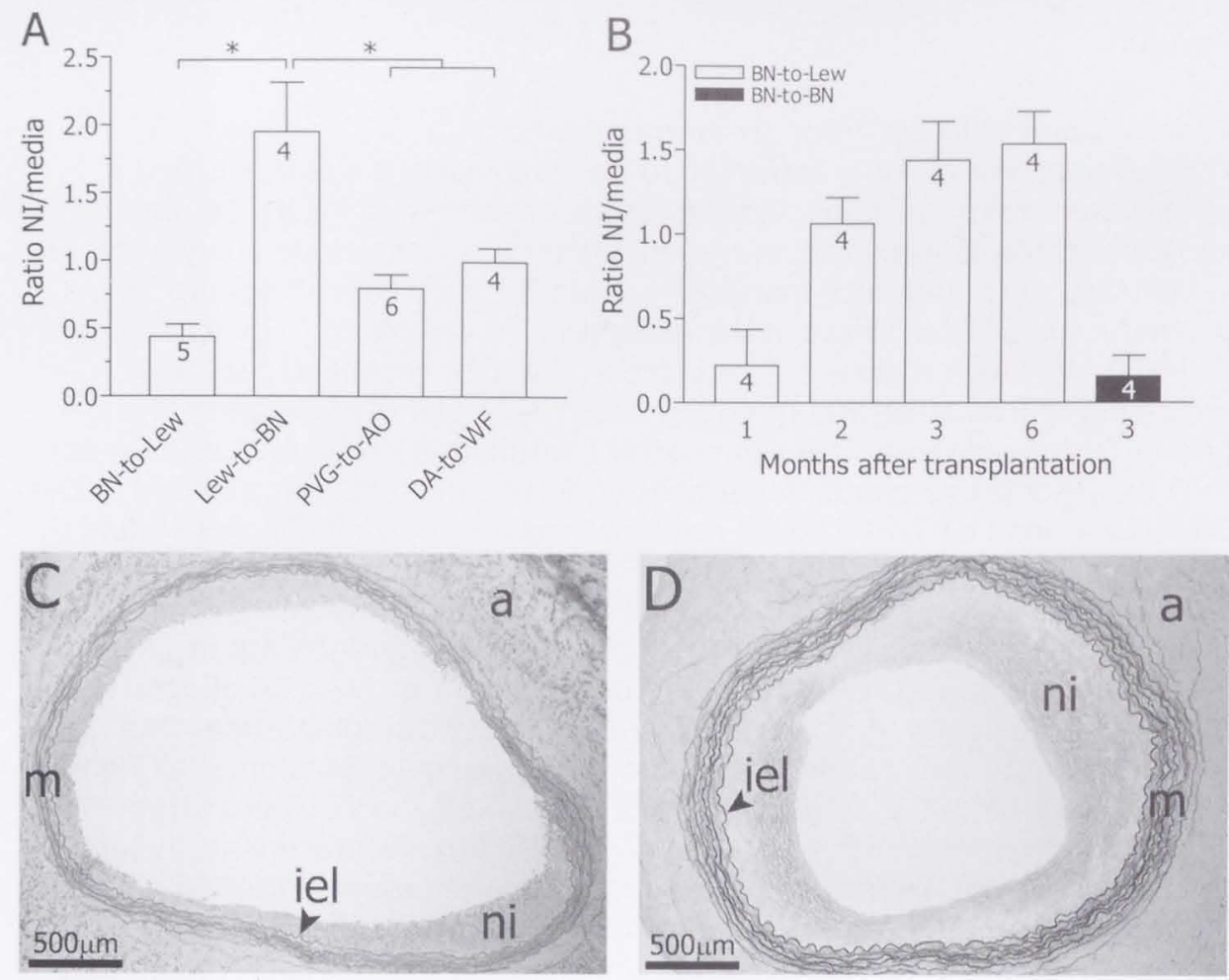

Figure 1. Severity of TA after allogeneic aorta transplantation (expressed as the ratio surface neointima/media) in different rat strain combinations. (A) BN recipients present with increased TA development 4 weeks after transplantation (* $p<0.05$ vs BN-to-Lew, PVGto-AO, and DA-to-WF combinations, Mann-Whitney $U$ test). (B) Development of TA in time after transplantation in the BN-to-Lew combination. The number of animals analyzed within each group are given within the bars. (C) and (D) show representative photomicrographs after Lawson-staining (elastin) of aortic allografts transplanted in the BN-to-Lew and Lew-to-BN strain combinations, respectively. Abbreviations: a, adventitia; iel, internal elastic lamina; m, media; ni, neointima. (magnification, x40)

\section{Effect of RCMV infection of the donor on the development of TA}

In clinical transplantation, primary CMV infection as a result of transplantation of an organ from a seropositive donor into a seronegative recipient has been associated with an increased risk for the development of TA. To analyze whether primary infection due to transfer of RCMV by an aortic allograft also enhances neointima formation, we studied the presence of virus in aortic tissue at several time points p.i. (5, 10, and 21 days), the capability to disseminate after transplantation, and its effects on the development of TA.

Using RCMV-specific immunohistochemistry (mAb8) no virus-infected cells could be detected in donor aorta and salivary glands at all three timepoints ( 5 days p.i. [n=4], 10 days p.i. [ $n=4]$ and 21 days [ $n=2]$ ). However, results from the plaque-assay indicated presence of infectious virus in aortic tissue 5 and 10 days p.i. ( 1 out of 4 animals at both time points). The salivary 

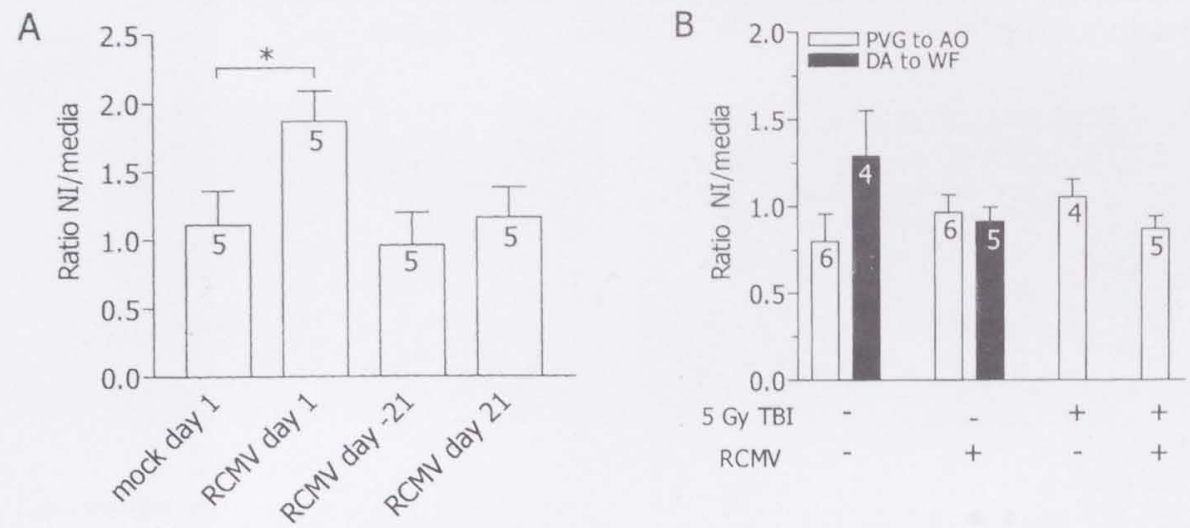

Figure 2. Kinetics of the development of TA after allogeneic aorta transplantation in different strain combinations with or without additional RCMV infection. Neointima formation is expressed as the ratio surface neointima/media. The number of animals analyzed within each group are given within the bars. (A) Effect of timing of RCMV infection on the development of TA in the BN-to-Lew combination 7 weeks after transplantation. (B) Effect of RCMV infection (+/ - 5 Gy TBI) on the development of TA after allografting in the PVG-to-AO and DA-to-WF strain combinations 12 weeks after transplantation. ( ${ }^{*}$ $p<0.05$, Mann-Whitney U test).

glands (SG) of the donor-rats contained infectious virus in all animals 10 [n=4] and 21 [ $n=2]$ days post infection. Although RCMV could not be detected by plaque-assay in aortic tissue transplanted 5 or 10 days post infection in most animals, transplantation of these grafts resulted in transmission of virus to the recipient. Seven weeks after transplantation 100\% (6/6) and 75\% (3/4) of the recipient rats (transplanted 5 and 10 days p.i., respectively) showed signs of systemic infection as indicated by the presence of infectious virus in their salivary glands (as detected by immunohistochemistry and plaque-asay). Figures $3 \mathrm{~A}$ and $3 \mathrm{~B}$ show representative photomicrographs of RCMV-infected cells in salivary glands of recipient rats transplanted with aortic allografts 5 days p.i. of the donor. RCMV was never detected by immunohistochemistry and plaque-asay in both graft and autologous aorta tissue.

To confirm these results, a more sensitive PCR-based approach was followed to detect viral DNA in aortic tissue and salivary glands after transplantation. RCMV specific nested PCR was performed on donor (aorta and SG) and recipient (autologous aorta, aorta graft, and SG) tissues. The results obtained by the nested PCR (Figure 3 C) confirmed the results obtained by IHC and plaque-assay and indicate that 21 days p.i. aortic tissue does not contain detectable levels of viral DNA and, as a result, also no viral transmission occurs after transplantation.

Infection of the donor 21 days before transplantation did, as expected, not influence neointima formation after transplantion (ratio neointima/media: $1.10 \pm 0.18$ [day $-21 \mathrm{RCMV}$ ] vs. $1.11 \pm 0.25$ [day 1 mock]), since we showed that no virus was present in aortic tissue at this time point and no viral transmission occurred after transplantation. However, also no enhancing effect on neointima formation was observed after transplantation of grafts 5 and 10 days p.i. despite the fact that at these time-points aortic 
tissue contained virus and caused effective viral transmission after transplantation.
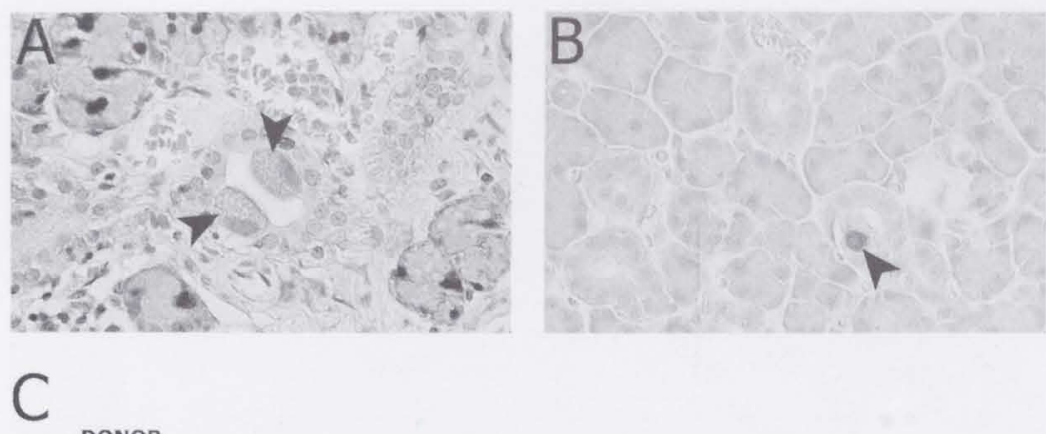

DONOR

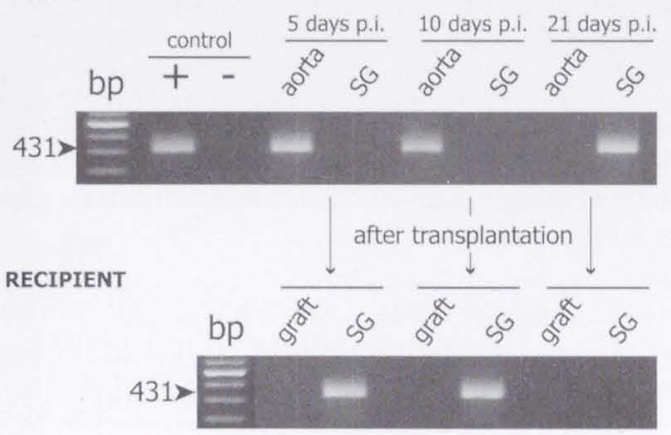

Figure 3. Transfer of RCMV by transplantation of RCMV-infected allografts. (A) HE staining and (B) mAb8 (RCMV) staining of recipient salivary gland tissue 7 weeks after transplantation of an aortic allograft obtained from a RCMV ifected donor 5 days p.i.. Arrowheads indicate RCMV infected ductal epithelial cells. (magnification, x400). (C) nested RCMV PCR performed on donor aorta and salivary gland tissue at the time of transplantation, and on graft tissue and recipient salivary gland tissue 7 weeks after transplantation. Grafts were transplanted 5, 10, and 21 days p.i. with RCMV.

Effect of RCMV infection on the development of TA in other strain combinations

Only RCMV infection shortly after transplantation (1 and/or 5 days) enhanced neointima formation in the $\mathrm{BN}$-to-Lew rat strain combination, suggesting that active RCMV infection and acute rejection should be present simultaneously. To study whether this effect can be generalized and is also present in other strain combinations that show weak TA in the absence of RCMV, we performed similar experiments in the MHC incompatible PVG-to-AO (groups 19-21) and DA-to-WF (groups 22 \& 23 ) strain combinations and results are shown in Figure 2B. In contrast to the BN-to-Lew strain combination, RCMV did not enhance neointima formation in the PVG-to-AO combination. Also in the DA-to-WF combination, no enhanced neointima formation was observed 12 weeks after transplantation following RCMV infection on day 1 after transplantation. 


\section{Discussion}

Transplant arteriosclerosis (TA) is the common histologic hallmark of CTD, which is the primary cause of long-term allograft loss. Cytomegalovirus (CMV) infection is one of the alloantigen-independent factors associated with increased risk for the development of TA. The role of CMV infection in the proces of TA development has been studied after human solid organ transplantation, but so far results are conflicting [8-12]. Using the aorta transplant model in rats, we and others showed that Rat Cytomegalovirus (RCMV) infection results in enhanced perivascular inflammation [21-23] and TA [23-27], indicating that also in this animal model CMV modulates TA development. Several studies suggest that CMV enhances development of TA only when active $C M V$ infection and acute rejection are present simultaneously [30-32]. In the experimental transplant models, recipient rats generally are infected 1 day after transplantation, however, evidence showing requirement of simultaneous acute infection and rejection for enhanced TA is lacking.

Therefore, we determined the relation between timing of RCMV infection and TA development using the aortic transplant model in rats. Since our previous results suggest that CMV only enhance TA in aortic grafts in rat strain combinations with weak TA development [26], we first analyzed the kinetics of TA development in different donor/recipient combinations. Lew recipients developed weak TA 4 weeks after transplantation, and reached maximal neointima formation 24 weeks after engraftment. BN recipients, however, presented maximal neointima formation already 4 weeks after engraftment, indicating that Lew rats are 'low-reponders' whereas BN rats are 'high-responders' and this is in line with data reported by Geerling et al. [40]. Similar to the Lew strain, AO and WF recipients also presented with weak TA compared to $B N$ recipients. So far, it is unknown which exact factors determine TA responsiveness, however we recently reported that these factors are most likely encoded by recipient non-MHC determinants [41]. Differences in such factors might also explain the differences in TA development between the strains analyzed in this study. Similar genetically determined differences might actually also contribute to the variety in the incidence and severity of CTD and TA as observed among the human transplant recipient population.

Since the Lew strain showed smallest TA development 4 weeks after transplantation, we used the $\mathrm{BN}$-to-Lew strain combination to study the effect of timing of RCMV infection on enhanced TA development. Only infection 1 day after transplantation resulted in enhanced neointima formation, indicating that indeed active infection and the developing acute rejection response should be present simultaneously to get enhanced neointima formation. Although we did not include histological analysis to characterize the rejection response in this study, it has been shown by others that, using the same strain combination, the rejection response starts to develop (appearance of invading CD8 $\mathrm{T}$ cells and macrophages in the adventitia) within the first week after engraftment [42]. Our data suggest that synergistic effects of RCMV infection on the developing alloresponse shortly after 
transplantation is the underlyits. N MV enhanced TA development.

In clinical organ trans, mary CMV infection after transplantation of a seropucive donor in a seronegative recipient increases the risk for $C T D$ and $T A[A 3,44]$. To mimick this situation, transplantation of a graft from an infected donor inco an uninfected recipient was performed. However, unexpectedly, infection of the donor 3 weeks before transplantation did not result in increased neointima formation. Subsequent analysis of donor aortic tissue by RCMV specific immunohistochemistry, plaque-assay and RCMVspecific PCR revealed however that 3 weeks p.i. no virus is present anymore in aortic tissue and this explains the observation that grafts retrieved from a chronically infected donor do not develop enhanced TA after transplantation. The course of RCMV infection can be divided in 3 distinct phases: acute phase (1-2 weeks p.i.), chronic phase (3-12 weeks p.i.) and latent phase (>12 weeks p.i.) $[33,35]$. In the acute phase several internal organs can be infected (e.g., kidney, liver, heart), whereas in the chronic phase infectious virus can only be detected in the salivary glands. Indeed, the donor salivary glands contained infectious virus 3 weeks p.i.. In contrast to aortic (and cardiac) allografts, however, kidney and lung allografts can effectively transfer virus to the recipient rats, also in the chronic phase of infection $[45,46]$. Even in the latent phase, kidney allografts have been shown to effectively transfer RCMV to the host [37]. Whether or not organs are able to transfer RCMV after transplantation might be related to the number of infected monocytes present in the respective organs. Also polymorphonuclear cells (PMN's) should be mentioned in this respect, since we recently showed that also PMN's can efficiently disseminate RCMV in vitro and in vivo [47]. To test dissemination of RCMV by aortic allografts in the acute phase of infection, al!ografts were transplanted 5 and 10 days p.i.. Although plaque-assay and nested PCR analysis confirmed presence of virus in aortic tissue and allografting resulted in systemic infection of virtually all recipients, the development of TA was not enhanced. A possible explanation is that the viral load is not sufficient during the acute rejection episode to enhance the development of TA. Alternatively, the acute infection phase is somewhat delayed after transplantation of an infected aortic allograft compared to intraperitoneal administration of high dosages of RCMV. In this situation, acute rejection and acute infection are not present simultaneously and consequently, RCMV does not enhance TA development.

In order to confirm our results on RCMV-enhanced TA in the BN-to-Lew combination, similar experiments were performed in two other 'weak TA' combinations: PVG-to-AO and DA-to-WF.

In both strain combinations, however, RCMV infection did not result in enhanced neointima formation. This was unexpected since the effect of RCMV on TA development after aortic allografting was for the first time described in the DA-to-WF rat strain combination by Lemström et al. [25]. In our attempt to reproduce these data, however, RCMV infection did not result in enhanced neointima formation. Although we used the same RCMV strain (Maastricht strain), we were not able to reproduce the data as described previously. Possibly, minor genetic differences between the rats used in our study and the 
rats used in studies described by Lemström et al. may account for this. In addition, differences in the microbiological status of the rats used in the different studies may also have influenced the experimental outcome. Caution is therefore warranted if designing experiments to dissect the pathogenesis of enhanced TA after allogeneic transplantation.

In conclusion, this study shows that the development of TA after allogeneic aorta transplantation differs between different rats strains, suggesting the existence of genetic predisposition for TA. RCMV infection enhances the development of TA only when active RCMV infection and the developing acute rejection response are present simultaneously, favouring synergy between the alloreponse and CMV infection as the underlying mechanism. This RCMV effect, however, cannot be generalized, indicating that obviously there are more factors than timing of infection and recipient TA responsiveness that determine whether RCMV will enhance TA after transplantation.

\section{Acknowledgments}

This work was supported by grants from the Dutch Kidney Foundation (C94.1421), the J.K. de Cock-stichting (JKDCS 98-29), and the University Medical Center Groningen. The authors thank Peter Kelderman and Ming Yin for help with aorta transplantation. 


\section{References}

1. Azuma H. Tilney NL. Chronic graft rejection. Curr Opin Immunol 1994; 6: 770.

2. Kouwenhoven EA, IJzermans JN. de Bruin RW. Etiology and pathophysiology of chronic transplant dysfunction. Transpl int 2000; 13: 385.

3. Hillebrands JL, Rozing J. Chronic transplant dysfunction and transplant arteriosclerosis: new insights into underlying mechansisms. Exp Rev Mol Med 2003; 13 January, 2003,

4. Libby P, Pober JS. Chronic rejection. Immunity 2001; 14: 387.

5. Hosenpud JD, Bennett LE, Keck BM, Boucek MM, Novick RJ. The Registry of the International Society for Heart and Lung Transplantation: eighteenth Official Report-2001. J Heart Lung Transplant 2001; 20: 805.

6. Costanzo MR, Naftel DC, Pritzker MR et al. Heart transplant coronary artery disease detected by coronary angiography: a multiinstitutional study of preoperative donor and recipient risk factors. J Heart Lung Transplant 1998; 17: 744.

7. 7. Hosenpud JD, Bennett LE, Keck BM. Fiol B, Boucek MM, Novick RJ. The registry of the International Society for Heart and Lung Transplantation: fifteenth official report-1998. J Heart Lung Transplant 1998; 17: 656.

8. Grattan MT, Moreno-Cabral CE, Starnes VA, Oyer PE, Stinson EB, Shumway NE.

Cytomegalovirus infection is associated with cardiac allograft rejection and atherosclerosis. JAMA 1989; 261: 3561

9. Almond PS, Matas A, Gillingham K et al. Risk factors for chronic rejection in renal allograft recipients. Transplantation 1993; 55: 752.

10. Cappel $R$, Hestermans $O$, Toussaint $C$ et al. Cytonegalovirus infection and graft survival in renal graft recipients. Arch Virol 1978; 56: 149.

11. Danesh J. Coronary heart disease, Helicobacter pylori, dental disease, Chlamydia pneumoniae, and cytomegalovirus: meta-analyses of prospective studies. Am Heart J 1999; 138: $5434-5437$.

12. Weimar W, Balk AH, Metselaar HJ, Mochtar B, Rothbarth PH. On the relation between cytomegalovirus infection and rejection after heart transplantation. Transplantation 1991; 52: 162.

13. Valantine HA, Gao SZ, Menon SG et al. Impact of prophylactic immediate posttransplant ganciclovir on development of transplant atherosclerosis: a post hoc analysis of a randomized, placebo-controlled study. Circulation 1999; 100:61.

14. Merigan TC, Renlund $\mathrm{DG}$, Keay $\mathrm{S}$ et al. A controlled trial of ganciclovir to prevent cytomegalovirus disease after heart transplantation. N Engl J Med 1992; 326: 1182.

15. Lemström K, Koskinen P, Krogerus L, Daemen M, Bruggeman C, Häyry P. Cytomegalovirus antigen expression, endothelial cell proliferation, and intimal thickening in rat cardiac allografts after cytomegalovirus infection. Circulation 1995; 92: 2594.

16. Kloover JS, Soots AP, Krogerus LA et al. Rat cytomegalovirus infection in kidney allograft recipients is associated with increased expression of intraceliular adhesion molecule-1 vascular adhesion molecule-1, and their ligands leukocyte function antigen-1 and very late antigen-4 in the graft. Transplantation 2000; 69: 2641.

17. Martelius T, Krogerus L, Höckerstedt K, Mäkisalo H, Bruggeman C, Lautenschlager I. CMV causes bile duct destruction and arterial lesions in rat liver allografts. Transplant Proc 1997; 29: 796.

18. Lemstrom K, Kallio $E$, Krebs R, Bruggeman C, Hayry P, Koskinen P. Cytomegalovirus infection accelerates obliterative bronchiolitis of rat tracheal allografts. Transpl Int 1996; 9 Suppl 1: S221-5222.

19. Streblow DN, Kreklywich C, Yin Q et al. Cytomegalovirus-mediated upregulation of chemokine expression correlates with the acceleration of chronic rejection in rat heart transplants. J Virol 2003; 77: 2182.

20. Mennander A, Tiisala S, Halttunen J, Yilmaz S, Paavonen T, Häyry P. Chronic rejection in rat aortic allografts: an experimental model for transplant arteriosclerosis. Arterioscler Thromb 1991; 11: 671 .

21. Koskinen P, Lemström K, Bruggeman C, Lautenschlager I, Häyry P. Acute cytomegalovirus infection induces a subendothelial inflammation (endothelialitis) in the allograft vascular wall. A possible linkage with enhanced allograft arteriosclerosis. Am J Pathol 1994; 144: 41.

22. Li F. Grauls G, Yin M. Bruggeman CA. Correlation between the intensity of cytomegalovirus infection and the amount of perivasculitis in aortic allografts. Transpl Int 1996; 9: S340-S344. 
23. Lemström K. Aho PT. Bruggeman CA. Häyry P. Cytomegalovirus infection enhances mRNA expression of platelet-derived growth factor-BB and transforming growth factor-pit in rat aortic allografts: possible mechanism for cytomegalovirus- enhanced graft arteriosclerosis. Arterioscler Thromb 1994: 14: 2043.

24. Lemström KB, Bruning JH, Bruggeman CA et al. Cytomegalovirus infection - enhanced allograft arteriosclerosis is prevented by DHPG prophylaxis in the rat. Circulation 1994; 90 : 1969.

25. Lemström KB, Bruning JH. Bruggeman CA, Lautenschlager IT. Häyry P. Cytomegalovirus infection enhances smooth muscle cell proliferation and intimal thickening of rat aortic allografts. J Clin Invest 1993: 92: 549.

26. Li F, Yin M, van Dam JG, Grauls G, Rozing J, Bruggeman CA. Cytomegalovirus infection enhances the neointima formation in rat aortic allografts. Effect of major histocompatibility complex class I and class II antigen differences. Tiansplantation 1998; 65: 1298.

27. Bruning JH, Persoons M, Lemström K, Stals FS, De Clerca E, Br uggeman CA. Enhancement of transplantation-associated atherosclerosis by $C M V$, which can be prevented by antiviral therapy in the form of HPMPC. Transpl Int 1994; 7: 5365-5370.

28. Orloff SL, Streblow DN, Soderberg-Naucler $\mathrm{C}$ et al. Elimination of donor-specific alloreactivity prevents cytomegalovirus-accelerated chronic rejection in rat small bowel and heart transplants. Transplantation 2002; 73: 679.

29. Tikkanen JM, Kallio EA, Bruggeman CA, Koskinen PK, Lemstrom KB. Prevention of cytomegalovirus infection-enhanced experimental obliterative bronchiolitis by antiviral prophylaxis or immunosuppression in rat tracheal allografts. Am J Respir Crit Care Med 2001; 164: 672 .

30. Evans PC, Soin A, Wreghitt TG, Taylor CJ, Wight DG, Alexander GJ. An association between cytomegalovirus infection and chronic rejection after liver transplantation. Transplantation 2000; 69: 30 .

31. Humar A, Gillingham KJ, Payne WD, Dunn DL, Sutherland DE, Matas AJ. Association between cytomegalovirus disease and chronic rejection in kidney transplant recipients. Transplantation 1999; 68: 1879.

32. Helantera I, Koskinen P, Tornroth T, Loginov R, Gronhagen-Riska C, Lautenschlager I. The impact of cytomegalovirus infections and acute rejection episodes on the development of vascular changes in 6-month protocol biopsy specimens of cadaveric kidney allograft recipients. Transplantation 2003; 75: 1858.

33. Bruggeman CA, Meijer H, Dormans PH, Debie WM, Grauls GE, van Boven CP. Isolation of a cytomegalovirus-like agent from wild rats. Arch Virol 1982; 73: 231.

34. Bruggeman CA, Grauls $G$, van Boven CPA. Susceptibility of peritoneal macrophages to rat cytomegalovirus infection. FEMS Microbiol Lett 1985; 27: 263.

35. Bruggeman CA, Mijer H, Bosman F, van Boven CPA. Biology of rat cytomegalovirus infection. Intervirology 1985; 24: 1.

36. Bruggeman CA, Debie WM, Grauls G, Majoor G, van Boven CP. Infection of laboratory rats with a new cytomegalo-like virus. Arch Virol 1983; 76: 189.

37. Bruning $\mathrm{JH}$, Bruggeman $\mathrm{CA}$, van Boven $\mathrm{CP}$, Breda Vriesman PJ. Passive transfer of cytomegalovirus by cardiac and renal organ transplants in a rat model. Transplantation 1986; 41: 695 .

38. Bruning JH, Debie WH, Dormans PH, Meijer H, Bruggeman CA. The development and characterization of monoclonal antibodies against rat cytomegalovirus induced antigens. Arch Virol 1987; 94: 55.

39. Beuken $E$, Slobbe R, Bruggeman CA, Vink C. Cloning and sequence analysis of the genes encoding DNA polymerase, glycoprotein B, ICP18.5 and major DNA-binding protein of rat cytomegalovirus. J Gen Virol 1996; 77 (Pt 7): 1559.

40. Geerling RA, Ansari AA, LaFond-Walker AM, Baumgartner WA, Wesselingh S, Herskowitz A. Accelerated arteriosclerosis in aortic grafts: a role for cytokines in progressive intimal lesion development. Transplant Proc 1998; 30: 946.

41. Hillebrands JL, Klatter FA, Bruggeman CA, Rozing J. Development of transplant arteriosclerosis after allogeneic aorta transplantation in the rat: influence of recipient genotype. Transplant Proc 2001; 33: 324.

42. Plissonnier $D$, Nochy $D$, Poncet $P$ et al. Sequential immunological targeting of experimental arterial allograft. Transplantation 1995; 60: 414.

43. Van der Bij W, Speich R. Management of cytomegalovirus infection and disease after solidorgan transplantation. Clin Infect Dis 2001; 33 Suppl 1: S32-537. 
44. Emery VC. Prophylaxis for CMV should not now replace 9 emptive therapy in solid organ transplantation. Rev Med Virol 2001; 11: 83.

45. Bruning JH, Bruggeman CA, van Boven CP, Breda Vicsman P.J. Passive transfer of cytomegalovirus by cardiac and renal organ transplants in a rat model. Transplantation 1986; 41: 695

46. Yagyu K, Breda Vriesman PJ, Duijvestijn AM, Bruggeman CA. Steinhoff G. Reactivation of cytomegalovirus with acute rejection and cytomegalovirus infection with obliterative bronchiolitis in rat lung allografts. Transplant Proc 1993: 25: 1152.

47. Van der Strate BW, Hillebrands JL, Nijehoit SS et al. Dissemination of rat cytomegalovirus through infected granulocytes and monocytes in vitro and in vivo. J Virol 2003; 77: 11274. 


\section{CHAPTER 7}

\section{Summary and general discussion}




\section{Summary and general discussion}

Infections with human cytomegalovirus (HCMV) are very common, but in an immunocompetent host most infections occur without any symptoms (67). Only in an immunocompromised host, e.g. transplant recipients, fetuses or AIDS-patients, HCMV infection results in severe disease. CMV is species. specific, therefore rats infected with rat CMV (RCMV) and mice infected with murine CMV (MCMV) are often used as models for CMV infection in humans (9, 56). In chapter 1 an overview of literature on the course of infection and its pathology, the immune response to the infection and the viral escape mechanisms is given.

Infection with CMV occurs in different phases. In the acute phase of the infection, the virus is spread through the body and can be detected in many organs. In the chronic phase, the virus only replicates in the salivary glands and is excreted in the saliva (10). During the latent phase viral antigens can no longer be detected, but low amounts of viral DNA remain present in the host $(26,58)$. The virus is able to reactivate from its latent state if the immune system fails, e.g. after transplantation $(35,55)$. The exact mechanisms for reactivation are yet unknown. CMV infection is associated with abortion, congenital disorders, pneumonia, retinitis, atherosclerosis, venous thrombosis, restenosis, graft-versus-host disease (GVHD) and allograft rejection $(3,22,49,52,61,63)$.

In solid organ transplant recipients, the development of chronic rejection is still a complicating factor to long-term graft survival. In allografts the vessels develop so called transplant associated arteriosclerosis (TXAA), the main course for progressive deterioration of graft function $(39,45,47)$. The most common pathological manifestations of TXAA are perivascular inflammation and intimal thickening in the grafted organ $(11,23,46,47)$. Risk factors for the development of chronic rejection are cold ischemia, differences in the major histocompatibility complex (MHC) between donor and recipient, number of rejection episodes and CMV infection $(24,29)$. CMV infections in transplant recipients can occur by reactivation of latent virus from either the recipient or the donor organ, or by other infection routes such as blood transfusion.

Both the cellular and the humoral immune response play a role in the control of CMV infection, although the humoral immune response is often not able to prevent disease (19). The cellular immune response consists especially of CD8 ${ }^{+}$T cells, CD4" T cells and natural killer (NK) cells. Studies trying to identify the most important factor in the cellular immune response show that especially the before mentioned different cells are involved in the immune response; in the absence of one of the subsets of these cells, other subsets are sometimes able to take over their task $(34,41,54)$. In transplant recipients an increase in the number of CD8 T cells, CD4 T cells and NK cells in the allograft is suggested to be related to the risk of developing CMV disease $(38,46,48,66)$. These cells may cause damage to the graft, resulting in TXAA $(39,46,48)$.

Infection with CMV results in an increased production of many cytokines, chemokines and growth factors. The production of some of these 
factors is directly induced by the presence of virus particles in the cell, while others are produced upon stimulation by an infected cell. Some of the produced factors help to clear the virus or control the viral infection, but others have immunosuppressive effects and thereby support the survival of the virus. The increase in the factors may result in increased blood clothing, inflammation and cell growth. In this way, CMV-related diseases like chronic rejection or atherosclerosis may be induced $(2,17,71)$. Cytokines may therefore be useful as markers for the development of CMV-disease or CMV. related diseases. CMV infection is also able to induce many adhesion molecules involved in different steps of leukocyte adhesion and migration (16, $18,31,65,74)$. Expression of adhesion molecules on both leukocytes and endothelial cells is necessary to enable leukocytes to leave the blood stream and expression of adhesion molecules on other cells can facilitate the interaction between leukocytes and their target cells (12). This results in efficient destruction of the infected cells or, in case of organ transplantation, in rejection of the graft. Due to CMV infection, the expression of MHC class $\|$ molecules on surrounding endothelial cells is upregulated $(44,70,74)$, increasing the efficiency of viral clearance. In summary, CMV infection either directly or indirectly, increases the expression of many molecules involved in the different steps that lead to clearance of the virus. Due to the immune response, the surrounding tissue may be damaged, leading to CMV-related diseases. However, after an acute infection period some of the virus particles are able to go into hiding and remain present in the host cells. Therefore CMV also needs mechanisms to escape the immune system. The most well documented mechanisms involve the downregulation of $\mathrm{MHC}$ class I and II expression. $\mathrm{MHC}$ class II molecules are constitutively expressed on antigen presenting cells and their expression can be induced on endothelial and epithelial cells. The MHC class II molecules are necessary for the CD4' T cell response. Studies have revealed two mechanisms for the CMV-mediated block of inducible $M H C$ class II transcriptions, one mechanism occurs early after infection $(25,42)$ and one later after infection (50). The constitutive $M H C$ class II expression is downregulated by the HCMV US2 encoded protein (69). Apart from these mechanisms, cytokines are also believed to play a role.

Studies with MCMV and HCMV have shown that they are capable of inhibiting the presentation of antigenic peptides by MHC class I molecules, and thereby clearance of infected cells by CD8 ${ }^{*} \mathrm{~T}$ cells, in numerous ways (76). The HCMV US3 encoded protein prevents intracellular transport of MHC class I molecules from the ER $(1,33)$, while US2 and US11 encode proteins that cause rapid degradation of $\mathrm{MHC}$ class I molecules by dislocating the class I heavy chain from the ER to the cytosol, where they are degraded by the proteasome $(32,75)$. The protein encoded by US6 blocks translocation of peptides into the ER by TAP. As a consequence the MHC class 1 molecules no longer form stable complexes and are degraded (43). MCMV encodes at least three glycoproteins that affect the expression of class I MHC complexes. The protein encoded by the m152 gene prevents export of class I complexes from the post-ER/early Golgi $(40,78)$, while the gene product of m06 binds to the MHC complex and reroutes the complex to the lysosomal compartment where it is degraded (60). A third product, the m04-encoded gp34, associates with 
the properly folded MHC class I molecil. ell

membrane, where it is believed to act as a $, 1,1 \mathrm{t}$

prevents recognition by $T$ cells and inhibits $M k$ cel! a

Nicelis

selectively kill targets that lack expression of MHC class I, and downregutation of MHC class I expression upon CMV infection places the infected cells at risk for NK-mediated lysis. Another mechanism to prevent attack by NK cells is the expression of virus- encoded MHC class I homologues by the genes UL18, m144 and $\mathrm{r} 144(5,7,14,21)$. The HCMV UL18 gene product binds to LIR-1, that results in an inhibitory signal in the LIR-1 expressing NK cells, B cells and T cells $(15,72)$. Apart from these mechanisms, the HCMV-encoded gpUL40 enhances the surface expression of human leukocyte antigen-E (HLA-E), a nonclassical MHC class I molecule, that can protect target cells from NK cell lysis $(13,68)$.

The genomes of HCMV, MCMV and RCMV all encode several genes that are capable of encoding G-protein coupled receptors (GCRs), receptors that function in signal transduction through cell membranes. Deletion mutants show a decrease in replication of the virus or mortality of the host, but the exact function of these genes is still unknown (6). The group of CMVs also encodes for homologues of chemokines, that may ensure the active recruitment of inflammatory cells during CMV infection, thereby providing efficient dissemination of the virus $(21,53)$.

In chapter 2 the effect of acute RCMV infection on the composition of leukocyte subsets in the peripheral blood of both immunocompetent and immunosuppressed rats was described. Using flow cytometry, special attention was paid to NK cells and T cells, known to be involved in the control of viral infections. In immunocompetent rats, infection caused a small increase in NK cells and a large increase in CD8 ${ }^{\circ} \mathrm{T}$ cells, whereas infection in immunosuppressed rats caused a marked increase in NK cells and a small increase in $C D 8^{+} T$ cells. These effects are similar to those in humans and mice. The fact that there is a difference in immuneresponse between the infected and mock-infected animals shows that in both immunosuppressed and immunocompetent animals the immune escape mechanisms fail to prevent the immunesystem from reacting to the virus. In the immunosuppressed rats, the increase in $C D 8^{+} T$ cells consisted of $T$ cells with reduced expression of both CD8 and TCR. This phenomenon is characteristic of anergic cells, cells which are unresponsive to antigen $(8,62,77)$. The presence of these cells suggests that RCMV interferes with the costimulatory signals upon antigen presentation of viral antigens (64). The effects found in the peripheral blood of the immunosuppressed rats can in general also be detected in the internal organs. The salivary gland, however, seems to escape additional NK cell infiltration upon RCMV infection. This could explain the long persistence of infectious virus in this organ.

In chapter 3 the question was answered if such a mechanism of CD8 and TCR downregulation might also be induced by HCMV infection. To study this, it was necessary to obtain blood from immunosuppressed, acutely infected patients. Therefore, we used peripheral blood of CMV seronegative patients receiving a kidney from a seronegative (control group) or from a seropositive donor. Of the latter group, only the patients undergoing acute 
CMV infection were included (experimental group). In this group, the development of acute CMV infection resulted in an increased NK cell number and activation of both CD4 and CD8. T cells, as determined by HLAexpression. An increase in the number of CD8 and CD4' $T$ cells could not be detected. In the infected patients, an aberrant CD8 T cell subset with decreased expression of both CD8 and TCR appeared in the infected patients. The number of CD8 ${ }^{\text {low }}$ TCR $^{\text {low }}$ cells was small $(0.5$ to $9.5 \%)$ compared to the immunosuppressed rat (up to $40 \%$ ). This might be due to the differences in immunosuppression regimen used. The size of the subpopulation of CD8 $T$ cells in the kidney transplant patients is, however, positively correlated with the viral load as detected with the pp65 antigenemia assay. This indicates that a productive CMV infection is necessary to result in the generation of CD8 ${ }^{\text {low }} T$ cells. The presence of a possibly anergic CD8 ${ }^{\text {low }}$ subpopulation of $T$ cells suggests that the virus has an extra way of escaping the immune response of its host, by interfering with the costimulatory signals upon antigen presentation.

In chapter 4 the effect of RCMV infection on the expression of $M H C$ class I complexes is described. We detected that RCMV infection induces downregulation of the expression of MHC class I complexes at the cell surface of rat fibroblasts. In contrast to MCMV and HCMV, this effect was temporarily and could be seen most prominent at 12 hours p.i.. At 24 hours p.i. the expression level of MHC class I molecules was normalized. Biochemical experiments reveal that RCMV infection does not interfere with the biosynthesis or stability of MHC class I molecules, but causes intracellular retention of MHC class I molecules. This mechanism is also used by other herpesviruses as a mechanisms for immune evasion. Our data suggest that RCMV may use a m152 or US3-like gene product to prohibit export of class I complexes from the ER/cis-Golgi compartment or inhibits TAP with a US6-like gene product. The RCMV genome contains several m152-like genes, and the most obvious homologue has been evaluated, but had no effect on MHC class 1 downregulation. The presence of $\mathrm{MHC}$ class I expression influencing genes may be subject of future studies.

The reason why there are so many viral proteins involved in immune evasion and the fact that they sometimes even seem to compete $(59,73)$ is not yet clear. Despite the broad range of immune-evasion genes, the virus is not (always) completely hidden from the immune response $(4,28)$. If the virus becomes latent in many cell types, a broad spectrum of immune evasion strategies may be necessary. However, for spreading of the virus an active infection and the presence of an immune response may be necessary. In this light it is not surprising that CMV uses different strategies in different stages of the infection, in different cell types or tissues and in a genetically diverse population $(51,57)$.

Chapter 5 and 6 show the effect of CMV infection on allograft rejection. In chapter 5 the effects of $C M V$ infection and prolonged cold ischemia $(\mathrm{Cl})$ and the combination of both on the progression of chronic rejection were investigated. At the same time a more detailed insight in their effects on the expression of adhesion molecules was obtained. Therefore a rat transplantation model was used. Lewis recipients of renal allografts (with 
or without $\mathrm{Cl}$ ) from $\mathrm{MHC}$-incompatible Brown Norway rats weo med rat CMV or left uninfected. The study demonstrated that CMV infoctori and Cl had additive effects on deterioration of the function of renal allografts. However, the histologic effects were not the same for CMV infection and $\mathrm{Cl}$. CMV infection tended to induce vascular changes (intimal proliferation and glomerular sclerosis), while $\mathrm{Cl}$ increased interstitial fibrosis, tubular atrophy and glomerular sclerosis. Both CMV infection and $\mathrm{Cl}$ also resulted in a different pattern in the expression of adhesion molecules. CMV infection led to an increase in the presence of $\mathrm{CD} 49 \mathrm{~d}$ positive leukocytes while $\mathrm{Cl}$ increased the expression of CD18 on leukocytes, of CD54 and CD62P on tubules and of $\mathrm{CD} 44$ on epithelium. The combination of $\mathrm{CNV}$ infection and $\mathrm{Cl}$ resulted in an additional effect on the expression of the adhesion molecules. The expression of MHC class II antigens on endothelial cells was increased only by CMV infection. The results of this study suggest that special attention should be paid to the CMV-infected recipient receiving an ischemic injured kidney allograft, since an accelerated development of chronic rejection may occur in this situation. CMV infection accelerates the renal graft deterioration probably through pathways different from ischemia-reperfusion injury. The knowledge about the expression of adhesion molecules due to CMV infection and $\mathrm{Cl}$ may be useful to judge the cause of rejection in biopsies and to develop new therapeutic approaches for the control and prevention of graft function.

In chapter 6 we studied the severity of TXAA development with or without RCMV infection, in different donor / recipient combinations. Moreover, the relation between timing of infection and enhanced development of TXAA was studied. Without CMV infection, the development of TXAA differed strongly between the different strains used. Lewis, AO and WF recipients only developed weak TXAA. In contrast, BN recipients showed a four-fold stronger development of TXAA. Hillebrands et al reported that the rate of development of TXAA is for a major part determined by the recipient genotype (27). Such differences might also explain the differences found in this study and among human transplant recipients. Infection with RCMV in Lewis recipients resulted in enhanced TXAA, only when the Lewis recipients were infected 1 day after transplantation. These data are in agreement with recent studies in man, that show that CMV plays a role in the pathogenesis of chronic rejection, only in the presence of acute rejection $(20,30)$. Moreover, these results suggest synergistic effects of CMV infection on the developing alloresponse as the underlying mechanism for CMV-enhanced development of TXAA. These data could, however, not be detected in any of the other strain combinations used. The fact that the effect of RCMV on chronic rejection cannot be generalized, suggest that there are more factors than time of infection and recipient-genotype determining RCMV enhanced development of TXAA.

When the donor BN rats were infected 5 or 10 days before transplantation, transmission of the virus to the recipients Lewis rats could be detected, but CMV-enhanced development of TXAA was not observed. A possible explanation might be that the viral load during the acute rejection episode is not sufficient to enhance the development of TXAA. Alternatively, 
the acute infection phase is somewhat delayed after transplantation of an infected aortic allograft, compared to intraperitoneal administration of high dosages of RCMV. Since similar effects have been detected in patients, we conclude that when acute rejection and acute infection are not present simultaneously, RCMV does not enhance the development of TXAA.

Our results show that the effect of CMV infection on TXAA depends on the recipient genotype, the differences between donor and recipient, the time period of cold ischemia and the moment of infection e.g. the presence of acute rejection. Since these factors all involve the complex mechanisms of the immune system, it is very likely that other factors (e.g. immunosuppressive drugs, other infections, antiviral agents) influencing the immunesystem also have an effect on CMV-induced chronic rejection. Determining the effect of $C M V$ infection on chronic rejection using data obtained from studies in patients may therefore be very difficult, since there are many factors that have to be examined. Animal models seem to be the best method to determine all factors that influence chronic rejection, leading to detailed understanding of allograft rejection. In the clinical situation, however, not all information can and will be translated into treatment regimens. It may still be of interest to further investigate the effects of acute rejection and acute infection on chronic rejection. If more information is available about the combination and especially the effect of time intervals between infection and rejection, this might be useful in the clinical situation concerning prophylactic therapy and immunosuppression regimen. 


\section{References}

1. Ahn, K, A Angulo, P Ghazel, PA Peterson, Y Yang, and K Fruh. 1996. Human cytomegalovirus inhibits antigen presentation by a sequential multistep process. Proc Natl Acad Sci USA. 93:10990-5.

2. Alcami, J, T Barzu, and S Michelson. 1991. Induction of an endothelial cell growth factor by human cytomegalovirus infection of fibroblasts. J Gen Virol. 72:2765-70.

3. Almond, P.S, A Matas, K Gillingham, D.L Dunn, W.D Payne, P Gores, R Gruessner, and J.S Najarian. 1993. Risk factors for chronic rejection in renal allograft recipients. Transpl. 55:752-6.

4. Arase, H, ES Mocarski, AE Campbell, AB Hill, and LL Lanier. 2002. Direct recognition of cytomegalovirus by activating and inhibitory NK cell receptors. Science. 296:1323-6.

5. Beck, S, and BG Barrell. 1988. Human cytomegalovirus encodes a glycoprotein homologous to MHC class-I antigens. Nature. 331:269-72.

6. Beisser, PS, G Grauls, CA Bruggeman, and C Vink. 1999. Deletion of the R78 G proteincoupled receptor gene from rat cytomegalovirus results in an attenuated, syncytiuminducing mutant strain. J Virol. 73:7218-30.

7. Beisser, PS, JS Kloover, GE Grauls, MJ Blok, CA Bruggeman, and C Vink. 2000. The r144 major histocompatibility complex class I-like gene of rat cytomegalovirus is dispensable for both acute and long-term infection in the immunocompromised host. J Virol. 74:1045-50.

8. Bellgrau, D, and AC Lagarde. 1990. Cytotoxic T-cell precursors with low-level CD8 in the diabetes-prone Biobreeding rat: Implications for generation of an autoimmune T-cell repertoire. Proc Natl Acad Sci USA. 87:313-7.

9. Bruggeman, CA, FL Li, and FS Stals. 1995. Pathogenicity: Animal models. Scand. J Infect Dis. 99:43-50.

10. Bruggeman, CA, H Meijer, F Bosman, and CP Van Boven. 1985. Biology of rat cytomegalovirus infection. Intervirol. 24:1-9.

11. Bruggeman, CA, and JG Van Dam. 1998. Role of cytomegalovirus infection in transplant arteriosclerosis, vol. 21. Karger, Basel.

12. Butcher, EC. 1991. Leukocyte-endothelial cell recognition: three (or more) steps to specificity and diversity. Cell. 67:1033-6.

13. Cerboni, C, M Mousavi-Jazi, A Linde, K Soderstrom, M Brytting, B Wahren, K Karre, and E Carbone. 2000. Human cytomegalovirus strain-dependent changes in NK cell recognition of infected fibroblasts. J Immunol. 164:4775-82.

14. Chapman, TL, and PJ Bjorkman. 1998. Characterization of a murine cytomegalovirus class I Major Histocompatibility Complex (MHC) homolog: comparison to MHC molecules and to the human cytomegalovirus MHC homolog. J Virol. 72:460-6.

15. Chapman, TL, AP Heikema, and PJ Bjorkman. 1999. The inhibitory receptor LIR-1 uses a common binding interaction to recognize class I MHC molecules and the viral homolog UL18. Immunity. 11:603-13.

16. Craigen, JL, and JE Grundy. 1996. Cytomegalovirus induced up-regulation of LFA-3 (CD58) and ICAM-1 (CD54) is a direct viral effect that is not prevented by Ganciclovir or Foscarnet treatment. Transplantation. 62:1102-8.

17. Craigen, JL, KL Yong, NJ Jordan, LP MacCormac, J Westwick, AN Akbar, and JE Grundy. 1997. Human cytomegalovirus infection up-regulates interleukin-8 gene expression and stimulates neutrophil transendothelial migration. Immunology. 92:138-45.

18. Dengler, TJ, MJ Raferty, M Werle, R Zimmerman, and G Schionrich. 2000. Cytomegalovirus infection of vascular cells induces expression of pro-inflammatory adhesion molecules by paracrine action of secreted interleukin-1beta. Transplantation. 69:1160-8.

19. Dix, RD, C Cray, and SW Cousins. 1997. Antibody alone does not prevent exeperimental cytomegalovirus retinitis in mice with retrovirus-induced immunodeficiency (MAIDS). Ophtalmic Res. 29:381-92.

20. Evans, PC, A Soin, TG Wreghitt, CJ Taylor, DGD Wight, and GJM Alexander. 2000. An association between cytomegalovirus infection and chronic rejection after liver transplantation. Transplantation. 69:30-5.

21. Farrell, HE, MA Degli Esposti, and NJ Davis Poynter. 1999. Cytomegalovirus evasion of natural killer cell responses. Immunol Rev. 168:187-97.

22. Fietze, E, S Prosch, P Reinke, J Stein, WD Docke, G Staffa, S Loning, S Devaux, F Emmrich, $R$ Von Baehr, DH Kruger, and HD Volk. 1994. Cytomegalovirus infection in transplant recipients. Transplantation. 58:675-80. 
23. Grattan, MT, CE Moreno-Cabral, VA Starnes, PE Oyer, EB Stinson, and NE Shurnway. 1989. Cytomegalovirus infection is associated with cardiac allograft rejection and atherosclerosis. JAMA. 261:3561-66.

24. Hayry, P, H Isoniemi, S Yilmaz, A Mennander, K Lemstrom, A Raisanen-Sokolowski, P Koskinen, J Ustinov, I Lautenschlager, E Taskinen, L Krogerus, P Aho, and T Paavonen. 1993. Chronic allograft rejection. Immunol Rev. 134:33 - 81.

25. Heise, MT, M Connick, and HW Virgin IV. 1998. Murine cytomegalovirus inhibits interferon gamma-induced antigen presentation to CD4 cells by macrophages via regulation of expression of Major Histocompatibility Complex class II-associated genes. J Exp Med. 187:1037-46.

26. Hendrix, MGR, E Beuken, RL Slobbe, and CA Bruggeman. 1996. Detection and sequence analysis of the Major Immediate Early and PP150 gene of latent human cytomegalovirus in spleen, liver and kidney tissues of trauma victims. J Med Virol. 50:193-7.

27. Hillebrands, JL, FA Klatter, CA Bruggeman, and J Rozing. 2001. Development of transplant arteriosclerosis after allogeneic aorta transplantation in the rat: influence of recipient genotype. Transpl Proc. 33:324 - 5.

28. Holtappels, R, NKA Grzimek, CO Simon, D Thomas, D Dreis, and MJ Reddehase. 2002. Processing and presentation of murine cytomegalovirus pORFm164-derived peptide in fibroblasts in the face of all viral immunosubversive early gene functions. J Virol. 76:604453.

29. Hosenpud, JD, LE Bennet, BM Keck, B Fiol, MM Boucek, and RJ Novick. 1998. The registry of the International Society for Heart and Lung Transplantation: fifteenth official report. J Heart Lung Transplant. 17:656 - 68.

30. Humar, A, KJ Gillingham, WD Payne, DL Dunn, DER Sutherland, and AJ Matas. 1999. Association between cytomegalovirus disease and chronic rejection in kidney transplant recipients. Transplantation. 68:1879-83.

31. Ito, M, M Watanabe, T Ihara, H Kamiya, and M Sakurai. 1995. Increased expression of adhesion molecules (CD54, CD29 and CD44) in fibroblasts infected with cytomegalovirus. Microbiol Immunol. 39:129-33.

32. Jones, TR, and L Sun. 1997. Human cytomegalovirus US2 destabilizes Major Histocompatibility Complex class I heavy chains. J Virol. 71:2980-9.

33. Jones, TR, EJHJ Wiertz, L Sun, KN Fish, and JA Nelson. 1996. Human cytomegalovirus US3 impairs transport and maturation of major histocompatibility complex Class I heavy chains. Proc Natl Acad Sci USA. 93:11327-33.

34. Jonjic, S, I Pavic, P Lucin, D Rukavina, and UH Koszinowski. 1990. Efficacious control of cytomegalovirus infection after long-term depletion of CD8+ T lymphocytes. J Virol. 64:545764.

35. Jordan, MC, and V Mar. 1982. Spontaneous activation of murine cytomegalovirus form murine spleen explants. Role of lymphocytes and macrophages in release and replication of virus. J Clin Invest. 70:762-8.

36. Kavanagh, DG, UH Koszinowski, and AB Hill. 2001. The murine cytomegalovirus immune evasion protein $\mathrm{m} 4 / \mathrm{gp} 34$ forms biochemically distinct complexes with class I MHC at the cell surface and in a pre-Golgi compartment. J Immunol. 167:3894-902.

37. Kleijnen, MF, JB Huppa, P Lucin, AE Campbell, UL Koszinowski, AB Hill, and HL Ploegh. 1997. A mouse cytomegalovirus glycoprotein, pg34, forms a complex with folded class I MHC molecules in the ER which is not retained but is transported to the cell surface. EMBO J. 16:685-94.

38. Koskinen, P, K Lemstrom, C Bruggeman, I Lautenschlager, and P Hayry. 1994. Acute cytomegalovirus infection induces a subendothelial inflammation (endothelialitis) in the allograft vascular wall. A possible linkage with enhanced allograft arteriosclerosis. Am J Pathol. 144:41-50.

39. Koskinen, P, K Lemstrom, H Bruning, M Daemen, C Bruggeman, and P Hayry. 1995. Cytomegalovirus infection induces vascular wall inflammation and doubles arteriosclerotic changes in rat cardiac allografts. Transplant Proc. 27:574-5.

40. Krmpotic, A, M Messerle, I Crnkovic-Mertens, B Polic, S Jonjic, and UH Koszinowski. 1999. The immunoevasive function encoded by the mouse cytomegalovirus gene m152 protects the virus against T cell control in vivo. J Exp Med. 190:1285-95.

41. Lathbury, LJ, JE Allan, GR Shellam, and AA Scalzo. 1996. Effect of host genotype in determining the relative roles of natural killer cells and $T$ cells in mediating protection against murine cytomegalovirus infection. J Gen Virol. 77:2605-13. 
42. Le Roy, E, A Muhlethater Mottet, C Davrinche, B Mach, and JL Davigno. 1999. Escape of human cytomegalovirus from HLA-DR-restricted CD4(+) T-cell response is mediated by repression of gamma interferon-induced class $\|$ transactivator expression. J Virol. 73:6582-9.

43. Lehner, PJ, JT Karttunen, GWG Wilkinson, and P Cresswell. 1997. The human cytomegalovirus US6 glycoprotein inhibits transporter associated with antigen processingdependent peptide translocation. Immunol. 74:6904-9.

44. Lemstrom, KB, JH Bruning, CA Bruggeman, PK Koskinen, PT Aho, 5 Yilmaz, IT Lautenschlager, and PJ Hayry. 1994. Cytomegalovirus infection-enhanced allograft arteriosclerosis is prevented by DHPG prophylaxis in the rat. Circulation. 90:1969-73.

45. Lemstrom, KB, JH Bruning, CA Bruggeman, IT Lautenschlager, and PJ Hayry. 1993. Cytomegalovirus infection enhances smooth muscle cell proliferation and intimal thickening of rat aortic allografts. J Clin invest. 92:549-58.

46. Li, F, G Grauls, JG van Dam, M Yin, and CA Bruggeman. 1997. Cytomegalovirus infection enhances the perivascular inflammatory reaction in transplanted aortic allografts. Cardiovasc Engin. 2:207-14.

47. Li, F, M Yin, JG Van Dam, G Grauls, J Rozing, and CA Bruggeman. 1998. Cytomegalovirus infection enhances the neointima formation in rat aortic allografts. Transplantation. 65:1298-304.

48. Martelius, T, L Krogerus, K Hockerstedt, C Bruggeman, and I Lautenschlager. 1998. Cytomegalovirus infection is associated with increased inflammation and severe bile duct damage in rat liver allografts. Hepatology. 27:996-1002.

49. Melnick, JL, E Adam, and ME DeBakey. 1995. Cytomegalovirus and atherosclerosis. Bioassays. 17:899-903.

50. Miller, DM, BM Rahill, JM Boss, MD Lairmore, JE Durbin, WJ Waldman, and DD Sedmak. 1998. Human cytomegalovirus inhibits Major Histocompatibility Complex class II expression by disruption of the Jak/Stat pathway. J Exp Med. 187:675-83.

51. Mocarski Jr., ES. 2002. Immunomodulation by cytomegaloviruses: manipulative strategies beyond evasion. Trends in Microbiologie. 10:332-9.

52. Pass, RF, S Stagno, GJ Myers, and CA Alford. 1980. Outcome of symptomatic congenital cytomegalovirus infection: results of long-term longitudinal follow-up. Pediatrics. 66:758-62.

53. Penfold, ME, DJ Dairaghi, GM Duke, N Saederup, ES Mocarski, GW Kemble, and TJ Schall. 1999. Cytomegalovirus encodes a potent alfa chemokine. Proc Natl Acad Sci USA. 96:983944.

54. Podlech, J, R Holtappels, N Wirtz, HP Steffens, and MJ Reddehase. 1998. Reconstitution of CD8 T cells is essential for the prevention of multiple-organ cytomegalovirus histopathology after bone marrow transplantation. J Gen Virol. 79:2099-104.

55. Porter, KR, DM Starnes, and JD Hamilton. 1985. Reactivation of latent murine cytomegalovirus from kidney. Kidney Int. 28:922-5.

56. Price, $P$, and SD Olver. 1996. Animal models of human immunopathological disease. Syndromes induced by Cytomegalovitus infection. Clin immunol immunopath. 80:215-24.

57. Raftery, MJ, M Schwab, SM Eibert, Y Samstag, H Walczak, and G Schonrich. 2001. Targeting the functions of mature dendritic cells by human cytomegalovirus: A multilayered viral defense strategy. Immunity. 15:997-1009.

58. Reddehase, MJ, KJ Podlech, and NKA Grzimek. 2002. Mouse models of cytomegalovirus latency: overview. J Clin Virol. 25:523-36.

59. Rehm, A, A Engelsberg, D Tortorella, Korner, IJ, I Lehnmann, HL Ploegh, and UE Hopken. 2002. Human cytomegalovirus gene product US2 and US11 differ in their ability to attack Major Histocompatibility Class I heavy chains in dendritic cells. J Virol. 76:5043-50.

60. Reusch, U, W Muranyi, P Lucin, HG Burgert, H Hengel, and UH Koszinowski. 1999. A cytomegalovirus glycoprotein re-routes $M H C$ class I complexes to lysosomes for degradation. EMBO J. 18:1081-91.

61. Rubin, RH. 1990. Impact of cytomegaloviris infection on organ transplant recipients. Rev Infect Dis. 12:S754-66.

62. Schonrich, G, U Kalinke, F Momburg, M Malissen, AM Schmitt-Verhulst, B Malissen, GJ Hammerling, and B Arnold. 1991. Down-regulation of T cell receptors on self-reactive T cells as a novel mechanism for extrathymic tolerance induction. Cell. 65:293-304.

63. Schooley, RT. 1990. Cytomegalovirus in the setting of infection with human immunodeficiency virus. Rev Infect Dis. 12:5811-9.

64. Schwartz, RH. 1996. Models of T cell anergy: is there a common molecular mechanism? J. Exp. Med. 184:1-8. 
65. Sedmak, DD, DA Knight, NC Vook, and JW Waldman. 1994. Divergent patterns of ELAM-1, ICAM-1, and VCAM-1 expression on cytomegalovirus-infected endothelial cells. Transplantation. 58:1379-85.

66. Steinmuller, C, G Steinhoff, D Bauer, XM You, H Denzin, G Franke-Ullmann, B Hausen, CA Bruggeman, TOF Wagner, ML. Lohmann-Matthes, and A Emmendorffer. 1997. Analysis of leukocyte activation during acute rejection of pulmonary allografts in non-infected and cytomegalovirus-infected rats. J Leukocyte Biol. 61:40-9.

67. Sterner, G, BO Agell, B Wahren, and A Espmark. 1970. Acquired cytomegalovirus infection in older children and adults. Scand J Infect Dis. 2:95-103.

68. Tomasec, P, VM Braus, C Rickards, MB Powell, BP McSharry, S Gadola, V Cerundolo, LK Beyrsiewicz, AJ MCMichael, and GWG Wilkinson. 2000. Surface expression of HLA-E, an inhibitor of natural killer cells, enhanced by human cytomegalovirus gpUL40. Science. $287: 1031.3$.

69. Tomazin, R, J Boname, NR Hedge, DM Lewinsohn, Y Altschuler, TR Jones, P Cresswell, JA Nelson, SR Ridell, and DC Johnson. 1999. Cytomegalovirus US2 destroys two components of the MHC class II pathway, preventing recognition by CD4+ T cells. Nature Medicine. 5:103943.

70. Ustinov, J, R Loginov, C Bruggeman, J Suni, P Hayry, and I Lautenschlager. 1994. CMVinduced class II antigen expression in various rat organs. Transplant Int. 7:302-8.

71. Visseren, FLJ, MSA Verkerk, KP Boutier, RJA Diepersloot, and DW Erkelens. 1999. Interleukin6 production by endothelial cells after infection with influenza virus and cytomegalovirus. $J$ Lab Clin Med. 134:623-30.

72. Vitale, M, R Castriconi, S Parolini, D Pende, ML Hsu, L Moretta, D Cosman, and A Moretta. 1999. The leukocyte Ig-like receptor (LIR)-1 for the cytomegalovirus UL18 protein displays a broad specificity for different HLA class I alleles: analysis of LIR-1+ NK cell clones. International Immunol. 11:29-35.

73. Wagner, M, A Gutermann, J Podlech, MJ Reddehase, and UH Koszinowski. 2002. Major Histocompatibility Complex class I allele-specific cooperative and competitive interactions between immune evasion proteins of cytomegalovirus. J Exp Med. 196:805-16.

74. Waldman, W.J, D.A Knight, P.W Adams, C.G Orosz, and D.D Sedmak. 1995. In vitro induction of endothelial adhesion molecule and MHC antigen expression by cytomegalovirus-activated CD4+ T cells. Transplant Proc. 27:1269-71.

75. Wiertz, EJHJ, TR Jones, L Sun, M Bogyo, HJ Geuze, and HL Ploegh. 1996. The human cytomegalovirus US11 gene product dislocates MHC class I heavy chains from the endoplasmatic reticulum to the cytosol. Cell. 84:769-79.

76. Wiertz, EJHJ, S Mukher jee, and HL Ploegh. 1997. Viruses use stealth technology to escape from the host immune system. Mol Med Today. march:116-23.

77. Zhang, L. 1996. The fate of adoptively transferred antigen-specific T cells in vivo. Eur J Immunol. 26:2208-14.

78. Ziegler, H, R Thale, P Lucin, W Muranyi, T Flohr, H Hengel, H Farrell, W Rawlinson, and UH Koszinowski. 1997. A mouse cytomegalovirus glycoprotein retains $\mathrm{MHC}$ class I complexes in the ERGIC/cis-Golgi compartments. Immunity. 6:57-66. 



\section{Samenvatting en discussie}

Infecties met humaan cytomegalovirus (HCMV) komen vaak voor, maar verlopen in de meeste gevallen zonder symptomen. Alleen als het afweersysteem van de gastheer verstoord is, zoals bijvoorbeeld bij transplantatiepatiënten, foetussen en Aids-patiënten, kan een infectie met HCMV leiden tot ernstige problemen. CMV is soortspecifiek, waardoor in proefdiermodellen gewerkt moet worden met rat CMV (RCMV) bij ratten en muis CMV (MCMV) bij muizen. In hoofdstuk 1 is een overzicht gegeven van de literatuur over het verloop van de infectie en de bijbehorende pathologie, de reacties van het immuunsysteem op de infectie en de ontsnappingsmechanismen van het virus.

Infecties met CMV verlopen in verschillende fases. In de acute fase van de infectie is het virus verspreid door het hele lichaam en kan het virus in alle organen worden aangetoond. In de chronische fase van de infectie vermenigvuldigt het virus zich alleen in de speekselklieren en wordt het uitgescheiden in het speeksel. Tijdens de latente fase kunnen er geen virale antigenen meer worden aangetoond, maar blijven er kleine hoeveelheden viraal DNA aanwezig in de gastheer. Het virus is in staat te reactiveren uit de latente fase, bijvoorbeeld na een transplantatie. De exacte mechanismen van de reactivatie zijn tot nu toe onbekend. CMV infectie wordt geassocieerd met abortus, aangeboren afwijkingen, longontstekingen, retinitis, atherosclerose, veneuze trombose, restenose, graft-versus-host disease (GVHD) en transplantaatafstoting.

Bij orgaantransplantatie is de ontwikkeling van chronische afstoting een groot probleem voor de lange termijn overleving van het transplantaat. In de transplantaten ontwikkelen de bloedvaten zogenaamde transplantaat geassocieerde arteriosclerose (TXAA), de belangrijkste oorzaak voor toenemende verslechtering van de functie van het transplantaat. De meest voorkomende uitingen van TxAA zijn ontsteking rond de vaten en verdikking van de intima in het getransplanteerde orgaan. Bekende risicofactoren voor de ontwikkeling van chronische afstoting zijn koude ischemie, verschillen in het major histocompatibility complex $(\mathrm{MHC})$ tussen donor en ontvanger, het aantal doorgemaakte afstotingsperiodes en CMV infectie. Een acute CMV infectie kan bij transplantatiepatiënten ontstaan door reactivatie van latent virus van de ontvanger of van het getransplanteerde orgaan, of door andere infectieroutes zoals bloedtransfusies.

Zowel de cellulaire als de humorale immuun respons spelen een rol in de onderdrukking van de CMV infectie. De humorale immuun respons is vaak niet in staat ziekteverschijnselen te voorkomen. De cellulaire immuun respons bestaat voornamelijk uit CD8 + T cellen, CD4+ T cellen en natural killer (NK) cellen. Onderzoek waarin getracht is de belangrijkste factor uit de cellulaire immuun respons te bepalen toont aan dat vooral de bovenvermelde cellen belangrijk zijn; bij afwezigheid van één van deze celsoorten zijn de andere celsoorten soms in staat deze taken over te nemen. Een verhoogd aantal CD8+ T cellen, CD4+ T cellen en NK cellen in het getransplanteerde orgaan zou samenhangen met het risico op de ontwikkeling van door CMV geinduceerde 
ziekteverschijnselen. Deze cellen kunnen schade veroorzaken aan het transplantaat en daardoor uiteindelijk TXAA veroorzaken.

Infectie met CMV leidt tot een verhoogde productie van veel cytokines, chemokines en groeifactoren. De productie van enkele van deze factoren wordt direct gestimuleerd door de aanwezigheid van virusdeeltjes in de cel, terwijl andere factoren juist geproduceerd worden door stimulatie door een geinfecteerde cel. Sommige factoren helpen het virus te verwijderen of houden de infectie onder controle, terwijl andere factoren het immuunsysteem juist onderdrukken en zodoende bijdragen aan de overleving van het virus. De toename van deze factoren kan leiden tot een verhoogde bloedstolling, ontsteking en celgroei, waardoor CMV gerelateerde aandoeningen zoals chronische afstoting en atherosclerose gestimuleerd kunnen worden. Cytokines kunnen daarom nuttig zijn als markers voor de ontwikkeling van CMV gerelateerde aandoeningen. CMV infectie kan ook een toename geven in de moleculen die betrokken zijn in de verschillende fasen van de hechting van leukocyten aan de bloedwand en het binnendringen in het weefsel. De expressie van adhesie moleculen op zowel de leukocyten als de endotheelcellen is noodzakelijk om de leukocyten in staat te stellen de bloedstroom te verlaten. Expressie op andere cellen kan de interactie tussen de leukocyten en de doelwitcellen verbeteren. Dit leidt dan tot efficiënte verwijdering van geïnfecteerde cellen of, bij getransplanteerde organen, tot afstoting. Door de CMV infectie is ook de expressie van MHC klasse II moleculen in de omringende endotheelcellen verhoogd, waardoor het opruimen van het virus beter kan verlopen. Kort gezegd kan CMV zowel direct als indirect de expressie van veel moleculen die betrokken zijn bij de verwijdering van het virus verhogen. Door de afweerreactie kan het omringende weefsel echter beschadigd raken, waardoor er een CMV gerelateerde aandoening ontstaat. Na een acute infectieperiode is het virus echter in staat zich te verbergen en aanwezig te blijven in de gastheercellen. Daarom moet CMV ook beschikken over mechanismen die het virus in staat stellen aan het afweersysteem te ontsnappen. De bekendste mechanismen hebben betrekking op de verminderde expressie van MHC klasse I en II moleculen. MHC klasse II moleculen zijn altijd aanwezig op antigeen presenterende cellen en de expressie van deze moleculen kan worden geïnduceerd op endotheelcellen en epitheelcellen. De MHC klasse II moleculen zijn noodzakelijk voor de activatie van CD4+ T cellen. Studies hebben aangetoond dat twee mechanismen in staat zijn de transcriptie van MHC klasse II te induceren. Het ene mechanisme werkt vlak na de infectie van de cel en het ander treedt op in een later stadium van de infectie. HCMV is in staat met het door US2 gecodeerde eiwit de expressie van MHC klasse II op antigeen presenterende cellen te verminderen.

Studies met MCMV en HCMV tonen aan dat zij in staat zijn op verschillende manieren de presentatie van antigenen door MHC klasse I moleculen, en daarmee de verwijdering van geïnfecteerde cellen door CD8+ T cellen, te voorkomen. Het eiwit dat gecodeerd wordt door HCMV US3 voorkomt het intracellulaire transport van MHC klasse I moleculen uit het ER, terwijl de eiwitten van US2 en US11 een versnelde degradatie van MHC klasse I moleculen veroorzaken door de moleculen te verplaatsen naar het 
cytoplasma, waar ze door het proteasoom worden afgebroken. Het door US6 gecodeerde eiwit blokkeert de verplaatsing van door TAP gevormde peptiden naar het ER. Hierdoor kunnen de MHC moleculen geen stabiele complexen vormen en worden ze afgebroken. MCMV doceert voor ten minste 3 glycoproteinen die de expressie van MHC klasse I beïnvloeden. Het eiwit dat wordt gecodeerd door het m152 gen voorkomt het transport van klasse I moleculen uit het post-ER/early Golgi, terwijl het genproduct van m06 aan het $\mathrm{MHC}$ complex bindt en het naar de lysosomen brengt, waar het eiwit wordt afgebroken. Het derde eiwit, gp34, dat wordt gecodeerde door m04, bindt met het MHC klasse I complex en gaat met het complex naar de celmembraan. Hier zou het werken als een niet functionele lokeend voor NK cellen. NK cellen verwijderen cellen die geen MHC klasse I tot expressie brengen, en het verlagen van de MHC klasse I expressie door CMV maakt dat geinfecteerde cellen het risico lopen door NK cellen te worden opgeruimd. Een ander mechanisme om een aanval door NK cellen te voorkomen is de expressie van door het virus gecodeerde $M H C$ klasse I moleculen door de genen UL18, m144 en r144. Het UL18 product van HCMV bindt aan LIR-1 en geeft een remmend signaal in de NK cellen, B cellen en T cellen die LIR-1 tot expressie brengen. Daarnaast codeert HCMV UL40 voor een glycoproteine dat de concentratie human leukocyte antigen-E (HLA-E) verhoogt. Dit MHC klasse I molecuul kan de doelwitcellen beschermen tegen lysis door NK cellen.

De genomen van HCMV, MCMV en RCMV bevatten allemaal verschillende genen die coderen voor G-eiwit gekoppelde receptoren (GCRs), receptoren die een belangrijke rol hebben bij de doorgifte van signalen over de celmembraan. Mutanten waarbij deze genen verwijderd zijn geven een vermindering van de virusreplicatie of van de mortaliteit van de gastheer, maar hun exacte functie is nog niet duidelijk. De verschillende CMVs coderen ook voor homologen van chemokines, die door de actieve aantrekking van ontstekingscellen zouden kunnen bijdragen aan de verspreiding van het virus.

In hoofdstuk 2 wordt de invloed van RCMV infectie op de samenstelling van de leukocyten in het bloed van zowel ratten met een normaal als een gestoord immuunsysteem beschreven. Met behulp van flow cytometry wordt vooral gekeken naar de NK cellen en de T cellen. In de ratten met een normaal immuunsysteem veroorzaakte de infectie een kleine toename in NK cellen en een grote toename in CD8 + T cellen, terwijl na infectie in ratten met een verminderde afweer er een flinke toename in NK cellen en een kleine toename in CD8+ T cellen gezien werd. Deze resultaten zijn vergelijkbaar met de resultaten die bij de mens en de muis gevonden zijn. Het feit dat er een verschil is tussen geinfecteerde en niet geïfecteerde dieren bij zowel de normale als de immuungestoorde dieren laat zien dat de ontsnappingsmechanismen van het virus niet in staat zijn een afweerreactie volledig te voorkomen. In de ratten met een gestoord afweersysteem bestaat de toename van de CD8 + T cellen uit T cellen met een verlaagde expressie van zowel CD8 als T cel receptor (TCR). Dit fenomeen is karakteristiek voor anergische cellen, cellen die niet reageren op stimulatie door antigeen. De aanwezigheid van deze cellen suggereert dat RCMV interfereert met de costimulatie die normaal aanwezig is bij antigeen presentatie. De effecten die in het bloed van de immuungestoorde dieren werden gezien, konden in 
het algemeen ook worden aangetoond in de interne organen. In de speekselklier kon echter na infectie geen verhoogd aantal NK cellen worden aangetoond. Dit verschijnsel zou de langdurige aanwezigheid van virus in de speekselklier kunnen verklaren.

In hoofdstuk 3 wordt onderzocht of deze expressievermindering van CD8 en TCR ook voorkomt bij infectie met HCMV. Voor dit onderzoek was het noodzakelijk om bloed te gebruiken van patiënten met een verlaagde weerstand die een acute CMV infectie doormaakten. Hiervoor werd bloed gebruikt van CMV seronegatieve patiënten die een nier kregen van een seronegatieve (controle groep) of een seropositieve donor. Van deze laatste groep werden alleen die patiënten meegenomen die een acute CMV infectie doormaakten (experimentele groep). Bij deze patiënten leidde de acute infectie tot een toename van het aantal NK cellen en activatie van zowel CD4+ als CD8+ T cellen. Er werd geen toename gemeten van het aantal CD8+ en $C D 4+T$ cellen. Bij de geinfecteerde patiënten werd een afwijkende populatie CD8 + T cellen gevonden met een verlaagde expressie van zowel CD8 als TCR. Het aantal CD $8^{\text {low }} T_{C R}{ }^{\text {low }}$ cellen was klein $(0,5$ tot $9,5 \%)$ vergeleken met de experimenten bij ratten (tot $40 \%$ ). Dit zou verklaard kunnen worden door de verschillende vormen van immuunsuppressie. De grootte van de subpopulatie van CD8+ T cellen bij de niertransplantatiepatiënten lijkt afhankelijk van de hoeveelheid virus die gedetecteerd wordt met de pp65 antigenemie test. Dit geeft aan dat een productieve CMV infectie noodzakelijk is voor de vorming van de $C D 8^{\text {low }} T$ cellen. De aanwezigheid van een anergische populatie CD8+ T cellen geeft aan dat het virus een extra manier heeft om het afweersysteem te ontduiken, door te interfereren bij de costimulatie die noodzakelijk is bij de antigeenpresentatie.

In hoofdstuk 4 wordt het effect van RCMV infectie op de expressie van MHC klasse I complexen beschreven. RCMV infectie leidt tot verlaagde expressie van MHC klasse I complexen op de celmembraan van rat-

fibroblasten. In tegenstelling tot HCMV en MCMV was dit effect tijdelijk en het was het duidelijkst aanwezig rond 12 uur na infectie. 24 Uur na infectie was de expressie van MHC klasse I moleculen weer genormaliseerd. Met biochemische experimenten is aangetoond dat RCMV infectie niet interfereert met de biosynthese of de stabiliteit van de MHC klasse I moleculen, maar zorgt voor intracellulaire retentie van de MHC klasse I moleculen. Dit mechanisme wordt ook door andere herpesvirussen gebruikt als mechanisme voor ontsnapping aan het afweersysteem. Onze data geven aan dat RCMV mogelijk een m152 of US3-achtig gen product gebruikt om export van MHC klasse I complexen uit het ER/cis-Golgi compartiment te voorkomen, of dat RCMV met een op het genproduct van US6 lijkend eiwit TAP remt. Het RCMV genoom bevat meerdere m152-achtige genen en de meest waarschijnlijke kandidaat is bestudeerd, maar bleek geen effect te hebben op de MHC klasse I expressie. De aanwezigheid van MHC klasse I expressie regulerende genen zou onderwerp kunnen zijn van nieuw onderzoek.

Waarom er zoveel virale eiwitten betrokken zijn bij de ontduiking van het immuunsysteem en het feit dat ze soms dezelfde effecten lijken te bewerkstelligen is nog niet duidelijk. Ondanks de enorme hoeveelheid genen die bij de virale ontsnappingsactiviteiten betrokken zijn is het virus niet 
(altijd) volledig verborgen voor het immuunsysteem. Als het virus in verschillende celtypen in de latente fase wil onderduiken, kan een grote variatie in strategieën noodzakelijk zijn. Echter, voor de verdere verspreiding van het virus is een actieve infectie en mogelijk de aanwezigheid van een immuunrespons noodzakelijk. Daarom is het niet verrassend dat CMV verschillende strategieën gebruikt in de verschillende stadia van de infectie, in verschillende celtypen of weefsels en in een genetisch diverse populatie. Hoofdstuk 5 en 6 laten het effect van CMV infectie zien op de transplantaatafstoting. In hoofdstuk 5 wordt het effect van CMV infectie, langdurige koude ischemie $(\mathrm{Cl})$ en de combinatie van beide op het ontstaan van chronische afstoting onderzocht. Tegelijkertijd wordt meer inzicht in hun effecten op de expressie van adhesiemoleculen verkregen. Hiervoor werd gebruik gemaakt van een niertransplantatie model in ratten. Lewis ratten kregen een nier (met of zonder $\mathrm{Cl}$ ) van een $\mathrm{MHC}$-incompatibele Brown-Norway rat en werden vervolgens al dan niet geïnfecteerd. Dit onderzoek laat zien dat $\mathrm{CMV}$ infectie en $\mathrm{Cl}$ een versterkend effect hebben op de verslechtering van de nierfunctie. De histologische effecten van $\mathrm{Cl}$ en $\mathrm{CMV}$ infectie verschillen echter duidelijk. CMV infectie geeft met name vasculaire veranderingen (intima proliferatie en glomerulosclerose), terwijl $\mathrm{Cl}$ leidt tot verhoogde interstitiële fibrose, tubulaire atrofie en glomerulosclerose. Infectie met CMV en $\mathrm{Cl}$ geeft ook duidelijke verschillen te zien in de expressie van adhesie moleculen. CMV infectie veroorzaakt een toename in de aanwezigheid van CD49d positieve leukocyten, terwijl Cl de expressie van CD18 op leukocyten, van CD54 en CD62P op de tubuli en van CD44 op het epitheel verhoogt. De combinatie van CMV infectie en $\mathrm{Cl}$ geeft versterkte expressie van de adhesiemoleculen. CMV infectie stimuleert ook de expressie van MHC klasse II op het endotheel. De resultaten van dit onderzoek geven aan dat extra aandacht moet worden besteed aan transplantatiepatiënten met een CMV infectie waarbij het donororgaan gedurende langere tijd is blootgesteld aan koude ischemie, aangezien hier een versnelde ontwikkeling van chronische afstoting zou kunnen plaatsvinden. De CMV infectie versterkt de verslechtering van de nierfunctie in het getransplanteerde orgaan mogelijk door de ischemie-reperfusie schade. De kennis van de expressie van adhesiemoleculen kan nuttig zijn om de oorzaak van afstoting in biopten te kunnen beoordelen en om nieuwe behandelingsmethoden te kunnen ontwikkelen.

In hoofdstuk 6 wordt de studie beschreven naar het effect van RCMV infectie op TxAA in verschillende donor / ontvanger combinaties. Daarnaast wordt gekeken naar de relatie tussen het moment van de infectie en de ontwikkeling van TxAA. Zonder CMV infectie verschilt de ontwikkeling van TXAA sterk tussen de verschillende rattenstammen. Lewis, AO en WF ontvangers ontwikkelen slechts zwakke TxAA. In tegenstelling hiermee ontwikkelen BN ontvangers een vier maal sterkere TxAA. Uit eerder onderzoek is naar voren gekomen dat de mate van TXAA ontwikkeling in grote mate bepaald wordt door het genotype van de ontvanger. In dit onderzoek zou dat de verschillen tussen de verschillende stammen kunnen verklaren. Infectie met RCMV in Lewis ontvangers leidde tot versterking van de TxAA, alleen als de ontvangers werden geinfecteerd met RCVM 1 dag na transplantatie. Dit is 
in overeenstemming met recente studies bij de mens waaruit blijkt dat CMV alleen een effect heeft op de chronische afstoting als er sprake is van acute afstotingsperiodes. Daarnaast geven de resultaten van dit onderzoek aan dat er een versterkend effect is van CMV infectie op de ontwikkeling van de allorespons, waarschijnlijk het onderliggende mechanisme voor de door CMV versterkte ontwikkeling van TxAA. Deze effecten konden niet worden aangetoond in een van de andere bestudeerde rattencombinaties. Dit suggereert dat er meer factoren dan moment van infectie en genotype van de ontvanger betrokken zijn bij de ontwikkeling van de door RCMV geinduceerde ontwikkeling van TXAA.

Als de $\mathrm{BN}$ donoren 5 of 10 dagen voor de transplantatie werden geinfecteerd, kon er wel virusoverdracht naar de ontvanger worden gedetecteerd, maar geen versterking van TXAA door de RCMV infectie. Een mogelijke verklaring zou kunnen zijn dat de hoeveelheid virus tijdens periode van de acute afstoting te laag was om een effect te kunnen waarnemen. Anderzijds kan het zijn dat de fase van de acute infectie in deze situatie wat later valt, omdat deze kleine hoeveelheid virus eerst tijd nodig heeft om te groeien. Hierdoor kan de piek in de periode van acute infectie te laat vallen voor een groot effect op de ontwikkeling van TxAA. Aangezien soortgelijke effecten zijn beschreven bij de mens, concluderen wij dat RCMV geen invloed heeft op de ontwikkeling van TXAA als de periode van acute afstoting en acute infectie niet samenvallen.

Onze resultaten geven aan dat het effect van CMV infectie op TXAA afhangt van het genotype van de ontvanger, de verschillen tussen donor en ontvanger, de doorgemaakte periode van koude ischemie en het moment van infectie gecombineerd met de aanwezigheid van acute afstoting. Aangezien al deze factoren het complexe immuunsysteem beïnvloeden is het zeer waarschijnlijk dat ook andere factoren die het immuunsysteem beïnvloeden, zoals het gebruik van immuunsuppressiva, andere infecties en het gebruik van antivirale middelen, de door CMV geïnduceerde chronische afstoting beïnloeden. Het bepalen van het effect van een CMV infectie op chronische afstoting uit studies bij de mens zal daardoor zeer moeilijk zijn, aangezien er zeer veel factoren onderzocht zouden moeten worden. Het gebruik van proefdiermodellen lijkt de beste methode om alle factoren te bepalen, zodat gedetailleerde kennis van de afstoting van getransplanteerde organen kan worden verkregen. Als er meer informatie beschikbaar komt over de combinatie en vooral het effect van de periode tussen infectie en acute afstoting, zou dit ook in de klinische situatie kunnen leiden tot nuttige aanpassingen in de profylactische behandeling van CMV infecties en het gebruik van immuunsuppressiva. 


\section{Dankwoord}

Een proefschrift schrijf je nooit alleen. Vandaar dat ik in dit stukje mijn uiterste best ga doen alle mensen te bedanken die hebben bijgedragen aan dit proefschrift. Ik hoop dat ik daarin slaag.

De persoon met wie ik als AlO de meeste tijd heb doorgebracht wil ik graag als eerste bedanken. Gert, we hebben samen menig uurtje in de proefdierverblijven en op het lab vertoefd, en de sfeer was altijd goed. Zelfs puntjes vullen op vrijdagmiddag was een evenement. Ik ben erg blij dat jij ook tijdens de verdediging van mijn proefschrift naast me staat.

Mijn promotor, Cathrien Bruggeman, wil ik bedanken voor het vertrouwen dat ze in mij stelde en voor de uitstekende begeleiding. Jij hebt me laten zien dat het voor een vrouw mogelijk is een gezin te combineren met een uitdagende baan, en toch een 'gewoon' mens te blijven. Voor mij blijf je een bijzonder voorbeeld.

Op het 'lab van Gert' was het vaak een komen en gaan van mensen. Fengling and Ming, thank you for introducing me into the RCMV-transplantation model. I enjoyed working with you. Renée en Marlea, bij jullie kon ik terecht met alle vragen over celkweek en voor een klaterende lach. Anita, je kwam als stagiaire maar mocht gelukkig nog een poosje blijven. Ik zal nooit de enorme hoeveelheid glaasjes vergeten die we met samen met Gert op één dag konden kleuren en beoordelen. De komst van Harry bracht niet alleen een goede analist met veel proefdierervaring, maar ook de in zijn ogen mislukte bonbons. Fijn dat je af en toe iets fout liet gaan. Jeroen, je kwam als jonge student een paar weken onderzoek doen en niet lang na je artsexamen promoveerde je. Petje af. Inge, voor je onderzoek was het voor ons omschakelen van ratten naar muizen en voor jou van België naar Nederland. Gelukkig konden we er samen ook vaak om lachen. Martine, bedankt voor alle uitgevoerde proeven en testen. Tenslotte kwamen Rajaa en Trifon onze gelederen versterken, zodat er nog meer culturen vertegenwoordigd waren. Bedankt voor jullie positieve inbreng. Wil Mullers, jou wil ik bedanken voor alle hulp bij de verwerking van de statistische gegevens.

Ook op de werkkamer was het een drukte van belang. Er werd natuurlijk hard gewerkt, maar daarnaast ook veel gelachen. Patrick, het werd al snel duidelijk dat jij een enorme fan was van Star Wars, aangezien je computer regelmatig vreemde geluiden produceerde. May the force be with you! Rien, je was onopvallend aanwezig, maar je droge opmerkingen waren goed voor veel komische momenten. Erik, altijd rustig en bereid te helpen. Dank je wel! Suzanne, Yvonne, Susan en Saskia, dankzij jullie was een middagje bureauwerk zeker niet saai.

Kees, als aanvoerder van het hierboven beschreven team had je natuurlijk je handen vol, maar je nam toch altijd tijd om mee te denken of een artikel door te lezen. Bedankt voor je soms ongezouten maar altijd eerlijke kritiek. 
Alle medewerkers van de Virologie Diagnostiek, het secretariaat, de Bacteriologie en de Spoelkeuken wil ik bedanken voor hun behulpzaamheid en natuurlijk voor alle gezellige momenten in de koffiekamer. Ook bij de Proefdierverblijven was iedereen bereid te helpen.

Een deel van mijn onderzoek is gedaan in samenwerking met het laboratorium voor Immunologie in Maastricht. Vooral Jan Damoiseaux wil ik hartelijk bedanken voor alle hulp die hij heeft gegeven, maar ook alle andere medewerkers waren nooit te beroerd om even iets op te zoeken of een handje te helpen.

Voor het transplantatieonderzoek is er nauw samengewerkt met Jan-Luuk Hillebrands en Jan Rozing uit Groningen. De grote afstand was soms wat lastig, maar jullie reden met de snelle bolide regelmatig 'even' naar Maastricht, met of zonder ratten in de kofferbak. Of we ontmoetten elkaar halverwege, in Utrecht. Het waren altijd nuttige en prettige bijeenkomsten. Bedankt!

Veel dank ben ik ook verschuldigd aan de medewerkers van de Medische Microbiologie in Leiden en het RIVM. Allereerst wil ik Emmanuel Wiertz bedanken voor de fantastische samenwerking. Ondanks enkele hindernissen zijn we gekomen tot een mooi verhaal. Je enthousiasme heeft daar veel aan bijgedragen. Jacqueline, samen met jou ben ik op het RIVM begonnen aan mijn allereerste immuunprecipitaties. Bedankt voor al je hulp. Danijela, thank you for al the help you gave and especially the pleasant companionship during the many hours of work. Gerco, ik ben blij dat jij bereid was mee te werken aan de afronding van het artikel.

En als laatste de mensen die me het meest na staan. Lieve papa en mama, ik ben blij dat jullie me mijn eigen keuzes lieten maken in die onbekende academische wereld. Bedankt voor alle steun en vooral voor het geschonken vertrouwen. Lieve zus Petra, fijn dat je me wilde helpen met de lay-out van het proefschrift. Volgens mij hebben we een mooi stukje werk geleverd! Broer Gert Jan, fijn dat je voor mij als paranimf wilt optreden in zo'n apenpak. Dirk, jij hebt me geholpen door regelmatig te vragen 'Mama, wil je me opdragen?' Bij deze. En last but not least: Lieve Jan, bedankt dat je er altijd bent, in goede en in slechte dagen. Een ding is zeker: Samen kunnen we alles, zelfs behangen! 


\section{Curriculum vitae}

De schrijver van dit proefschrift, Joanne Duijvestijn-van Dam werd geboren op 7 januari 1971 te Kamerik. Zij behaalde in 1989 haar VWO diploma aan het F.C. de Bruijnelyceum in Utrecht. In datzelfde jaar begon ze haar studie Biomedische Wetenschappen (toen nog Gezondheidswetenschappen) aan de Rijksuniversiteit Leiden. Tijdens haar studie was ze bestuurslid van de medische faculteitsvereniging M.F.L.S. en actief binnen verschillende onderwijs evaluerende en beleidsbepalende commissies van de faculteit Geneeskunde. Na het behalen van haar doctoraal in 1995 is zij als AlO gaan werken bij de Medische Microbiologie in Maastricht. Onder leiding van Prof. Dr. C.A. Bruggeman verrichtte zij onderzoek naar de interacties tussen Cytomegalovirus en het immuunsysteem. Daarnaast was zij van 1996 tot 1999 bestuurslid van de AVUM, de AlO-vereniging van de Universiteit Maastricht. $\mathrm{Na}$ in 20003 maanden te hebben gewerkt bij het Stedelijk Lyceum Enschede, locatie Zuid, is zij in datzelfde jaar als docent biologie gaan werken bij de OSG Hengelo, vestiging Bataafse Kamp. Sinds augustus 2004 is zij daarnaast coördinator VWO bovenbouw. Ze is getrouwd met Jan Duijvestijn en zij hebben een zoon Dirk. 



\section{Publications}

- Van Dam JG, Damoiseaux JGMC, Van der Heijden HAMD, Grauls G, Van Breda-Vriesman PJC and Bruggeman CA. Infection with rat cytomegalovirus (CMV) in the immunocompromised host is associated with the appearance of a T cell population with reduced CD8 and T cell receptor (TCR) expression. Clin Exp Immunol 1997; 110: 349-57

- Beisser PS, Vink C, Van Dam JG, Grauls G, Vanherle SJ and Bruggeman CA. The R33 $\mathrm{G}$ protein-coupled receptor gene of rat cytomegalovirus plays an essential role in the pathogenesis of viral infection. J Virol 1998; 72: 235263

- Li F, Yin M, Van Dam JG, Grauls G, Rozing J and Bruggeman CA. Cytomegalovirus infection enhances the neointima formation in rat aortic allografts: effect of major histocompatibility complex class I and class II antigen differences. Transpl 1998; 65: 1298-304

- Bruggeman CA and Van Dam JG. Role of cytomegalovirus infection in transplant arteriosclerosis. Chapter in: Scholz M, Rabenau HF, Doerr HW and Cinatl J Jr. CMV-related immunopathology. Monographs in Virology, Karger 1998; 21: 158-172

- Van Dam JG, Li F, You XM, Yin M, Li F, Grauls G, Steinhoff G and Bruggeman CA. Effects of cytomegalovirus infection and prolonged cold ischemia on chronic rejection of rat renal allografts. Transpl Int 2000; 13: 54- 63

- Van Dam JG, Damoiseaux JGMC, Christiaans, MHL and Bruggeman, CA. Acute primary infection with cytomegalovirus (CMV) in kidney transplant recipients results in the appearance of a phenotypically aberrant CD8+ T cell population. Microbiol Immunol 2000; 44; 1011 - 7

- Kloover JS, van den Boogaard, AE, van Dam JG, Grauls, GE, Vink, C, Bruggeman CA. Persistent rat cytomegalovirus (RCMV) infection of the salivary glands contributes to the anti-RCMV humoral immune response. Virus Res 2002; 10; $163-72$

- Van Dam JG, Hillebrands JL, Klatter FA, Grauls G, Bruggeman CA, Rozing, J. Cytomegalovirus-enhanced development of transplant arteriosclerosis in the rat: effect of timing of infection and recipient responsiveness. Submitted

- Duijvestijn-van Dam JG, Hassink GC, Koppers-Lalic D, Van Gaans-Van de Brink J, Van Leeuwen D, Vink C, Bruggeman CA, Wiertz EJHJ. Rat Cytomegalovirus induces a temporal downregulation of Major Histocompatibility Complex class I cell surface expression. Submitted 